\title{
VIETNAMESE EFL TEACHER SELF-EFFICACY IN PRACTICE
}

\section{BY}

\section{HOANG THI THU HA}

A thesis submitted to Victoria University of Wellington in fulfilment of the requirements for the degree of Doctor of Philosophy in Education

Victoria University of Wellington 
VIETNAMESE EFL TEACHER SELF-EFFICACY IN PRACTICE

\begin{abstract}
Research has shown the importance of understanding self-efficacy and teacher selfefficacy. In general, self-efficacy influences humans' actions in various ways. Efficacy expectations control the degree of effort and persistence that people expend in dealing with obstacles and unexpected situations. These expectations also impact people's thought patterns and emotional reactions. These influences make self-efficacy a strong determinant of the level of accomplishment that individuals finally attain. For teachers, self-efficacy influences not only their general perception about teaching but also their specific instructional activities.
\end{abstract}

This research aimed to provide insights into Vietnamese English as a Foreign Language (EFL) teacher self-efficacy at the tertiary level in Vietnam. Firstly, this study collected data in the form of teacher self-efficacy profiles using an adapted version of the Teacher Sense of Efficacy Scale (Tschannen-Moran and Hoy, 2001) and demographic information. Then, it investigated the sources of Vietnamese EFL tertiary teacher selfefficacy and the interaction among these sources. In addition, this study examined the personal, classroom, institutional, and cultural influences on teacher self-efficacy. The research also investigated the relationship between teacher self-efficacy and the teachers' teaching practices. As teacher self-efficacy closely relates to teacher well-being, teacher burn out, persistence, commitment, and teaching practice and has a close relationship with student outcomes and student motivation, a better understanding of self-efficacy has the potential to improve the teaching and learning English in the research university in Vietnam.

A sequential exploratory mixed methods design was selected for this study. The data were collected in two phases. In the quantitative phase, I adapted a validated questionnaire to gather quantitative information about 52 teachers' self-efficacy profiles across three aspects: managing the classroom, engaging students, and using instructional strategies. In the following qualitative phase, I purposively selected eight teachers with a range of total selfefficacy scores. These teachers came from three groups. They were grouped according to lower, medium and higher total self-efficacy scores from the questionnaire. I interviewed each of these teachers prior to observing their teaching in their class. Then, the teachers were interviewed again about particular incidents in their class with a focus on recalling what influenced their actual teaching. Data from both interviews were collated and analyzed thematically across each group to address the research questions. 
VIETNAMESE EFL TEACHER SELF-EFFICACY IN PRACTICE

This study has provided a view of the self-efficacy of EFL teachers, a distinctive subject at the tertiary level in Vietnam. The research found that the results from TschannenMoran and Hoy's (2001) scale measuring teacher self-efficacy were not linked to how each group of teachers performed in their classes. Individual elements such as teachers' personal characteristics and knowledge, classroom and institutional issues like class size and availability of classroom equipment influenced the teachers' self-efficacy in their classroom practices. Self-efficacy was also influenced by institutional policies about professional and personal collegiality, the autonomy of the teachers to make decisions about matters such as assessment, and student and staff feedback about teaching. Self-efficacy was also impacted by Vietnamese cultural elements such as teachers' roles outside of their profession and how the teachers evaluated feedback about their teaching from students, colleagues and administrators. This study highlights the dynamic interaction among the sources of teacher self-efficacy.

The findings have implications for enhancing teacher self-efficacy, by improving teacher knowledge, providing relevant professional development, and increasing support from administrators. There are recommendations for future research. 
VIETNAMESE EFL TEACHER SELF-EFFICACY IN PRACTICE

\section{Acknowledgements}

I would like to express my gratitude to the people who have supported me throughout my $\mathrm{PhD}$ journey.

First and foremost, my sincere appreciation goes to my supervisors, Dr. Carolyn Tait and A.Prof. David Crabbe for their patience, encouragement and professional supervision. I am indebted to them for their dedicated and meticulous attention to my work. I am also grateful for their understanding of and sympathy for my personal life. Carolyn, your advice and warm-heartedness made my journey much easier. David, I will always admire the way you see the big picture.

I am very grateful for the Vietnamese government and Victoria University of Wellington (VUW) for providing financial support for my study while living in New Zealand. My gratitude is also extended to the staff at Victoria University, especially the staff at the Faculty of Education and the Faculty of Graduate Research for their help and encouragement for the last five years.

My sincere appreciation goes to the participants in my research. Their enthusiastic sharing and cooperation have provided valuable data that gave insights into Vietnamese EFL teacher self-efficacy. Without their participation, this work would have been impossible.

I would like to acknowledge my $\mathrm{PhD}$ peers and friends for sharing their experiences and giving suggestions to improve my work. I especially thank Shelley Dawson for proofreading my thesis. I would like to express my gratitude to Pham Quang Vinh and Mr. Dinh Van Nghia for helping me with the diagrams. I am grateful to Nguyen Thuy Duong for babysitting my little boy with much love and care.

Last but not least, my deepest and most sincere appreciation goes to my family who have empowered and motivated me to complete the $\mathrm{PhD}$ journey. I would like to dedicate this work to my parents who love me unconditionally and give me their best. I would especially like to express my wholehearted gratitude to my beloved husband, Mr. Vu Quang Chien and our two beautiful angels, Vu Kieu Khanh (Vicky) and Vu Hoang Khoi (Sam) for their love and sacrifice throughout the years.

To you all, my love and my thankfulness. 
Abstract

Acknowledgements. iii

Table of Contents iv

List of Tables viii

List of Figures $i x$

Chapter I Introduction. 1

1. EFL Teaching in Tertiary Education in Vietnam ..............................................1

2. Statement of the Problem and Significance of the Study .....................................2

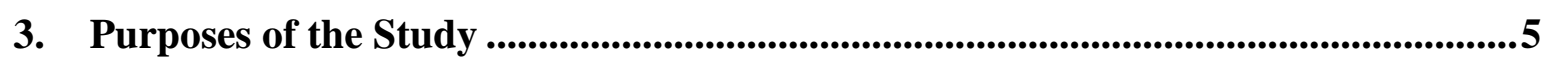

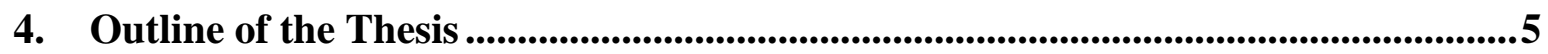

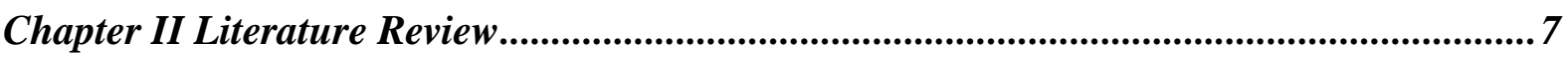

1. What is Teacher Self-Efficacy and Why it is Important? ........................................7

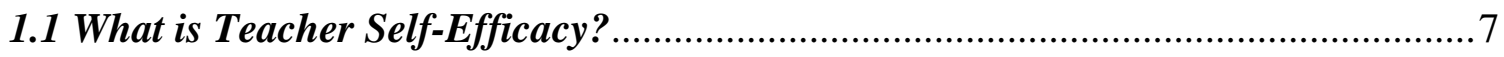

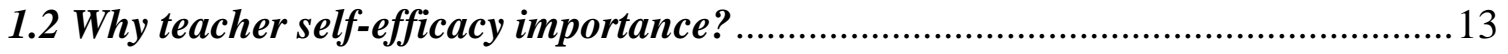

1.2.1 How does Teacher Self-Efficacy Link to Students' Performance? ...................... 13

1.2.2 How does Teacher Self-Efficacy Link to Teachers' Professional Life?.............. 15

2. How is Teacher Self-Efficacy Measured? ...................................................21

3. Sources of Self-Efficacy and Sources of Teacher Self-Efficacy ..............................25

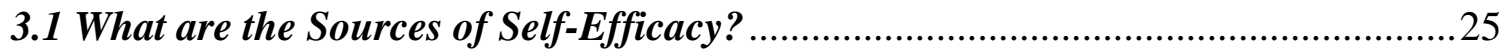

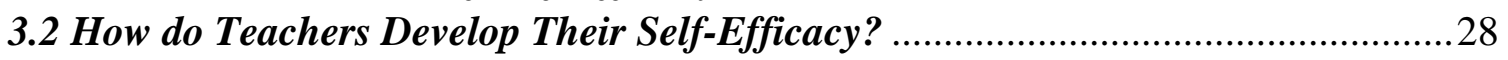

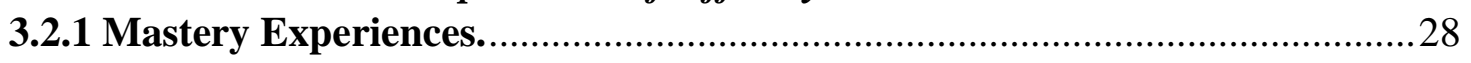

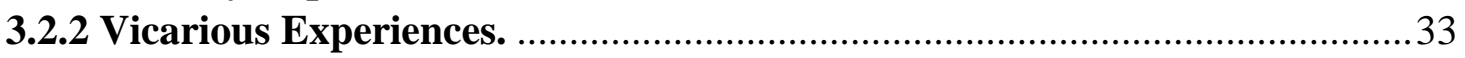

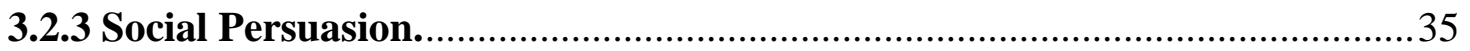

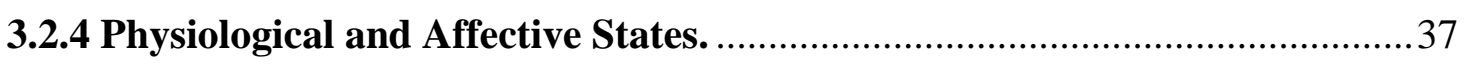

4. What can be the Other Influences on Teacher Self-Efficacy? ...............................38

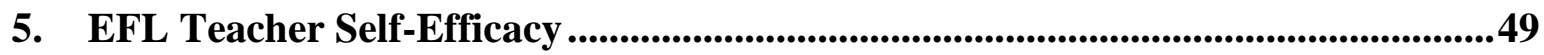

6. Teacher Autonomy and Teacher Self-Efficacy .................................................51

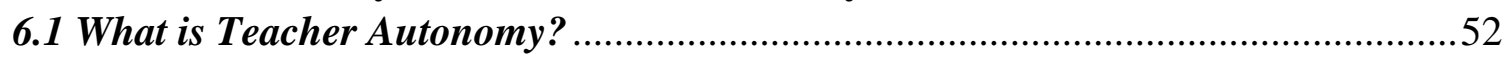

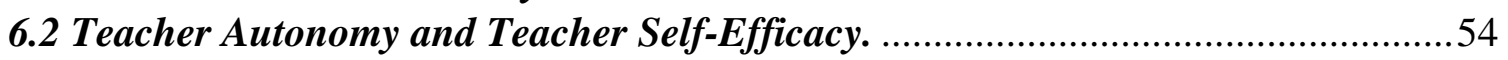

7. Teacher Beliefs and Practices ...................................................................................55

7.1 Relationship between Teacher Beliefs about Teaching and Learning and Teacher

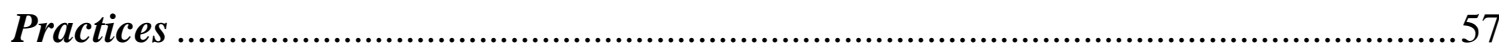

7.1.1 The Consistency between Teacher Beliefs and Practice.................................57

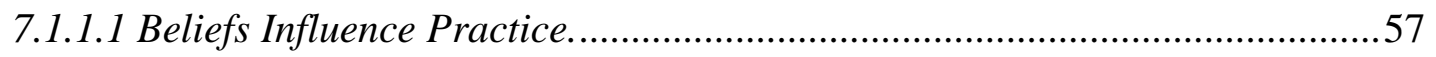




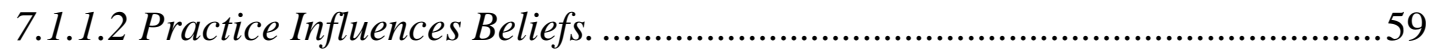

7.1.1.3 Reciprocal and Complex Relationship....................................................59

7.1.2 The Inconsistency between Teacher Beliefs and Teaching Practice. ............60

7.2 Language Teacher Beliefs about Teaching and Learning and Their Teaching

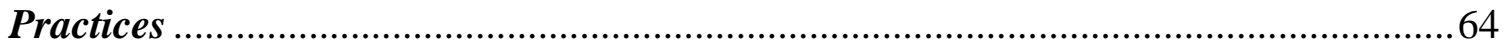

8. What is the Relationship Between Language Teacher Self-Efficacy and

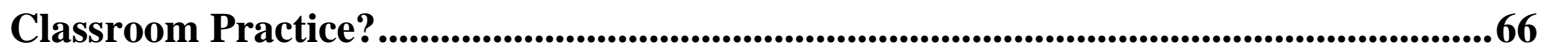

9. Chapter Summary ..........................................................................................................69

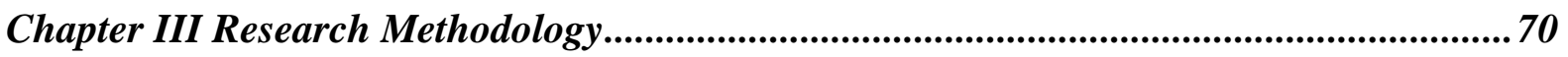

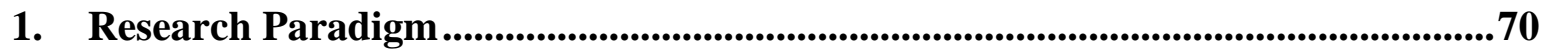

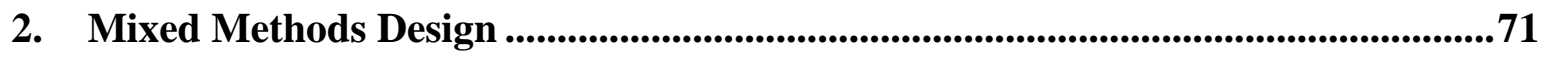

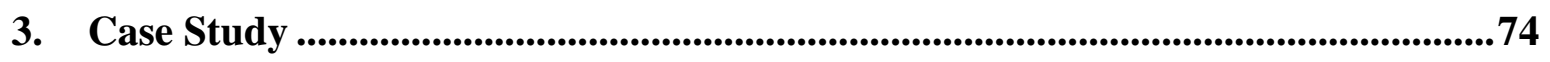

4. Sampling Method .........................................................................................................76

5. Data Collection Instruments and Procedures .................................................76

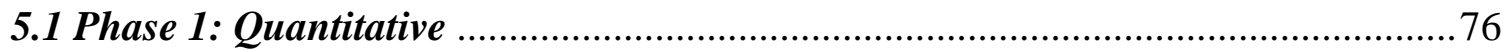

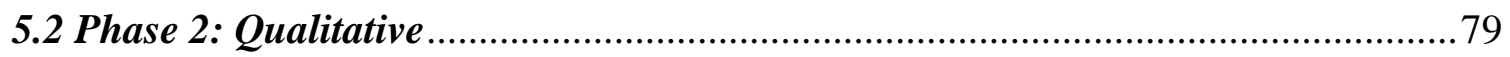

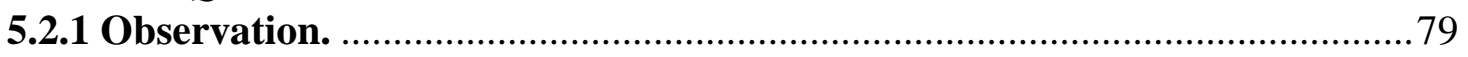

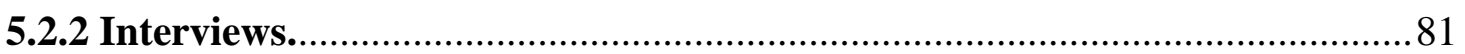

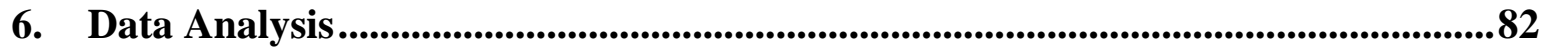

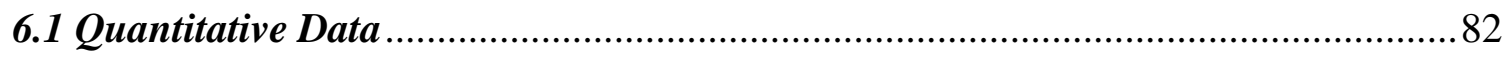

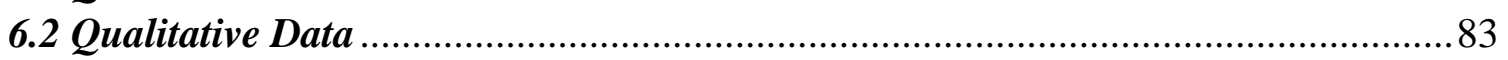

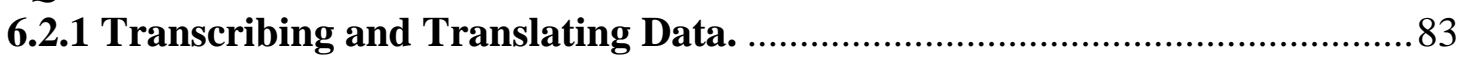

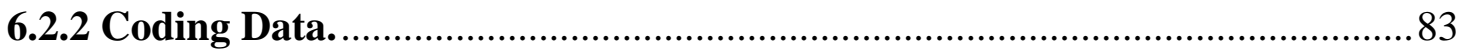

7. Validity and Trustworthiness of the Study......................................................85

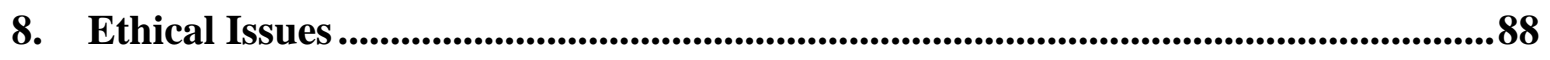

9. Summary of the Research Methodology ............................................................8

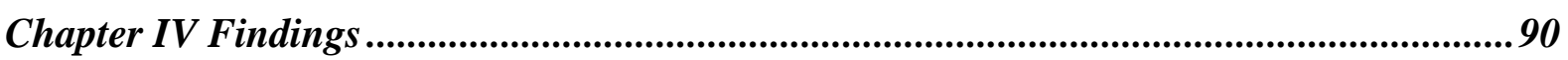

1. What are the Self-Efficacy Profiles of EFL Teachers Working in a Public

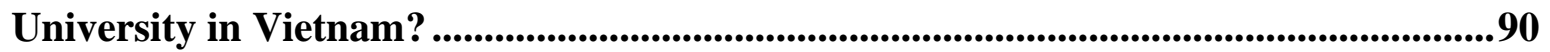

2. What do These EFL Teachers Report as Influences on Their Self-Efficacy in

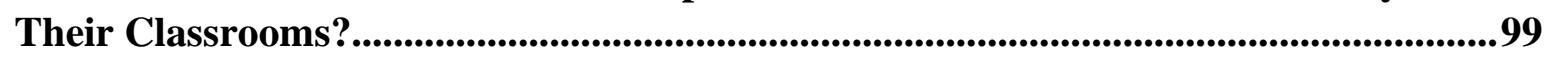

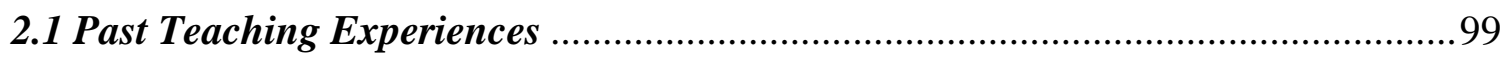

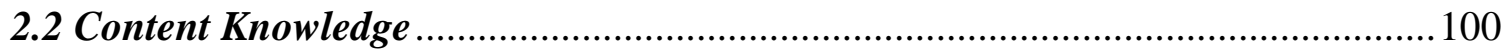

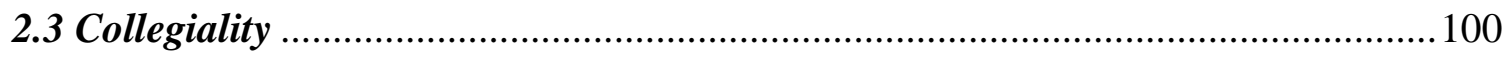

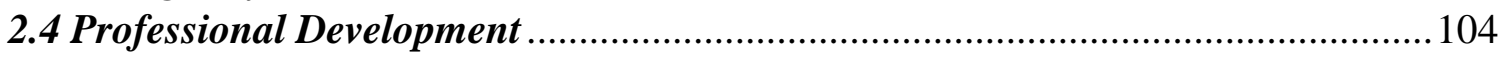

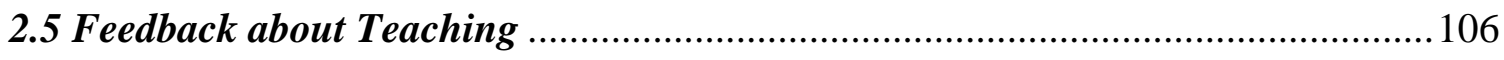

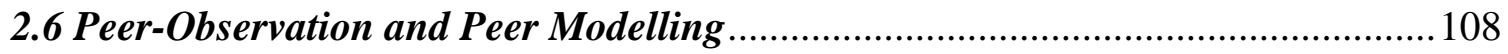

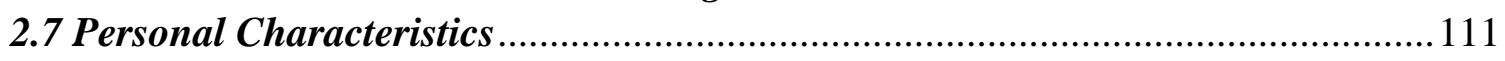

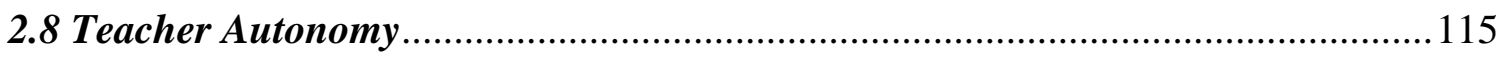

2.8.1 Teacher Autonomy in Selecting Teaching Contents................................ 115 


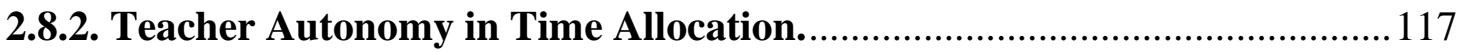

2.8.3 Teacher Autonomy in Assessing and Giving Feedback. ........................... 117

2.8.4 Teacher Autonomy in Using Supplementary Documents. .......................... 118

2.8.5 Teacher Autonomy in Professional Development...................................... 120

2.8.6 Teacher Autonomy in Selecting Teaching Resources................................. 122

2.9 Teachers' Perception of Teaching Context ........................................................... 123

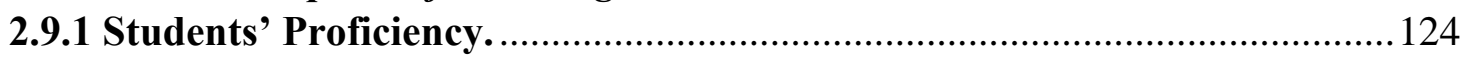

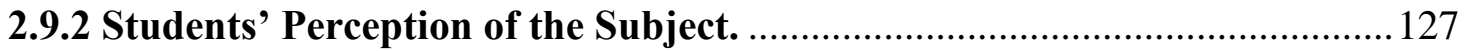

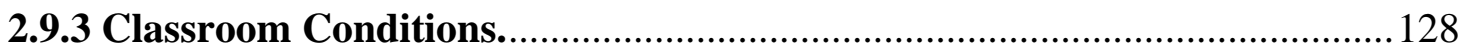

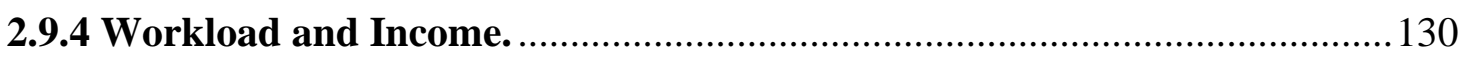

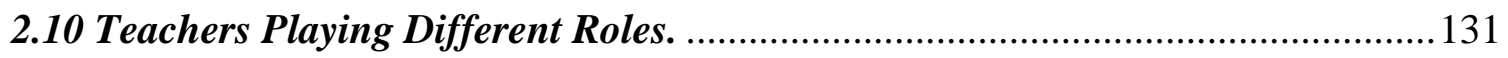

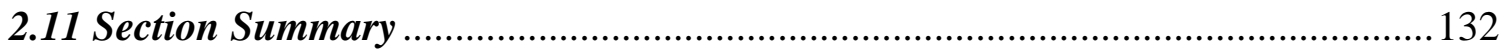

3. How do Teachers with Different Profiles of Self-Efficacy Differ in Their Teaching

Practice? ..........................................................................................................................133

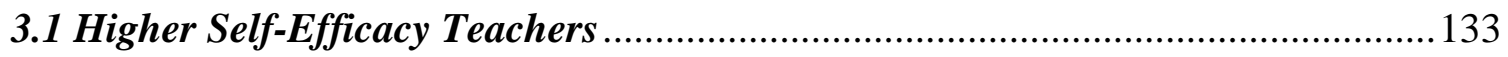

3.1.1 Classroom Contexts and the Teachers' Reflection on Their Satisfaction with

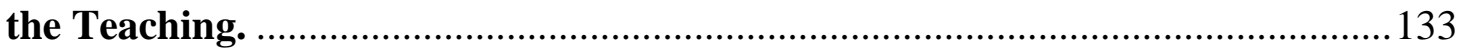

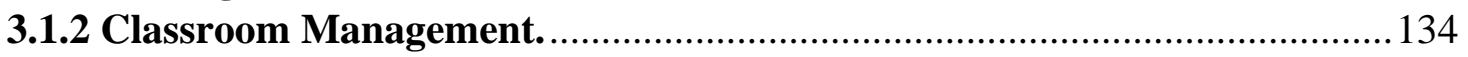

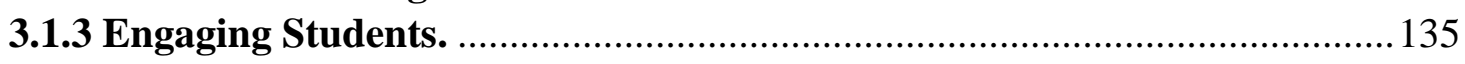

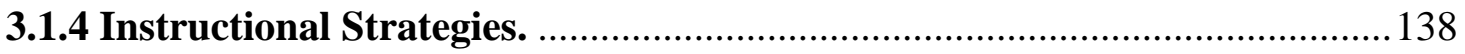

3.1.4.1 Dealing with Students' Different Levels of English Proficiency................. 138

3.1.4.2 Giving Feedback and Assessing Students. .............................................. 141

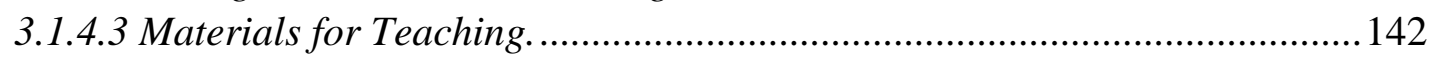

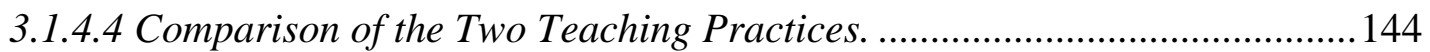

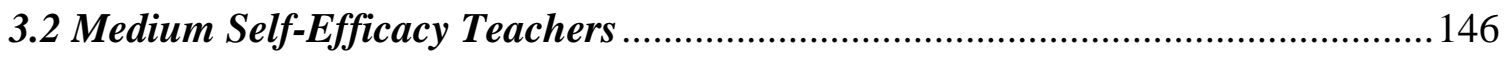

3.2.1 Classroom Contexts and the Teachers' Reflection on Their Satisfaction with

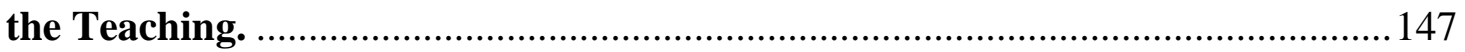

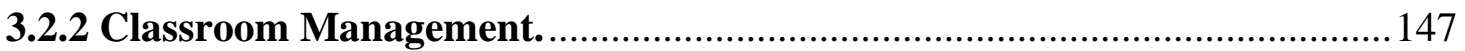

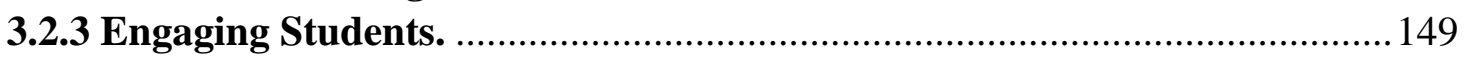

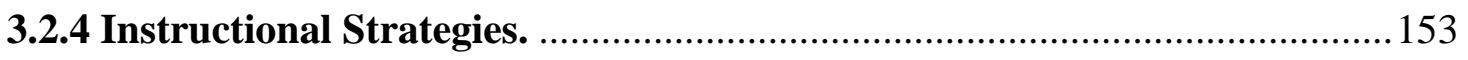

3.2.4.1 Dealing with Students' Different Levels of Proficiency. ............................ 153

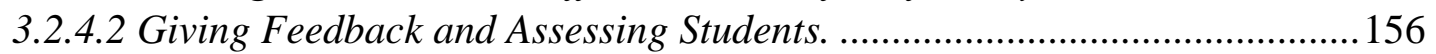

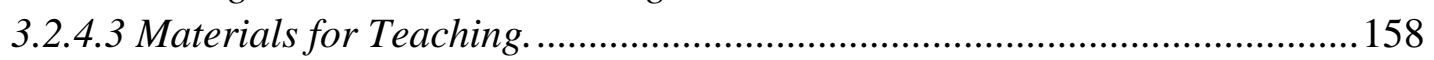

3.2.4.4 Comparison of Three Teachers' Teaching Practices................................. 159

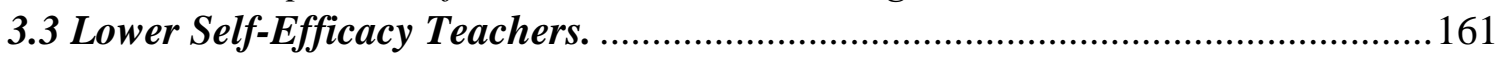

3.3.1 Classroom Contexts and the Teachers' Reflection on Their Satisfaction with

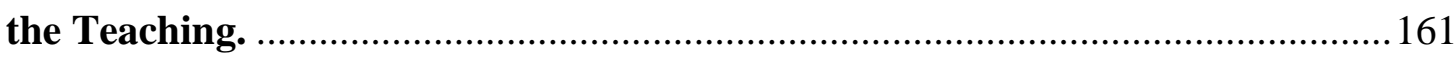

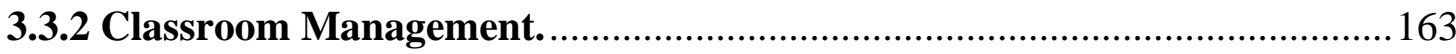

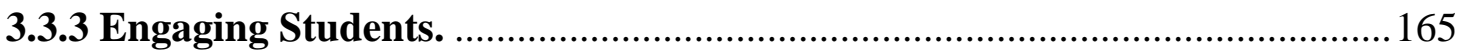

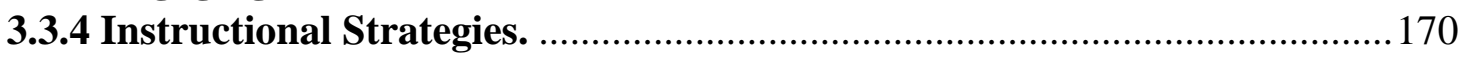

3.3.4.1 Dealing with Students' Different Levels of Proficiency............................. 170

3.3.4.2 Giving Feedback and Assessing Students. ................................................ 172

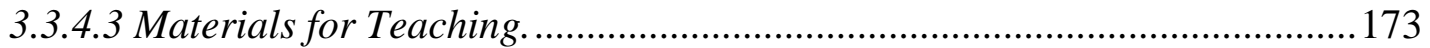

3.3.4.4 Comparison of Three Teachers' Teaching Practices................................. 175

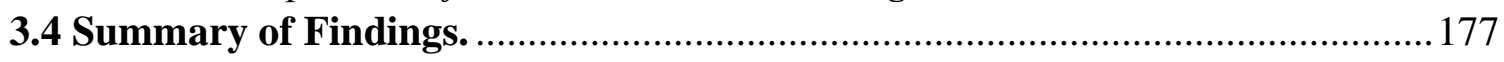

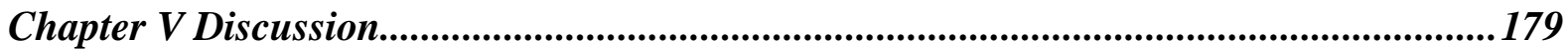


1. Do the Teacher Efficacy Scale Scores Have a Relationship with Teaching Practice?. 179

2. Interaction among Sources of Teacher Self-Efficacy ...............................................181

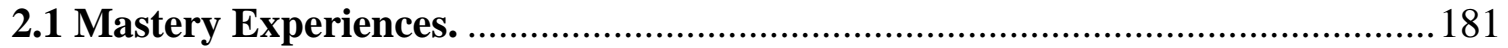

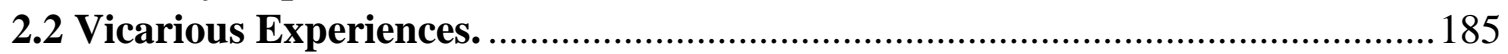

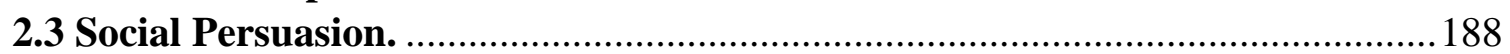

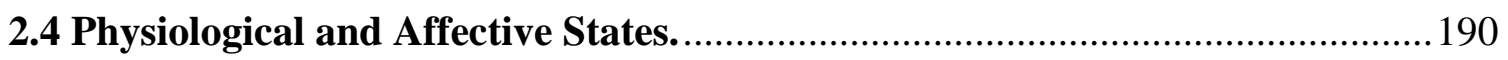

3. What Makes the Relationship between Teacher Self-Efficacy and Teaching

Practice so Complex? ......................................................................................................191

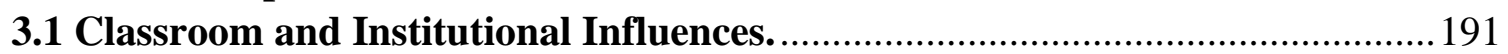

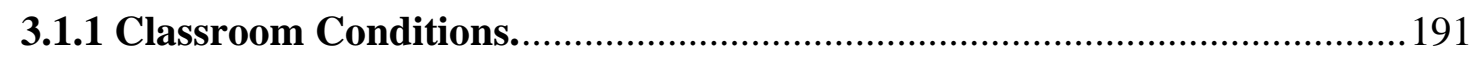

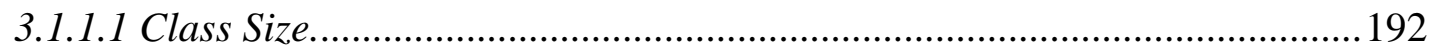

3.1.1.2 Availability of Classroom Equipment and Teaching Resources. ................ 192

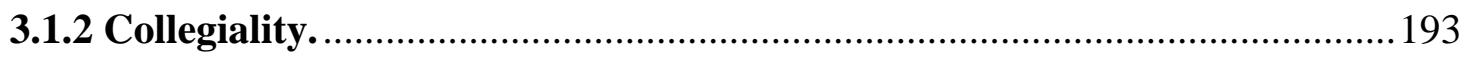

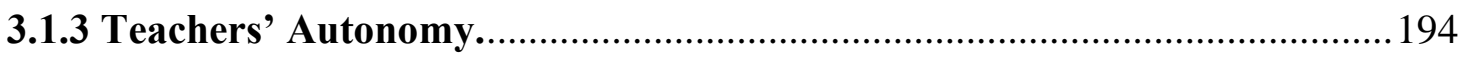

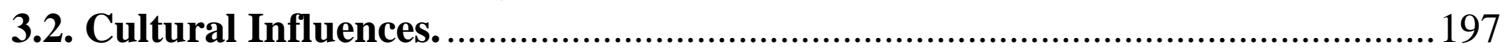

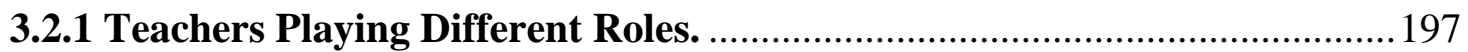

3.2.2 Teachers' Evaluation of Feedback about Their Teaching. ........................... 198

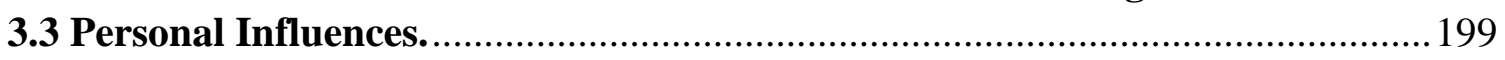

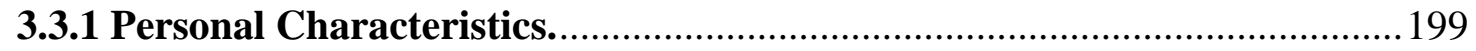

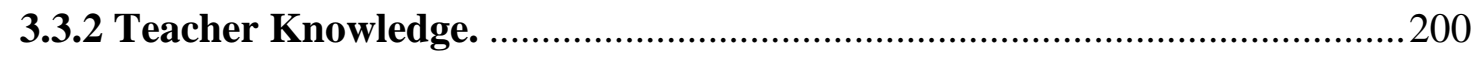

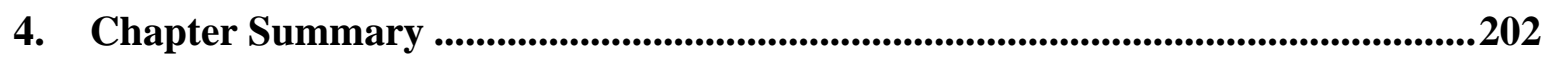

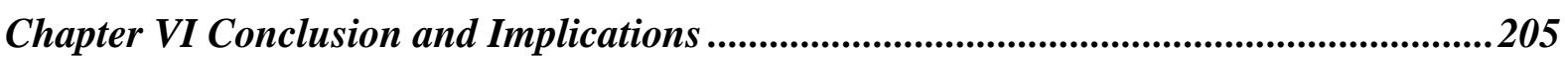

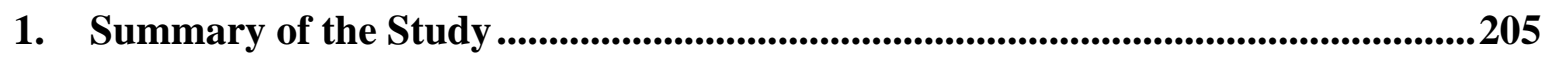

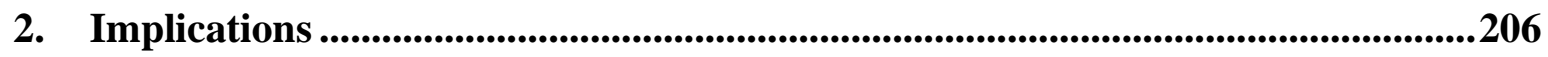

2.1 Teacher Knowledge and Professional Development …..................................206

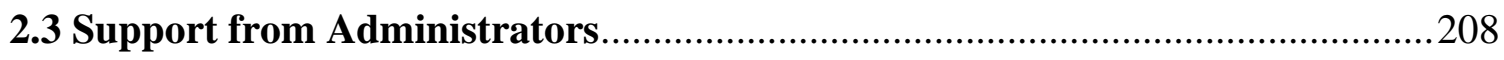

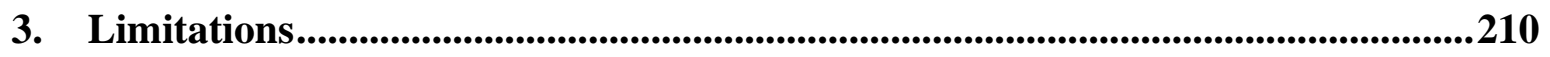

4. Areas for Future Research ............................................................................211

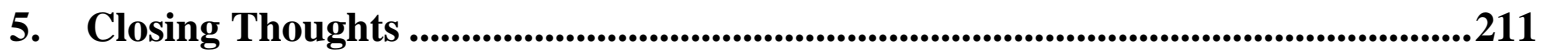

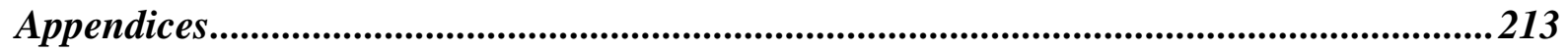

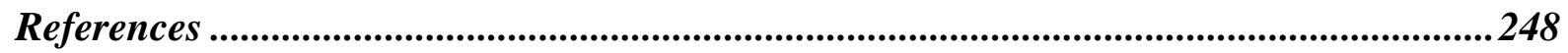




\section{List of Tables}

Table 1 Categories of Teacher Knowledge................................. 32

Table 2 Teaching Efficacy Sources Inventory (adapted from Poulou, 2007)......... 41

Table 3 Principals' Behaviours Supporting Teaching Self-Efficacy (Walker \& Slear, 43 2011)

Table 4 Factors Affecting Vietnamese Teachers' Sense of Self-Efficacy (adapted from Phan, 2015)................................................... 46

Table 5 Influences on Teacher Self-Efficacy 48

Table 6 Validity Strategies for Qualitative Data (adapted from Creswell, 2013)... 87

Table 7 Cronbach's $\alpha$ for Components of Teacher Self-Efficacy Scale............. 91

Table 8 Participants' Qualifications.......................................... 91

Table 9 Levels of Students' Proficiency..................................... 92

Table 10 Numbers of Levels Teaching......................................... 93

Table 11 Teaching Hours................................................... 94

Table 12 Teachers' Participation in Professional Development Activities............ 95

Table 13 Teachers' Confidence in Using English in the Classroom.................. 96

Table 14 Overview of the Participating Teacher Self-Efficacy................... 96

Table 15 Correlation among Three Aspects of Teacher Self-Efficacy.............. 97

Table 16 Correlation between Teacher Self-Efficacy and Some Socio-Demographic 97

Factors

Table 17 Classification of Teacher Self-Efficacy Profiles........................ 98

Table 18 Self -Efficacy Profiles of Teachers Selected for the Second Phase.......... 99

Table 19 Beliefs about Influences on Teacher Self-Efficacy...................... 132

Table 20 Overview of Teachers with Higher Self-Efficacy Scores.................. 133

Table 21 Similarities and Differences in the Teaching Practice of Teachers with 146

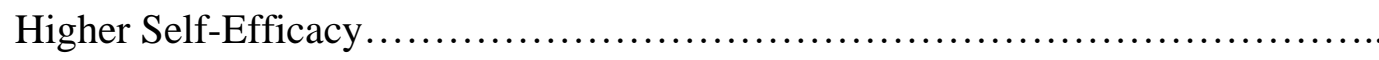

Table 22 Overview of Teachers with Medium Self-Efficacy Scores ................. 146

Table 23 Similarities and Differences in the Teaching Practice of Teachers with 160

Medium Scores of Self-Efficacy ........................................

Table 24 Self-Efficacy Profiles of Teachers with Lower Scores................... 161

Table 25 Similarities and Differences in the Teaching Practice of Teachers with Lower Scores of Self-Efficacy .......................................... 176 
VIETNAMESE EFL TEACHER SELF-EFFICACY IN PRACTICE

\section{List of Figures}

Figure 1: Differences between Teacher Efficacy and Teacher Self-Efficacy (adapted from Dellinger et al., 2008).

Figure 2: Relationship between Teacher Self-Efficacy and Classroom Processes (adapted from Zee and Koomen, 2016)

Figure 3: Relationship between Teacher Beliefs and Teacher Practices and Supporting and Hindering Factors (adapted from Buehl \& Beck, 2014).

Figure 4: Multidirectional Relationship between Teacher Self-Efficacy, Classroom Practices, and Student Motivation (adapted from Thoonen, et al., 2011).

Figure 5: Relationship between Teacher Community, Teacher Collective Efficacy, Teacher Self-Efficacy, and Classroom Goal Structure (adapted from Ciani, Summers, and Easter, 2008).

Figure 6:Data Collection Procedure

Figure 7: Collegiality among Teachers, Managers, and Colleagues.

Figure 8: Teaching as Inquiry (adapted from New Zealand Ministry of Education, 2015 ). 196

Figure 9: Influences on Teacher Self-Efficacy. 201

Figure 10: Internal and External Supports and Hindrances to Teacher Self-Efficacy and Teaching Practice 202 
VIETNAMESE EFL TEACHER SELF-EFFICACY IN PRACTICE

\section{Chapter I Introduction}

This thesis examines profiles of Vietnamese EFL teachers' self-efficacy and the contextual influences on their self-efficacy in their teaching practice. This chapter begins by providing the background of EFL teaching in Vietnam, before moving to a statement of the problem under investigation and the purpose of the research. It finishes with an outline of the study.

\section{EFL Teaching in Tertiary Education in Vietnam}

Vietnam is located in South East Asia with a population of over 97 million people according to UN data (Worldometer, 2020). Vietnamese is the country's official national language (Hoang, 2020). Other languages taught and learnt in the education system are considered foreign languages. Among the foreign languages being taught in Vietnam, "English is given a special status, second only to Vietnamese - the national language - in terms of time allocation [in schools and tertiary education], and the knowledge and skills required" (Hoang, 2020, p. 8). The General School Education English Curriculum mandates English as a compulsory subject for students from Grade 3 through to Grade 12 (MOET, 2018). At tertiary level, English courses are categorized into two groups: English as a major, and English as a nonmajor subject. Colleges and universities in the former category prepare students to become EFL teachers or interpreters. Institutions in the latter category do not offer a degree in English-related studies. Unlike English-major students who must reach a certain proficiency requirement upon graduation, non-English major students vary in their English competence (Trinh \& Mai, 2018). The tertiary EFL curriculum requires students to be able to communicate independently and confidently in English and to study and work in a multilingual and multicultural environment (Vietnamese Prime Minister, 2008). The English proficiency requirement for English-major graduates is level five and non-English major graduates is level three of the Common European Framework of Reference for Languages (CEFR) (Appendix A).

To improve the quality of teaching and learning English in Vietnam, the Vietnamese Prime Minister issued Decision N0 1400/QĐ-TTg to approve the national foreign languages project entitled "Teaching and Learning Foreign Languages in the National Education System for the Period 2008-2020" (Vietnamese Prime Minister, 2008) then reviewed and extended it to 2025. Despite government efforts, English teaching in Vietnam still faces some problems. Many university graduates struggle to communicate in English because of insufficient vocabulary, pronunciation problems, inadequate communication skills or because of their shyness (Giang, 2011; Le, 2011; Ngoc \& Iwashita, 2012; Vu \& Burns, 2014). Many college graduates 
VIETNAMESE EFL TEACHER SELF-EFFICACY IN PRACTICE

cannot meet the foreign language requirement of employment recruiters (Le, 2013). Vu and Burns (2014) suggested some causes such as insufficient number of qualified ELT teachers in lower education levels, unsystematic English programmes, and reading and grammar-oriented teaching and testing programmes. Other researchers presented other issues, for instance, a lack of motivation to communicate in English, a lack of authentic English speaking environment outside the classroom, a knowledge-focused curriculum, a large number of students in a language class, learners' mixed levels of English proficiency in a class, and grammar-based teaching methodology (Do, 2006; Nguyen, 2013; Thanh, 2011; Trinh \& Mai, 2018), and the teachers' low language proficiency (Ngoc \& Iwashita, 2012; Sullivan, 2000; Vu \& Burns, 2014). Trinh and Mai (2018) also discussed the influences of the teaching and learning culture in the Vietnamese EFL context, such as large classes, the lack of teaching facilities, and the use of inappropriate materials.

EFL teachers at universities face many challenges because of some other reasons such as their students come from various provinces, ranging from big cities to remote areas, with very different English learning backgrounds. Students from urban areas tend to start to learn English earlier, and learn it for a longer time with better resources while students from rural regions have only basic language learning opportunities (Lam, 2007). Furthermore, not all students intend to take English at the National University Entrance Exam. Yet, new students are usually organised into the same class regardless of their proficiency. This situation challenges EFL teachers' confidence in many aspects, for example motivating students, adjusting their teaching methodology to meet the needs and levels of students, and managing classes (Le, 2013).

To summarise, English plays a crucial role in Vietnamese education, especially in higher education. Nevertheless, the teaching of EFL in Vietnam is still facing many challenges.

\section{Statement of the Problem and Significance of the Study}

I was an EFL lecturer at one of the most prestigious university in Vietnam for over eight years. Having seen many students struggling to find a job after graduating because of their poor language competence, I often asked myself: "What can I do to help my students improve their English?” Once I read about teacher self-efficacy, I became aware of the influence of this concept on student achievement. I saw the potential of extending knowledge of teacher self-efficacy in EFL teaching in Vietnam to answer my own question.

Teacher self-efficacy has become a growing research interest. It was defined as "the teacher's beliefs in his or her capability to organise and execute courses of action required to 
VIETNAMESE EFL TEACHER SELF-EFFICACY IN PRACTICE

successfully accomplish a specific teaching task in a particular context" (Tschannen-Moran \& Hoy, 2001, p. 233). According to Kleinsasser (2014), the number of articles on the topic published in Teaching and Teacher Education Journal has increased steadily since its commencement in 1985. Before 2000, there were only 18 articles. This number leapt to 63 over the following fifteen years.

This increasing interest may be attributed to the relationship between teacher selfefficacy and teachers' behaviours in the classroom. It determines teachers' level of effort, their teaching targets, and their aspirations. Teachers who have high self-efficacy are open to innovation and more enthusiastic about adjusting their teaching methods to meet their students' needs. They seem to display higher levels of preparation and planning. TschannenMoran, Hoy, and Hoy (1998) found that teachers tended to be more tolerant of students' mistakes and more patient with students who have difficulties. Another finding shows that self-efficacy also affects teachers' perseverance and flexibility when dealing with obstacles and challenges. Highly efficacious teachers are more committed to teaching and display less occupational attrition. In contrast, teachers who have low self-efficacy show low confidence in their capability and tend to blame their failures on external factors. They also avoid or put less effort into challenging teaching tasks. They consider those situations as threats and are unlikely to succeed in them (Bandura, 1993).

More importantly, research has indicated a significant connection between teacher self-efficacy and students' academic achievement. for example, Allinder (1995), Hines (2008), Mojavezi and Tamiz (2012), and Throndsen and Turmo (2013). Moreover, Guo, Piasta, Justice, and Kaderavek (2010) found profound effects of teacher self-efficacy on students' critical thinking, social skills, and positive academic outcomes. The researchers also found that a level of teacher self-efficacy improves teaching quality. This consolidates a finding from Justice, Mashburn, Hamre, and Pianta (2008) that teacher self-efficacy plays an essential role in educational quality. Such findings suggest that a better understanding of Vietnamese EFL teacher self-efficacy is likely to improve the teaching and learning English in tertiary institutions in Vietnam.

In educational settings, teacher efficacy has been studied in various subjects such as mathematics (Allinder, 1995; Hines, 2008; Throndsen \& Turmo, 2013), science (Çakiroglu \& Boone, 2005; Gencer \& Cakiroglu, 2007; Roberts, Henson, Tharp, \& Moreno, 2001; Rubeck \& Enochs, 1991), early childhood education (Garvis \& Pendergast, 2011; Guo, Dynia, Pelatti, \& Justice, 2014), physical education (Martin \& Kulinna, 2004; Martin, McCaughtry, Kulinna, \& Cothran, 2009; Pan, Chou, Li, \& Hu, 2013), and language teaching (Chacón, 
VIETNAMESE EFL TEACHER SELF-EFFICACY IN PRACTICE

2005; Chiang, 2008; Ortaçtepe \& Akyel, 2015; Phan \& Locke, 2015; Yavuz, 2007). Klassen, Tze, Betts, and Gordon (2011) reviewed 218 studies from 1998-2009. Over half of them researched teacher self-efficacy in general. Among the studies on specific domains, most of them were on teaching science, followed by teaching with technology, teaching math, and teaching physical education/sports, respectively. Few studies were found in the domain of teaching language and literacy. In this review, Klassen et al. (2011) also calculated that over three quarters of the studies were quantitative; nearly fifteen percent of them were mixed methods, and just over eight percent applied a qualitative approach. None of the research reviewed involved tertiary teachers. Moreover, teacher self-efficacy is a context-specific construct (Haq \& Akhtar, 2013; Phan \& Locke, 2015). It is influenced by school conditions such as "school level, school repute and facilities available at the school" (Haq \& Akhtar, 2013, p. 645). Research has shown that teachers of different school levels possess different degrees of self-efficacy (Haq \& Akhtar, 2013; Wolters \& Daugherty, 2007). Therefore, it is important to study teacher self-efficacy in a specific tertiary education environment.

There have also been studies about self-efficacy in EFL settings, such as Best (2014), Chacón (2005), Phan and Locke (2015), Yilmaz (2011), and (Ghasemboland \& Hashim, 2013). These studies examined EFL teacher self-efficacy in different settings, from urban to rural, in Venezuela, Iran, Turkey, Thailand, Vietnam and the Middle East. These studies mostly focus on EFL teachers in primary schools (Best, 2014; Yilmaz, 2011), secondary and high schools (Chacón, 2005; Eslami \& Fatahi, 2008; Jafarigohar \& Ganjabi, 2012). Only a few studies have investigated EFL teachers in tertiary education environments (Saeidi \& Kalantarypour, 2011; Yavuz, 2007) with only one in Vietnam (Phan \& Locke, 2015). This Vietnamese study uses qualitative methods to focus on the factors fostering Vietnamese EFL teacher self-efficacy. Teacher self-efficacy is context specific. There has been little research on EFL teacher self-efficacy in tertiary education, especially in Vietnam. Teacher selfefficacy is context-specific so it is important to investigate this topic in the specific context of teachers teaching EFL to non-English major students at a public university in Vietnam.

For these reasons, my qualitatively driven, mixed-methods research examines how teacher self-efficacy is enacted in teaching practice by a purposively selected group of teachers in a specific context.

The following questions will guide this study:

1. What are the self-efficacy profiles of EFL teachers working in a public university in Vietnam? 
VIETNAMESE EFL TEACHER SELF-EFFICACY IN PRACTICE

2. What do these EFL teachers report as influences on their selfefficacy in their classrooms?

3. How do teachers with different profiles of self-efficacy differ in their teaching practice?

\section{Purposes of the Study}

This study examines EFL teachers' self-efficacy and its relationship to their classroom practice at a public university in Vietnam. To address that overarching purpose, the research firstly explores profiles of self-efficacy of EFL teachers working at a university in Vietnam by using a survey questionnaire. It examines teacher self-efficacy in three aspects: engaging students, managing the classroom, and using instructional strategies. It also investigates the relationships between their self-efficacy and some socio-demographic factors. Secondly, the research investigates the relationship between EFL teacher selfefficacy and teaching practice through classroom observation and interviews. This study explores how teachers' perceptions of external factors like classroom and institutional elements and cultural elements influence their self-efficacy. In summary, the research provides a deep understanding of the role of teacher self-efficacy in a specific EFL classroom context.

\section{Outline of the Thesis}

This thesis is organised into six chapters. This chapter has provided the background of learning and teaching English in Vietnam. The second chapter reviews the theoretical framework of self-efficacy in general and teacher self-efficacy in particular, the measures and sources of teacher self-efficacy, and highlights the importance of teacher self-efficacy. This second chapter also reviews some studies on language teacher self-efficacy. In addition, it reviews the literature on teacher beliefs and practices. This chapter concludes with a review of the relationship between language teacher self-efficacy and classroom practice.

Chapter three justifies the research methodology of the study, including the research paradigm, the mixed methods design, the case study design, sampling method, data collection instruments, data analysis, validity and trustworthiness of the study. This chapter also addresses ethical issues relating to the research.

Chapter four presents the research findings to answer the research questions. It presents teacher self-efficacy profiles of the participants in the quantitative phase. Then it describes 
VIETNAMESE EFL TEACHER SELF-EFFICACY IN PRACTICE

what the teacher participants reported as influences on their self-efficacy. This chapter ends with a description of the teaching practice of teachers with different self-efficacy profiles.

Chapter five discusses the research findings to emphasise three main points: the relationship between teaching practice and the teacher self-efficacy scale, the interaction among sources of teacher self-efficacy, and the elements that contribute to the complexity of the relationship between teacher self-efficacy and teaching practice.

Chapter six suggests implications to enhance teacher self-efficacy by improving teacher knowledge, professional development, and teacher autonomy. This chapter also presents the limitations of the current research and recommendations for further study. 


\section{Chapter II Literature Review}

Teacher self-efficacy has had ongoing interest in educational research for several decades (Klassen et al., 2011; Tschannen-Moran et al., 1998). Researchers have presented different definitions of teacher self-efficacy. They have developed various measures to evaluate general teacher self-efficacy as well as teacher self-efficacy in teaching specific subjects. They have also investigated teacher self-efficacy in relation to positive teacher attributes and student outcomes. This chapter will review definitions of teacher self-efficacy, sources and measures of teacher self-efficacy, the importance of teacher self-efficacy, and the relationship between teacher selfefficacy and teaching practice with a focus on language teachers.

\section{What is Teacher Self-Efficacy and Why it is Important?}

In this section, I review the development of teacher self-efficacy concepts, starting with a historical perspective. Then I summarise research on the impacts of teacher self-efficacy on students and teachers. This adds further weight to the importance of this study.

\subsection{What is Teacher Self-Efficacy?}

Teacher self-efficacy has a long history of research and development as a concept. There are several streams of research that feed into this history of definitions of self-efficacy, such as Rotter's theory of locus of control which lead to a seminal study on teacher self- efficacy (Rotter, 1966) and Bandura's social cognitive theory Bandura (1977), and Dellinger, Bobbett, Olivier, and Ellett (2008)

The initial studies on efficacy were undertaken by researchers of the Research and Development Corporation (RAND) in the United States. Researchers developed their work based on Rotter's social learning theory (Rotter, 1966), specifically around the construct of locus of control. According to this theory, some people believe that events are controlled externally. In contrast, people who believe in internal control perceive that the event is subject to their own behaviour. For these people, the achievement, or reward, is believed to originate from their effort and abilities to control surrounding factors. In 1975, the Los Angeles Unified School District contracted the RAND Corporation to conduct a study to identify the policies and factors that successfully promote students' reading scores. Researchers interviewed all principals and 


\section{VIETNAMESE EFL TEACHER SELF-EFFICACY IN PRACTICE}

reading specialists and surveyed 83 teachers who were teaching grade 6 at twenty elementary schools. The teachers responded to two statements by showing their degree of agreement. The first item asked for their evaluation of the influence of external factors on their teaching such as students' family background, their gender, and physical, social, emotional states. Their answers were taken to indicate general teaching efficacy. The second statement referred to personal teaching efficacy as they were requested to assess their confidence in their own teaching. Their responses to the two questions were combined as a measure of their sense of efficacy in dealing with minority students. It was defined as "the extent to which the teacher believes he or she has the capacity to produce an effect on the learning of students" (Armor et al., 1976, p. 23). The study showed that the higher the efficacy the teachers claimed to have, the more progress their students made in reading. In addition, the researchers found that the most effective reading teachers applied different techniques to deal with students' individual needs despite the students' socioeconomic challenges. They were able to deal with those issues and used techniques to motivate their students. They were constantly confident that their teaching would produce positive results. Rotter's theories were subsequently used in many studies such as Greenwood, Olejnik, and Parkay (1990), Rose and Medway (1981), Webb and Ashton (1987).

After the RAND study, Bandura (1977) introduced the social cognitive theory. In this theory, people's psychosocial functioning is formed through mechanisms of personal agency. Among those mechanisms, self-efficacy plays a key role. When people think that their actions can produce certain positive outcomes, they will have motivation to perform those actions. Bandura (1997) defined that "perceived self-efficacy refers to beliefs in ones' capabilities to organise and execute the courses of action required to produce given attainments" (p.3).

Self-efficacy influences human actions in various ways. For example, in certain situations, when people feel threatened or unsure that they are able to cope, they tend to avoid these situations. People's judgement of their abilities influences their effort. Efficacy expectations control the degree of effort and persistence that people expend in dealing with obstacles and unexpected situations. These expectations also impact people's thought patterns and emotional reactions (Bandura, 1977, 1991, 1997). Pajares (1996) concluded that "these influences make self-efficacy a strong determinant and predictor of the level of accomplishment that individuals finally attain" (p.545). 


\section{VIETNAMESE EFL TEACHER SELF-EFFICACY IN PRACTICE}

According to Bandura (1997), self-efficacy regulates human functioning through four processes, namely cognitive, motivational, affective and selective processes. These processes interrelate with each other rather than working separately.

In cognitive processes, self-efficacy impacts thought patterns which can strengthen or weaken performance. There are several forms of these cognitive effects. When structuring their lives, highly self-efficacious people take a future time perspective. People's forethoughts regulate much of their behaviour to reach goals which are set based on their evaluation of their own abilities. People tend to establish higher targets and be more committed to them if they possess higher levels of self-efficacy.

Motivational processes originate from cognitive activities (Bandura, 1997), because "future states cannot be causes of current motivation and action" (p.122). However, Bandura also stated that people's forethoughts could create an expected image of the future. Future states are cognitively represented in present time and are converted into incentives and controllers of behavior. Once people have set a specific target, they will act in order to achieve it. Forethought is transformed into motivations and actions. Bandura (1997) argues that most human motivation is cognitively generated. In cognitive motivation, people's forethought produces incentives and directs their actions in an anticipatory manner. People form beliefs about what they can do and predict possible outcomes of different pursuits. They plan courses of actions to reach the goals. In the cognitive regulation of motivation, efficacy beliefs hold a key role.

Human emotional states are self regulated by self-efficacy beliefs in three fundamental ways. These are the processes of thought, action, and affect (Bandura, 1997). The impact on the thought process has two forms. First, self-efficacy generates attentional biases and affects whether life events are interpreted, cognitively presented and retrieved in ways that are benign or emotionally perturbing. The other form is the ability to control disturbing thoughts if they appear in the flow of consciousness. Secondly, self-efficacy influences action by supporting effective courses of action that can transform the environment to change its emotive potential. Thirdly, this affect-oriented mode of influence refers to the process in which self-efficacy restructures aversive emotive conditions. These processes control "anxiety arousal, depressive mood, and biological stress reactions" (Bandura, 1997, p. 137). 


\section{VIETNAMESE EFL TEACHER SELF-EFFICACY IN PRACTICE}

According to Bandura's (1997) logic, people are partly the products of their environment. The choice of environment determines what people want to become. Choices are made based on people's beliefs about their personal abilities. Such beliefs influence people's selection of activities and environments and the types of environments they produce. People tend to stay away from activities and environments that they believe to exceed their abilities but they are willing to undertake the ones they believe they are capable of doing (Meyer, 1987). The more self-efficacious they are, the more challenging tasks they take on. People with higher selfefficacy prefer more demanding activities. They also display a higher level of persistence. Bandura (1997) emphasised that self-efficacy is a reproductive ability that allows a person to plan and establish cognitive, social, emotional, and behavioural subskills to serve different purposes. Self-efficacy is not primarily about the skills that one person possesses but about what they believe they are able to do with their skills in various conditions. So rather than predominantly about skills, teacher self-efficacy is also about what they believe they can do in different teaching situations.

How a teacher accomplishes the task of creating learning environments relies on teachers' self-efficacy and competences (Bandura, 1997). Reviewing previous literature, Bandura (1997) said that teachers' beliefs in their pedagogical abilities partially decide the organisation of classroom activities and influence students' judgements of teachers' intellectual competences. Gibson and Dembo (1984) used Bandura's concept to develop a scale to measure teachers' self-efficacy in working with difficult students. When they observed classes to search for differences in the teaching practice of teachers with different levels of self-efficacy, they found that more highly self-efficacious teachers believed that they could educate difficult students with appropriate techniques and efforts. They felt they could make their teaching more effective by recruiting family support and defeating negating community impact. In contrast, low self-efficacious teachers thought that they were limited in their ability to teach those students. They believed that uncooperative and conflicting influences from students' home and neighbourhood environments restricted their ability to enable their students to progress. From the observation data, Gibson and Dembo (1984) found that there was not much difference in teacheruse-of-time in academic and non-academic activities between high and low efficacy teachers. Yet, differences were recorded in academic activities. For example, high efficacy teachers spent 


\section{VIETNAMESE EFL TEACHER SELF-EFFICACY IN PRACTICE}

less time in small group instructions than low-efficacy teachers but more time to monitor and check students' work and more time on paper work than their counterparts. .

According to Bandura (1997), teachers' self - efficacy influences not only teachers' general perception about teaching but also their specific instructional activities. Low selfefficacy teachers prefer a protective orientation. These teachers view students' incentives negatively, use strict rules to control students' behaviour in class, and force students to study using negative sanctions and external stimuli (Woolfolk \& Hoy, 1990). Low self-efficacious teachers find themselves stuck in classroom problems. As a result, they doubt their ability to deal with such situations. They get stressed and angry easily because of students' disruptive behaviours. Additionally, they are suspicious of students' progress. They view their job as custodial and tend to use restrictions and punishments to maintain discipline in the class. Their teaching concentrates more on content knowledge than students' improvement. If they could turn back time, they would not select the teaching profession (Melby, 1995). On the other hand, teachers with high self-efficacy use more convincing methods than authoritarian rules. They support "students' intrinsic interest and academic self-directedness" (Bandura, 1997, p. 241).

Tschannen-Moran et al. (1998) defined teacher self-efficacy slightly different from Bandura's (1997). They defined it as “the teacher's belief in his or her capability to organise and execute courses of action required to successfully accomplish a specific teaching task in a particular context" (p.233). Compared to Bandura's definition, Tschannen-Moran and her colleagues considered a person's ability in a specific situation. They claimed that their definition improved the prior models of efficacy because it integrates both theoretical and practical implications. Teacher efficacy is not only about teachers' perceptions of their personal teaching competence but also their beliefs about specific teaching task requirements. In other words, teacher efficacy reflects teachers' assessment of their internal abilities and constraints as well as external elements.

Self-efficacy beliefs are task- and context-specific (Tschannen-Moran \& Hoy, 2001; Tschannen-Moran et al., 1998). Therefore, self-efficacy is not a permanent trait of a person. It is a dynamic system that changes in different conditions. According to Dellinger et al. (2008), selfefficacy differs in strength, level, and generality. Strength means to what extent a person believes 
VIETNAMESE EFL TEACHER SELF-EFFICACY IN PRACTICE

that they able to perform a certain task. Level refers to how challenging a person judges the task. Generality is how much people think they can perform similar tasks.

According to Dellinger et al. (2008), researchers have used the terms teacher efficacy and teacher self-efficacy synonymously. They highlighted the significance of differentiating teacher efficacy and teacher self-efficacy. Teacher efficacy focuses on successfully affecting student performance. In contrast, teacher self-efficacy concentrates on successfully performing specific teaching tasks in a teacher's teaching situation. As my research is about teachers' beliefs about their abilities to teach in their classes, teacher self-efficacy would be a more relevant concept than teacher efficacy. Dellinger et al. (2008), defined teacher self-efficacy as "teacher's individual beliefs in their capabilities to perform specific teaching tasks at a specified level of quality in a specified situation" (p.752). Teacher efficacy was defined as "teachers' beliefs in their abilities to affect student performance" (Dellinger et al., 2008, p. 753). The difference is demonstrated in the following diagram (see Figure 1).

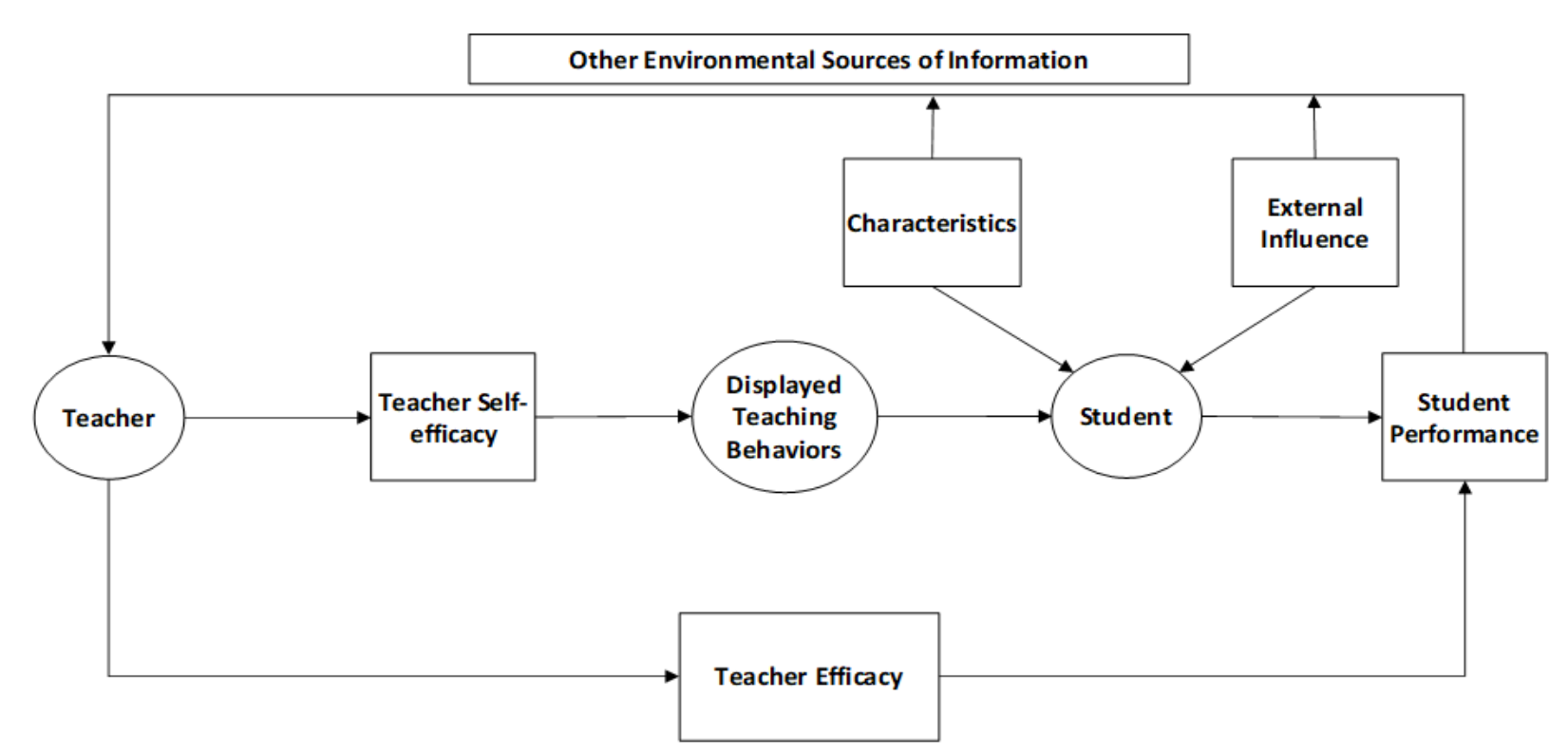

Figure 1: Differences between Teacher Efficacy and Teacher Self-Efficacy (adapted from Dellinger et al., 2008).

Figure 1 shows that student performance is one potential outcome of teaching and learning processes which include both teachers' and learners' behaviours. In Dellinger's definition of teacher efficacy, the importance of teachers' beliefs in their competence to execute 
VIETNAMESE EFL TEACHER SELF-EFFICACY IN PRACTICE

various teaching tasks in different teaching and learning contexts was undermined. Teacher efficacy refers to successfully influencing student performance, which is the desired outcome of effective teaching behaviours and student characteristics and behaviours. In contrast, teacher self-efficacy refers to successfully performing specific teaching tasks.

This can be compared to the efficacy and outcome expectations in Bandura's work (Bandura, 1977). In this article, outcome expectation refers to certain behavioural outcomes, while, efficacy expectation is "the conviction that one can successfully execute the behaviours required to produce the outcome" (Bandura, 1977, p.193). Put another way, self-efficacy refers to efficacy expectations and efficacy refers to outcome expectation such as student performance.

Unlike Tschannen-Moran and Hoy's agent-ends concept (1998), Dellinger's and colleagues' (2008) definition of teacher self-efficacy can be classified as agent-means because it emphasises teachers' perceptions about their ability to take action without any concern about the outcome (Wheatley, 2005). This definition also highlights the specific features of teacher selfefficacy: "specific teaching task" and "specified situation".

In short, teacher self-efficacy has been developed within different theories, including the locus of control (Rotter, 1966), social cognitive theory (Bandura, 1997), and socio-cultural theory (Dellinger et al., 2008). While the early definitions primarily emphasis cognitive features, Dellinger's definition expresses the complex nature of teacher self-efficacy and the role of context. This study will adopt the definition that self-efficacy is the "teacher's individual beliefs in their capabilities to perform specific teaching tasks at a specified level of quality in a specified situation” (Dellinger et al., 2008, p. 752).

Research has shown a strong association between teacher self-efficacy and student achievement, learning motivation, and teachers' professional lives. The upcoming section will review the literature on such relationships.

\subsection{Why teacher self-efficacy importance?}

\subsubsection{How does Teacher Self-Efficacy Link to Students' Performance?}

Researchers have found a positive relationship between teacher self-efficacy and students' achievement in mathematics, literacy, and other subjects. With maths, there is evidence suggesting that students' mathematical competence developed better when studying with highly 
VIETNAMESE EFL TEACHER SELF-EFFICACY IN PRACTICE

self-efficacious teachers than when learning with low self-efficacious teachers (Allinder, 1995; Hines, 2008; Mojavezi \& Tamiz, 2012; Throndsen \& Turmo, 2013). Mojavezi and Tamiz (2012) surveyed eighty senior high school teachers and 150 students in Iran who were randomly selected based on their teachers' levels of self-efficacy. The teachers responded to the long version of the Teacher Sense of Efficacy Scale by Tschannen-Moran and Hoy (2001). In the questionnaire, students answered questions about their intrinsic and extrinsic motivation, their attitudes towards learning English, and expressed their opinion about their teachers. The analysis shows positive correlations between teacher self-efficacy and students' intrinsic motivation, attitudes toward learning English, and their opinion about their English teachers, but a negative correlation with students' extrinsic motivation. It can be inferred that the higher the teacher's self-efficacy, the higher the student's motivation. The researchers also found substantial differences among groups of students. The students whose teachers had high selfefficacy gained better scores in the tests than the others. This finding suggests a significant correlation between teacher self-efficacy and students' achievement.

With similar research objectives, Shahzad and Naureen (2017) surveyed fifty teachers using the Teacher Sense of Efficacy Scale by Tschannen-Moran and Hoy (2001). They assessed a hundred secondary school students' progress through means of a test. The analysis showed a positive relationship between teacher overall self-efficacy, teacher self-efficacy in student engagement, teacher self-efficacy in instructional strategies and student academic achievement. These findings were in accordance with earlier research such as Caprara, Barbaranelli, Borgogni, Petitta, and Rubinacci (2003), Caprara, Barbranelli, Steca, and Malone (2006), Guo, Connor, Yang, Roehrig, and Morrison (2012), Lumpe, Czerniak, Haney, and Beltyukova (2012), and Throndsen and Turmo (2013).

However, in some other studies, the relationship between teacher self-efficacy and student performance was found to be inconsistent, for example, Heneman, Kimball, and Milanowski (2006), Reyes, Brackett, Rivers, White, and Salovey (2012), and Tournaki and Podell (2005). Heneman et al. (2006) conducted a longitudinal study with over a thousand teachers responding to their online survey of the Teacher Sense of Efficacy Scale (TSES) (Tschannen-Moran, Hoy, 2001) to measure their self-efficacy. Among those, 180 teachers whose student performance was recorded were selected to investigate the relationship between teacher 
VIETNAMESE EFL TEACHER SELF-EFFICACY IN PRACTICE

self-efficacy and student performance. The data showed a significant direct effect of teacher selfefficacy scores on teachers' performance but no significant direct effect on student achievement. Heneman et al. (2006) explained that the TSES was developed as task- and context-specific within the domain of actual teacher behavior. The measure was not designed as a predictor of student achievement. With this scale, teacher self-efficacy should be measured within the teaching role rather than the ability to influence student achievement or reaching specific achievement goals. Zee and Koomen (2016) stated that the relationship between teacher selfefficacy and student progress is complex and reciprocal, and it is influenced by various factors like environmental forces, personal factors and behaviour that mediate or moderate this relationship.

To summarize, research has shown an inconsistent relationship between teacher selfefficacy and students' performance, which means that in some situations, teacher self-efficacy may influence students' performance but in some other situations, it may not.

\subsubsection{How does Teacher Self-Efficacy Link to Teachers' Professional Life?}

Not only does teacher self-efficacy play a crucial role in direct or indirect influencing of student learning motivations and achievements, but teacher self-efficacy also appears to be related to various aspects of teachers' professional life such as job stress (Klassen \& Chiu, 2010; McCormick \& Ayres, 2009; McCormick, Ayres, \& Beechey, 2006; Schwarzer \& Hallum, 2008), job satisfaction (Canrinus, Helms-Lorenz, Beijaard, Buitink, \& Hofman, 2012; Caprara et al., 2006; Klassen \& Chiu, 2010; Skaalvik \& Skaalvik, 2014), teacher burnout (Egyed \& Short, 2006; Schwarzer \& Hallum, 2008; Shoji et al., 2016; Skaalvik \& Skaalvik, 2007, 2010), and occupational commitment (Canrinus et al., 2012; Chesnut \& Burley, 2015; Ford, Van Sickle, Clark, Fazio-Brunson, \& Schween, 2017; Klassen \& Chiu, 2011). Below are examples of relevant studies.

Klassen and Chiu (2010) found a relationship between teacher self-efficacy, job stress and satisfaction, and contextual factors including personality characteristics and school level. The researchers recruited a sample of 1,430 teachers from Western Canada, who were working at various school levels in different locations. The majority of them were European Canadian. They were only performing teaching tasks. No administrator or counsellor was recruited. The teachers responded to a questionnaire comprising measures of teacher self-efficacy: job satisfaction, 


\section{VIETNAMESE EFL TEACHER SELF-EFFICACY IN PRACTICE}

overall job stress, and sources of job stress. Analysis showed that the teachers who were suffering from a high level of classroom stress displayed a lower level of self-efficacy across three domains of classroom management, student engagement and instructional strategies with significantly less self-efficacy in classroom management. For example, the teachers suffering from stress because of students' misbehaviour in the classroom reported high levels of stress and low self-efficacy for classroom management. However, the teachers with more workload stress reported higher self-efficacy in classroom management but not much difference in other aspects of self-efficacy. Klassen and Chiu (2010) suggested that teachers with extensive classroom stress from student misbehaviour may have had unsuccessful experiences, which in turn resulted in their low self-efficacy to manage such behaviour. In contrast, teachers with more severe workload stress would exert more effort when planning their teaching and would be more prepared to manage student behaviours in their class. Comparing male and female teachers, Klassen and Chiu (2010) also found significant differences. The women teachers suffered from more extensive classroom and workload stress. In this study, the researchers also found a link between teacher self-efficacy and job satisfaction. Teachers who reported they were highly selfefficacious in classroom management and instructional strategies were more satisfied with their job. Teachers experiencing high levels of overall stress expressed lower job satisfaction.

In a later study, Klassen and Chiu (2011) recruited 434 practicing teachers with over half of them were teaching in primary schools. A similar number of about $20 \%$ were working at secondary and middle schools. They also surveyed 379 preservice teachers who were in the final year of an undergraduate education programme at a university in Western Canada. The participants responded to a measure of occupational commitment and intention to quit. This questionnaire was developed by Hackett, Lapierre, and Hausdorf (2001). In addition, their selfefficacy was measured using the Teacher Sense of Efficacy Scale (Tschannen-Moran \& Hoy, 2001). Job stress was investigated based on a single item. The research findings showed that the teachers' self-efficacy in managing classroom stress and instructional strategies was linked to occupational commitment. Teachers who reported greater levels of classroom stress expressed less occupational commitment. In contrast, teachers who were more self-efficacious in instructional strategies showed a greater level of commitment to their job. Results from the preservice teachers' data showed a slight difference from the practising teachers. Their stress and self-efficacy in classroom management were linked to occupational commitment. Those teachers 


\section{VIETNAMESE EFL TEACHER SELF-EFFICACY IN PRACTICE}

with a high level of overall teaching stress and teaching assignment stress expressed less commitment to their occupation. Moreover, the teachers who reported higher self-efficacy in managing the class had more occupational commitment.

Research has found a connection between teacher self-efficacy and teacher burnout (Brouwers \& Tomic, 2000; Bumen, 2010; Egyed \& Short, 2006; García-Ros, Fuentes, \& Fernández, 2015; Sarıçam \& Sakız, 2014; Skaalvik \& Skaalvik, 2007, 2010). Teacher burnout is defined as "a syndrome of emotional exhaustion, depersonalization, and reduced personal accomplishment" (Skaalvik \& Skaalvik, 2007, p. 613). However, according to Skaalvik and Skaalvik (2007), there is less agreement about how to explain the relationship between teacher self-efficacy and teacher burnout. They suggested a possible explanation whereby a feeling of burnout is the result of low self-efficacy. Similarly, in another study, Skaalvik and Skaalvik (2010) examined the relationship between teacher self-efficacy and teacher burnout. Over two thousand teachers working in 113 elementary and middle schools in Norway took part in the research. The analyses showed that teacher self-efficacy was negatively related to both dimensions of teacher burnout (emotional exhaustion and depersonalisation). Teachers' job satisfaction was negatively related to emotional exhaustion and weakly, but directly related to self-efficacy, depersonalisation, autonomy, and time pressure. Also, all five school context variables (time pressure, autonomy, relations with parents, discipline problems, supervisory support) in this study were indirectly related to job satisfaction through self-efficacy and burnout. Sarıçam and Sakız (2014) used the Maslach Burnout Inventory (MBI) developed by Maslach and Jackson (1981) to measure teacher burnout in three domains: emotional exhaustion, depersonalisation, and personal accomplishment. Teacher self-efficacy was measured by the Teachers' Sense of Efficacy Scale (TSES) by Tschannen-Moran and Hoy (2001). 118 teachers working in special education schools in different cities in Turkey participated in this study. The researchers found significant correlations between teacher self-efficacy and dimensions of teacher burnout. They found that emotional exhaustion, depersonalisation, and total burnout scores of teachers related negatively to teacher self-efficacy. Conversely, the research findings showed a positive association between personal accomplishment and teacher self-efficacy. In addition, the study also found significant correlations between domains of teacher self-efficacy and dimensions of teacher burnout. This finding indicates that the strength of teachers' beliefs in their abilities to employ appropriate instructional strategies, engaging students, and managing the 


\section{VIETNAMESE EFL TEACHER SELF-EFFICACY IN PRACTICE}

class can predict the unlikelihood of burnout risk. This relationship indicates that teachers with higher sense of efficacy are less likely to experience depersonalisation and emotional exhaustion.

Research has found an association between teacher self-efficacy and their occupational commitment, for example, Rots, Aelterman, Vlerick, and Vermeulen (2007), Chan, Lau, Nie, Lim, and Hogan (2008), Canrinus et al. (2012), and Chesnut and Burley (2015).

Rots et al. (2007) collected data from 209 teachers from Belgium. The researchers translated existing questionnaires to measure the participants' perception of teacher education preparation, faculty support in their teacher education programme, mentoring support during their teaching practice, teacher efficacy using The Teachers' Sense of Efficacy Scale. The questionnaire also measured professional orientation, teaching commitment, entrance into teaching, and background information. Teaching commitment was found to positively and directly relate to teacher self-efficacy. The higher the self-efficacy the participants reported, the higher commitment to teaching they expressed.

To study the relationship among indicators of teacher professional identity, Canrinus et al. (2012) surveyed over one thousand secondary school teachers. The researchers used an online questionnaire to measure four constructs relevant to teachers' sense of professional identity, namely job satisfaction, self-efficacy, occupational commitment and change in level of motivation. The findings showed a significant relationship among those constructs. The researchers also expected that the effects of teacher self-efficacy on their occupational commitment were mediated by changes in their motivation.

In a meta-analysis of research on the impacts of self-efficacy on pre-service and inservice teachers' professional commitment, Chesnut and Burley (2015) reviewed 33 studies that covered over sixteen thousand teachers across North America, Europe, Australia, and Asia. The analysis found a significant relationship between teacher self-efficacy and teacher commitment to their occupation. However, there was no significant difference between pre-service and inservice teachers.

Zee and Koomen (2016) proposed a model showing the relationship between teacher selfefficacy and classroom processes, academic adjustment, and teacher well-being, which is shown in Figure 3. 
VIETNAMESE EFL TEACHER SELF-EFFICACY IN PRACTICE

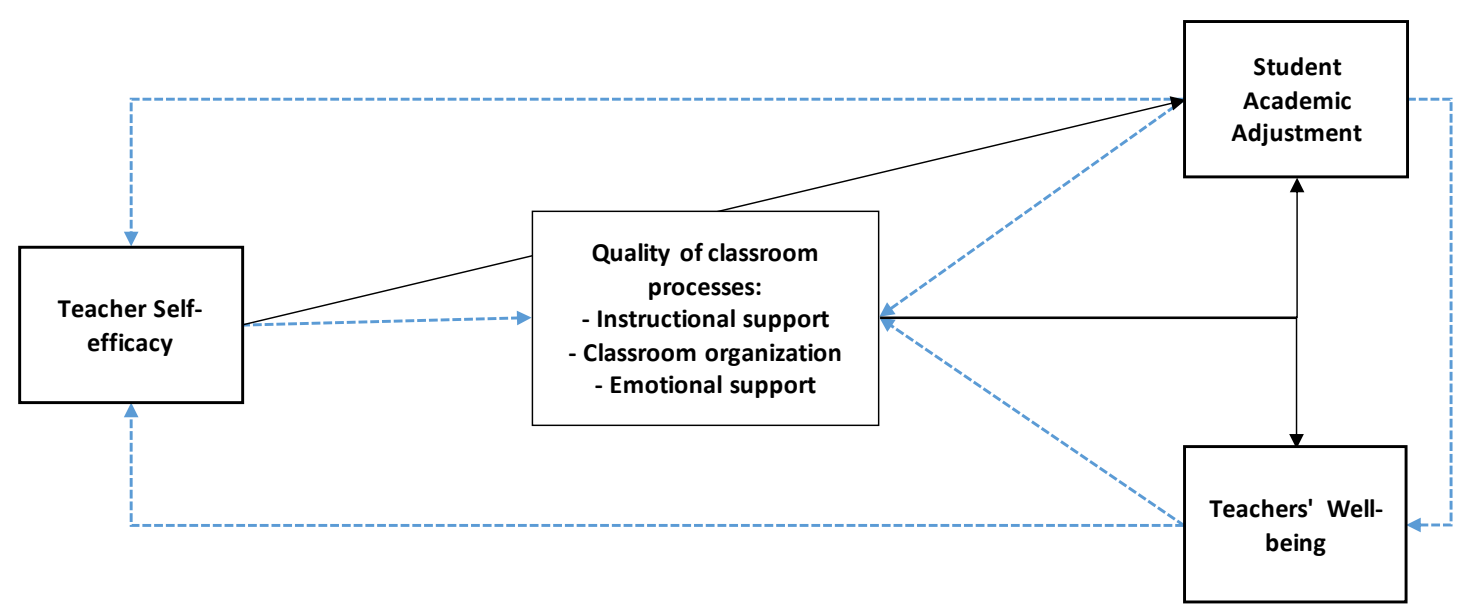

Figure 2: Relationship between Teacher Self-Efficacy and Classroom Processes (adapted from Zee and Koomen, 2016).

This model came from the process of reviewing articles on the consequences of teacher self-efficacy published between 1976 and March 2016. They primarily focused on pre-service and in-service teachers' individual self-efficacy. All the articles selected for the review presented at least one direct or indirect relationship between teacher self-efficacy and classroom processes, academic adjustment, and teacher well-being. In addition, the researchers selected only quantitative studies which used Bandura-based instruments to measure teacher self-efficacy. First, the authors attempted to find how teachers' self-efficacy influenced the quality of classroom processes. They summarised that pre-service teachers' self-efficacy did not have any influence on their overall levels of instructional support. However, in-service teachers' selfefficacy affected their instructional practices in different aspects such as "process-oriented instruction and differentiation, the number of goal changes made, the ability to connect to students' lives and employ effective teaching strategies, and their choices of differentiated instructional strategies supporting inclusive education" (Zee \& Koomen, 2016, p. 990) They also found that teachers who reported themselves as efficacious involved themselves in professional learning activities more frequently than those who were not. They kept their career up-to-date and attempted to improve their teaching by applying new approaches. They changed the focus of their lessons to cater for more process-oriented approaches to student learning.

Researchers have found a connection between teacher self-efficacy and three domains of classroom organisation: managing classroom behaviours, conducting inclusive practices and 


\section{VIETNAMESE EFL TEACHER SELF-EFFICACY IN PRACTICE}

making referral decisions, and using instructional management strategies (Zee \& Koomen, 2016). However, because of the relevance to my study, I will focus on the first and the third aspects only. In the first area of managing classroom behaviour, small-scale and correlational research on the link between teacher self-efficacy in organising and managing students' behaviours and time has yielded consistent results. For example, highly efficacious teachers deal with problems like low achievement, social rejection, shyness, disobedience, hostility, hyperactivity and students' bullying behaviour better than teachers with low self-efficacy (Almog \& Shechtman, 2007). Aiming to provide validity evidence for a newly developed measure called "the classroom appraisal of resources and demands" (CARD), Lambert, McCarthy, O' Donnell, and Wang (2009) recruited 521 teachers working in 16 elementary schools in a large urban area in the United States. The researchers found that students' behaviour problems in the classroom diminished teacher self-efficacy and resulted in their taking a critical attitude towards their teaching ability. Abu-Tineh, Khasawneh, and Khalaileh (2011) collected data from 566 public school teachers in Jordan with two measures: the Teacher Self-Efficacy Scale (Woolfolk \& Hoy, 1990) and the Attitudes and Beliefs on Classroom Control Inventory (Martin, Yin, \& Baldwin, 1998). The Teacher Self-Efficacy Scale gathered information about teacher personal efficacy referring to their ability to help "difficult or unmotivated students from homes with environments that are not supportive of education to learn effectively" (Martin et al., 1998, p. 178). In addition, the scale measured teacher general efficacy and the teachers' ability to deal with negative influences of students' backgrounds. The participating teachers reported high levels of personal efficacy but moderate levels of general efficacy. Regarding the relationship between the type of teacher self-efficacy and management styles, the researchers found a moderate, positive, and significant correlation between personal teacher efficacy and instructional management style. A similar relationship was found between teacher personal efficacy and people management and a moderate, positive but insignificant relationship between personal teaching efficacy and behaviour management.

In the area of instructional management, studies such as Dunn and Rakes (2011) and Temiz and Topcu (2013) have found differences in teaching approach. While low self-efficacy preservice teachers preferred a traditional, teacher-centred approach, those who saw themselves as highly self-efficacious were more likely to apply a learner-centred and constructivist approach. 
VIETNAMESE EFL TEACHER SELF-EFFICACY IN PRACTICE

Similarly, elementary school teachers with a high level of self-efficacy tended to use more learner-centred and constructivist instructions (Nie, Tan, Liau, Lau, \& Chua, 2013).

In summary, research has shown a link between teacher self-efficacy and different domains of their professional life. These are positive aspects such as job satisfaction, occupational commitment, innovative teaching, and teacher well-being. The negative aspects include teacher burnout and job stress. In other words, teacher self-efficacy plays an important role in teachers' professional life.

\section{How is Teacher Self-Efficacy Measured?}

Researchers have developed instruments to measure general teacher self-efficacy and self-efficacy of specific subjects. Those measures were constructed using three different strands of theory. These strands are the locus of control (Rotter, 1966), social cognitive theory (Bandura, 1997), and social culture theory (Dellinger et al., 2008). This section will review the popular measures of teacher self-efficacy.

The first group of researchers theorized their teacher efficacy scales drawing on Rotter's locus of control. As mentioned earlier, RAND researchers introduced a scale with two items as follows:

1. When it comes right down to it, a teacher really can't do much (because) most of a student's motivation and performance depends on his or her home environment.

2. If I try really hard, I can get through to even the most difficult or unmotivated students. (Armor et al., 1976, p. 23)

Teachers who strongly agree with the first statement indicate their beliefs in power influences of external factors on students' motivation and performance. Such factors can be classified into groups of environmental issues like the value of home education, the violence, tension, substance abuse in students' homes or the community; the social and economic realities regarding students' gender, race, and class; and the physiological, emotional and cognitive needs of individual student. Teachers' beliefs about these factors have been labelled as general teacher efficacy (GTE). Teachers who express agreement with the second statement indicate beliefs in their abilities to overcome obstacles to student learning either from their experience or training. This belief has been labelled as personal teaching efficacy (PTE). RAND researchers used this 


\section{VIETNAMESE EFL TEACHER SELF-EFFICACY IN PRACTICE}

measure in their studies (Armor et al., 1976, Berman et al., 1977). However, the reliability of this two-item scale was a concern for researchers (Tschannen-Moran \& Hoy, 2001). This concern led to attempts to develop more comprehensive and longer scales.

Guskey (1981) established a 30-item scale measuring "responsibility for student achievement" (RSA). Each item represented one event with two alternatives. Either that event was caused by the teacher or by elements external to the teachers' control. Participants rated the relative influence of the two options as percentages. The scores indicate a measure of how much teachers believe they are responsible for the student outcomes in general, and student success and failure, in particular. However, this measure has not been used in any other study (Tschannen-Moran, Hoy, 2001).

At the same time that the RSA was developed, Rose and Medway (1981) proposed a 28item instrument called "the teacher locus of control" (TLC) that described both student success and failure. Each item has two explanations, internal teacher attribution, and external factors.

At the same time as the RSA and TLC, the Webb scale was developed by Ashton, Olejnik, Crocker, and McAuliffe (1982) This scale aimed to increase the reliability of the RAND efficacy scale but still maintain the narrow conceptualization of teacher efficacy. In order to reduce the problem of social desirability bias, a forced-choice format with items matched for social desirability was used. There were seven items with two choices for each item. Participants were asked to decide if they agreed most strongly with the first or the second statement. According to Tschannen-Moran and Hoy (2001), (Tschannen-Moran \& Hoy, 2001) these measures have never been widely used.

While the above measures followed Rotter's social learning theory, other instruments were developed based on Bandura's social cognitive theory. Ashton, Buhr, and Crocker (1984) created a series of vignettes in which teachers judge how effectively they handle certain situations. Two frames of reference for each judgement were tested. In one version, teachers were asked to judge whether their performance would be "extremely ineffective" or "extremely effective" in certain situations. In another version, they were asked to compare their performance with other teachers' performance to find if they would be "much less effective" or "much more effective" than the others. The scale also asked about the level of stress in each situation. The result signified that "stress could not be used as a proxy for efficacy" (Tschannen-Moran \& Hoy, 2001, p. 788). Outside the original study, this scale was used in only other study. The teacher 


\section{VIETNAMESE EFL TEACHER SELF-EFFICACY IN PRACTICE}

efficacy scale (TES) received more extensive attention. The Scopus database shows 605 studies citing Gibson and Dembo. Their instrument consists of 30 items on a 6-point Likert scale from strongly disagree to strongly agree. Although this measure was widely used in the decade of its development, there remained some problems with the consistency of the items and the clarity about the meaning of the two factors. Factor analysis showed that some items seemed to belong to both factors. Therefore, some researchers modified this scale. For example, Riggs and Enochs (1990) developed the Science Teaching Efficacy Belief Instrument (STEBI) to measure teacher self-efficacy in teaching science. Rubeck and Enochs (1991) adapted Gibson and Dembo's scale to differentiate teacher self-efficacy in teaching chemistry and teaching science.

In an attempt to better reflect the domain of classroom management, Emmer (1990) adapted the Gibson and Dembo measure. A 36-item instrument using a 5-point Likert scale was divided into three subscales, including efficacy for classroom management and discipline, external influences, and personal teaching efficacy. With this instrument, Emmer (1990), Emmer and Hickman (1990) found that teacher efficacy correlated with strategies aiming at increasing or encouraging desirable student responses through praise, encouragement, attention, and rewards.

While people were struggling to find the best measure of teacher efficacy, Bandura (1997) pointed out that teacher efficacy was not identical across different tasks and subject matters. He constructed a 30-item instrument with seven subscales: efficacy to influence decision making, efficacy to influence school resources, instructional efficacy, disciplinary efficacy, efficacy to enlist parental involvement, efficacy to enlist community involvement, and efficacy to create a positive school climate. Participants responded to each item on a nine-point Likert scale with the notations: "nothing, very little, some influence, quite a bit, a great deal". This scale aimed to provide a multifaceted picture of teachers' efficacy beliefs without becoming too narrow or specific. However, there is no information about the reliability and validity of this measure (Tschannen-Moran, Hoy, 2001).

Dellinger and colleagues (2008) pointed out some problems with the above measures. The conceptualization of teacher efficacy and teacher self-efficacy was not firmly grounded in the self-efficacy theory. Teacher self-efficacy was defined in various and discordant ways. It was commonly confused with other constructs like self-esteem, locus of control, self-concept, and outcome expectancy. These measures of teacher self-efficacy involved extraneous factors and the 


\section{VIETNAMESE EFL TEACHER SELF-EFFICACY IN PRACTICE}

scales did not consider the specificity and generality of the task performance, nor the role of context and situation. The measures failed to conceptualize and analyze teacher self-efficacy from different dimensions.

With the aim of developing a valid and reliable measure, Tschannen-Moran and Hoy (2001) developed the Ohio State Teacher Efficacy Scale (OSTES) with a long form of 24 Likert items and a short form of 12 items. In this scale, the term teacher efficacy" and "teacher selfefficacy" were used synonymously. Therefore, from Dellinger's perspective it measures teacher self-efficacy beliefs (Dellinger et al., 2008). The scale asks teachers to rate their capabilities to perform different tasks in different situations. Dellinger et al. (2008) praised the instrument because it addressed most of the problems with the earlier instruments. It included specific teaching tasks in various domains of functioning, which could capture the multidimensional nature of teaching. However, Dellinger et al (2008) criticized the scale because most of the items on the scale were not explicitly relevant to research on effective teaching and learning. Additionally, the context in which teachers form their self-efficacy was not clearly captured. Some items refer to the context like students and classrooms rather than teachers' ability. Despite such deficits, this scale has been widely used in educational research (Chacón, 2005; Shore, 2004).

Subsequently Dellinger et al. (2008) developed a system of measures to assess teacher self-efficacy, teacher work-group collective efficacy, and teacher faculty collective efficacy. Teacher work-group collective efficacy referred to "individual teachers' perceptions of their designated work-group's shared beliefs in their abilities to accomplish various goals such as enhancement of learning, non-instructional tasks, and school improvement goals" (Dellinger, 2001, p. 30). Teacher faculty collective efficacy was defined as "individual teachers' perceptions of their faculty's shared beliefs in its abilities to accomplish various goals such as enhancement of learning, non-instructional tasks (e.g. increasing parental involvement), and school improvement goals" (Dellinger, 2001, p. 31). The teacher efficacy beliefs system-self (TEBSSelf) was designed to assess teacher beliefs about their self-efficacy in performing teaching tasks in their own classrooms that foster effective teaching and learning. The TEBS-Self consists of 30 items with a four-point response ranging from very weak, moderate, strong, and very strong 


\section{VIETNAMESE EFL TEACHER SELF-EFFICACY IN PRACTICE}

belief in the respondent's capabilities. Dellinger et al. (2008) described the process of developing this measure and three studies that used it. They claimed that the measure was valid and reliable.

In addition to scales to measure teacher self-efficacy in general, there have been measures of teacher self-efficacy in specific subjects. For example, Riggs and Enochs (1990) developed the Science Teaching Efficacy Belief Instrument which shows two uncorrelated factors of personal science teaching efficacy and science teaching outcome expectancy. Then Rubeck and Enochs (1991) distinguished chemistry teaching efficacy from science teaching efficacy. As mentioned earlier, these measures were adapted from the scale of Gibson and Dembo (1984). Ritter, Boone, and Rubba (2001) developed the SEBEST to measure prospective elementary teacher self-efficacy about equitable science teaching and learning. This measure was modelled after Science Teaching Efficacy Belief Instrument for Prospective Teachers (STEBI-B) (Riggs \& Enochs, 1990). According to Ritter et al. (2001), the instrument is content and construct valid with high internal reliability qualities. In special education, Coladarci and Breton (1997) modified Sherri Gibson and Myron H. Dembo (1984) scale to make a 30-item instrument. In addition, Meijer and Foster (1988) developed 11-Likert questions to measure Dutch teacher self-efficacy in special education. Enochs, Smith, and Huinker (2000) developed an instrument to measure self-efficacy of math teachers.

Among the number of measures of teacher self-efficacy outlined in this section, the Ohio State Teacher Efficacy Scale (OSTES) (Tschannen-Moran \& Hoy, 2001) has been most widely used and validated in various contexts. For these reasons, this instrument was adapted in this study in order to make an initial assessment of self-efficacy before collecting qualitative data to understand how self-efficacy operates in context in selected individuals.

\section{Sources of Self-Efficacy and Sources of Teacher Self-Efficacy}

This section will firstly review the sources of self-efficacy in general then specifically focus on the sources of teacher self-efficacy.

\subsection{What are the Sources of Self-Efficacy?}

Four sources of self-efficacy were described by Bandura (1977), namely enactive mastery experience, vicarious experience, social persuasion, and physiological and affective states. 


\section{VIETNAMESE EFL TEACHER SELF-EFFICACY IN PRACTICE}

Enactive mastery experiences are variously referred to as "performance accomplishments" (Bandura, 1977), “enactive attainments" (Bandura, 1986), and past performance attainments (Bandura, 1997). These experiences are considered the most influential source of self-efficacy (Bandura, 1997; Usher \& Pajares, 2008). In other words, "mastery experiences involve the achievement of goals (i.e., accomplishment/attainment) through direct and personal action (i.e., enactive)" (Morris, Usher, \& Chen, 2017). They most genuinely demonstrate a person's ability to manage to succeed. People's achievements strengthen their belief in their abilities. Conversely, failures weaken their self-efficacy. Bandura (1997) also showed that if people reach success easily, they may expect similar results. Consequently, unsuccessful experiences make them feel pessimistic. Persistent self-efficacy is formed with experiences of success in dealing with difficulties through "perseverant effort" (Bandura, 1997, p. 80). It is further explained that some obstacles and hindrances in life teach people how much effort they have to make in order to succeed. Such incidents also suggest what they can learn from their failures and turn them into achievements by adjusting their abilities to manage the event better. Once people are persuaded that they have the ability to succeed, they persevere in their attempt to deal with any obstacles. As a result, they become more self-efficacious.

The second source is vicarious experience, which is derived from observing either a model or oneself performing a task. According to Bandura (1997), in order to have an adequate evaluation of their abilities, people need to compare themselves with others. This kind of social comparison helps to diagnose one's abilities. Therefore, people can increase their self-efficacy when seeing someone perform a task successfully. They are convinced that if others can do it, they are capable of doing it too. Conversely, watching others' failures can lower one's belief in their competences. However, as Bandura (1997) emphasised, "the greater the assumed similarity, the more persuasive are the model's successes and failures" (p.87). One person builds selfefficacy not only from observing other people but also from self-modelling. If a person overcomes specially arranged conditions then achieves some success, his/her belief in his/her ability will increase. Moreover, Bandura (1997) highlighted that vicarious experience significantly influences self-efficacy formation when the task is relatively novel.

Self-efficacy is also derived from social persuasion in the form of evaluative feedback. When dealing with obstacles, a person feels more effective if they are encouraged in their 


\section{VIETNAMESE EFL TEACHER SELF-EFFICACY IN PRACTICE}

abilities to overcome difficulties. However, if other people doubt their competence, they will lose their sense of efficacy. Bandura (1997) proposes that if people are verbally convinced of their abilities to perform certain tasks, they tend to rally a greater effort to achieve those tasks. To the extent that persuasive boosts in the perception of efficacy lead people to try hard to succeed, selfaffirming beliefs promote the development of skills and a sense of personal efficacy. Persuasory efficacy attributions, therefore, have their greatest impact on people who have some reasons to believe that they can produce effects through their actions. To raise unrealistic beliefs in personal capabilities, however, only invites failures that will discredit the persuaders and further undermine the recipients' beliefs in their capabilities. According to Bandura (1997), the knowledge and credibility of the person providing feedback mediates the influence of the feedback. It is who delivers and how the feedback is delivered that matters. For example, Pajares (2006) said that "knee-jerk praise or empty inspirational homilies" (p.349) seemed to have insignificant influence. In contrast, if the feedback is detailed and sincere, it may have a substantial impact on one's self-efficacy development. It is worth mentioning that discouraging or negative feedback can actually have a more significant impact on one's self-efficacy than positive feedback. As Bandura (1997) stated, one's self-beliefs may be more easily damaged by discouraging messages than enhanced by positive persuasions. He also emphasised that social persuasions become exceptionally influential for a person with little experience in the field.

Another source of self-efficacy is physiological and affective states (or emotional arousal) (Bandura, 1997). These physiological indicators are especially important in performing activities which involve physical accomplishments, healthy functioning, and coping with stressors. For example, a faster heartbeat and respiratory rate, shaky hands which imply a person's nervousness or over-anxiety may damage one's ability to function and prevent a person from making the best of his competence (Tschannen-Moran et al., 1998).

The above four sources of self-efficacy are divided into two clusters. The first cluster comprises direct personal experience, including mastery experience, emotional arousal, and social persuasion. The other cluster reflects indirect experience, which is vicarious experience (Poulou, 2007).

The four sources are believed to have unequal roles in efficacy information. According to Bandura (1997) and Usher and Pajares (2008), enactive mastery experiences were the most 
VIETNAMESE EFL TEACHER SELF-EFFICACY IN PRACTICE

powerful source of self-efficacy because they provided genuine evidence of a person's competence to execute a task. Vicarious experiences were significantly important when people depended on modelled experiences because they had little or no direct knowledge or experience of performing a task. Social persuasion had only modest influence over the escalation of a durable self-efficacy level but might have a temporary impact on people's attempts and persistence. Physiological and affective states were not consistently indicative of one's competence, therefore they were considered the least significant source of efficacy information.

\subsection{How do Teachers Develop Their Self-Efficacy?}

The previous section has reviewed sources of self-efficacy in general. My study is about Vietnamese EFL teacher self-efficacy, it is important to review the literature on how the four general sources of self-efficacy are manifested in teachers' performance. This pertains to the aims of my study which include teachers' performance in classrooms.

\subsubsection{Mastery Experiences.}

According to Morris et al. (2017), among the four sources, mastery experiences have received the most attention, likely because Bandura (1997) stated that this is the most powerful source. The mastery experiences are measured by teachers' exposure to teaching and/or teaching experiences (Aydin \& Hoy, 2005; Bautista \& Boone, 2015; Cantrell, Young, \& Moore, 2003; Smolleck \& Mongan, 2011).

Pre-service teachers are claimed to develop their mastery experiences as a source of teacher self-efficacy after attending courses that provide them with pedagogical knowledge (Cantrell et al., 2003; Smolleck \& Mongan, 2011), especially with guided teaching practice or teaching practicum (Atay, 2007; Cantrell et al., 2003; Chiang, 2008; Smolleck \& Mongan, 2011).

Pre-service teachers have been found to be more self-efficacious after completing their teaching practicum or student teaching experiences. For example, Cantrell et al. (2003) explored possible effects on self-efficacy beliefs of pre-service elementary science teachers who were taking three consecutive courses: seminars, advanced methods, and student teaching. The students who experienced success when teaching for more than 3 hours across the span of their 3-week practicum showed the most substantial increase in their personal science teaching 


\section{VIETNAMESE EFL TEACHER SELF-EFFICACY IN PRACTICE}

efficacy. The knowledge that they learnt during the course and their successful implementation "act as a performance assessment that feeds into an individual's efficacy beliefs that future performances will be similar" (Cantrell et al., 2003, p. 189). This aligns with Bandura's (1997) theory that successful past performance helps to increase teacher self-efficacy.

Smolleck and Mongan (2011) drew a similar conclusion from their research. The data analysis showed that pre-service teacher self-efficacy grew after the science methods course and after the students' teaching experience. In the interviews, the participants revealed their thoughts that "field placement" and "teaching lessons to elementary-aged children" helped them better understand teaching science as inquiry.

Practising teachers gained their mastery experiences from their actual teaching (Morris \& Usher, 2011; Tschannen-Moran \& McMaster, 2009) or virtual teaching experiences (Bautista \& Boone, 2015). Bautista and Boone (2015) attempted to measure the impact of a mixed reality teaching environment called TeachMETM Lab on early childhood teacher self-efficacy beliefs in teaching science. Sixty two early childhood student teachers practised teaching science in a realtime simulated classroom where the students involved were digital avatars. The participants reported an increase in their self-efficacy. They named different sources of self-efficacy that the lab provided them with, including instructor modeling, peer observations, and act of teaching avatars. They especially praised the opportunity to teach as if in a real-life classroom without worrying about negatively influencing real students. Morris and Usher (2011) interviewed twelve award-winning associate and full professors working at five universities in the southeastern United States to investigate their sources of self-efficacy. Among the four sources, mastery experiences appeared to be the most dominant. However, there was a wide range of types of mastery experiences and how much a certain event influenced self-efficacy varied according to variables such as "the temporal heuristics used in recollection, the manner in which professors defined their role as teachers, and the combinatory rules they used to integrate information from multiple sources" (Morris and Usher (2011, p. 237). When describing the development of their self-efficacy, rather than identifying single favourable events, the professors mentioned the influences of cumulative events such as repeated successes or failures. According to Morris and Usher (2011), these past teaching experiences gave them "some indication of their present capabilities" (p.238). It is interesting to note that many professors in this research said that their 


\section{VIETNAMESE EFL TEACHER SELF-EFFICACY IN PRACTICE}

self-efficacy was reinforced by students' behaviours. They cited students' understanding of course material, their engagement in the lessons, their interest in the course, their accomplishments, and even students' body language as indexes of instructional effectiveness.

However, Hoy and Spero (2005) found that the relationship between teacher self-efficacy and their teaching experience was not always positive. During their student teaching, the participants expressed a growth in their self-efficacy but after their first year as classroom teachers, they reported a significant decrease in their self-efficacy. The researchers explained that during their student teaching, the participants had more support than during their first year as teachers. When the support was withdrawn, their self-efficacy deteriorated.

Research has shown that the relationship between teacher self-efficacy and the teachers' years of experience is not consistent. For example, Tschannen-Moran and Johnson (2011) found that there was no relationship between teacher self-efficacy beliefs in general, teacher selfefficacy beliefs for literacy instruction in particular, and their years of teaching experience. They noted that their findings align with Bandura's (1997) assertion that "self-efficacy beliefs tend to be established early in learning and that once set, they are stable and resistant to change without some kind of shock to provoke a reassessment" (Tschannen-Moran \& Johnson, 2011, p. 758). Conversely, Wolters and Daugherty (2007) administered an online questionnaire to a large number of 1,024 teachers who were teaching from pre-kindergarten level to grade 12 in a large suburb. The participants responded to questions about their demographic details, the Teachers' Sense of Efficacy Scale (Tschannen-Moran \& Hoy, 2001), and nine items from the Patterns of Adaptive Learning Scales (Midgley et al., 2000). Their research findings indicated that the teachers with more years of teaching experience demonstrated greater efficacy to apply assessment and instructional practices to teach even the most-difficult-to-reach students. They also displayed a greater level of confidence in their ability to minimise negative influences of disruptions to the teaching and learning process. The above findings indicate that teaching experience alone does not persuade teachers of their self-efficacy. It is important to consider whether the teaching experiences were successful, or, in other words, mastery experiences. How do teachers judge their past teaching experiences as successful? Research shows that teachers rely on different sources to assess their performance. For example, in Morris and Usher (2011) study, one of the twelve professors with many university-wide teaching awards mentioned that 


\section{VIETNAMESE EFL TEACHER SELF-EFFICACY IN PRACTICE}

his students and the people observing his classes complimented his teaching. In this case, rather than originating from mastery experiences, his teacher's self-efficacy derived from social persuasion. Similarly, Phan and Locke (2015) found that the teacher interpreted their past performance based on their students' feedback, student behaviour, and students' completion of classroom tasks. Morris et al. (2017) concluded that teachers' judgements of their past teaching experiences are not original sources of self-efficacy. Instead, the appraisals are an interpretation of existing information and mediate the relationship between teacher self-efficacy and its different sources such as social persuasion, enactive attainments, and physiological and affective states.

So far, I have reviewed studies on past performance and teaching experiences as mastery experiences of teacher self-efficacy. In addition, researchers have highlighted the role of teacher knowledge in the formation of teacher self-efficacy; for example, Bautista and Boone (2015); (Mishra \& Koehler, 2006; Morris \& Usher, 2011; Phan \& Locke, 2015; Tschannen-Moran \& McMaster, 2009). These researchers considered teachers' mastery of knowledge in some areas as a form of mastery experience. Palmer $(2006,2009)$ distinguished enactive mastery and cognitive mastery experience. Enactive mastery refers to "success in understanding something rather than success in doing something" (Palmer, 2006, p. 339). Meanwhile, cognitive mastery relates to teachers' understanding of content and pedagogical knowledge. Cognitive mastery was described as a form of mastery experience.

In the literature, teacher knowledge is classified in various ways. According to BenPeretz (2011), "teacher knowledge has been expanded and broadened significantly". Elbaz (1983) divided teacher knowledge into five categories, namely, knowledge of the self, the milieu of teaching, the subject matter, curriculum development, and instruction. Shulman (2013) categorised content knowledge into three subgroups of subject matter: content knowledge, pedagogical knowledge, and curricular knowledge. Content knowledge refers to the quantity and organisation of knowledge in teachers' minds. Pedagogical knowledge refers to teachers' knowledge for teaching. Curricular knowledge refers to the knowledge of the programmes designed for teaching particular subjects and topics. Grossman (1990) presented four groups of general pedagogical knowledge, subject matter knowledge, pedagogical content knowledge, and knowledge of context. Grossman and Richert (1988) defined teacher knowledge as "a body of 
VIETNAMESE EFL TEACHER SELF-EFFICACY IN PRACTICE

professional knowledge that encompasses both knowledge of general pedagogical principles and skills and knowledge of the subject matter to be taught" (p. 54). Teacher knowledge has been extended from knowledge of subject matter, curriculum and pedagogical content knowledge, to include general themes like global issues and multiculturalism (Holden \& Hicks, 2007).

Teachers' content and pedagogical knowledge has been characterised as cognitive mastery experiences (Palmer, 2006). Table 1 summarises categories of teacher knowledge.

Table 1

Categories of Teacher Knowledge

\begin{tabular}{ll}
\hline Research & Categories \\
\hline Elbaz (1983) & Knowledge of the self \\
& Knowledge of the milieu of teaching \\
& Knowledge of the subject matter \\
& Knowledge of the curriculum development \\
& Knowledge of instruction \\
\hline Shulman (2013) & Content knowledge (including subject matter content knowledge, \\
& pedagogical knowledge, and curricular knowledge) \\
& Pedagogical knowledge \\
& Curricular knowledge \\
\hline Grossman (1990) & General pedagogical knowledge \\
& Subject matter knowledge \\
& Pedagogical content knowledge \\
& Knowledge of context \\
\hline Grossman and & Knowledge of general pedagogical principles and skills \\
Richert (1988) & Knowledge of the subject matter \\
\hline Holden and Hicks & Knowledge of subject matter \\
(2007). & Knowledge of the curriculum \\
& Pedagogical content knowledge, \\
& Knowledge of global issues and multiculturalism \\
\hline
\end{tabular}

Research has shown that a significant increase in self-efficacy is related to teachers' mastery of content and pedagogical knowledge (Bautista, 2011; Morris \& Usher, 2011; Phan \& Locke, 2015)

In Phan and Locke (2015), the EFL teachers reported that their self-efficacy beliefs were strengthened by their perceptions of content knowledge which was their English proficiency and their pedagogical knowledge. These participants said they were confident about their teaching 
VIETNAMESE EFL TEACHER SELF-EFFICACY IN PRACTICE

ability because the students' English level was low, and they could deliver lessons and address students' questions in English. Moreover, the teachers said they could teach effectively because of their relevant pedagogical knowledge and skills. However, in later interviews, some teachers also expressed doubt about their self-efficacy because of a lack of particular knowledge and skills. They mentioned in informal meetings and interviews with the researcher that they felt a lack of confidence in teaching unmotivated and struggling students. Although the teachers did not clearly state the skill and knowledge that they felt needed improving, they did express a desire to "observe colleagues teach", or to "discuss...teaching strategies", to "improve teaching instruction", "deal with classroom situations", or "motivate students to learn"(Phan \& Locke, 2015, p. 78). Phan and Locke (2015) concluded that in their study, cognitive mastery experiences were more powerful than enactive mastery experiences in the formation of the participating teachers' self-efficacy.

In addition to other sources of self-efficacy, the professors in Morris and Usher (2011) also appraised the role of their knowledge or how knowledgeable they judged themselves in a particular content area. The professors expressed their confidence when they felt like a "knowledge expert" or knew material well. Therefore, they may be efficacious in teaching one subject but not another. Together with content knowledge, the professors also complimented the influence of pedagogical knowledge on their self-efficacy. As one of them said, "there's this bridge between mastering the content and being able to teach content' (Morris \& Usher, 2011, p. 239).

In conclusion, along with teachers' successful past performance, teacher knowledge of subject content, pedagogy, content pedagogy, and context play a crucial role in the development of teacher self-efficacy. Such knowledge serves as mastery experiences. The following section will review the literature on what can be referred to as vicarious experiences.

\subsubsection{Vicarious Experiences.}

Researchers have found different forms of vicarious experiences that play an important role in the development of teacher self-efficacy (Bautista, 2011; Bautista \& Boone, 2015; Martinussen, Ferrari, Aitken, \& Willows, 2015). These forms include effective actual modelling and symbolic modelling, cognitive self-modelling, multimedia-enhanced workshops, and teaching a virtual classroom. 
VIETNAMESE EFL TEACHER SELF-EFFICACY IN PRACTICE

Bautista (2011) presented two forms of vicarious experiences, namely, effective actual modelling and symbolic modelling, and cognitive self-modelling. In weekly class meetings, the course instructor modelled effective teaching practices (simulated modelling) and the pre-service teachers modelled a learning cycle. The pre-service teachers also got vicarious experiences in the form of symbolic modelling when they watched videos of experienced teachers practising science teaching in real classrooms (symbolic modelling). The pre-service teachers also engaged in an assignment which involved planning an inquiry-based student-centred science lesson and presentation. They visualised themselves teaching the lessons to foresee possible misconnections between objectives, the assessment plan and classroom activities. The lesson plans were presented during class meetings and at the end of the semester. This assignment promoted cognitive self-modelling. The data collected on the first and last day of the course showed that the majority of the pre-service teachers (93\%) increased their self-efficacy in teaching science.

Martinussen et al. (2015) found similar evidence of vicarious experience as a source of self-efficacy. Fifty three teacher candidates who had just finished a four-week-teaching practicum in a school attended a multimedia-enhanced workshop with five digital videos illustrating effective teaching practices of phonological and phonemic awareness instruction. The participants took notes of relevant information and participated in activities in pairs while watching the videos. After that, the instructor discussed the teaching practices in the videos with the pre-service teachers and answered their questions. The research findings indicated a significant relationship between the workshop and teacher self-efficacy.

After teaching a virtual classroom, the participants in Bautista and Boone's (2015) study described in section 3.2.1 of this chapter also reported a higher sense of self-efficacy. Evidence from the above research shows that vicarious experiences equipped teachers with content and pedagogical knowledge, which, as a result, enhanced their self-efficacy.

It is important to consider the similarity between the student teachers and their mentors as the influence of vicarious experiences depends on the perceived model similarity. As Bandura (1997) stated "the greater the assumed similarity, the more persuasive are the model's successes and failures" (p. 87). In Aydin and Hoy's (2005) research, the student teacher self-efficacy did not significantly correlate with their vicarious experience. The researchers explained that the participants acknowledged great differences between themselves and their mentors in terms of 


\section{VIETNAMESE EFL TEACHER SELF-EFFICACY IN PRACTICE}

teaching experience and teaching style. As a result, their vicarious experience was not a powerful source of self-efficacy. In contrast, Bruce, Esmonde, Ross, Dookie, and Beatty (2010) found that after watching their peers' teaching (with whom they likely considered themselves similar), the instructors became more self-efficacious.

Professional development activities have been found to contribute substantially to teacher self-efficacy. For example, Zonoubi, Eslami Rasekh, and Tavakoli (2017) studied how teacher self-efficacy developed in professional learning communities which have five characteristics: "reflective dialogue, focus on learning, collaboration, shared values and norms, and deprivatisation of practice which encourages peer observation with the purpose of giving and receiving feedback" (Kruse, Louise, Bryk, 1995, as cited in Zonoubi et al, 2017, p.2). Through collaboration with other colleagues, teachers learnt innovative teaching ideas and strategies and then employed them in their teaching practice. The effective employment encouraged their belief that they have abilities to perform the teaching task (mastery experience). Such successful experiences and teachers' reactions to tensions and frustrations fostered the formation of teacher self-efficacy (physiological and affective states). Through the observation of others' teaching, teachers reflected on their own teaching then gauged self-efficacy (vicarious experiences). During the activities of professional development communities, supervisors and colleagues gave teachers feedback. Those constructive and positive compliments fostered their beliefs in their teaching capability (social persuasion). In short, the researchers claim that the collaborative nature of professional learning communities provides "access to all four sources of efficacy information and thus can help teacher revisit and improve their efficacy beliefs" (Zonoubi et al., 2017, p. 3).

In summary, through the activities of watching other people teaching (either direct observation or watching videos), modelling (teaching practice with feedback from other people), and self-modelling, teachers reflect on their own teaching and improve their self-efficacy.

\subsubsection{Social Persuasion.}

As a source of teacher self-efficacy, social persuasion originates from the feedback about teaching. The specific and sincere comments from a credible observer are found to be most powerful (Bandura, 1997; Usher \& Pajares, 2008). Research has found positive influence of feedback on teacher self-efficacy. 
VIETNAMESE EFL TEACHER SELF-EFFICACY IN PRACTICE

In a quasi-experimental study to test the influences of four different professional development formats on teacher self-efficacy, Tschannen-Moran and McMaster (2009) found that the treatment group with a follow-up coaching session after a workshop had a significant impact. The treatment provided the teachers with individualised and specific social persuasion because they had personal communication with the presenter about their teaching. This kind of sincere feedback played a "double-edged role" (Klassen \& Durksen, 2014, p. 167) in which positive feedback fosters teacher self-efficacy. Negative feedback, on the other hand, may diminish teacher self-efficacy.

Phan and Locke (2015) interviewed eight EFL teachers who were working at a technical university in Vietnam. They found that social persuasion could be the most powerful source of diminishing the participating the self-efficacy of the participating teachers. The teachers reported feeling confused and experiencing self-doubt because the university leaders did not comment on their teaching ability. Additionally, they reported the feeling of being disregarded when they were not genuinely engaged in institutional decision making. The teachers also expressed their discomfort when the leaders observed their teaching through the classroom windows, resulting in self-doubt about their competence to teach. The research findings also indicated that the teacher self-efficacy deteriorated because of the lack of institutional support for providing professional development opportunities. The meetings with "irrelevant topics", "no important contents", "no contribution to professional knowledge" had a negative impact on the teachers' self-efficacy (Phan \& Locke, 2015, p. 79). However, Phan and Locke (2015) highlighted the teachers considered students' feedback as an interpretation of their performance.

However different sources of social persuasion can influence teacher self-efficacy differently. Milner (2002) interviewed and observed a high school English teacher who struggled with criticism for not being tough enough in her teaching and grading and encountered many challenges in her job. The positive feedback from her students, students' parents and colleagues enabled her perseverance and served as a source of self-efficacy. However, in some studies, student feedback in the form of end-of-course evaluation was considered a poor indicator of instructional quality, and therefore, less influential for some instructors (Braga, Paccagnella, \& Pellizzari, 2014; Carrell \& West, 2010). Braga et al. (2014) explained that the questionnaire to 


\section{VIETNAMESE EFL TEACHER SELF-EFFICACY IN PRACTICE}

collect student feedback reflected the students' enjoyment of the class experience rather than the quality of teaching. The students' evaluations were influenced by environmental conditions.

In short, feedback that teachers receive about their teaching contributes to self-efficacy. Positive feedback makes teachers feel more self-efficacious. Negative or even no feedback can result in teachers doubting their self-efficacy. However, research has emphasised the importance of considering the credibility of the feedback.

\subsubsection{Physiological and Affective States.}

Among the four sources of self-efficacy, physiological and affective states receive the least attention (Morris et al., 2017), probably because according to some researchers, these states are most relevant to clinical research (Labone, 2004). The majority of research has focused on negative states (Morris et al., 2017) such as anxiety and stress (Milner \& Woolfolk Hoy, 2003; Palmer, 2006), depression (Kim \& Kim, 2010), fear, doubt and pressure (Milner, 2002; Milner \& Woolfolk Hoy, 2003; Palmer, 2006; Poulou, 2007), tiredness, exhaustion and fatigue (Morris \& Usher, 2011; Poulou, 2007), sleep loss, worry, and uncertainty (Wyatt, 2013). Little research has investigated positive states like happiness and excitement (Morris \& Usher, 2011).

In their research, Milner and Woolfolk Hoy (2003) found that both positive and negative emotional states influenced teacher self-efficacy. They interviewed and observed a teacher who was reflective and articulate with twenty-five years of teaching experience in total. In a school of over a hundred teachers, she was one of only three African American teachers. In addition to the social persuasion experiences including students' and parents' perceptions and respect and successful self-reflective experiences as presented in section 3.3, the teacher reported negative states of feeling socially and collegially isolated. Since the beginning of her teaching at the school, the teacher did not feel welcome and part of a school environment because she was a minority, the first African American teacher there. She described the avoidance and isolation as hurtful and as affecting her confidence. Because of these experiences, she emphasised her responsibilities to demystifying or changing students' negative stereotypes about African Americans. Then she was observed many times in her class sharing her own experience to represent the African-American experience. She also reported a sense of responsibility to enlighten her colleagues' perceptions of African-Americans. These challenging tasks were not 


\section{VIETNAMESE EFL TEACHER SELF-EFFICACY IN PRACTICE}

always successful. The teacher considered her experiences of isolation and stereotyping as creating "an endangered sense of efficacy" (Milner \& Woolfolk Hoy, 2003, p. 271).

A teacher in Wyatt's study (2013) expressed changes in her self-efficacy because of the negative feelings she experienced when her teaching context changed. She was a senior English teacher who had been teaching grade nine for more than a decade before she was asked to teach grade one. Although she reported high self-efficacy in teaching grade 9, it was not maintained when she taught at a different level. The teacher articulated her continual anxiety with expressions like worried, feeling negative, and sleep loss. The feeling of inadequacy contributed to negative physiological and affective states, which made her doubt her self-efficacy.

In their study about the sources of self-efficacy of award-winning professors, Morris and Usher (2011) found that participants considered their feelings as an indication of their teaching effectiveness. For example, one professor used the phrase "visceral response" (Morris \& Usher, 2011, p. 240) to explain how she knew that a class discussion was successful. Another professor recalled how the "feeding off of the energy of the crowd" (Morris \& Usher, 2011, p. 240) gave him direction during his early years of teaching. His interpretation of the energy of the classroom as a positive index of his teaching competence reinforced his self-efficacy. It is interesting that the participants in this study were aware of the fluctuation in their physiological states. Most of them mentioned feeling nervous, especially on the first day of class. However, they regarded this as a "positive thing" and "a normal feeling". Therefore, they still approached the class as they should and maintained their self-efficacy.

In summary, teacher self-efficacy is influenced by both positive and negative physiological and affective states. While positive feelings such as happiness and excitement enhance teachers' belief in their teaching abilities, negative ones like stress, anxiety, and feeling isolation diminish it. In the literature, there has been more research on negative states than on positive ones. It is important to highlight that teachers' physiological states in some situations arise from their interpretations of students' feedback or behaviour in the classroom. In other words, it is their perception of social persuasion.

\section{What can be the Other Influences on Teacher Self-Efficacy?}

In addition to the four sources of teacher self-efficacy reviewed in the previous section, research has shown other influences of teacher self-efficacy such as gender, teachers' perception 


\section{VIETNAMESE EFL TEACHER SELF-EFFICACY IN PRACTICE}

of professional development needs, individual characteristics, abilities, motivations, and university training, places of work, school levels, principal's behaviour, and cultural values.

There have been inconsistent results of research comparing gender differences in teacher self-efficacy. Brennan and Robinson (1995) surveyed 30 volunteer university teachers (15 men and 15 women) from Eastern New Mexico University using the self-efficacy quiz constructed by DiBella-McCarthy, McDaniel, and Miller (1995). The quiz measured three factors: teachers' general sense of teaching efficacy, teachers' belief in their ability to affect student change when considering external factors, and personal teaching efficacy. The research data showed no significant differences between male and female university teachers across three factors. However, there was evidence that male teachers reported a slightly lower sense of efficacy to affect student change when considering external factors than female teachers did. Moreover, male teachers' belief in this aspect is limited by their students' family background and student characteristics. In contrast, Klassen and Chiu (2010) found that female teachers experienced more severe workload stress, a higher level of classroom stress due to students' misbehaviour, and lower self-efficacy in classroom management. On average, male teachers reported to have $5 \%$ higher scores in classroom management than their female counterparts. Significant differences have been found between male and female teacher self-efficacy in Fives and Looney (2009) study. Fifty four male and sixty three female graduate students with and without teaching experience responded to a questionnaire with socio-demographic items and an adaptation of the Teacher Sense of Efficacy Scale (Tschannen-Moran \& Hoy, 2001). The results showed that female teachers expressed higher self-efficacy in both student engagement and overall efficacy. According to the researchers, women tended to have higher levels of efficacy for teaching because of "the role of teacher in society and the socialization practices that result in women more closely aligning themselves with this work (p.188).

The influence of teacher gender on their self-efficacy was also found in Perera's study (2019). Aiming to identify self-efficacy profiles of lower and upper secondary school teachers and to examine the replicability of the profiles, Perera (2019) used existing data from the TALIS 2013 study (Rutkowski et al., 2013). The data provided information about six areas, namely (a) self-efficacy and job satisfaction, (b) learning environment, (c) appraisal and feedback, (d) teaching practices and classroom environment, (e) development and support, and (f) school 
VIETNAMESE EFL TEACHER SELF-EFFICACY IN PRACTICE

leadership; and key socio-demographic information. Perera (2019) analysed data of 37,351 teachers working in 247 schools in Australia. They found six profiles of highly inefficacious (profile 1), moderate globally and instructionally confident (profile 2), highly efficacious (profile 3), globally unconfident (profile 4), student engagement efficacious (profile 5), and student engagement inefficacious (profile 6). Among those profiles, female teachers were found least significantly in profile 1 than in any other profiles except for profile 4 . Furthermore, female teachers were substantially more likely to be in profile 2 and 3 than in profile 4 and 5 . These findings aligned with an earlier study by Raudenbush, Rowan, and Cheong (1992) showing that females tended to have higher overall self-efficacy than male teachers. Similar to Fives and Looney (2009), Perera explained female teachers' higher self-efficacy as a result of gender-role socialisation experiences. Female teachers are culturally believed to be more appropriate for teaching jobs. "Stakeholders may have more favourable expectations for, and react more favourably to, female teachers' performance attainments” (Perera, Calkins, \& Part, 2019, p. 201).

Perera et al. (2019) also highlighted the importance of teachers' participation in professional development activities and their experiences with mentoring services and the role of teachers' perceptions of their professional development needs. When performing novel teaching tasks, teachers were found to evaluate their abilities to meet the task requirements in the selfefficacy development process. The higher their sense of professional development needs, the lower self-efficacy teachers may perceive.

When investigating primary school student teachers' practicum experiences, Poulou (2007) found that the participants derived their teaching efficacy from some other sources along with psychological sources (see Table 2). These include their individual characteristics, abilities, motivations, and university training. Among those, the student teachers' motivation to advance their efficacy was the most influential source of efficacy. Their personalities, enactive mastery experiences with social persuasion also contributed greatly to teacher efficacy. In contrast, vicarious experiences and physiological/ affective states were rated as having least influence on teacher efficacy. 
VIETNAMESE EFL TEACHER SELF-EFFICACY IN PRACTICE

Table 2

Teaching Efficacy Sources Inventory (adapted from Poulou, 2007)

Teaching Efficacy

Sources

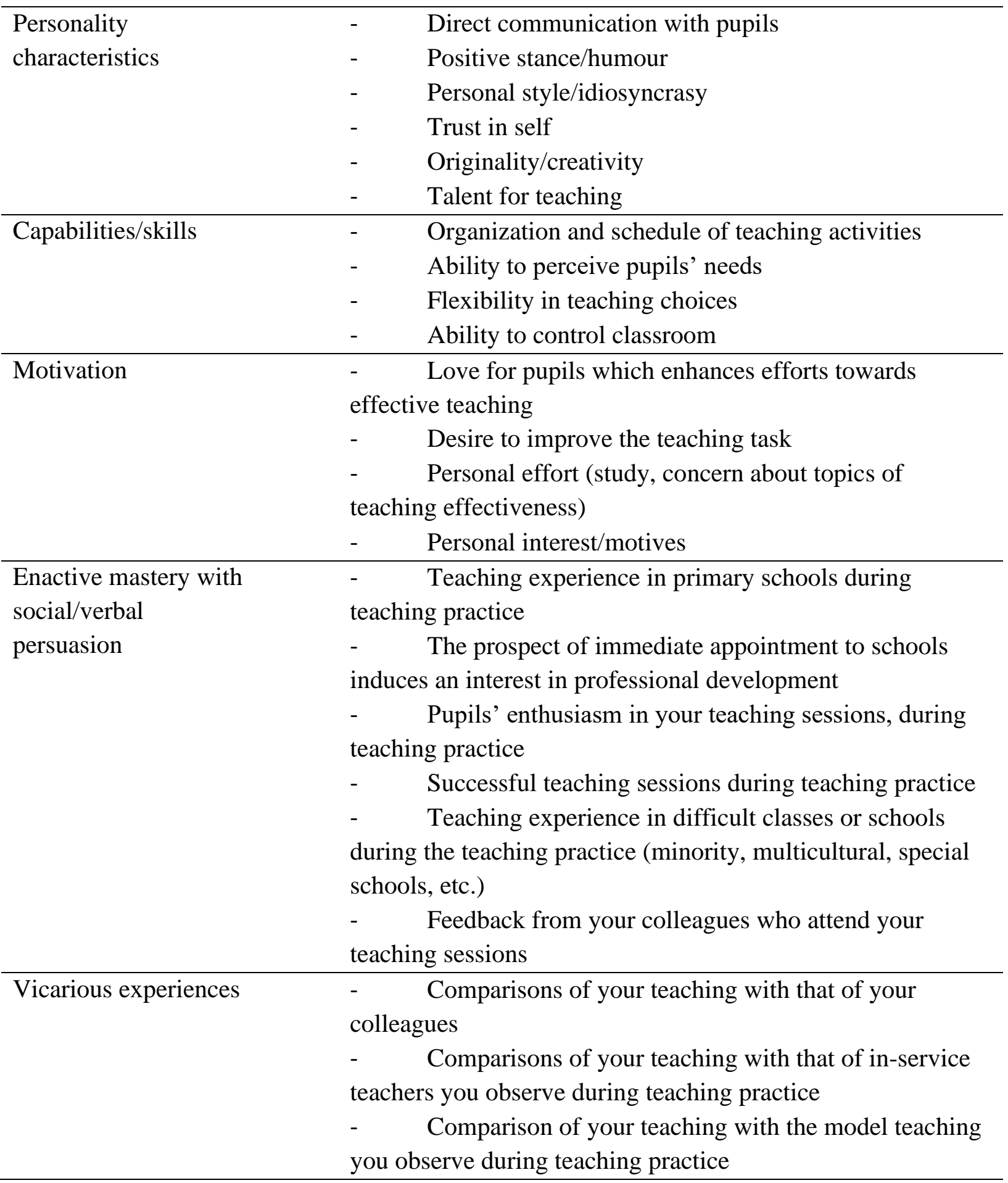


VIETNAMESE EFL TEACHER SELF-EFFICACY IN PRACTICE

\begin{tabular}{ll}
\hline & $-\quad$ Comparison of your teaching with that of your tutors \\
& at university \\
\hline Physiological/affective & $-\quad$ Feelings of stress or anxiety during your teaching \\
state & sessions \\
& $-\quad$ Feelings of fatigue following your teaching sessions \\
& as an indication of lack of ability or disappointment \\
& $-\quad$ Recovery of negative feelings during your teaching \\
& sessions \\
\hline University training & $-\quad$ Frequency of course attendance during teacher \\
& training programmes \\
& $-\quad$ Type of courses offered during teacher training \\
& programmes (compulsory or optional) \\
& $-\quad$ Number of courses offered during teacher training \\
& programmes \\
\hline
\end{tabular}

Places of work and student background were found to have an influence on teacher self-efficacy. When comparing the prospective teachers' perceptions of preparedness to teach at urban and rural schools, and their self-efficacy to use particular cultural responsive teaching strategies, Siwatu (2011) found that the pre-service teacher participants, whether White or of African-American or Hispanic origin, judged themselves readier to teach in a suburban school than in an urban school. This finding contradicts the Tschannen-Moran and Hoy (2007) finding that there was no difference in teacher self-efficacy when teaching in urban or rural areas. Moreover, they reported to be most prepared to teach White American, African-American, and Hispanic students and English Language Learners in rural schools. The researcher then proposed some contextual factors such as class size and students' socio-economic background which might influence the teachers' self-efficacy levels.

In a survey of 818 school teachers from four districts in a province in Pakistan, Haq and Akhtar (2013) found that teachers working in different school levels with varied years of experience perceived different levels of self-efficacy. The teachers exhibited significantly different levels of efficacy in student engagement and classroom management but not in instructional strategies. Primary teachers rated themselves more efficacious than middle school teachers but when compared with high school teachers, primary school teachers did not differ substantially. In the 'instructional strategies' efficacy dimension, primary school teachers displayed the highest scores. A similar result was found in the area of 'classroom management'. 


\section{VIETNAMESE EFL TEACHER SELF-EFFICACY IN PRACTICE}

The differences among these groups indicate that teacher self-efficacy is context-specific and may vary according to the ages of the students in the class. Teaching experience greatly influenced teacher self-efficacy in student engagement, instructional strategies but not in classroom management. Interestingly, it was found that teachers with over 25 years of experience had lower self-efficacy than the teachers with less experience. The school policies, working environment and student characteristics also contributed to these differences in teacher self-efficacy in different school levels.

Teacher self-efficacy has also been found to be impacted by school principals' behaviour (Walker \& Slear, 2011) which are presented in table 3.

Table 3

Principals’ Behaviours Supporting Teaching Self-Efficacy (Walker \& Slear, 2011)

\begin{tabular}{ll}
\hline Principal's behaviours & Descriptions \\
\hline Communication & $\begin{array}{l}\text { The principal establishes strong lines of communication } \\
\text { with and among students and teachers }\end{array}$ \\
\hline Consideration & $\begin{array}{l}\text { The principal expresses genuine concern for the welfare of } \\
\text { teachers and makes efforts to get to know each individual }\end{array}$ \\
\hline Discipline & $\begin{array}{l}\text { The principal protects teachers from intrusion into their } \\
\text { instructional time. This includes limiting announcements } \\
\text { and preventing disruptions to class time }\end{array}$ \\
\hline Empowering Staff & $\begin{array}{l}\text { The principal provides opportunities for teachers to make } \\
\text { decisions about their work and to be involved in school- } \\
\text { wide decisions }\end{array}$ \\
\hline Flexibility & $\begin{array}{l}\text { The principal uses varied leadership behaviours as } \\
\text { necessary based on specific situations and circumstances } \\
\text { in the school }\end{array}$ \\
\hline Influence with supervisors & $\begin{array}{l}\text { The principal effectively garners support from supervisors } \\
\text { and district-level administrative offices to assist in } \\
\text { meeting the needs of the school }\end{array}$ \\
\hline Inspiring group purpose & $\begin{array}{l}\text { The principal creates an environment where all teachers } \\
\text { are part of a team and work together toward shared goals } \\
\text { that result in student and teacher success }\end{array}$ \\
\hline $\begin{array}{l}\text { The principal models his/her belief in the instructional } \\
\text { process and emphasises the importance of the instruction } \\
\text { that takes place in each classroom }\end{array}$ \\
\hline
\end{tabular}


VIETNAMESE EFL TEACHER SELF-EFFICACY IN PRACTICE

\begin{tabular}{ll}
\hline $\begin{array}{l}\text { Monitoring and evaluating } \\
\text { instruction }\end{array}$ & $\begin{array}{l}\text { The principal "keeps an eye" on what is happening in the } \\
\text { school and provides feedback to teachers regarding the } \\
\text { instructional impact of classroom strategies }\end{array}$ \\
\hline Providing contingent rewards & $\begin{array}{l}\text { The principal formally and informally recognizes } \\
\text { outstanding work inside and outside of the classroom and } \\
\text { shares this recognition in tangible and visible ways }\end{array}$ \\
\hline Situational awareness & $\begin{array}{l}\text { The principal is aware of the details and concerns } \\
\text { regarding the functioning of the school and uses this } \\
\text { information to address current and potential problems }\end{array}$ \\
\hline
\end{tabular}

Walker and Slear (2011) surveyed 366 middle-level school teachers in urban, rural, and suburban areas. The participants responded to a three-part questionnaire to provide data about their self-efficacy, their perceptions about eleven principals' behaviours, and demographic information. All participating teachers reported that three out of eleven principals' behaviours had significant influences on their self-efficacy (modelling instructional expectations, communication, and providing contingent rewards). Among these three behaviours, the first two had a positive relationship with teacher self-efficacy while the last one had a negative correlation. This negative relationship indicated that for teachers with lower self-efficacy, providing contingent rewards played a more critical role in their self-efficacy formation than for higher self-efficacy teachers. Divided into groups of new, experienced, and very experienced teachers, the participants brought in different results. The novice teachers with less than three years of teaching experience indicated the importance of principals' modelling instructional expectations. These teachers expressed their interest "in working with principals who are able and willing to provide direction and support specific to instructional expectations as efforts are made to provide the best classroom instruction" (Walker \& Slear, 2011, p. 54). Data collected from the experienced group with four to seven years of teaching experience showed teachers' interest in principals' modelling instructional expectations and communication. Different from the novice teachers, these participants' concerns were to understand the school culture and things happening outside of their classrooms. Communication from the principal could address their concerns. For very experienced teachers with between seven and fourteen years of experience, their self-efficacy was significantly influenced by the principal's communication, consideration, and modelling instructional expectations. The behaviour of consideration emphasised the experienced teachers' evaluation of their relationship with the principal. The highly experienced 


\section{VIETNAMESE EFL TEACHER SELF-EFFICACY IN PRACTICE}

teachers with over fifteen years of experience acknowledged only one principal's behaviour which is inspiring group purpose. These teachers valued their contributions to the school and community. Therefore, when the principal created a collaborative working environment to promote school achievement and benefit student learning, they felt highly self-efficacious.

Teacher self-efficacy was found to be influenced by class types. Raudenbush et al. (1992) administered a questionnaire to teachers in sixteen urban and suburban high schools. The questionnaire gathered information about teacher self-efficacy for each class they were teaching and its characteristics, teachers' personal and professional backgrounds, and their perceptions of organisational settings. The research findings showed the influence of the class track (the-type of class). Teacher self-efficacy was found to be highest when teaching honours classes, lower when teaching academic classes and lowest in vocational and general track classes. In addition, the track effects on teacher self-efficacy depended on the teachers' disciplinary specialisation. These effects were most powerful for science and math teachers and less for English and social studies teachers. Raudenbush et al. (1992) also found a connection between the track effects and teacher perceptions of students' engagement. The track effects diminished and nearly disappeared when teachers could control students' engagement. Teachers reported a different level of self-efficacy when teaching students of different ages. They expressed lower self-efficacy when teaching younger students. However, similar to the track effects, this effect is reduced when students' engagement is controlled. Another intra-teacher variable having an influence on teacher selfefficacy is their preparedness. The teachers felt differently prepared about teaching different classes, which predicts differences in self-efficacy. The final intra-teacher factor found was the class size. Teachers reported higher levels of self-efficacy in teaching larger classes than smaller classes. Among the hypothesised inter-teacher variables, the organisational environment was found to have the greatest effect on teacher self-efficacy. Teachers who better controlled instructional conditions and collaborated with colleagues reported being more self-efficacious.

Tschannen-Moran and Hoy (2007) highlighted the impact of teaching resource availability and interpersonal support on teacher self-efficacy. 255 teachers working in elementary, middle, and high schools with various years of teaching experience participated in the study. For novice teachers, the availability of teaching resources contributed significantly to their self-efficacy. In contrast, experienced teachers only acknowledged the contribution of grade 
VIETNAMESE EFL TEACHER SELF-EFFICACY IN PRACTICE

level to their self-efficacy. Teachers who were teaching the youngest students expressed higher self-efficacy. Support from parents and the community had a greater effect on experienced teachers' self-efficacy than that of novice teachers. These findings align with earlier research by Tschannen-Moran et al. (1998).

Tschannen-Moran et al. (1998) emphasised the role of task analysis in judging teacher self-efficacy. They found that it is crucial to consider students' capabilities and motivation, suitable instructional strategies, administrative issues, the accessibility of instructional resources, access to technology, and the physical conditions of the teaching space. Contextual factors such as the principal's leadership, the working environment, and relationships with colleagues also contributed to teachers' level of self-efficacy.

Together with the contextual factors, researchers have found that there are some cultural factors which influence teacher self-efficacy. For example, Ho and Hau (2004) found differences in the efficacy of Australian and Chinese teachers. While this study was able to distinguish guidance, discipline and instruction efficacy of Australian teachers, the Chinese sample displayed an integrated efficacy. The teachers' role in the two contexts was used to explain this. Chinese teachers were expected to be like a parent and direct students' behaviours. Accordingly, guidance efficacy became a more dominant source of teaching efficacy in China than in Australia.

In a qualitative case study research, Phan (2015) conducted focus groups and interviews, observed six university EFL lecturers, and asked them to write research journals. Her findings show the factors that enhance and hinder teacher self-efficacy(summarised in Table 4).

Table 4

Factors Affecting Vietnamese Teachers' Sense of Self-Efficacy (adapted from Phan, 2015)

\begin{tabular}{lll}
\hline $\begin{array}{l}\text { Vietnamese EFL } \\
\text { teacher self-efficacy }\end{array}$ & Factors & \\
\hline $\begin{array}{l}\text { Perceptions of personal } \\
\text { teaching competence }\end{array}$ & Strengths & $\begin{array}{l}\text { Perception of English proficiency and } \\
\text { pedagogical knowledge } \\
\text { Personal characteristics }\end{array}$ \\
\cline { 2 - 2 } & & $\begin{array}{l}\text { Students' and colleagues' feedback about } \\
\text { teaching }\end{array}$ \\
& & Personal characteristics \\
& Deficits & Leaders' feedback about teaching \\
\hline
\end{tabular}


VIETNAMESE EFL TEACHER SELF-EFFICACY IN PRACTICE

\begin{tabular}{lll}
\hline Contextualized & Constraints & Administration roles \\
teaching demand & Collegiality \\
& Professional development opportunities \\
\cline { 2 - 2 } & Working & Teaching resources \\
constraints & Syllabus \\
& & \multicolumn{1}{c}{ Classroom management } \\
\cline { 2 - 2 } & Unmotivated and/or less-able learners \\
& Job security pressure \\
& Supervision and decision-making process \\
\cline { 2 - 2 } & $\begin{array}{l}\text { Status of the target language in the curriculum } \\
\text { Traditional educational values and norms }\end{array}$ \\
\cline { 2 - 2 } & $\begin{array}{l}\text { Highly-motivated, highly achieving learners } \\
\text { Resources }\end{array}$ \\
& Syllabus \\
\hline
\end{tabular}

Although most of the teachers in the study judged their proficiency lower than it was when they were university students, they still believed that they were qualified to teach at their faculty. This belief strongly supported their perception of their teaching competence. The teachers' beliefs about their pedagogical knowledge and skills and their personal qualities such as temperament and work ethics influenced their self-efficacy either positively or negatively, depending on the context. Students' and colleagues' recognition of successful teaching experiences made the teachers feel positive about their teaching ability. On the other hand, little or no recognition from leaders disappointed the teachers and made them doubt their teaching competence.

Phan (2015) also found various external factors that affect teacher self-efficacy. Most of the teachers complained about their other roles of being a housewife, and/or a mother, considering these roles as a constraint on their teaching. Little support from colleagues and very few professional development opportunities also negatively impacted the participants' selfefficacy. There were also constraints regarding teaching resources, including out-of-date textbooks, insufficient technical support, and unclear syllabus guidelines, as well as physical constraints such as the classroom location, desk distribution, class size, and student groupings. Teacher self-efficacy was diminished because of the way the teachers were supervised and their limited voice in the school decision-making process. Being afraid of losing their jobs also undermined teachers' beliefs in their effectiveness. The teachers' perceptions of their students' learning attitudes and achievements affected teacher self-efficacy. On one hand, teaching highly 
VIETNAMESE EFL TEACHER SELF-EFFICACY IN PRACTICE

motivated, high achieving students brought positive feelings to teachers. On the other hand, teaching unmotivated, less able learners seemed to cause "a sense of the unmanageability" (Phan \& Locke, 2015, p. 166).

To recap, this section has reviewed external influences on teacher self-efficacy. Together with psychological sources of mastery experiences, vicarious experiences, social persuasion, and physiological and affective states, teacher self-efficacy appears to be influenced by personal, contextual, and cultural elements. These elements are summarised in Table 5 below.

Table 5

Influences on Teacher Self-Efficacy

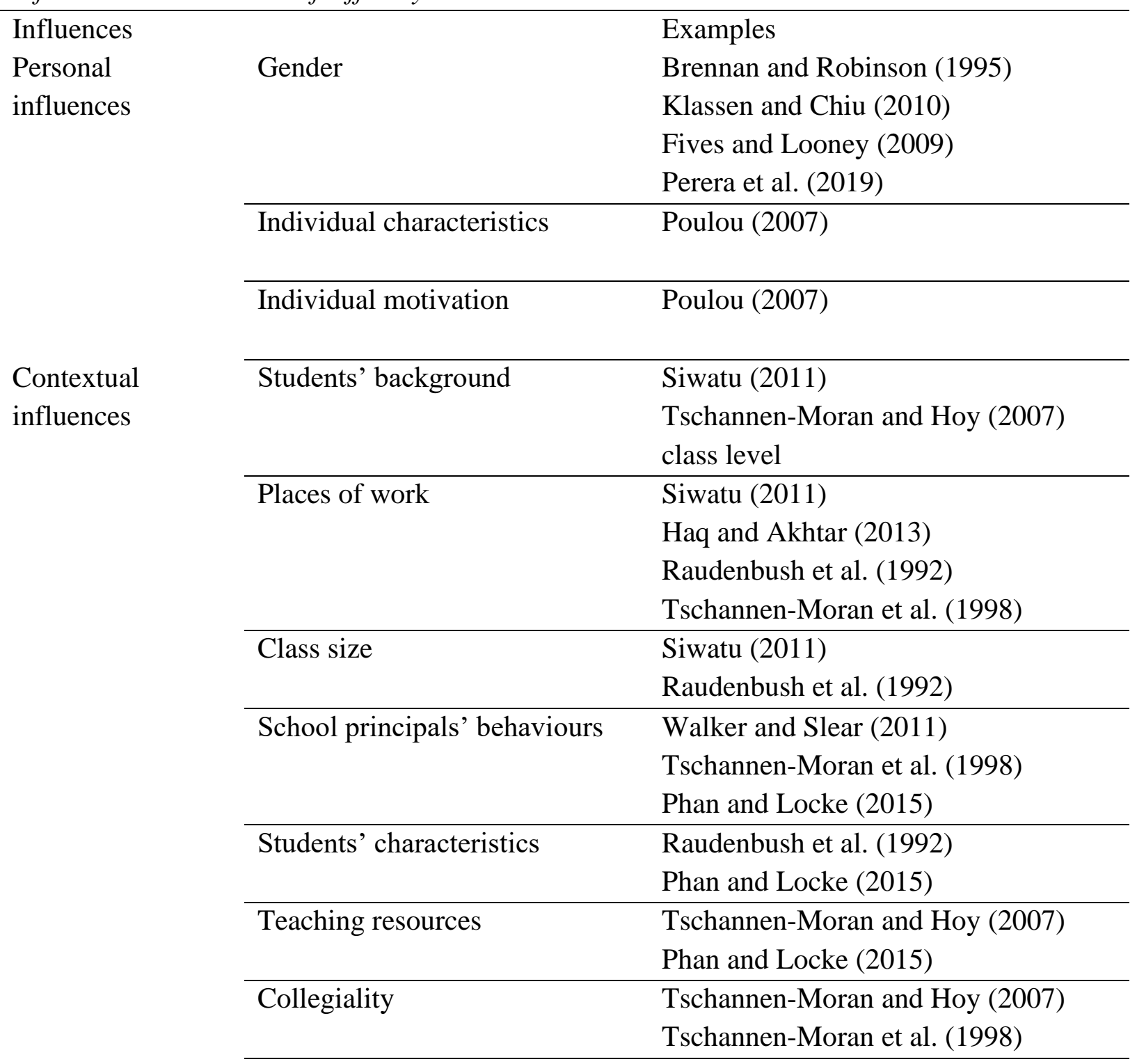


VIETNAMESE EFL TEACHER SELF-EFFICACY IN PRACTICE

\begin{tabular}{lll}
\cline { 2 - 3 } Cultural & Phan and Locke (2015) \\
\cline { 2 - 3 } influences & Cultural norms and values & Ho and Hau (2004) \\
& & Phan and Locke (2015) \\
& Phan and Locke (2016) \\
\hline
\end{tabular}

\section{EFL Teacher Self-Efficacy}

Hoang (2018) conducted a systematic review of 27 research with non-native EFL teacher's self-efficacy in EFL contexts from 2002 to 2017. He found that the majority of the studies were carried out in the Middle East, resulting in a lack of diversity in research contexts, especially in areas such Africa and China, the biggest EFL context. Two thirds of the articles that were reviewed involved practising teachers at different school levels. In the following section, I will review studies which provide evidence for the connection between teacher self-efficacy and other variables such as their self-reported proficiency, instructional practice, and demographic factors.

Research has shown an inconsistent association between proficiency in the target language and teacher self-efficacy. This relationship has been found to be strong in some studies. For example, Ghasemboland and Hashim (2013) and Chacón (2005) found that teachers who considered themselves more fluent in the target language demonstrated more confidence in student engagement than in instructional strategies and classroom management. Similarly, Jafarigohar and Ganjabi (2012) indicated that the correlation between teacher efficacy and language proficiency was low but significant. In contrast, Eslami and Fatahi (2008) found that the teachers' proficiency level did not correlate with teacher efficacy in motivating and engaging students. Best (2014) found no correlation between these teachers' proficiency and their selfefficacy.

Teachers' proficiency in each language skills influenced teacher self-efficacy differently. Chacón (2005) found positive connections between teachers' self-reported proficiency in listening, speaking, reading, writing and the teachers' self-efficacy for student engagement and instructional strategies. In contrast, only the teachers' proficiency in writing was found to be correlated with teacher self-efficacy for classroom management. These mean that teacher selfefficacy in managing the classroom seemed to increase as their proficiency in the target language improves. The higher the teachers' writing proficiency, the more self-efficacious the 


\section{VIETNAMESE EFL TEACHER SELF-EFFICACY IN PRACTICE}

teachers are in managing students. In Eslami and Fatahi's (2008) study, they found a positive relationship between teachers' proficiency and teacher self-efficacy in managing classes. Teachers who scored their listening, speaking, and writing higher expressed higher self-efficacy for instructional strategies. In contrast, their reading ability did not show any relationship with their efficacy. Eslami and Fatahi's (2008) findings slightly diverge from Yilmaz's (2011). Yilmaz found that the more proficient in listening and writing, the more efficacious the teachers were in instructional strategies design and classroom management. In contrast, there was no statistically significant relationship between EFL teachers' efficacy subscales and their reading and speaking competence.

There are inconsistent results in the findings of the correlation between teacher selfefficacy and teachers' instructional practices. Chacón (2005) found that the teachers'level of self-efficacy did not seem to correlate with their teaching strategies. The findings indicated the higher the teachers' self-efficacy, the more likely they were to use either communicationoriented or grammar-oriented strategies. In contrast, higher self-efficacy participants in Eslami and Fatahi's (2008) study preferred using communication activities to grammatical teaching activities. Karimi, Abdullahi, and Khales Haghighi (2016), in their study of the influence of teacher's self-efficacy on EFL teachers' reading instructional orientations and their corresponding instructional practices, compared two groups of teachers with high and low selfefficacy. The researchers found closely similar theoretical orientations, but significantly different reading teaching practices. The findings from these studies indicate the complexity and context specific nature of self-efficacy.

Researchers have investigated the relationship between teacher self-efficacy and their demographic factors and working conditions and got contradicting results. Regarding teaching experience, Chacón (2005) found no connection between the number of years of English teaching experience and teacher self-efficacy across three aspects of classroom management, student engagement, and instructional strategies. This contradicts with Best's (2014) findings that the more experienced the teachers were, the more efficacious they seemed to be. Teachers in Yavuz (2007) reported slightly different result. The researcher found significant correlation between teacher self-efficacy for classroom management and teaching experience. 
VIETNAMESE EFL TEACHER SELF-EFFICACY IN PRACTICE

Conversely, Yavuz's (2007) findings indicated that teachers' participation in professional development activities was the most important factor to predict teacher efficacy in all its domains. Teacher efficacy for student engagement was most influenced by the class size. All socio-demographic factors were found to correlate with teacher efficacy for student engagement. Among those, the number of activities for professional development, class size, teachers' working position, and teachers' majors had the most significant correlation. Together with teachers' involvement in professional development activities and their working position, the type of institutions that teachers worked at correlated significantly with teachers' efficacy for instructional strategies. Those working at private universities reported being more efficacious than their counterparts working in public universities. The teachers performing dual roles of teaching and administration expressed a higher level of efficacy in instructional strategies than teachers without any administrative roles. Regarding teacher efficacy in classroom management, teachers' participation in professional development activities, and their age, gender, and experience showed a significant relationship with this dimension of teacher efficacy. Female teachers were found to be more efficacious than male teachers.

Among the three aspects of teacher self-efficacy in Tschannen-Moran and Hoy's (2001) measure (classroom management, instructional strategies, and student engagement), teachers rated themselves more efficacious in designing instructional strategies and managing the class than engaging students , (Chacón, 2005; Eslami \& Fatahi, 2008; Jafarigohar \& Ganjabi, 2012; Yavuz, 2007; Yilmaz, 2011)

It is commonly assumed that the more proficient in the target language, the more selfefficacious teachers tend to be because language proficiency is the fundamental requirement for language teachers. However, this review section has shown inconsistent findings of the relationship between teachers' language competence and their beliefs in their teaching abilities. Additionally, research has found differences in the connections between teacher self-efficacy and the teacher participants' demographic factors and working conditions.

\section{Teacher Autonomy and Teacher Self-Efficacy}

Teacher self-efficacy has been found to correlate closely with teacher autonomy. First, this section reviews the concept of teacher autonomy. Then, it will re-examine some studies on teacher autonomy in relation to teacher self-efficacy. 


\section{VIETNAMESE EFL TEACHER SELF-EFFICACY IN PRACTICE}

\subsection{What is Teacher Autonomy?}

Teacher autonomy is defined in many different ways (Benson, 2000; Dikilita \& Griffiths, 2017; La Ganza, 2008; McGrath, 2000; Rahimi \& Riasati, 2015), but the most common element of conceptual importance for this study is teachers' freedom in teaching.

McGrath (2000) presented two perspectives on teacher autonomy. From the perspective of self-directed professional development, he defined teacher autonomy as the teacher's control over his or her progress in their career. From the second perspective, teacher autonomy was viewed as "freedom from control by others" (p.101). The word "others" refers to those who might constrain teacher autonomy. He divided the constraints into macro and micro groups. The former category denotes the institution-external decisions made by the bureaucracies over which teachers usually have no controls. The latter category indicates the institution-internal decisions about syllabus, examination system, and textbooks. Teachers should have their voices heard on these issues. The teachers who make independent judgements and establish their own strategies are considered autonomous. In other words, autonomous teachers "have the capacity and freedom for self-direction and have demonstrated that capacity" (McGrath, 2000, p. 102). There is a correlation between two perspectives: how others' decisions control one's actions influence one's freedom to be self-directed.

Benson (2000) studied both learner autonomy and teacher autonomy. According to him, theoretically, teachers are the ones to influence learners' autonomy. The more freedom the learners have in learning, the more control the teachers would have to transfer to the students. Nevertheless, in reality, the transfer is usually constrained. In this case, teachers act as "mediating between the leaners' right to autonomy and the broader constraints that inhibit the exercise of this right" (Benson, 2000, p. 115). He noted that the exercise of teacher autonomy is potentially limited by policy constraints, institutional constraints, conceptions of language, and language teaching methodologies. The first group refers to external policies that decide, for example, which language can or cannot be learnt at schools. The second group represents schoolinternal factors such as school policies, authorisation, assessing systems, and teaching programmes. The third component signifies the popular conceptions of the target language and ideologies of appropriate language usage. The last group of factors includes academic expertise and professional assumptions. 
VIETNAMESE EFL TEACHER SELF-EFFICACY IN PRACTICE

La Ganza (2008) viewed teacher autonomy with regard to other people who might influence teaching practice. More precisely, these people may impact the teacher's freedom to be an innovative teacher, to create and practise new ideas, and pursue their own ethics. La Ganza (2008) concluded from another study of his that teacher autonomy should have several dynamic dimensions. First, he mentioned the relationship between teacher autonomy and the influence of other teachers, mentors, and other people in the institution. These people may support or limit teachers' creativity and learner autonomy. The second dimension is the correlation between teacher autonomy and learners. He gave an example that learners might support the teacher's freedom to encourage learner autonomy. La Ganza (2008) also claimed the teacher's autonomy is influenced by other people's decisions. These people can be in the institutions or bureaucracies in society. The dimensions are interconnected.

According to Dikilita and Griffiths (2017), "teacher autonomy is generally defined as teachers having control over their own professional development and practice" (p.35). In their context, teachers build up their freedom and interdependence. They make their own decisions about their teaching plans, teaching practice, and teaching improvement. The researchers concluded from a literature review that critical reflection can foster teacher autonomy, especially for enhancing their cognition about learning as a teacher. For instance, studying students' perceptions of learning can promote teacher autonomy. Dikilita and Griffiths (2017) commented that doing this kind of learning allows teachers to attain direct data from their learners. They concluded that action research "provides ample investigative, discovery-based, and inquirybased learning experiences that promote teacher autonomy" (Dikilita \& Griffiths, 2017, p. 35). Conducting action research, teachers investigate their own contexts, experiment and reflect on their teaching practices, then acquire practical knowledge. Having experience in answering students' questions and solving classroom problems enhances teachers' self-confidence. In other words, doing action research gives teachers opportunities to be independent and become learnerteachers and understand themselves better.

In summary, different researchers have conceptualised teacher autonomy slightly differently. In my study, teacher autonomy refers to teachers' control of their own professional development and teaching practice. 
VIETNAMESE EFL TEACHER SELF-EFFICACY IN PRACTICE

\subsection{Teacher Autonomy and Teacher Self-Efficacy.}

Researchers have investigated the relationship between teacher self-efficacy and teacher autonomy and found significant connections between them (Ghaemi, Shokrolahi, \& Hashemizadeh, 2015; Kass \& Rajuan, 2012; Rahimi \& Riasati, 2015; Skaalvik \& Skaalvik, 2014).

Kass and Rajuan (2012) reported autonomy as the predominant element influencing their self-efficacy. Autonomy was described in three categories of intra-personal, inter-personal, and organisational. Intra-personal autonomy was described as inner freedom or a personality trait, functioning to help with feeling active and innovative in their job. In other words, inner freedom closely related to teacher self-efficacy. Inter-personal autonomy refers to the interpersonal relationship between the pedagogical advisors and student teachers. Considering student teachers as future teachers, the advisors build trust and empower the students. The advisors had initiatives to respond to each student teacher's individual needs. Their freedom also encouraged them to demonstrate models of flexible and autonomous teachers. This was different from teachers who worked in a school under the direct supervision of the principal because the pedagogical advisors worked with many schools and did not feel they belonged to any school. As a result, they were still confident regardless of any organisational changes.

Skaalvik and Skaalvik (2014) recruited 2,569 elementary and middle school teachers in Norway in their survey. Results collected from the questionnaire showed that teacher selfefficacy and teacher autonomy positively related to teacher engagement and job satisfaction. However, they were negatively associated with emotional exhaustion. The correlation between teacher self-efficacy and teacher autonomy was positive but moderate. The researchers concluded that high self-efficacy teachers considered autonomy their freedom in teaching. They used their resources to teach to their own values. Their teaching was adapted to meet the situation and students' needs. In contrast, low self-efficacy teachers used their autonomy to avoid challenges and hide self-perceived weaknesses. On the one hand, high self-efficacy teachers' willingness to experiment with new teaching methods and change teaching practices would lead to the teachers' personal learning and development. On the other hand, low self-efficacy teachers' avoidance of challenges prevented their personal learning and development. 
VIETNAMESE EFL TEACHER SELF-EFFICACY IN PRACTICE

Rahimi and Riasati (2015) conducted a quantitative study with 49 Iranian EFL teachers teaching at two universities. They responded to two questionnaires measuring teacher selfefficacy and teacher autonomy. The results showed that the relationship between teacher autonomy and teacher self-efficacy was positive, low, and significant. Regarding the sub-scales of teacher efficacy, there was a positive, medium, and significant relationship between teacher autonomy and efficacy to influence decision-making. The relationship between teacher autonomy and other components of efficacy was not significant.

Ghaemi et al. (2015) surveyed 80 EFL teachers from an English institution in Tehran, Iran. Both teacher self-efficacy and autonomy had a positive correlation with teacher engagement. However, the correlation between autonomy and engagement was stronger than it was between teacher self-efficacy and teacher engagement. The author concluded that autonomy provides teachers with freedom to select their own instructional practices, making them responsible for their practices and results. Autonomy fosters teachers' engagement. Teacher self-efficacy can also enhance teachers' engagement because self-efficacy is teachers' beliefs about their teaching abilities. The researchers also found that teacher autonomy was the better predicator of engagement than teacher self-efficacy.

In summary, research has shown a strong association between teacher autonomy and teacher self-efficacy.

\section{Teacher Beliefs and Practices}

Teacher self-efficacy has been defined as "the teacher's belief in his or her capability to organise and execute courses of action required to successfully accomplish a specific teaching task in a particular context" (Tschannen-Moran et al., 1998, p. 233) or "teachers' individual beliefs about their own abilities to successfully perform specific teaching and learning related tasks within the context of their own classroom" (Dellinger et al., 2008, p. 751). In general, selfefficacy can be considered a belief about one's ability to do something (Pajares, 1992). Teachers' self-efficacy plays an important role in forming their specific instructional activities (Bandura, 1997). Therefore, it is important to review studies on the relationship between teacher beliefs and practice. In this section, I will draw largely on three major literature reviews by Fang (1996), Buehl and Beck (2014) and Gao (2014) together with some other relevant studies to review the definitions of teacher beliefs and the relationship with teaching practices. 


\section{VIETNAMESE EFL TEACHER SELF-EFFICACY IN PRACTICE}

Although teachers' beliefs and practices have been extensively researched, especially in ELT, the concept of a belief is not clearly defined in the literature (Borg, 2001; Pajares, 1992). Pajares (1992) defined beliefs as "an individual's judgement of the truth or falsity of a proposition" (Pajares, 1992, p. 316). This definition has been considered the most comprehensive (Fang, 1996) and remains the most widely cited (Borg, 2018). According to Borg (2001), there are some core features of belief definitions. First, a belief is "a mental state which has as its content, a proposition that is accepted as true by the individual holding it" (Borg, 2001, p. 186). Different people may hold different beliefs. Second, beliefs dispose or guide people's thinking and actions. Third, people may be conscious of some beliefs and unconscious of others. Fourth, beliefs demonstrate individuals' value commitments. From the above summary, Borg defined beliefs as "a proposition which may be consciously or unconsciously held, is evaluative in that it is accepted as true by the individual, and is therefore imbued with emotive commitment; further, it serves as a guide to thought and behaviour" (Borg, 2001, p. 186)

According to Schott (2014), despite researchers' efforts to distinguish teachers' beliefs from knowledge, goals, values, conceptions, and emotions, researchers in this area have not been able to agree on a definition. Consequently, they defined teachers' beliefs implicitly. However, there is sufficient consensus about the key elements of the concept. First, beliefs are generally described as individual mental constructs which a person subjectively considers true. Second, beliefs have both cognitive and affective dimensions. Even when considered distinctive, beliefs still closely connect to affective issues. Third, beliefs are usually regarded as "temporally and contextually stable reifications" (Schott, 2014, p. 18). Only extensive involvement in relevant social practices can change beliefs. Fourth, teachers' practice is significantly influenced by their beliefs.

In addition to defining teacher beliefs, Pajares (1992) also discussed possible sub-themes for studies on teacher beliefs. These include:

beliefs about confidence to affect students' performance (teacher efficacy), about the nature of knowledge (epistemological beliefs), about causes of teachers' or students' performance (attributions, locus of control, motivation, writing appreciation, math anxiety), about perceptions of self and feelings of self-worth (self-concept, self-esteem), about confidence to perform specific tasks (self-efficacy). There are also educational beliefs about specific subjects or 
VIETNAMESE EFL TEACHER SELF-EFFICACY IN PRACTICE

disciplines (reading instruction, the nature of reading, whole language"

(Pajares, 1992, p. 316).

From this classification, researchers categorised teacher beliefs into explicit/espoused/stated and implicit/enacted. The former group refers to beliefs that an individual can readily articulate. The latter ones are held unconsciously and can be inferred from actions.

In her review of beliefs, Borg (2001) said that teacher beliefs commonly refer to teachers' pedagogic beliefs about what is relevant to their teaching such as beliefs about teaching, learning, learners, subject matter, self as a teacher, and the teachers' role. Teachers' beliefs play an important role in their teaching practice.

In short, teacher beliefs are what a teacher considers true when teaching and these beliefs may connect with teacher practices. This is explored further in the next section.

\subsection{Relationship between Teacher Beliefs about Teaching and Learning and Teacher} Practices

\subsubsection{The Consistency between Teacher Beliefs and Practice.}

Research has shown three possible interactive relations between teacher beliefs and practice: beliefs influence practice, practice influences beliefs, and a reciprocal and complex relationship.

\subsubsection{Beliefs Influence Practice.}

There are a number of studies reflecting the consistency between teacher beliefs and practice. This happens when 'teachers' beliefs are correlated with, aligned to, or reflected in their practice" (Buehl \& Beck, 2014, p. 68). An example of the alignment is from Rupley and Logan (1985). The teachers in their research reported that their instructional decisions were affected by their beliefs about reading. Richardson, Anders, Tidwell, and Lloyd (1991) had similar findings from their study. The teachers who believed that learners had to learn subskills of reading before determining the meaning of the text, used a skills/word approach. In contrast, their counterparts, who believed that the process of learning to read is accomplished by reading, used a literary structuralist approach. This indicated a direct correspondence between beliefs about how literacy is acquired and pedagogical practices. Other research on literacy instruction also sawcongruence between teacher beliefs and practices. For example, Johnson's study (1992) showed that ESL teachers' literacy instruction for non-native speakers of English was consistent 


\section{VIETNAMESE EFL TEACHER SELF-EFFICACY IN PRACTICE}

with the teachers' theoretical beliefs; and teachers with different beliefs differed greatly in their literacy instruction.

Wilkins (2008) investigated the teachers' content knowledge of mathematics, attitudes towards the subject, teachers' beliefs about the effectiveness of inquiry-based instruction, and how they use this pedagogical approach. Wilkins analysed the relationship among the variables. She found that teachers' beliefs about effective mathematics instructions significantly related to their frequency of using inquiry-based instruction. It is interesting to highlight that although acknowledging a belief that inquiry-based instruction was effective, some teachers did not frequently use it in their classroom. Some teachers reported a high frequency of using such techniques but possessed a relatively weak belief in its effectiveness. However, most of the teachers reported a consistent relationship between beliefs and practices.

Another study considered the relationship between beliefs about feedback and the implementation of feedback in classrooms in all curriculum areas. Primary and secondary school teachers in New Zealand responded to a questionnaire about their conceptions of feedback (Brown, Harris, \& Harnett, 2012). They found that "there were conceptually meaningful relations between teachers' conceptions of feedback and the practices they associate with it" (Brown et al., 2012, p. 974).

Unlike quantitative studies that collected data simultaneously through self-report measures (Thoonen, Sleegers, Peetsma, \& Oort, 2011; Wilkins, 2008), some qualitative research triangulated data from various sources like student artifacts, lesson plans, surveys, and observations, interviews with teachers and learners and may also involve the researchers themselves over a period of time (Song \& Looi, 2012; Tsangaridou, 2008). Researchers found the influence of teacher beliefs on their practices. For example, before a 13-week teaching experience in a school, Tsangaridou (2008) interviewed and observed two student teachers in six periods of physical education per teacher, and analysed their unit plans, lesson plans, and reflective journals. The data showed an alignment between the teachers' beliefs and practices. The teachers believed that physical education primarily helps learners develop their psychomotor, cognitive, and affective skills. To reach the objective, they planned and employed learning activities that enhance all three above mentioned aspects in their teaching. Song and Looi (2012) observed, video-recorded, and wrote field notes of the teaching practices of two 


\section{VIETNAMESE EFL TEACHER SELF-EFFICACY IN PRACTICE}

primary mathematics teachers. They found that the two participants held different beliefs about how learning happens and about the evidence of student understanding. Even though they were using the same lesson plans, their teaching practices contrasted.

To summarise, teachers in general tend to depend on their beliefs to decide on their teaching strategies and classroom activities or teaching practice. The upcoming section will review some studies on the influence of teaching practice on teacher beliefs.

\subsubsection{Practice Influences Beliefs.}

The congruence between teacher beliefs and practice also suggests that practice influences beliefs Buehl and Beck (2014). This is seen most clearly in research on the changes in teachers' beliefs after experiencing specific teaching practices like professional development activities or field experiences. For example, Swain, Nordness, and Leader-Janssen (2012) found that after completing an introductory special education class with 20-hours of field work to observe and work with students with disabilities, the teacher beliefs about their ability to include those students in their class increased. Likewise, Rushton, Lotter, and Singer (2011) found that chemistry teachers who took part in a two-week professional development programme were more likely to adopt inquiry views of science teaching in their practice. Conversely, Yilmaz and Cavas (2008) found that after experiencing a teaching practicum, the student teachers' beliefs about managing students became more controlling but their beliefs about managing instruction were less controlling.

\subsubsection{Reciprocal and Complex Relationship.}

The sections above have shown that in some research, teacher beliefs influenced teaching practice. In some other studies, teaching practice influenced teacher beliefs. This section reviews studies showing a reciprocal and complex relationship between teacher self-efficacy and teaching practice (Buehl \& Beck, 2014). Beliefs influence practices and vice versa. In addition, the relationship differs among individuals and contexts and the type of beliefs and practices examined.

Evidence can be found in Kang's study (2008) which aims to understand personal epistemologies and science teaching goals of preservice secondary science teachers and how such beliefs influence their actions. During the course, the teachers spent six hours a week observing and teaching science lessons. The researchers used a set of essay questions and 


\section{VIETNAMESE EFL TEACHER SELF-EFFICACY IN PRACTICE}

observed and video-recorded the teaching practice. Lesson plans and self-video reflection were also collected. The data showed that $48 \%$ of the participants maintained their personal epistemologies and science teaching goals and enacted the beliefs in their teaching. In other words, these teachers' beliefs influenced their teaching practice. Conversely, $30 \%$ of the teachers engaged in teaching practices that differed from their initial beliefs. Five teachers demonstrated more complicated practices than their beliefs. They tried out new methods that they learnt in their science methods classes. With the success achieved in these practices, the teachers' personal epistemologies and teaching goals changed significantly. Five other teachers who were not satisfied with their teaching practices with new methods planned to try different ones in the future. In those situations, teaching practice influenced teacher beliefs.

In short, the literature has shown consistency in the relationship between teacher beliefs and teaching practice, meaning that teacher beliefs are demonstrated in teaching practice and that teaching practice is reflected in beliefs. However, research has also found inconsistencies between teacher beliefs and teaching practice. This will be reviewed in the next section.

\subsubsection{The Inconsistency between Teacher Beliefs and Teaching Practice.}

In contrast to the consistency in the relationship of teacher beliefs and teaching practice, research has shown the complexity in this relationship.

Researchers have noticed that the complexities of classroom life were powerful influences on teachers' beliefs which then impacted their practice (Ashton, 1990; Duffy \& Anderson, 1984; Kilgore, Ross, \& Zbikowski, 1990). For example, the reading teachers' instructional practices were based upon classroom realities rather than what they articulated about their beliefs about reading outside the classroom. Examples of external realities are student learning style, teacher-student mutual respect, the amount of assistance for students of different competences, social and emotional characteristics, and textbooks (Ashton, 1990). In addition, novice teachers' effectiveness can either be fostered or diminished by the administrators and collegial attitudes towards the teachers' beliefs about themselves and their students (Kilgore et al., 1990). Other contextual factors influencing teacher beliefs which then affect teaching practice comprise district evaluation and grouping policies (Sapon-Shevin, 1990); individual teacher'sagendas, school climate, and resources (Davis, Konopak, \& Keadence, 1993) 


\section{VIETNAMESE EFL TEACHER SELF-EFFICACY IN PRACTICE}

Similarly, Buehl and Beck (2014) also found that a disconnection between teachers' beliefs and their practices.). In Liu's (2011) study, over three quarters of the participants reported to have learner-centred beliefs; however, most of them said that they were lecturing more than using other constructivist practices. Jorgensen, Grootenboer, Niesche, and Lerman (2010) found inconsistency between teacher beliefs and practices in four aspects, namely inclusiveness, importance of culture, group work, connectedness of ideas, and multiple pathways. The teachers acknowledged the essence of practices but rarely used them in their teaching or used them ineffectively. Lim and Chai (2008) also found a disconnection between teacher beliefs and practices. They observed and interviewed six primary teachers in two Singapore schools to investigate the influence of teachers' pedagogical knowledge on the planning and conduct of computer-mediated lessons. The subjects of the eighteen observed classes were mathematics, English, and science. Five out of the six interviewed teachers expressed pedagogical beliefs of a constructivist orientation to teaching, and their teaching practice did reveal some elements of constructivist teaching. However, the majority of the lessons were still predominantly traditional with a teacher-centred orientation for the purpose of information acquisition for examination.

The findings of studies point to the complexity of the relationship between beliefs and practices. Hence, an interest in researching sources of inconsistency has arisen. Fang (1996) presented one source of this inconsistency: the construct validity of the measures. Most of the reviewed studies used statements or categories pre-determined by earlier research. However, participants may perceive these statements or categories differently. The incongruence was also attributed to methodological issues because the majority of research collected self-reported data, which can create issues of reliability and validity (Fang, 1996). According to Fang, there were three common tools, namely policy capturing, repertory grid technique, and process tracing. The first of these three tools, policy capturing "uses simulated cases or vignettes of students, curriculum materials or teaching episodes to study teachers' judgement processes" (Fang, 1996, p. 56). For example, teachers are given the materials in which certain features or cues are highlighted. They give their judgements about those features on a Likert scale, then their judgments are transformed into linear regression equations. The results from multiple regression equations indicate teachers' policies. According to Armour-Thomas (1989), the reliability of making generalisations from a particular sample judgement to represent a broader domain is questionable. Borg and Gall (1989) (as cited in Fang 1996) presented possible sources of error 
VIETNAMESE EFL TEACHER SELF-EFFICACY IN PRACTICE

associated with teacher judgement as "observer/experimenter drift, error of leniency, halo-effect, personal bias, reliability decay, contamination and error of central tendency" (p.56). ArmourThomas (1989) also presented other ecological validity problems with the policy capturing process. First, data collected from simulated situations may not reflect teacher's actual thought processes. Second, the laboratory settings for many policy capturing studies may not indicate teachers' judgement and decision making in an authentic classroom because such settings are not as dynamic and interactive as an authentic classroom (Lave, 1989, cited in Fang (1996). Another commonly used method in studies about teacher beliefs and practice is the repertory grid technique. This technique was used particularly to uncover the personal constructs that influence their behaviour. Researchers provide their participants with a set of statements or scenarios relating to their research interests. The participants then decide on the ones that best describe their beliefs about a subject-matter. Researchers categorise and label the responses as constructs then put them in a grid format to show their relationships. The reliability of this method is worth noticing because data were collected in simulated situations that represent what teachers would do rather than what they actually do in their classrooms (Fang, 1996).

The third method used to solicit teacher beliefs is process tracing. This is a superordinate term that includes a variety of verbal report methods like think aloud, retrospective interview, stimulated recall, and journal keeping. Researchers use these methods to ask for teachers' judgements or decisions about an instructional task. Because of the introspective nature of selfreported data, some researchers criticised the validity of process tracing (Nisbett \&Wilson, 1977 as cited in Fang, 1996). They claimed that "there may be little or no introspective access to highorder cognitive processes" (Nisbett \&Wilson, 1977, as cited in Fang, 1996, p.57). Moreover, individuals may have difficulties in reporting their cognitive processes because they are not aware of the existence of a stimulus, a response, and how the stimulus influences the response.

To summarise, I present an adapted diagram from Buehl and Beck (2014) showing the factors supporting and hindering the enactment of beliefs in the following diagram. 
VIETNAMESE EFL TEACHER SELF-EFFICACY IN PRACTICE

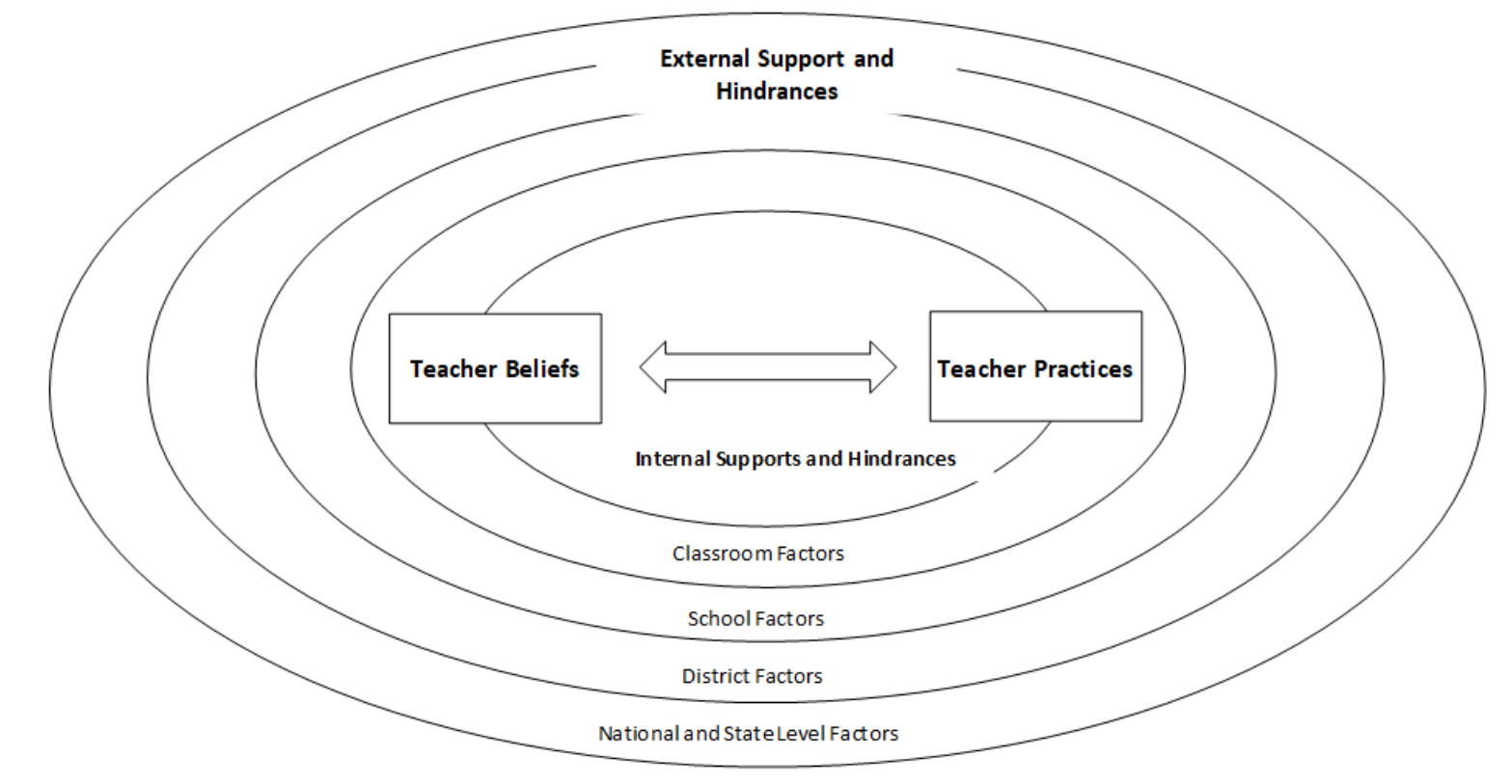

Figure 3: Relationship between Teacher Beliefs and Teacher Practices and Supporting and Hindering Factors (adapted from Buehl \& Beck, 2014).

There are some internal factors (i.e within teachers) influencing the process of enacting teacher beliefs in practice, namely, other beliefs, experience, knowledge, self-awareness and selfreflection. Teachers hold beliefs about various topics such as teaching, learning, learners. In a multidimensional system, some beliefs may play a more central role than others. Some of them may even contradict each other. Therefore, different aspects of the teacher belief system may support or impede the enactment of beliefs into practice. Another factor acting as mediator and moderator in the alignment of teacher beliefs and practice is their sense of responsibility for students' learning. Teacher beliefs about teaching contexts also influence their teaching practice. In addition to the other beliefs, teacher content knowledge, pedagogical knowledge, and pedagogical content knowledge also play an important role (Mouza 2009). The external factors are classified into levels that are embedded within one another "such that similar pressures or issues at one level may be instantiated differently depending on the context and they may affect other external factors at different levels" (Buehl \& Beck, 2014, p. 76). Classroom-context factors refer to student ability, student attitudes, classroom management, and class size. School-context factors include administration, parental support, and colleagues, available resources, school culture and community. National-, state-, and district-level factors refer to education policies and curriculum standards. 
VIETNAMESE EFL TEACHER SELF-EFFICACY IN PRACTICE

\subsection{Language Teacher Beliefs about Teaching and Learning and Their Teaching Practices}

Language teacher beliefs and their connection to language teaching practice have been extensively researched. According to Gao (2014), during the last decade of the $20^{\text {th }}$ century, there existed two opposing themes in the literature. On the one hand, researchers found consistency between language teacher beliefs and their teaching practice. On the other hand, other studies showed that the relationship is inconsistent. Some examples of the congruence were presented in section 6.2.1.1 such as Richardson et al. (1991), (Johnson, 1992). Another study conducted by Cundale (2001) attained a similar finding. The researcher firstly interviewed two teachers at a private language school in Mexico about their views on communicative language teaching (CLT) then observed their classes. The interview data showed that both interviewees expressed their interest in using the communicative approach in their teaching. The observation data showed the alignment between their beliefs and their practice. For example, both teachers were in favour of asking their students referential and open questions, which enhance language acquisition.

Aiming to examine the relationship between teachers' beliefs about the use of Singlish in their classrooms and their teaching practice, Farrell and Tun (2008) observed and then interviewed three elementary school teachers working in three state schools in Singapore. They found that most of the teachers' practices were consistent with their espoused beliefs. For example, the participants believed that teachers should not always correct students' use of Singlish in English classes. They seldom corrected the students' utterances. Instead, they asked the students to rephrase the expressions.

In a different study in Singapore, Farrell and Lim (2005) interviewed two primary school teachers, then observed their classes, and interviewed them again to compare their stated beliefs about teaching grammar and their practices. They found both congruence and incongruence between them. One teacher expressed firm beliefs in explicit instruction on grammar rules. Her teaching practices were mainly work-sheet based and teacher-centred. The other teacher said, in the pre-study interview, that grammar should be taught through speaking, reading and writing activities. In her lesson on adverbs of manners, students actively discussed, wrote poems and short stories. However, incongruence was also noticed. The teacher gave explicit grammar explanations. Her teaching was structured and prescriptive rather than incidental. The activities were not meaningful communicative situations. Farrell and Lim (2005) presented possible 


\section{VIETNAMESE EFL TEACHER SELF-EFFICACY IN PRACTICE}

explanations for the divergence including time over which the teachers had little or no control, and their perception of traditional grammar teaching and learning. Powers, Zippay, and Butler (2006) also found non-alignment between teacher beliefs and practice in their study. However, this was explained as being influenced by "classroom management and environment issues and requirements and limitations set forth by administrative and district policies" (Powers et al., 2006, p. 131).

Kartchava, Gatbonton, Ammar, and Trofimovich (2018) research involved 99 pre-service ESL teachers in three universities in Canada. After completing a background questionnaire and a belief questionnaire part 1, ten first-year student teachers were asked to respond to the belief questionnaire part 2 and 3 and have their teaching practices observed. The research findings indicate a "multifarious relationship" (Kartchava et al., 2018, p. 220) between teacher beliefs and practice. For example, during their teaching, they corrected fewer mistakes than they said they would do. However, they were in favour of the same corrective techniques both hypothetically and in reality.

Gao (2014) also highlighted the recent period after the 2000s when researchers studied teacher beliefs through the lens of Vygotsky's sociocultural theory. In addition to a school of thought that focused on investigating the relationship between teacher beliefs and practice, there has been another school of thought with research scholars interested in the sociocultural and political factors influencing teacher beliefs and practice (Gao, 2014). According to Gao, most studies using this approach regarded beliefs as mediators of learner/teacher actions. For example, Peng (2011) examined the changes in beliefs about language teaching learning of a first year student with six interviews, six observations, and 22 journal entries. The learner beliefs were found to change substantially thanks to meaningful classroom affordances such as meaningfocused activities, teacher's and peers' support, familiar topics, and lesson goals.

In conclusion, similar to research findings of the relationship between general teacher beliefs and practice, researchers have found alignment and divergence between language teacher beliefs and teaching practice. The following section will review the relationship between teacher self-efficacy and classroom practice. 
VIETNAMESE EFL TEACHER SELF-EFFICACY IN PRACTICE

\section{What is the Relationship Between Language Teacher Self-Efficacy and Classroom Practice?}

While research on teacher beliefs has focused largely on teacher pedagogical beliefs, this is rarely integrated with research on teacher self-efficacy, which is a sub-theme of teacher beliefs (Pajares, 1992) and its relationship with teaching practice. Parallel with research on the relationship between teacher pedagogical beliefs and teaching practice, research has shown a reciprocal relationship between teacher self-efficacy and classroom practice. This section will summarise studies in this area.

First, teacher self-efficacy has been identified as a predictor of practice. In their research, Thoonen et al. (2011) aimed to explain variation in student motivation by investigating the relationship between teacher self-efficacy and their teaching. 194 teachers from 34 varied background primary schools in the Netherlands were involved in the study, a part of which was about teaching practices and teachers' sense of self-efficacy. The findings indicated a multidirectional relationship between teacher self-efficacy, classroom practices, and student motivation.

\section{Teacher self-}

efficacy

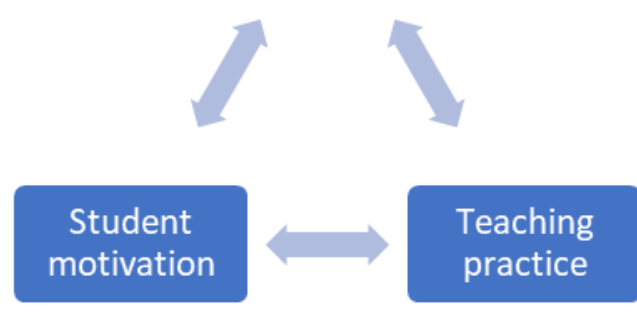

Figure 4: Multidirectional Relationship between Teacher Self-Efficacy, Classroom Practices, and Student Motivation (adapted from Thoonen, et al., 2011).

More specifically, teachers who reported to have high sense of self-efficacy tended to use more process-oriented instruction and better match students' personal lives with school life. In addition, they described their use of cooperative learning activities in their classes. They also showed more differentiation in their instruction. In an analysis of high school teachers' motivation, Ciani, Summers, and Easter (2008) surveyed 156 teachers from four public high schools from the same area. They measured a teacher's sense of community using the Bay Area 
VIETNAMESE EFL TEACHER SELF-EFFICACY IN PRACTICE

School Reform Collaborative Teacher Survey (BASRC, 2002). The Patterns of Adaptive Learning Scales (Midgley et al., 2000) was used to measure teachers' perceptions of the school goal structure. Teachers' perceived collective efficacy was evaluated by the Collective Efficacy Scale (Goddard, 2002). Teacher self-efficacy was judged by the Teachers' Sense of Efficacy Scale (Tschannen-Moran \& Woolfolk Hoy, 2001). The researchers presented a diagram showing the relationship between different elements as follows:

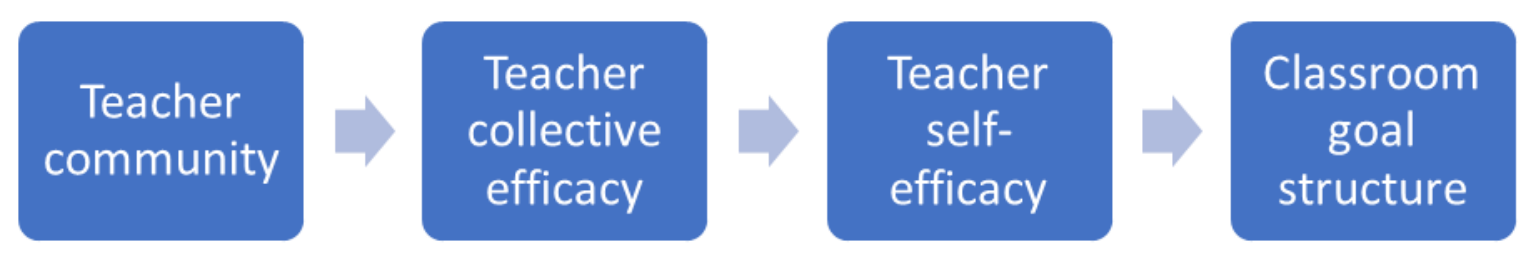

Figure 5: Relationship between Teacher Community, Teacher Collective Efficacy, Teacher SelfEfficacy, and Classroom Goal Structure (adapted from Ciani, Summers, \& Easter, 2008).

Second, there is evidence from the literature that teachers' engaging in specific practices influences teacher self-efficacy (Malinen et al. (2013). In a quantitative study, Malinen et al. (2013) surveyed 1911 in-service teachers from China, Finland, and South Africa to explain their self-efficacy in teaching inclusive classrooms. Using the scale "Teacher self-efficacy for inclusive practices" together with items about teachers' demographic factors, the researchers found that experience in teaching students with disabilities "had the strongest explanatory power" (Malinen et al., 2013, p. 41) for teachers' judgement of their self-efficacy. This finding fits with Bandura's theory of self-efficacy with mastery experience to be the strongest source of self-efficacy. Tschannen-Moran and McMaster (2009) conducted a quasi-experimental study to test the influences of four different professional development formats on teacher self-efficacy. The first format offered a three-hour workshop on Tucker Signing Strategies for Reading. The presenter provided the participants with a lecture and verbally answered questions arising. In other words, this format provided social persuasion to the participants. The second group had vicarious experience added. In addition to giving the lecture, the presenter modelled how to use hand cues with local students. Seeing the students' success in decoding the new words, many teachers expressed their interest in using the strategies in their classes. The third group experienced social persuasion and vicarious experience like the second group and, in addition, 


\section{VIETNAMESE EFL TEACHER SELF-EFFICACY IN PRACTICE}

mastery experience. The participants were given an opportunity to practise teaching for one hour and a half. During these sessions, the participants discussed how to use the strategies, make lesson plans, and practise implementation of the strategies. Tschannen-Moran and McMaster (2009) added stronger mastery experience to the fourth group. The treatment included a followup coaching session after the workshop. The coaching included a 30-minute review of hand gestures in small groups, a 15-minute one-on-one coaching dialogue with the presenter, and a 30minute coaching session with the presenter in the teachers' classrooms. Tschannen-Moran and McMaster (2009) claimed that the teachers attained mastery experience because they practised the new strategy in their teaching. They acquired "individualized and specific experience of verbal persuasion" (Tschannen-Moran \& McMaster, 2009, p. 235) because they had personal conversations with the presenter about their implementation of the new strategy. For some teachers, coaching may have also provided them with second-hand vicarious experience when they observed the presenter using the strategy in their classrooms with their students. Questionnaires measuring the teachers' sense of efficacy and their sense of efficacy for literacy instruction were administered before and after the workshop. The research results showed an increase in teacher self-efficacy, regardless of the treatment group. However, Tschannen-Moran and McMaster (2009) said this development may be a result of a time effect.

In another study, Lumpe et al. (2012) investigated the influences of a professional development programme for elementary school teachers self-efficacy to teach science. The researchers used the "Science teaching efficacy beliefs inventory" (Rigss \& Enochs, 1990) and "Context beliefs about teaching science" (Lumpe, Haney, Czerniak, 2000) to measure teacher beliefs about self-efficacy, outcome expectancy, and context. They found that after taking part in the professional development for one year, there was a significant increase in teacher selfefficacy.

To conclude, in some research, teacher self-efficacy was found to have an influence on teaching practice. In some other studies, researchers found that teachers' engagement in certain activities had an impact on their beliefs about their teaching ability. It is possible that the relationship between teacher self-efficacy and teaching practice is reciprocal. 
VIETNAMESE EFL TEACHER SELF-EFFICACY IN PRACTICE

\section{Chapter Summary}

In this chapter, I have reviewed the development of teacher self-efficacy over time. It is an important topic because it relates to students' achievement and learning motivations. In particular, self-efficacy influences teachers' professional lives in terms of job stress, job satisfaction, commitment, teacher burn-out, teacher well-being and teaching practice. Research has included pre-service, elementary, secondary, and high school teachers of various subjects. Only a few studies have investigated teacher self-efficacy at tertiary level. Only one research study was conducted at a university in Vietnam. The review has also summarized the inconsistency in the relationship between teacher self-efficacy and teaching practice. This inconsistency indicates a possible dynamic aspect in teacher self-efficacy.

This research was designed to investigate self-efficacy in the specific context of EFL teachers at a tertiary institution in Vietnam. This study investigated the relationship between teacher self-efficacy and teaching practice, to provide an understanding of the influences of contextual elements on both teacher self-efficacy and teaching practice. This has the potential to improve the quality of teaching and learning English at universities in Vietnam. The thesis will address the overarching research question of "How does self-efficacy influence the teaching practice of Vietnamese EFL tertiary teachers?'. It will systematically answer the following subquestions:

1. What are the self-efficacy profiles of EFL teachers working in a public university in Vietnam?

2. What do these EFL teachers report as influences on their selfefficacy in their classrooms?

3. How do teachers with different profiles of self-efficacy differ in their teaching practice?

The upcoming chapter will describe the methodology of this study. 
VIETNAMESE EFL TEACHER SELF-EFFICACY IN PRACTICE

\section{Chapter III Research Methodology}

\section{Research Paradigm}

A research paradigm is a worldview or perspective about research (Johnson \& Christensen, 2014). To answer research questions, researchers choose appropriate methodologies based on their "assumptions, concepts, values, and practices" (Johnson \& Christensen, 2014, p. 31) or beliefs (Guba, 1990). A research paradigm consists of three concepts, namely ontology, epistemology, and methodology (Mertens, 2010). This section addresses my ontological, epistemological, and methodological views.

The ontology of research refers to the nature of knowledge (Burton \& Bartlett, 2009; Mertens, 2010). Epistemology refers to the creation of knowledge (Burton \& Bartlett, 2009) or the theory of knowledge (Johnson \& Christensen, 2014). It indicates the relationship between researchers and the study topic (Denzin \& Lincoln, 2005). The ontology and epistemology of research closely relate to each other because our knowledge about the world influences our perception of knowledge creation and how it can be understood. Furthermore, epistemology determines research methodology (Burton \& Bartlett, 2009) or approach to systematic inquiry (Mertens, 2010).

According to Creswell and Plano Clark (2011), in educational research, there are four paradigms or worldviews which are typically associated with certain research approaches, namely postpositivism, social constructivism, advocacy and participatory, and pragmatic. In the first paradigm, postpositivists commence their research with a theory, then collect data which either proves or disproves the theory. This worldview is typically seen as an approach to quantitative studies. Different from the postpositivists, the social constructivist worldview is usually employed in qualitative research. It enables researchers to study a situation from various participants' views in specific research contexts. Researchers' position and backgrounds such as their personal and cultural experiences influence their interpretation. In other words, "rather than starting with a theory (as in postpositivism), inquirers generate or inductively develop a theory or pattern of meaning" (Creswell, 2009, p. 8). Researchers who employ the advocacy and participatory worldview intertwine their inquiries with politics and a political agenda which may change either the participants' or their own lives, or the place in which they live or work. The fourth paradigm, pragmatism, is often correlated to mixed methods research which emphasises 


\section{VIETNAMESE EFL TEACHER SELF-EFFICACY IN PRACTICE}

the utility of multiple methods to collect data to answer the research questions and the significances of research (Creswell \& Plano Clark, 2011). Creswell (2014) defined pragmatism as "a worldview or philosophy that arises out of actions, situations, and consequences rather than antecedent conditions" (p.245). Pragmatism views truth, meaning, and knowledge as changeable over time and in different contexts (Johnson \& Onwuegbuzie, 2004). Inquirers are suggested to use multiple methods (Creswell, 2013; Greene, 2007).

My research employed pragmatism paradigm. I investigated Vietnamese EFL teacher self-efficacy. The research literature shows that self-efficacy is influenced by many factors such as students' characteristics, school types, availability of teaching resources, and classroom conditions (see Chapter II). In other words, teacher self-efficacy is task and context-specific and teachers' knowledge is "subjective, personal, and unique" (Cohen, Manion, \& Morrison, 2007, p. 7). Each teacher is likely to report their self-efficacy differently and demonstrate it in their teaching in a variety of ways. Therefore, it is necessary to understand not only the participants' self-report of efficacy beliefs but also all other factors relating to them. This study was conducted in the participants' workplace, in other words, within classrooms in a university. I surveyed, observed, and interviewed the participants to understand their educational background, teaching experiences, working conditions, and their students. The data arose from their beliefs about their self-efficacy and how they demonstrated these beliefs in their classroom. Multiple methods were used to report multiple realities of their self-efficacy beliefs.

My educational background as an English as a foreign language (EFL) teacher at tertiary level, and my experience of nearly ten years' teaching have shaped my beliefs about teacher selfefficacy. As the main research instrument (Eisner, 1998), my assumptions possibly influence the research design, data collection, data analysis, and my interpretation of the results.

\section{Mixed Methods Design}

I used a pragmatic paradigm leading to a qualitatively-driven mixed methods design in this study. According to Hesse-Biber and Johnson (2015), most approaches to mixed methods refer to "the mixing of at least one qualitative and one quantitative method in the same research project or set of related projects" (p.41). According to Hesse-Biber and Johnson (2015), one important characteristic of qualitatively-driven mixed methods is the privileging of a qualitative approach in terms of epistemology and methodology. Within qualitatively-driven inquiry, the 


\section{VIETNAMESE EFL TEACHER SELF-EFFICACY IN PRACTICE}

epistemology is to understand multiple subjectivities through which we understand human behaviours. This type of research aims to address what, how, and why research questions, collects data in naturalistic settings with participant observation, in-depth interviews, focus groups, and unobtrusive data. The data are analysed inductively using thick description, looking for general themes or patterns in the data then comparing and contrasting thematic data. HesseBiber (2010) points out that through the deployment of qualitative methodologies, researchers can capture the nuance of social reality through multilayered view. More importantly, this approach tends to be open to new information. Howe (2004) also emphasised that qualitative approach offers better understanding between researchers and the researched to get "deeper and more genuine expressions of beliefs and values that emerge through dialogue [and] foster a more accurate description of views held" (Howe, 2004, p. 54). This approach to mixed methods contrasts with other researchers who traditionally have said that a researcher should have strong quantitative and qualitative skills before conducting a mixed methods study (Creswell \& Plano Clark, 2011; Mertler \& Charles, 2011) to overcome the challenges of "the need for extensive data collection, the time-intensive nature of analysing both text and numeric data" (Creswell, 2009, p. 205)

Mixed methods research has some advantages over other methods. Creswell and Plano Clark (2011) stated that this method can amend the weaknesses of both quantitative and qualitative approaches. Additionally, mixed methods can address the questions that cannot be answered by a single approach alone. Because mixed methods researchers can make use of several instruments to collect data, they can generate more evidence for their studies. Similarly, Denscombe (2008) found that mixed methods research can increase the accuracy of data, construct a more complete picture of what being studied by collecting different sources of data, minimise single-method research bias, develop analysis and build on initial findings, and aid sampling.

I used a mixed methods approach to make use of complementary data sources (Hesse-Biber \& Leavy, 2006). I used multiple data collection methods including an online questionnaire, observations and interviews to collect data, and to strengthen the robustness of the study (data triangulation). This triangulation aims to converge and corroborate the research findings (Yin, 2014), enabling insight into teacher self-efficacy in a more comprehensive and nuanced way compared to only using a single method (Silverman, 2011). Moreover, triangulation helps to 
VIETNAMESE EFL TEACHER SELF-EFFICACY IN PRACTICE

foster the validity and credibility of the findings (Creswell, 2014; Yin, 2014). In this study, teacher self-efficacy was not only investigated through self-report data from the teachers' responses to the online survey but also through the researcher's observation of the teaching practices of the participants and through interviews, including stimulated recall. Consequently, the limitations of single quantitative or qualitative research on this topic were minimised. The quantitative data were complemented by the qualitative data, which brings "broader, deeper, and more comprehensive social understandings" of the studied issue (Greene, 2007). From the analysis of 52 respondents to the online survey, eight teachers were selected for the qualitative phase.

My research aimed to obtain a more nuance understanding of the dynamic of teacher selfefficacy by addressing the research questions to measure their self-efficacy scores, unpack the influences on teacher self-efficacy, and find the complex nature of the relationship between teacher self-efficacy, teaching practice, and contextual factors. To collect data, first, the teachers were invited to respond to an online survey in the quantitative phase. Descriptive statistics of the quantitative data described the self-efficacy scores of the participants. SPSS (version 23) was used to rank the participants' scores according to four quartiles. From each quartile, I then considered those who had agreed to be interviewed and selected three of them from the upper and lowest quartile and three participants from the combination of the two middle quartiles. Basing on the matching between their and my availability, I ended up with two participants in higher self-efficacy group, three participants in each of the medium and lower self-efficacy group for the qualitative phase. The purposively selection of participants from each category was to ensure that participants of all levels of self-efficacy were included in the qualitative phase. These teachers were then observed in their classes for their teaching practice (observations) and interviewed about the observation of their practice (stimulated recall interviews). Their teaching practices were described (thick description), analysed to identify general themes. I also compared and contrasted those themes to find similarities and differences in teaching practice of the participants.

Based on quantitative data, I investigated the teaching practice of teachers with different selfefficacy profiles in the qualitive phase. According to Hesse-Biber (2010), using quantitative data to initiate a qualitative research question promotes the understanding of the research problem and 
VIETNAMESE EFL TEACHER SELF-EFFICACY IN PRACTICE

research findings. Moreover, Hesse-Biber and Johnson (2015) said that "conducting a quantitative demographic survey on a random sample of the researcher's target population first (quan), followed by a qualitative study (QUAL), enables the researcher to select a qualitative subsample from this population that is representative of the target population" (p.7). For the above reasons, the qualitatively driven mixed methods design is appropriate for my study. Representing the study with the (QUAL) and (quant) uses the notation of Creswell and Plano Clark (2011) to indicate of the dominance of the qualitative phase of the study.

\section{Case Study}

Case study is one of the most widely used methodologies in qualitative research (Yazan, 2015). However, research methodologists have presented different and sometimes, contrasting approaches to this research method. Yin (2003) explicitly defined a case as "a contemporary phenomenon within its real-life context, especially when the boundaries between a phenomenon and context are not clear and the researcher has little control over the phenomenon and context" (p.13). Stake (1995), in contrast, did not provide a precise definition of cases. However, he depicted some features of a case. For example, a case is a specific, complex, and functioning thing or integrated system which has a boundary and working parts. Case boundaries are "the time period, social groups, organizations, geographic locations, or other conditions that fall within (as opposed to outside of) the case in a case study" (Yin, 2014, p. 237). Case study is usually used to study complex phenomena (Johnson \& Christensen, 2014) within its natural settings (Yin, 2012). In a case study, researchers examine cases as holistic entities and how their parts operate together (Johnson \& Christensen, 2014).

Research has shown that teacher self-efficacy is a specific but complex phenomenon with interactive sources. My study aimed to study Vietnamese EFL teacher self-efficacy in its natural classroom setting in which I, as an observer, would not participate or be involved in the teaching procedures. For these reasons, a case study design was appropriate for the qualitative phase of my study. The case in this research was bounded by the eight EFL teachers from the research university in the first semester of 2016-2017 academic year.

Methodologists have classified case studies differently. Yin (2014) categorized four types of case study design, namely single case holistic, single-case embedded, multiple holistic, and multiple embedded designs. Holistic designs require one unit of analysis, whereas embedded 
VIETNAMESE EFL TEACHER SELF-EFFICACY IN PRACTICE

designs require multiple units of analysis. Stake (1995) presented three types of case study. When we are given a case that we are intrinsically interested in studying, and we need to learn about that particular case, the research is labelled as intrinsic case study. In contrast, when we study a particular case to address (a) research question(s) or to get general understanding, we conduct instrumental case study. Unlike intrinsic case study in which the case is dominant, for instrumental case study, the issue is dominant. The third type presented by Stake (1995) is collective case study which requires the coordination of individual studies. This type of case study is usually designed with more concern for representation (Stake, 1995, p.5).

The collective case study was the most appropriate design for my study. This type of case study allowed me to investigate the case of self-efficacy of teachers with different self-efficacy profiles. From the results of the quantitative data analysis, I selected eight teachers to follow-up from those surveyed. The eight participants were classified into three groups of lower, medium, and higher self-efficacy scores. These three groups represented different levels of self-efficacy. Collective case study design allowed me to compare and contrast teacher self-efficacy with varied scores of self-efficacy.

According to Yin (2014), case study researchers should collect data from multiple evidentiary sources. Stake (1995) suggested using observation, interview and document review to gather information about the case. My study collected data from three sources: pre-observation interviews, classroom observations, and post-observation interviews.

Stake (1995) suggested two strategic ways to analyse data in case studies: Categorical Aggregation and Direct Interpretation (p.74). In my analysis, I relied on both methods. Data on teachers' perceptions about sources of and influences on teacher self-efficacy were analysed through the aggregation of each individual teacher. The teachers' teaching practices were described according to their groups of self-efficacy scores to find the similarities and differences within and across the groups. Then, the data were aggregated to provide an overview of teacher self-efficacy.

To recap, this study used the collective case study design (Stake, 1995) for the qualitative phase. 
VIETNAMESE EFL TEACHER SELF-EFFICACY IN PRACTICE

\section{Sampling Method}

A convenience sampling method was used for the quantitative phase. However, criteria were applied. I selected lecturers of English as a Foreign Language in the Faculty of English for Specific Purposes in a public university in Vietnam. I chose them because of their accessibility and because they were from the same institutional context. First, the Dean of that faculty was emailed an information sheet describing the research together with a consent form. This is a big university with over seventy lecturers teaching English to students of various majors such as Law, External Economics, and Business Administration. A large number of potential participants for the quantitative study enabled me to have enough volunteers in the quantitative phase for some descriptive analysis and ensure sufficient interviewees for the qualitative research. With the Dean's agreement, a similar email and attachments were sent to all the EFL teachers in the faculty. Those people who were willing to take part in the study were invited to complete the online questionnaire. There were 52 responses, which, according to Wiersma and Jurs (2005) was an ideal number because it provides sufficient data for the study.

After initial analysis of the quantitative data, the teachers with different self-efficacy profiles were purposefully chosen to participate in the qualitative phase. In total, there were eight teachers observed and interviewed. These participants were selected from those who volunteered for the second phase of the study. This method of purposive sampling is defined as "a nonrandom sampling technique in which the researcher solicits persons with specific characteristics to participate in a research study" (Johnson \& Christensen, 2014, p. 264).

\section{Data Collection Instruments and Procedures}

\subsection{Phase 1: Quantitative}

According to Sue and Ritter (2012), survey is a data collection process. It starts with defining research objectives and ends with the analysis of data and reporting findings. In this process, the questionnaire plays an important role. More precisely, Johnson and Christensen (2014) define a questionnaire as "a self-report data collection instrument that each research participant fills out as part of a research study" and explains their use as "obtain[ing] information about thoughts, feelings, attitudes, beliefs, values, perceptions, personality, and behavioural intentions of research participants" (p.227). Denscombe (2003) states that questionnaires are most beneficial when they are used to collect data from a large sample; when the participants are 
VIETNAMESE EFL TEACHER SELF-EFFICACY IN PRACTICE

willing to give fairly straightforward responses; when the researcher needs strong evidence, or standardised data from the same questions without individual, face-to-face interaction; when there is no time and cost pressure; and when the questions are comprehensible to the participants. Traditionally, researchers conduct their surveys through telephone interviewing, face-to-face interviewing, and mail questionnaires. Nowadays, thanks to the development of technology, online surveys that comprise email, web-based, and mobile surveys have become more and more popular. In my study, an invitation email with the link to the questionnaire was sent to the participants. They followed the link and completed the questionnaire. This method is defined as e-mail survey (Sue \& Ritter, 2012)

Previously, researchers pointed out problems of using an online survey. The first disadvantage is limited populations (Sue \& Ritter, 2012) because online surveys are limited to people with email or access to the web, i.e. to people with computers and the skills to use them (Mills \& Gay, 2015; Wiersma \& Jurs, 2005) and limited to literate people (Mills \& Gay, 2015). Usually, respondents to the surveys are volunteers, which results in sampling bias and coverage error (Cohen, Manion, \& Morrison, 2011). The second drawback of online surveys relates to technical problems (Cohen et al., 2011). For example, informants may experience different configuration, layout, and presentation from the researcher's initial design due to the use of different web browsers, hardware, and software. This may result in participants losing interest, feeling unfamiliar and irritated, and have the effect of a low response rate or abandonment of the survey (Cohen et al., 2011; Sue \& Ritter, 2012). Slow loading time or bad internet connections can also lead to drop out (Cohen et al., 2011). Ethical issues can be another shortcoming of online surveys in that respondents may wonder whether the survey is bona fide research (given the little information they have about the researcher). As respondents can be identified by their email addresses, research anonymity can be problematic (Cohen et al., 2011; Sue \& Ritter, 2012).

However, the participants in my study were lecturers at a university in a big city in Vietnam. They all had computers with Internet access. To minimise the other above disadvantages, I employed Cohen's strategies (Cohen et al., 2011). My survey was designed to be short, clear, and simple. The instructions are succinct and easy to understand. Prior to the main research, the questionnaire was trialled by various users on different computer systems and 


\section{VIETNAMESE EFL TEACHER SELF-EFFICACY IN PRACTICE}

browsers. Their comments and feedback were used to make any necessary amendments. The identity of the respondents was protected because they were directed to Qualtrics website to complete the questionnaire. They did not need to provide their personal contact details unless they wished to participate in the second phase of the study. Most of them were anonymous.

To boost the response rate and to mitigate the ethical concerns mentioned above, I differentiated my invitation from spam in their mailbox by using my institutional email address from Victoria University of Wellington (Wiersma \& Jurs, 2005). Brief information about me and detailed information about the research, including informed consent were included to gain the participant's trust and to provide any further required clarification or explanation. Follow-up emails were sent to thank those who had completed the survey and to gently remind the others to answer (Sue \& Ritter, 2012). To increase the reliability of the data collected, the participants were allowed to respond only once (Cohen et al., 2011).

Importantly, there are also advantages in using online surveys (Cohen et al., 2011). First, it saves time because it decreases the response time as well as the time to distribute, collect and analyse data. Second, it can reach a wide range of the population (Sue \& Ritter, 2012), even with sensitive informants because of its anonymity and non-traceability (Cohen et al., 2011; Sue \& Ritter, 2012). In my project, the questionnaire was accessible to teachers with different sociodemographic factors. For example, participants varied in age, qualifications, years of experience, and working positions, all of which helped to maximize the generalisability. Third, an online survey is considered convenient as respondents can complete the questionnaire at the time and place that suits them. The software can help respondents check their incomplete or inconsistent answers (Cohen et al., 2011). Moreover, budget-saving was a substantial benefit (Cohen et al., 2011; Sue \& Ritter, 2012; Wiersma \& Jurs, 2005) in that no other cost is required for postage, printing, photocopying, and processing data, except for initial set-up expenses.

The participants in my study were invited to do a web-based questionnaire with two parts adapted from other validated surveys (see Appendix B). The first part was modified from Tschannen-Moran and Hoy (2001) to measure EFL teacher self-efficacy in tertiary education. The second part is an adaptation of Yavuz (2007) with items about the participants' sociodemographic factors. The adapted questionnaire was trialled by my colleagues and friends who 
VIETNAMESE EFL TEACHER SELF-EFFICACY IN PRACTICE

were EFL lecturers at other universities. They gave me feedback which was used to make changes before collecting data.

\subsection{Phase 2: Qualitative}

\subsubsection{Observation.}

Because people do not usually act the way they think and "because of the potential incongruence between attitudes and behaviour, researchers can mitigate this incongruity by collection observational data in addition to self-report data" (Johnson \& Christensen, 2014, p. 236). Observation gathers data in its natural setting and records actual behaviour (Creswell, 2012; Denscombe, 2003). Instead of depending on self-reported data, researchers can look directly at what is taking place. This is considered the unique strength of observation (Cohen et al., 2011). Cohen et al. (2011) also note that observation provides a reality check in that it allows researchers to look afresh at everyday behaviour. It helps researchers avoid problems caused when there is a time gap between the act of observation and the recording of the event. Moreover, some participants prefer the presence of an observer to an intrusive, time-consuming interview or questionnaire (Cohen et al., 2011, p. 456).

However, there are some disadvantages of observation. The presence of the researcher may influence its naturalness (Creswell, 2012; Denscombe, 2003; Wragg, 2012). Low structured observation can be time-consuming and data need extended presentations (Gillham, 2008). Wragg (2012) points out that the focus of attention is a common problem faced by both experienced and inexperienced researchers when observing a classroom because there are so many incidents happening in the classroom that distract the observer. Such incidents "could be subject of pages of notes and hours of discussion" (Wragg, 2012, p. 4).

In my study, I employed semi-structured observation which "have an agenda of issues but will gather data to illuminate these issues in a far less predetermined or systematic manner" (Cohen et al., 2011, p. 457). During this stage of the research, I took on the role of nonparticipant observer (Mills \& Gay, 2015) to maintain the naturalness of the class and ensure the validity of the data. In other words, I acted as a complete observer (Cohen et al., 2011) and did not participate in the teaching and learning process. 
VIETNAMESE EFL TEACHER SELF-EFFICACY IN PRACTICE

To record observations, incidents witnessed in the classroom were written in reflective field notes (see Appendix O). On the one hand, written records can be insignificant or unreliable because the observer needs to decide immediately what to record without any chance of action replay (Wragg, 2012). On the other hand, this method brings immediate and fresh data which are helpful for follow-up discussion. It also saves time (Wragg, 2012). The reflective field notes record the salient events or incidents during the teaching practice together with the researchers' personal thoughts (Creswell, 2012), and also personal reactions to observations and experiences (Mills \& Gay, 2015). An observational protocol (see Appendix D) was used to chronologically record the events in the classroom. The top of the protocol sheet comprised information about time, place, setting, and the researcher's role. Under the header, there were two columns representing the description of the classroom events and my reflection (Creswell, 2012).

To complement the reflective field notes, the observations were video-recorded. Videorecording helps observers overcome the tendency of taking notes of the most frequently happening incidents (Cohen et al., 2011). Instead of having to make immediate decisions while observing, researchers can scrutinize data more carefully by watching the video from time to time (Cohen et al., 2011; Wragg, 2012). Furthermore, researchers can discuss the recordings with participants after the observation (Wragg, 2012). Selecting particular incidents from the video will save the researcher's and participants' time in the stimulated recall as it is difficult and timeconsuming to watch the whole video (Wiersma \& Jurs, 2005). Video-record can also catch nonverbal behaviours (Wiersma \& Jurs, 2005). This is important in my study as it aims to explore the contextual influences on teacher self-efficacy. Together with the above advantages, Wragg (2012) points out some disadvantages of video-recording. It may miss information on the settings of the classroom such as room temperature and smells. There are corners of the classroom which the cameras cannot reach. The presence of the camera may influence teacher's and students' behaviours, which results in an obtrusive data source (Mills \& Gay, 2015). In particular, researchers need considerable time to analyse data (Mills \& Gay, 2015; Wragg, 2012). To deal with those problems, I recorded the information on classroom settings in reflective field notes. Two digital cameras were used to minimise any obtrusive influence (Mills \& Gay, 2015). One camera was placed at the back of the classroom which mainly focused on the teacher. The other one was positioned above the blackboard so that it could catch most of the students. Those 


\section{VIETNAMESE EFL TEACHER SELF-EFFICACY IN PRACTICE}

students who declined to participate in my observation were seated so that they were out of the camera's view.

\subsubsection{Interviews.}

To clarify what was happening in the videos, the participants were interviewed. According to Johnson and Christensen (2014), qualitative interviews are useful to "obtain indepth information about a participant's thoughts, beliefs, knowledge, reasoning, motivations, and feelings about a topic" (p. 233). In order to get trustworthy data, interviewers must build trust and rapport with the interviewees (Johnson \& Christensen, 2014), which is usually a lengthy and labour intensive process. In this study, semi-structured interviews and stimulated recall interviews were conducted in Vietnamese to help the participants feel more confident, relaxed and convey their thoughts more easily. The aims of the interviews were to elicit the teachers' views about their sense of efficacy and to encourage them elaborate on them. I aimed to "explore people's view of reality" (Hesse-Biber \& Leavy, 2006, p. 126) and gain insights into teachers' beliefs about their self-efficacy.

Before the classroom observations, the participants were interviewed about their beliefs about their teaching. After the observation of each participant, I selected particular incidents during the teaching practice which were captured in the video. These incidents were associated with teacher self-efficacy in managing the classroom, engaging students, and giving instructions. The teachers recalled the events and reflected on them aloud. This stimulated recall found some of teachers' thought processes and strategies (Gass \& Mackey, 2000). However, as Gass (2001) states, it is difficult to distinguish participants' recall of and reflection on an incident. Instead of recalling their thinking of the original event, participants may respond to the event while watching it (Yinger, 1986). The interviewees may also be influenced by their preparedness for the interview (Gass \& Mackey, 2000). Therefore, prompts were used to help the participants recall the incidents in their classes and reflect on them (see Appendix C).

The interviews were audio-recorded and I took notes during the interviews as well. These two methods support each other because field notes can fill in some relevant information about the setting, the atmosphere, and the feelings that an audio-recording might miss as "it captures only speech, and misses non-verbal communication and other contextual factors" present in interviews (Denscombe, 2003, pp. 175,176). 
VIETNAMESE EFL TEACHER SELF-EFFICACY IN PRACTICE

The data collection procedure is illustrated in the following figure.

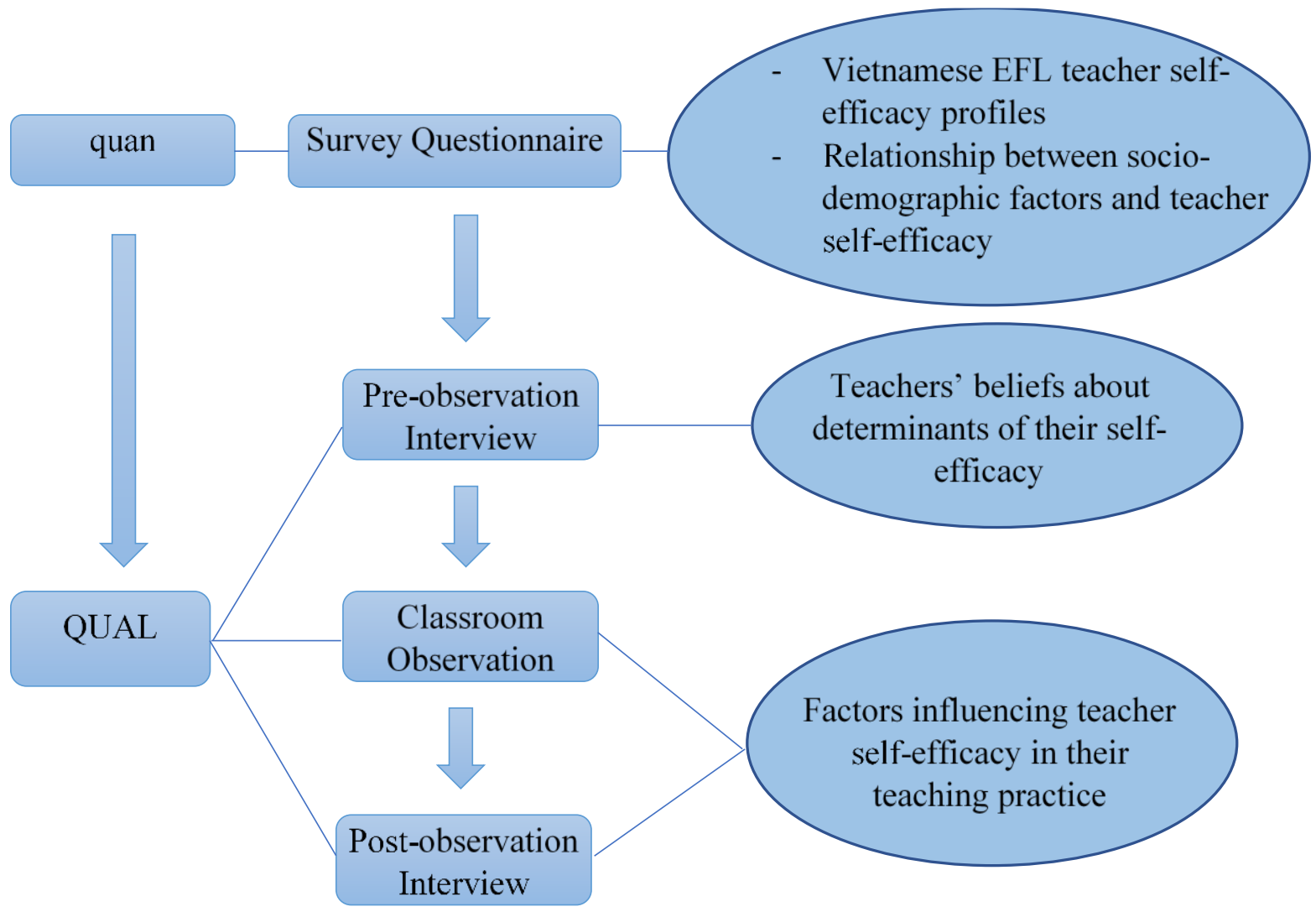

Figure 6:Data Collection Procedure.

\section{Data Analysis}

\subsection{Quantitative Data}

As this study collected both quantitative and qualitative data, there were multiple data to analyse (multi-analysis) (Johnson \& Christensen, 2014).

Vietnamese EFL teacher self-efficacy was explored by using descriptive statistics then further analysed using correlational and inferential statistics. The descriptive statistics showed the mean (the average score), the median (the point on the scale of measurement below which one-half of the scores distribution scores lie), and the mode (the score with the greatest frequency) (Wiersma \& Jurs, 2005). It was also necessary to describe the measures of variability. Researchers usually do this by using variance and standard deviation which indicate the dispersion in the distribution (Wiersma \& Jurs, 2005). This enabled the variations in the teachers' self-efficacy scores to be seen. 


\section{VIETNAMESE EFL TEACHER SELF-EFFICACY IN PRACTICE}

\subsection{Qualitative Data}

\subsubsection{Transcribing and Translating Data.}

Lapadat and Lindsay (1999) stated that understandings of data originates from "the process of constructing a transcript by listening and re-listening, viewing and re-viewing" and that "transcription facilitates the close attention and the interpretive thinking that is needed to make sense of the data" (p.82). The process of transcribing can produce significant insights. Therefore, the task of transcribing should not be done by other people like research assistants or professional transcribers (Lapadat, 2000; Merriam, 2009; Temple, Edwards, \& Alexander, 2006; Tilley, 2003; Tilley \& Powick, 2002). Instead, researchers themselves should transcribe their recordings (Lapadat \& Lindsay, 1999; Seidman, 2013). Therefore, I transcribed the interviews.

After transcribing the data, I translated the transcripts from Vietnamese into English and coded them. Then I translated the transcript of the interviews from Vietnamese into English. The translations were then emailed to the participants to ensure that I did not misinterpret any information. In other words, this method of member checking was to ensure the trustworthiness of qualitative findings (Creswell, 2014). As the informants were all EFL teachers at the university, they were assumed to have sufficient English proficiency to do this. Although this process was time-consuming and required effort, it resulted in a data set which was better suited for an analysis and discussion with my supervisors as I coded it. As Denscombe (2003) suggests, I took notes alongside the interviewees' words when transcribing the interviews to support the data analysis later.

\subsubsection{Coding Data.}

At this stage, researchers divide data into sections, then categorize and label them with symbols or descriptive words (Johnson \& Christensen, 2014). In general, researchers conduct open, axial, and selective coding successively (Merriam, 2002). In open coding, the data is examined carefully either by line, sentence, paragraph or incident and assigned code words. They are then categorised as code notes. Next, in axial coding, the categories are put back together, compared, and connected to find main categories which are finally integrated to create a substantive theory in selective coding. Similarly, Charmaz (2013) states that the coding process comprises at least two steps of initial coding and focused coding. The codes should be concise and precise. Importantly for my study, grounded theorists consider their codes as temporary and 
VIETNAMESE EFL TEACHER SELF-EFFICACY IN PRACTICE

changeable to improve their fit with the data (Thornberg \& Charmaz, 2013). After finding the most frequent or significant initial codes, researchers classify them as focused codes then identify a core category. While open and selective codes are data-driven, theoretical codes arise from a range of theories that researchers apply to their studies.

Thematic analysis is believed to be a flexible and effective research tool. It can describe the data in a comprehensive and multifaceted way (Braun \& Clarke, 2006). Braun and Clarke defined thematic analysis as "a method for identifying, analysing and reporting patterns (themes) within data" (Braun \& Clarke, 2006, p. 79). There are two types of thematic analysis. In inductive analysis, rather than basing on any coding frame or the researcher's analytic preconceptions, codes arise from the data itself. In contrast, theoretical thematic analysts are driven by existing theories and their preference in analysing data. My analysis moved between these two methods as it was influenced by Bandura's theory (1997) but there was space for themes that that were outside of this theory.

I followed the steps recommended by Braun and Clarke (2006) to analyse data. First, I translated and transcribed the interviews. I read the transcripts carefully before sending them back to the participants for member-checking. After getting feedback from the interviewees, I repeatedly read the transcripts to become familiar with them. While reading, I noted down salient patterns or incidents. These notes helped to generate initial codes in the second phase. I used Nvivo software to code and collate the data systematically. I included the relevant context to the data in the codes. An extract could be coded in different themes. Following this, I collated the codes and combined them into themes. I considered the relationship between them and categorised them into overarching themes and sub-themes. Next, I read each theme and its extracts again to decide whether together they made a coherent pattern. If not, I worked on the theme to either create a new theme or put those extracts into other themes. This process was repeated with the entire data. After this, I defined each theme and analysed it in detailed to answer the research questions. I also considered the relationship among the themes. Finally, I wrote a report for my analysis which was "concise, coherent, logical, non-repetitive, and interesting” (Braun \& Clarke, 2006, p. 93) with vivid and sufficient data examples. 
VIETNAMESE EFL TEACHER SELF-EFFICACY IN PRACTICE

\section{Table 4}

Phases of Thematic Analysis (adapted from Braun \& Clarke, 2006)

\begin{tabular}{cll}
\hline Phase & Description of the process \\
\hline with data & $\begin{array}{l}\text { Transcribing data (if necessary), reading and re-reading the data, } \\
\text { noting down initial ideas. }\end{array}$ \\
\hline $\begin{array}{l}\text { 2. } \\
\text { initial codes }\end{array}$ & $\begin{array}{l}\text { Coding interesting features of the data in a systematic way across } \\
\text { the entire data set, collating data relevant to each code. }\end{array}$ \\
\hline 3. $\begin{array}{l}\text { Searching for } \\
\text { themes }\end{array}$ & $\begin{array}{l}\text { Collating codes into potential themes, gathering all data relevant } \\
\text { to each potential theme. }\end{array}$ \\
\hline $\begin{array}{l}\text { 4. } \\
\text { themesiewing }\end{array}$ & $\begin{array}{l}\text { Checking if the themes work in relation to the coded extracts } \\
\text { (Level 1) and the entire data set (Level 2), generating a thematic } \\
\text { "map" of the analysis. }\end{array}$ \\
\hline $\begin{array}{l}\text { 5. Defining and } \\
\text { naming theme }\end{array}$ & $\begin{array}{l}\text { Ongoing analysis to refine the specifics of each theme, and the } \\
\text { overall story the analysis tells, generating clear definitions and } \\
\text { names for each theme. }\end{array}$ \\
\hline 6. & $\begin{array}{l}\text { Producing the } \\
\text { report }\end{array}$ & $\begin{array}{l}\text { The final opportunity for analysis. Selection of vivid, compelling } \\
\text { extract examples, final analysis of selected extracts, relating back } \\
\text { the analysis to the research question and literature, producing a } \\
\text { scholarly report of the analysis. }\end{array}$ \\
\hline
\end{tabular}

\section{Validity and Trustworthiness of the Study}

Wiersma and Jurs (2005) defined the validity of educational research as having components of internal and external validity. The first element, internal validity, is how accurately and confidently the research results can be interpreted. External validity is the circumstances in which the research results can be generalised. The researchers conceptualised the reliability of educational research as the consistency of the research results and the conditions under which the research can be repeated.

As Johnson and Christensen (2014) stated when conducting a mixed method study, we must ensure that it has "strong quantitative and qualitative validity" (p.309). Therefore, I tried to minimise the threats to the validity of the quantitative phase and threats to the trustworthiness of the qualitative phase. 
VIETNAMESE EFL TEACHER SELF-EFFICACY IN PRACTICE

\section{Table 5}

Validity Strategies for Quantitative Data

\begin{tabular}{|c|c|c|}
\hline & $\begin{array}{l}\text { Threats for the } \\
\text { quantitative phase }\end{array}$ & Solutions \\
\hline \multirow[t]{3}{*}{$\begin{array}{l}\text { Quantitative } \\
\text { validity }\end{array}$} & $\begin{array}{l}\text { Small number of } \\
\text { responses to the } \\
\text { questionnaire }\end{array}$ & $\begin{array}{l}\text { - To distinguish the survey from the SPAM } \\
\text { in their emails, an invitation email was sent } \\
\text { from my VUW institutional email address to } \\
\text { the population (Wiersma \& Jurs, 2005). } \\
\text { - A reminder was sent later to those who did } \\
\text { not respond to the online survey within two } \\
\text { weeks after the invitation. }\end{array}$ \\
\hline & $\begin{array}{l}\text { Misunderstanding of the } \\
\text { questionnaire }\end{array}$ & $\begin{array}{l}\text { To avoid any misunderstanding of the } \\
\text { questionnaire, I followed the principles of } \\
\text { questionnaire construction by Johnson and } \\
\text { Christensen (2014). } \\
\text { Additionally, a trial was sent to other } \\
\text { Vietnamese EFL teachers who were } \\
\text { pursuing their PhD at Victoria University } \\
\text { and to my colleagues in Vietnam. Having } \\
\text { similar characteristics to the target } \\
\text { population, their responses helped me } \\
\text { identify "misunderstandings, ambiguities, } \\
\text { and useless or inadequate items" and suggest } \\
\text { additional items (Wiersma \& Jurs, 2005, p. } \\
\text { 171). }\end{array}$ \\
\hline & Managing data & $\begin{array}{l}\text { As there were } 52 \text { respondents to the } \\
\text { questionnaire, the quantitative data was quite } \\
\text { big. To avoid mistakes while recording, } \\
\text { storing and analysing. the data, it was } \\
\text { uploaded directly from Qualtrics to SPSS } \\
\text { software version } 23 \text {. }\end{array}$ \\
\hline
\end{tabular}

To minimise the threats to the trustworthiness of the qualitative phase, six out of eight procedures presented by Creswell (2013) were applied. Details are shown in Table 6. 
VIETNAMESE EFL TEACHER SELF-EFFICACY IN PRACTICE

Table 6

Validity Strategies for Qualitative Data (adapted from Creswell, 2013)

Threats for the Solutions

qualitative phase

\begin{tabular}{|c|c|c|}
\hline Insufficient data & Triangulation & $\begin{array}{l}\text { Data was collected using different methods } \\
\text { (method triangulation). These comprised a } \\
\text { questionnaire survey (quantitative), } \\
\text { classroom observation, and interview } \\
\text { (qualitative). The triangulating of } \\
\text { information was used to increase the } \\
\text { validity of the findings. }\end{array}$ \\
\hline Mistranslation & Member checking & $\begin{array}{l}\text { The English transcripts of the interviews } \\
\text { were emailed to the participants to ensure } \\
\text { the accuracy and credibility of their } \\
\text { responses. }\end{array}$ \\
\hline $\begin{array}{l}\text { Misunderstanding of the } \\
\text { research context }\end{array}$ & $\begin{array}{l}\text { Rich and thick } \\
\text { description }\end{array}$ & $\begin{array}{l}\text { Vietnamese EFL teaching at tertiary level } \\
\text { in general, the study setting in particular, } \\
\text { and the data were described in details. The } \\
\text { comprehensive description of the research } \\
\text { context, participants, and research } \\
\text { methodology helps readers decide whether } \\
\text { the conclusions and implications of the } \\
\text { study can be applied to other contexts. }\end{array}$ \\
\hline \multirow[t]{3}{*}{ Bias } & Bias clarification & $\begin{array}{l}\text { I commented on past experiences, biases, } \\
\text { prejudices, and orientations that shaped the } \\
\text { interpretation and approach to the study by } \\
\text { writing reflective field notes and had } \\
\text { discussions with my supervisors. }\end{array}$ \\
\hline & Peer debriefing & $\begin{array}{l}\text { The entire research process was supervised } \\
\text { and reviewed by my supervisors to } \\
\text { minimise any mistakes or incorrect } \\
\text { information. }\end{array}$ \\
\hline & $\begin{array}{l}\text { Reporting negative } \\
\text { case }\end{array}$ & $\begin{array}{l}\text { To provide a realistic assessment of EFL } \\
\text { teacher self-efficacy, negative evidence } \\
\text { which did not fit the pattern of a code or a } \\
\text { theme was also reported together with the } \\
\text { positive ones. }\end{array}$ \\
\hline
\end{tabular}

Nvivo software was used to store the qualitative data

systematically and undertake iterative coding. 


\section{VIETNAMESE EFL TEACHER SELF-EFFICACY IN PRACTICE}

Cohen, Manion, and Morrison (2000) suggested that the validity can be ensured throughout the process of research design, data analysis, and reporting findings. In the first stage

of planning a study, I established a proper timeline for my entire research project. As explained earlier, the data collection instruments and sampling methods were appropriate for my study. When analysing data, I ensured validity by using respondent validation, which means the interviewees were sent the transcriptions of their interviews to check for clarification and accuracy. I minimised threats to validity in the stage of reporting data by avoiding presenting inaccurate data or reporting them very selectively and unrepresentatively. The research context was described in detail so that readers understand the circumstances in which the results can be generalised. Additionally, I ensured that the research questions were answered and would make claims which are sustainable by the data (Cohen et al., 2000).

\section{Ethical Issues}

All research procedures closely followed the Victoria University of Wellington Ethics Policy to protect the researcher's as well as the participants' rights.

After receiving ethics permission (see Appendix P) from the Faculty of Education at Victoria University of Wellington, I contacted the Dean of the study faculty, who was considered the "gatekeeper" of the research site (Wiersma \& Jurs, 2005). I emailed her the information sheet (see Appendix G) providing information about my study together with a consent form (see Appendix J). With this permission, an information sheet for the quantitative phase (see Appendix E) was sent to all the teachers in the faculty explaining thoroughly the objectives of the study, the research procedures, and the participants' roles. Furthermore, they were given a form to consent (see Appendix K) to being part of the research. Their participation was "voluntary and equitable" (Wiersma \& Jurs, 2005, p. 450). Teachers who volunteered to participate in the second phase of this study were given another information sheet (see Appendix F) and consent form (see Appendix L).

The concept of privacy was strictly applied in this study because according to Johnson and Christensen (2014), "respecting the privacy of research participants is at the heart of the conduct of ethical research" (p141). The first aspect of this concept is managing accessibility to information about other people. The participants were fully informed of the research procedures as well as the storage and destruction of data. To protect the privacy of the participants, the 
VIETNAMESE EFL TEACHER SELF-EFFICACY IN PRACTICE

researcher reported data confidentially by using pseudonyms and kept the data secure (Johnson $\&$ Christensen, 2014). All data were kept in a secure place and were password protected. The second aspect is the participants' right to decline to be part of the project. As there were two phases, they could choose either to take part in the quantitative phase only or both of them.

The students of the observed classes were sent an information sheet (see Appendix $\mathrm{H}$ and I)) explaining the research project and what I would do in their class, and a consent form (see Appendix $\mathrm{M}$ and $\mathrm{N}$ ). It was their own decision whether to be included in the video data in the observation. The students who did not want to be present in the video were seated so that they would not be filmed. More importantly, it was made clear that the video recordings themselves would not be used as data. They would be used for stimulated recalls with the teacher later. In those interviews, the teachers were only shown parts of the video with students who had agreed to be filmed. The video data were only viewed by myself and the teacher participants.

\section{Summary of the Research Methodology}

This section has presented the methodology for this study, highlighting the research paradigm, rationale for its design, the processes of collecting and analysing data, validity and trustworthiness of the study and relevant ethical issues. I have argued that the mixed methods design was appropriate for my study because it enabled the teachers' self-efficacy scores produced from a validated scale to be further explored through a qualitative approach using interviews and observations. I have evaluated the trustworthiness of my research design, including the data collection methods and analysis. Most importantly, I have considered the participants' rights and my responsibility as a researcher to adhere to ethical guidelines. The following chapter reports the research findings. 
VIETNAMESE EFL TEACHER SELF-EFFICACY IN PRACTICE

\section{Chapter IV Findings}

The findings are organised into three main sections. The first section draws data from the quantitative phase to answer the first research question; that is, it provides a description of the self-efficacy profiles of the teachers who participated in the survey. It also describes how the participants were selected for the second phase of the study. The second section draws on qualitative data from the pre-observation interview to address the second research question about the sources of and influences on teacher self-efficacy. The third section considers the third research question by describing the similarities and differences in teaching practice of the teacher participants in the qualitative phase with higher, medium, and lower self-efficacy scores. The qualitative data from the observations and stimulated recall interviews are then presented for these three groups to gain insight into how teachers with different self-efficacy profiles differ in their teaching practices. Finally, unique aspects of these findings will be summarized and highlighted.

\section{What are the Self-Efficacy Profiles of EFL Teachers Working in a Public University in Vietnam?}

This section analyses the quantitative data collected from the questionnaire. It provides an overview of teacher self-efficacy profiles which include scores of overall teacher self-efficacy and self-efficacy in three domains of classroom management, student engagement, and instructional strategies. This section also gives an indication of composition of the group of teachers who responded in terms of gender, qualifications, teaching experience, and level of the classes that were taught. In addition, I provide data about teacher workload, teacher professional development that was undertaken, and the teachers' self-reported English language proficiency. These items were included as a result of the literature which showed a significant relationship between teacher self-efficacy and socio-demographic factors such as teachers' participation in professional development activities, class size, teachers' position at work, teachers' majors (Yavuz, 2007), types of institutions (Ghasemboland \& Hashim, 2013; Yavuz, 2007), and teacher proficiency (Jafarigohar \& Ganjabi, 2012; Yavuz, 2007; Yilmaz, 2011). This provides an overall snapshot of the group of teachers from which the participants in the qualitative phase were purposively selected. 
VIETNAMESE EFL TEACHER SELF-EFFICACY IN PRACTICE

An adapted version of Tschannen-Moran and Hoy's scale to measure teacher selfefficacy was used to fit the research context of the university. The questionnaire was assessed for its reliability using Cronbach's $\alpha$. The overall Cronbach $\alpha$ of the teacher self-efficacy questionnaire was of .840 which shows that the internal consistency of the items was relatively high. Factor analysis was used to check that the individual items loaded on to the components of teacher self-efficacy in student engagement, instructional strategies, and classroom management (Tschannen-Moran \& Hoy, 2001). The Cronbach's $\alpha$ of individual components of teacher selfefficacy (classroom management, student engagement, and instructional strategies) are shown in Table 7. The figures indicate that the categorizing of the items was reasonable (Cortina, 1993).

\section{Table 7}

Cronbach's a for Components of Teacher Self-Efficacy Scale

\begin{tabular}{ll}
\hline Component of teacher self-efficacy & Cronbach's $\alpha$ \\
\hline Self-efficacy in classroom management & .745 \\
\hline Self-efficacy in student engagement & .707 \\
\hline Self-efficacy in instructional strategies & .787 \\
\hline
\end{tabular}

All the respondents were female. Among 52 teachers, 49 of them (94\%) had a Master degree, and three of them (6\%) had a doctoral level qualification (see Table 8). Their qualifications varied in areas of study but related to the following fields.

\section{Table 8}

Participants' Qualifications

\begin{tabular}{lll}
\hline Fields of study & Frequency & Percentage \\
\hline English language teaching & 38 & 77.55 \\
\hline Business English & 5 & 10.20 \\
\hline Business & 6 & 12.25 \\
\hline
\end{tabular}

Over half of the participants $(52 \%)$ had been teaching for less than ten years. Nearly half of them $(42 \%)$ had been teaching from ten to twenty years. Only one teacher $(2 \%)$ had been working for over 20 years. 
VIETNAMESE EFL TEACHER SELF-EFFICACY IN PRACTICE

When considering workload, most of the respondents (92\%) were primarily teachers. Only four percent of them were working as both a teacher and an administrator. Workload was also impacted by the level of the students who were being taught and the range of proficiency levels that the teachers were working with.

Many of the teachers (42\%) reported that they were teaching pre-intermediate classes. About the same number of teachers were teaching elementary and intermediate classes. Very few of them were working with advanced students (see Table 9).

Table 9

Levels of Students' Proficiency

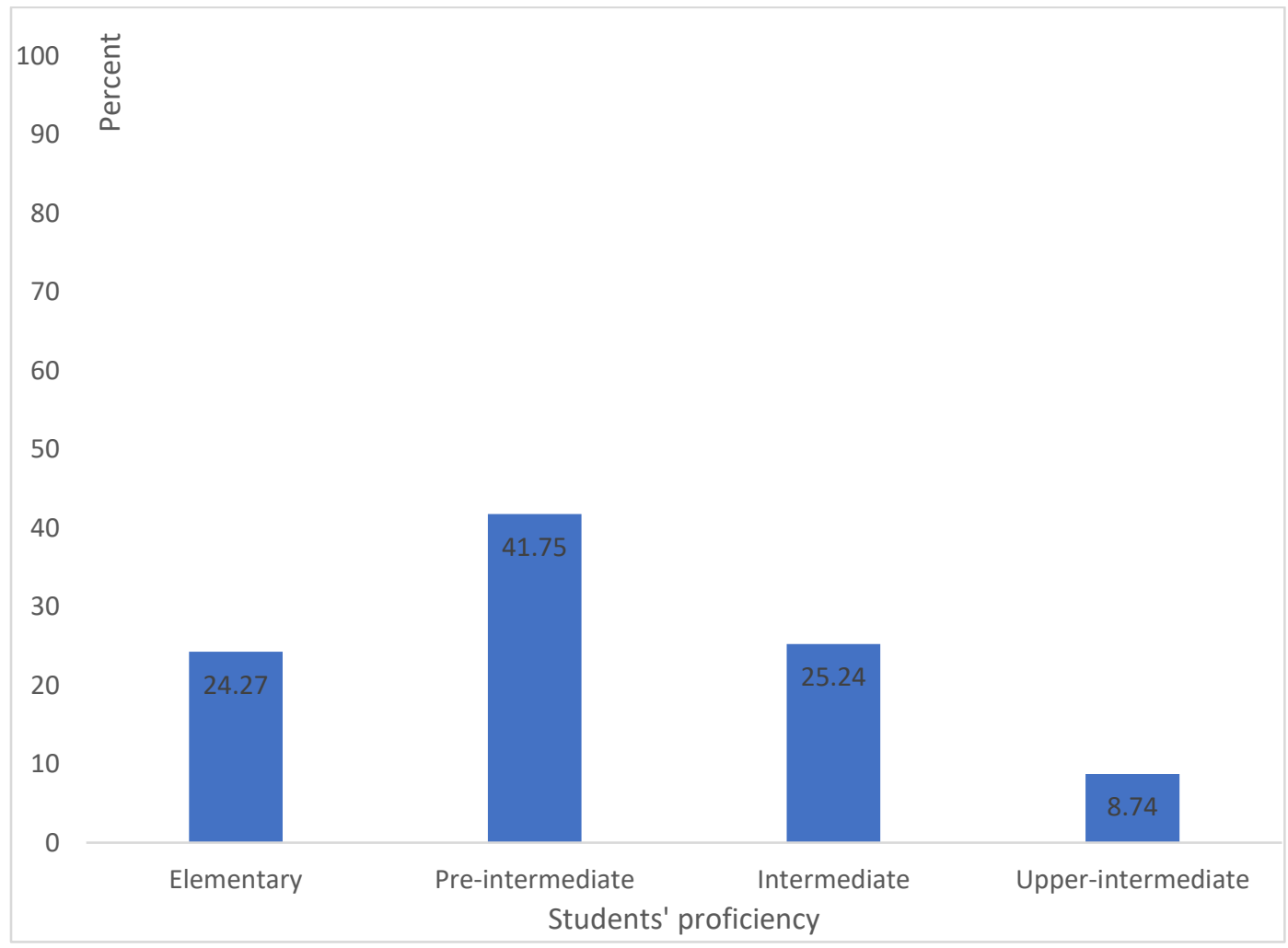

Over half of the teachers were teaching students of two different levels of proficiency. The number of teachers teaching students of only one level of proficiency and three levels was nearly the same, $22 \%$ and $20 \%$, respectively. Only $4 \%$ of the respondents were teaching classes at all four levels (see Table 10). 
VIETNAMESE EFL TEACHER SELF-EFFICACY IN PRACTICE

Table 10

Numbers of Levels Teaching

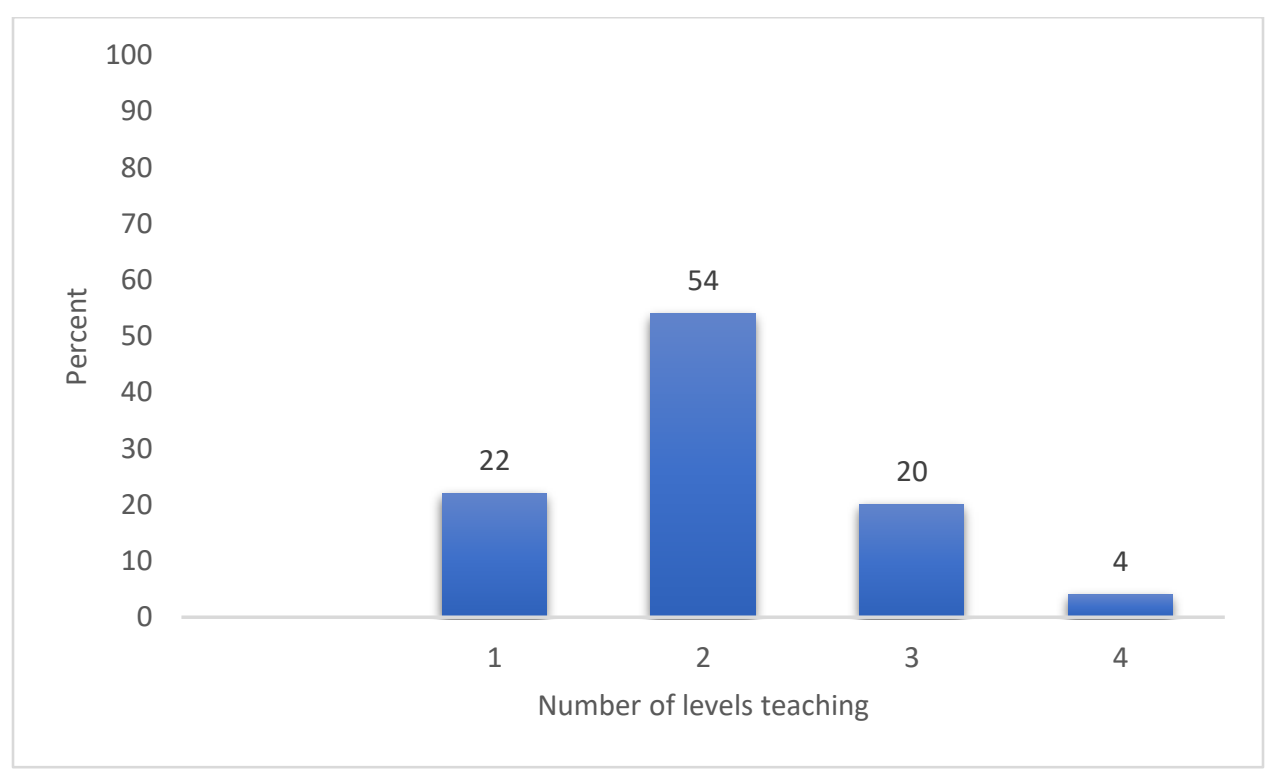

Sixteen teachers (32\%) were teaching less than five classes and the majority of 34 teachers $(68 \%)$ had at least five classes. Nearly $90 \%$ of the respondents reported that the average number of students in their classes was under 40 . 
VIETNAMESE EFL TEACHER SELF-EFFICACY IN PRACTICE

Table 11 shows the number of teaching hours that the teachers reported. Only $10 \%$ said that there were more than 40 students in their classes. Just over a third of the informants were teaching under 12 hours per week. $70 \%$ of them were teaching for over 13 hours a week.

Table 11

Teaching Hours

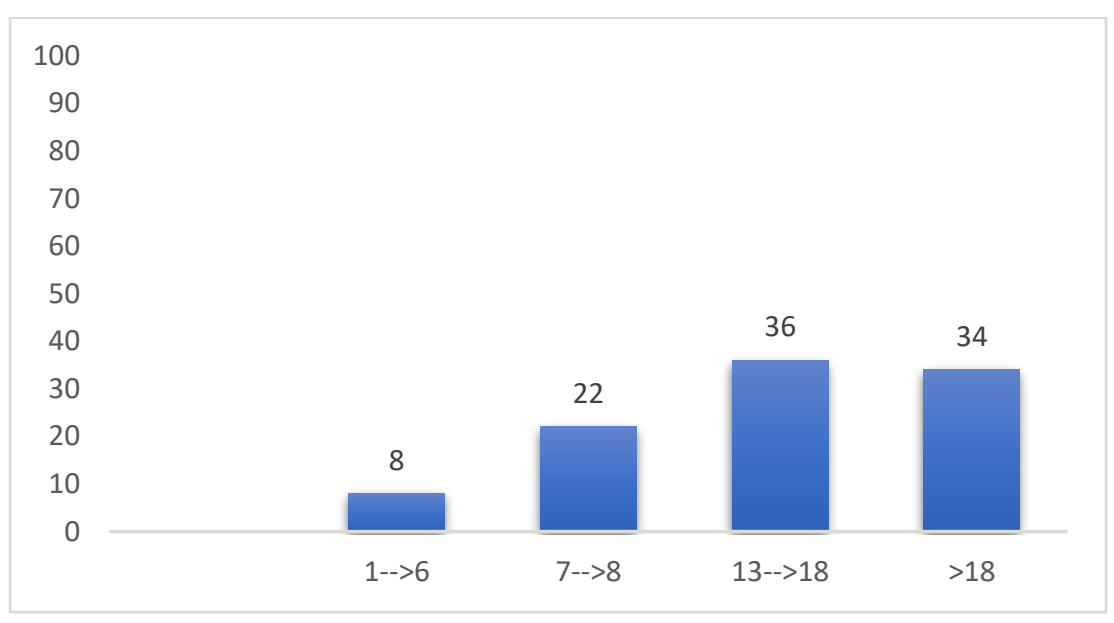


VIETNAMESE EFL TEACHER SELF-EFFICACY IN PRACTICE

Table 12 shows the frequency of teachers' participation in different types of professional activities. About half of the participants either sometimes attended in-services training courses or conferences. Nearly $40 \%$ of the teachers often or sometimes read books and journals on English language Teaching (ELT). Nearly half of the teachers sometimes carried out research in their classes.

Table 12

Teachers' Participation in Professional Development Activities

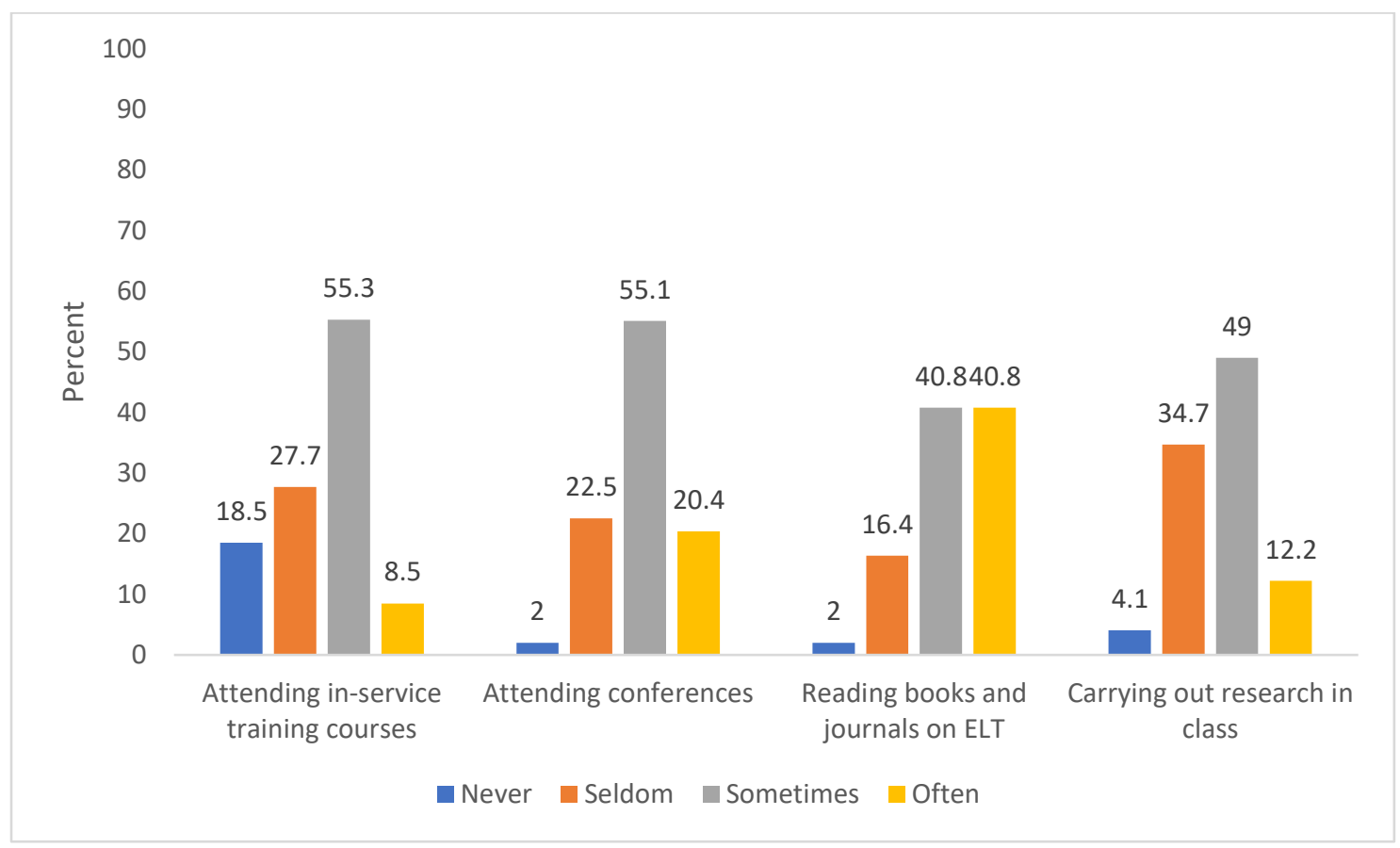

Over half of the participants attended in-service training courses. Around a fifth of them reported seldom participating in such courses. Just under 10\% of them often joined in professional development courses. Compared with other kinds of activities, in-service training courses attracted the least attention from the teachers with almost a fifth of them never participating. Reading books and journals on ELT was the most frequent activity with $40 \%$ of the participants often doing this. A third of the teachers seldom carried out research in their classes. 
VIETNAMESE EFL TEACHER SELF-EFFICACY IN PRACTICE

When asked about their own English language proficiency, the teachers reported to be most confident in reading, followed by listening, writing, and speaking with means of 4.59, $4.51,4.45,4.43$ respectively (see Table 13 ).

Table 13

Teachers' Confidence in Using English in the Classroom

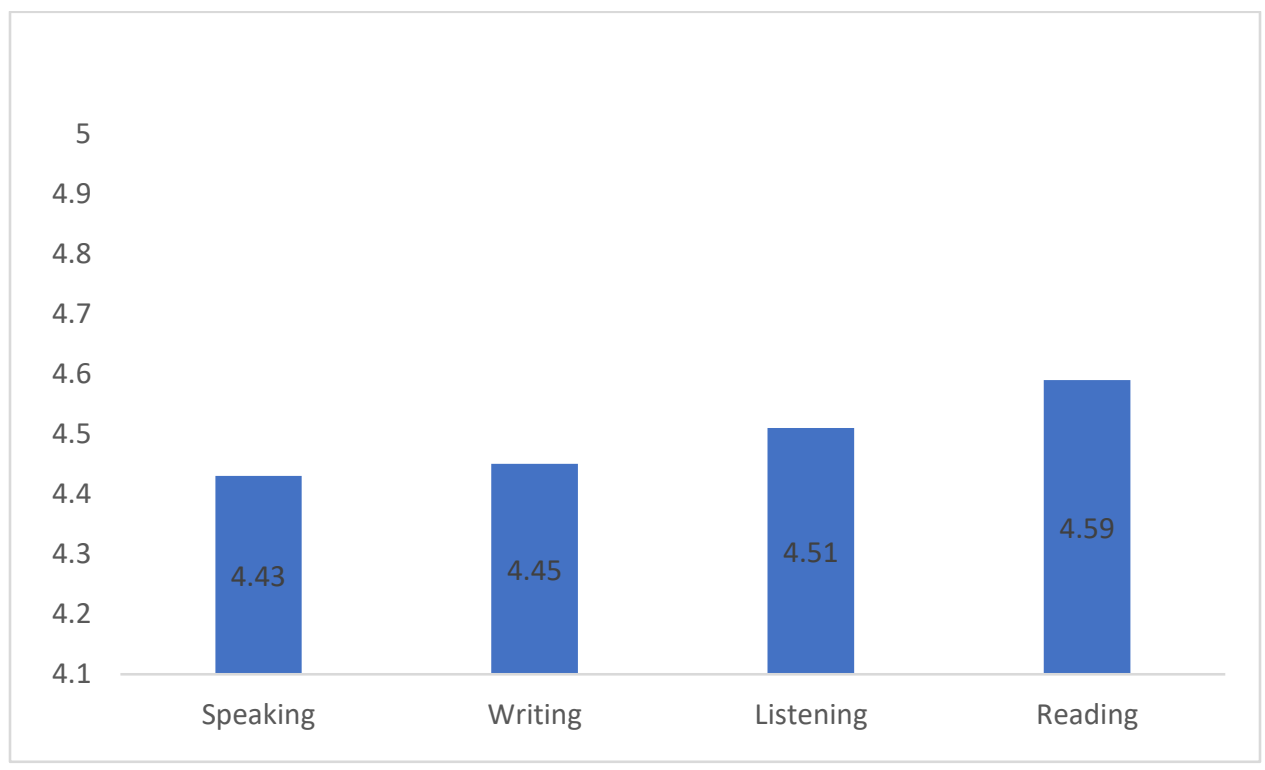

Table 14 shows that the overall teacher self-efficacy scores among the participants was high with a mean of 3.9129. The mean for teacher self-efficacy in classroom management ranked the highest (3.9773), followed by teacher self-efficacy in instructional strategies (3.9152) and student engagement (3.8528), respectively. There was little difference among the means for the three aspects of teacher self-efficacy with the standard deviation for each component differing slightly (see Table 14).

Table 14

Overview of the Participating Teacher Self-Efficacy

\begin{tabular}{lll}
\hline Teacher self-efficacy & Mean & Std. Deviation \\
\hline Overall self-efficacy & 3.90 & .30 \\
\hline $\begin{array}{l}\text { Self-efficacy in classroom } \\
\text { management }\end{array}$ & 3.97 & .35 \\
\hline $\begin{array}{l}\text { Self-efficacy in student } \\
\text { engagement }\end{array}$ & 3.85 & .39 \\
\hline $\begin{array}{l}\text { Self-efficacy in instructional } \\
\text { strategies }\end{array}$ & 3.91 & .39 \\
\hline
\end{tabular}


VIETNAMESE EFL TEACHER SELF-EFFICACY IN PRACTICE

There was a significant correlation between teacher self-efficacy in classroom management and teacher self-efficacy in student engagement and instructional strategies at a $p<$ .5 level (see Table 15). This suggests that the three domains interacted and influenced each other.

Table 15

Correlation among Three Aspects of Teacher Self-Efficacy

\begin{tabular}{llll}
\hline & $\begin{array}{l}\text { Classroom } \\
\text { management }\end{array}$ & $\begin{array}{l}\text { Student } \\
\text { engagement }\end{array}$ & $\begin{array}{l}\text { Instructional } \\
\text { strategies }\end{array}$ \\
\hline Classroom management & 1 & $.422^{* *}$ & $.471^{* *}$ \\
\hline Student engagement & $.422^{* *}$ & 1 & $.468^{* *}$ \\
\hline Instructional strategies & $.471^{* *}$ & $.468^{* *}$ & 1 \\
\hline
\end{tabular}

**. Correlation is significant at the 0.01 level (2-tailed).

ANOVA was used to investigate whether there is a link between the dependent variable of overall teacher self-efficacy and independent variables such as the teachers' qualifications, their majors at university, years of experience, position in the faculty, number of classes they were teaching, their working hours, the number of students in the class, their involvement in professional development activities, and their confidence in using English in the classroom. The results are presented in Table 16.

Table 16

Correlation between Teacher Self-Efficacy and Some Socio-Demographic Factors

\begin{tabular}{lll}
\hline & Independent variables & $p$ value \\
\hline Overall teacher self-efficacy & Qualifications & 0.012 \\
\cline { 2 - 3 } & Years of experience & 0.654 \\
\cline { 2 - 3 } & Position in the faculty & 0.085 \\
\cline { 2 - 3 } & Numbers of classes teaching & 0.81 \\
\cline { 2 - 3 } & Average number of students in a class & 0.597 \\
\cline { 2 - 3 } & Hours of teaching a week & 0.998 \\
\cline { 2 - 3 } & Students' proficiency & 0.633 \\
\cline { 2 - 2 }
\end{tabular}

The table shows a significant relationship between teacher self-efficacy and their qualifications at $p<0.05$; and a significant relationship between teacher self-efficacy and their position in the faculty at $p<0.1$. The relationship between teacher self-efficacy and their 
VIETNAMESE EFL TEACHER SELF-EFFICACY IN PRACTICE

experience, number of classes taught, number of students in a class, hours of teaching and students' proficiency were not significant.

The teachers who participated in the quantitative phase can be then divided into three groups of lower, medium and higher self-efficacy by looking at the distribution of scores as percentiles in SPSS, according to their total self-efficacy scores (see Table 17). The analysis shows that those teachers whose total self-efficacy score was lower than 3.7407 belong to the first group of lower self-efficacy because their scores were in the lower third of the total scores. Teachers of the medium self-efficacy group had a total score from 3.7408 to 4.0370, while the higher self-efficacy group range from 4.0371 to 4.7692.

Table 17

Classification of Teacher Self-Efficacy Profiles

\begin{tabular}{lll}
\hline Percentiles & $0-33$ & 3.7407 \\
\hline & $34-66$ & 4.0370 \\
\cline { 2 - 3 } $65-100$ & 4.7692 \\
\hline
\end{tabular}

The participating teachers were categorised into three groups of higher, medium, and lower self-efficacy according to their overall self-efficacy scores. From the volunteers to participate in the qualitative phase, I selected five teachers from each group to contact. These teachers were selected because their self-efficacy scores varied across three aspects (see Table 18). Based on their availability for interviews and observations, two teachers in the higher group, three teachers from the medium, and three teachers from the lower self-efficacy group were selected. 
VIETNAMESE EFL TEACHER SELF-EFFICACY IN PRACTICE

Table 18

Self-Efficacy Profiles of Teachers Selected for the Second Phase

\begin{tabular}{llllll}
\hline Teacher & $\begin{array}{l}\text { Overall self- } \\
\text { efficacy }\end{array}$ & $\begin{array}{l}\text { TSE in } \\
\text { student } \\
\text { engagement }\end{array}$ & $\begin{array}{l}\text { TSE in } \\
\text { classroom } \\
\text { management }\end{array}$ & $\begin{array}{l}\text { TSE in } \\
\text { instructional } \\
\text { strategies }\end{array}$ & Group \\
\hline Minh & 4.04 & 3.70 & 4.67 & 3.75 & Higher \\
\hline Duong & 4.04 & 3.78 & 4.20 & 4.13 & Higher \\
\hline Mai & 3.85 & 3.80 & 4.00 & 3.75 & Medium \\
\hline Trang & 3.93 & 4.00 & 4.00 & 3.75 & Medium \\
\hline Huong & 4 & 4.10 & 4.10 & 3.75 & Medium \\
\hline Quynh & 3.48 & 3.60 & 3.53 & 3.30 & Lower \\
\hline Huyen & 3.74 & 3.70 & 3.67 & 3.88 & Lower \\
\hline Linh & 3.41 & 3.40 & 3.22 & 3.63 & Lower \\
\hline
\end{tabular}

These teachers were chosen for the second phase of the study because their overall selfefficacy scores varied across three groups of lower, medium, and higher scores. The following sections use qualitative data to explore whether the differences in self-efficacy scores can predict their beliefs about their ability and their teaching practice.

\section{What do These EFL Teachers Report as Influences on Their Self-Efficacy in Their Classrooms?}

This section reports data collected from the interviews before the classroom observations. It presents what the teachers described as influencing their teaching self-efficacy.

\subsection{Past Teaching Experiences}

Two teachers mentioned how their experience influenced their confidence in teaching. Minh commented that each textbook had its own advantages and disadvantages. When teaching, she tended to exploit the good things from the books she had been using and use various strategies to avoid the drawbacks. Doing this, she said she could highlight the most important and relevant issues in her lessons.

Experience also contributed greatly to Quynh's belief about her effectiveness in teaching. She knew what materials were suitable, how to design appropriate activities, and how to apply proper strategies in her lessons. 
VIETNAMESE EFL TEACHER SELF-EFFICACY IN PRACTICE

I've been teaching for about ten years. And I've been teaching these subjects for a couple of years. So I'd say that I'm experienced. I know what I should prepare for the lessons and how I should modify my teaching according to the students' proficiency. (Quynh-Pre-observation interview)

The familiarity in teaching allowed Minh and Quynh feel confident in making good use of the teaching materials such as the textbook to address students' needs.

\subsection{Content Knowledge}

The teachers' self-efficacy was also influenced by their content knowledge. Duong graduated from a teacher training university. She used to teach general English. She said she just had linguistic knowledge, and not much knowledge about business. However, her current university specialised in business. She considered her lack of knowledge about business English as a drawback. She considered that this lack of knowledge constrained her when she taught business books like Market Leader. Her perceived lack of content knowledge had a negative influence on Duong.

Huong complemented her education background and professional development.

Moreover, I'm officially trained to be an EFL teacher. I frequently take

part in seminars, workshops, and conferences as a way to develop my

professional career.

The pedagogical knowledge and teaching methodology that she learnt at university made her a confident teacher. She usually updated her pedagogical knowledge by participating in professional development activities.

The teachers' content knowledge as well as their experiences in teaching influenced their selection of teaching materials and methodologies which, in return, impacted their self-efficacy.

\subsection{Collegiality}

All the teachers said that collegiality had a considerable influence on their self-efficacy. Collegiality can be divided into support from colleagues and support from managers. The sharing of teaching experiences and materials and compiling of supplementary documents helped the 
VIETNAMESE EFL TEACHER SELF-EFFICACY IN PRACTICE

teachers reflect on their teaching and make them feel prepared for class. Such reflections and positive feelings enhanced their self-efficacy.

The relationship with colleagues fostered the sharing of teaching materials and experience with each other. Minh recalled one time when she could not install software recommended for teaching in her MacBook, and some other teachers shared with her the audio files that they had decoded. She said she could not imagine what she would do without her friends' help that time.

The sharing of teaching materials was very evident in Quynh's interview. Quynh said that the teachers who were teaching the same subject worked together to compile supplementary documents for that subject. Then they shared it with other teachers. They also discussed similar teaching content and teaching methodologies in their classes. This made Quynh feel equal to other teachers. Moreover, they shared their experiences in seminars or workshops organised by the faculty managers. Quynh considered their contribution to those professional activities a support to her teaching.

They organise the conferences, seminars and workshops for us to join . They also involve us in some projects as the head-researchers. (Quynh-Preobservation interview)

Huyen and Minh reported that they shared the teaching materials with their colleagues.

The teachers in my faculty share teacher's book and audio files with each other. That time when I installed the software into my laptop, it didn't support MacBook. Some other teachers shared with me what they had decoded. I had some extra documents for my lessons. In general, the support from the faculty is just to make sure that every teacher has the textbook, teacher's book, and audio files. (Minh-Pre-Observation interview)

In addition to sharing teaching materials, Minh revealed that they shared teaching experience in seminars and conferences.

According to Minh, the subject manger as well as the faculty managers would try to address each teacher's personal problem. The teachers could come to talk to them in person or 


\section{VIETNAMESE EFL TEACHER SELF-EFFICACY IN PRACTICE}

raise the issue in either faculty meetings or seminars. In Minh's case, the support that she received from her colleagues made her more confident about teaching, which, as a result, strengthened her belief about her teaching.

The managers supported Huyen in a different way.

They are quite supportive to us. For example, they assign our classes reasonably so that we can manage both our personal jobs like taking care of our family and our teaching job. They usually organise seminars and workshops for us to share.

The managers were providing support to the teachers in two different layers: personal and professional issues. Regarding support for teachers' personal issues, the managers considered individual teacher's preferred teaching hours. For example, some teachers wanted to teach the early morning session while some others wished to have afternoon classes. The managers would consider their preference and allocate the most suitable teaching time for them. Huyen said that when her needs were heard, she felt more relaxed at work. She explained further that she felt more effective when she was happy in teaching. In addition, the managers organised the professional events such as seminars, workshops, and conferences. They sometimes joined in some research projects. They led other members to cooperate and contribute to the projects.

In contrast, Trang reported that she did not receive much help from the board of faculty managers. However, she particularly appreciated what the subject manager did.

In faculty meetings, they always show us that they are very willing to help but I haven't received much from them except for the subject manager. When we teach a new book or when we design the test, if I have any problem, I can call her to ask about the focus of the lessons or the format of the test. (Trang - Preobservation interview)

The subject manager provided individual support to the teacher. She directly responded to a teacher's inquiry. Moreover, the subject manager was sympathetic to Trang's situation.

Because I'm pregnant so the subject manager gave me fewer classes than other teachers. I'm teaching four classes. 
VIETNAMESE EFL TEACHER SELF-EFFICACY IN PRACTICE

The support that Trang received from the subject manager made her feel respected. As a result, she devoted more to her teaching. Trang shared her teaching experiences as well as her problems in her daily conversations with her colleagues.

When we have problems in teaching, we can talk to our colleagues during break time and ask for advice. But this sharing is just between teachers. I mean it's just private talk about minor issues, not public like a seminar or workshop. (Trang -Pre-observation interview)

The support they had was quite personal. It was built upon the existing relationship. Usually, Trang shared with her close friends at work. Trang explained that when they were teaching a new book, they talked to each other about the difficulties they encountered. Then they showed their solutions. They also talked about the strategies to manage the students.

We also talk about the students, for example, if they are too noisy and excited, how to calm them down; or they are too quiet and passive, how to engage them. (Trang - Pre-observation interview)

Mai shared the same experience with Trang. Although Mai's workmates were friendly, she did not receive much support. The reasons were the nature of their job and the faculty policy.

First, it's the nature of our work. We only come to university when we have classes. We don't have much interaction with other teachers. So, we only do our own job. Only when we have problems, we talk to the others so that they can help. We don't have any routine to support each other. The faculty doesn't have any policy or scheme saying that this teacher needs to help that teacher. Nothing like that.

The support they had was tailored to each individual. As Mai explained, it was built upon teachers' relationship and how close their relationships were. The board of managers did not provide much support about teaching to the teachers. They were dealing with macro issues. Only the subject manager was very supportive and caring. When the teachers had any problems, she was willing to help them immediately. 
VIETNAMESE EFL TEACHER SELF-EFFICACY IN PRACTICE

These teachers, including Minh, Huyen, Trang, and Mai complimented the support they received from their colleagues and managers. The assistance made them feel more confident when teaching. However, Linh claimed that she did not receive much support for her teaching, neither from her colleagues nor her managers. She complained that she did not get any professional assistance from the subject manager and faculty managers. There were no professional training courses. She was not provided supplementary documents. The library resources were in very poor condition. She only shared her experiences with some of her close friends in their daily conversations. To deal with inadequate teaching resources. she had to either search on the Internet or buy reference books for herself.

Figure 7 summarises the layers of support that the participating teachers reported.

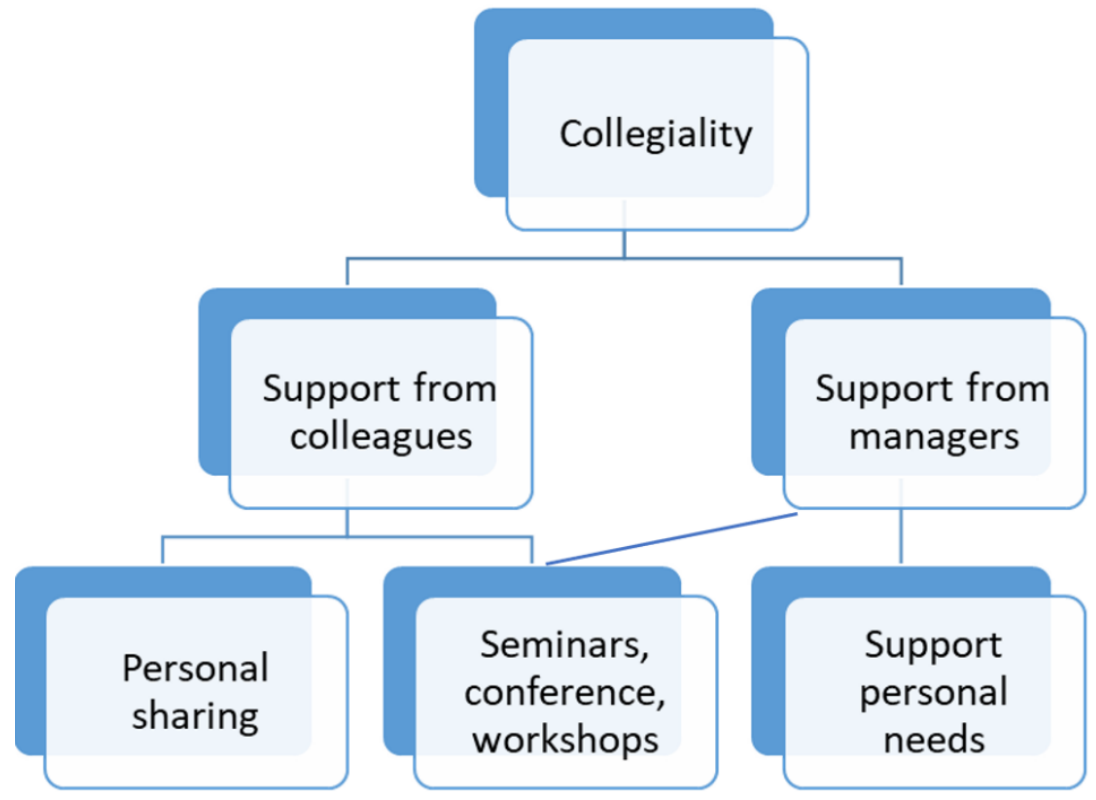

Figure 7: Collegiality among Teachers, Managers, and Colleagues.

\subsection{Professional Development}

Professional development activities provided teachers with opportunities to share and learn from others' experiences. They improved their knowledge about the subject content and teaching methodology, which seemed to foster teacher self-efficacy.

Because of the busy teaching schedule, Huong participated in only a few workshops and conferences. 
VIETNAMESE EFL TEACHER SELF-EFFICACY IN PRACTICE

Due to heavy workload, I can only participate in some activities. When the publisher organises a workshop to train teachers how to use a textbook, even though it's not what I'm teaching, I still join them to learn the way they teach. I also join in some conferences. I have gained lots of interesting ideas for my classes.

Huong said that teachers should be trained continuously because knowledge keeps changing every day. In her opinion, teachers needed to remain updated on both knowledge and teaching methodology. However, she did not frequently have opportunities to be updated in her teaching materials and practices. She considered this lack of professional development a constraint for her teaching.

The faculty and the university did not have many policies for professional development. Teachers were expected to have a degree of autonomy and to have their own development plan. However, like most other teachers, Huong did not put professional development as her first priority.

We work like a machine. We go the class and teach. When we finish the lesson, we go home. We don't feel satisfied. If we do like that for one or two years, that's fine. But if we do it for ten or twenty years, we lose our passion. We cannot maintain our love for our career if we don't have any development.

Huong did not get much from the faculty professional development policy. Consequently, she felt she did not progress much in her career which, in return, negatively influenced her teaching self-efficacy.

Linh rarely joined in any professional development activities except for some seminars and workshop organised by her faculty. However, she did not see any benefits for her teaching. She said that the workshops and seminars were on general themes, not specific aspects of teaching. The suggestions were applicable to certain classes under certain conditions. She would make adjustments based on her own judgement of her lessons. Linh added that she did not have any motivation to regularly take part in professional development activities. According to Linh, other teachers in her faculty frequently joined in conferences, wrote articles, and conducted research because they either had a plan to study a $\mathrm{PhD}$ overseas or they wished to be promoted. 
VIETNAMESE EFL TEACHER SELF-EFFICACY IN PRACTICE

She did not have that ambition. She was happy with her current position. Moreover, she complained that her workload was very heavy. In some semesters, she had to teach up to eight classes. She felt exhausted. She did not have the time or the incentive for such professional development activities.

Although the managers organised some seminars and conferences, Huyen said that she did not receive much professional support from the faculty. She felt that the themes of the activities were too general. She needed specified topics. For example, she wished to have suggestions on how to exploit the main textbooks and which supplementary books to use. Those teachers who wanted to progress in their career have to make their own plan and develop it outside the university.

In contrast, Duong and Mai enthusiastically participated in seminars and conferences. They usually attended as both presenters and an audience. In their point of view, they were very useful for their teaching. In addition, they joined in some conferences outside the university. However, there was no research grant or research leave for the teachers. They had to manage by themselves.

Additionally, Duong took in-service training course. She reported that she joined a course about Formative Assessment and Action Research. The course was sponsored by the Foreign Language Project 2020. It provided teachers with knowledge about assessing methods in the class and how to do action research to assess their teaching methodology. Then they could adjust or introduce suitable teaching and learning strategies to her students. Mai also read books, searched for useful websites, and read news from the internet to keep herself updated.

Professional development activities did not seem to have a positive influence on some teachers like Linh and Huyen. This contrasts to those teachers such as Huong and Duong who benefited from those activities.

\subsection{Feedback about Teaching}

Students' feedback about teaching influences teachers' feelings about their teaching effectiveness. This section presents how the participants in this study considered their students' feedback and how such feedback impacted their self-efficacy. 
VIETNAMESE EFL TEACHER SELF-EFFICACY IN PRACTICE

According to the teachers, the Centre of Quality Assurance in the university conducted a survey at the end of each term. Then they informed the teachers about the results. Each teacher had an online account. When they logged into the account, they could see the students' feedback and how their teaching was evaluated. They knew what their students liked and disliked about our teaching.

Quynh stated that she highly valued the students' feedback.

They have positive influence on my teaching. When I read the students feedback, I know what they think about me. For example, they may comment that the teacher often went to class late, she usually finished early, she spoke too fast, or sometimes she speaks too much English and the students couldn't understand. We can adjust our teaching accordingly. (Quynh-Pre-observation interview)

Although Mai got very little feedback from students, she still considered it carefully. Students'feedback is very helpful. Sometimes we think that we are doing well in class but we need to hear from the other side to have fair judgement. Then we can have suitable adjustment. In the survey, students are asked about different aspects like teachers' attitude, teachers' knowledge, and teaching methodology. We develop ourselves based upon students' feedback.

Mai really appreciate her students' feedback. She considered her students the centre of her teaching.

By contrast, Huong doubted the reliability of the data collected. She gave an example that in the latest survey, only 11 out of over 30 students in her class responded to the questionnaire. She thought that the result could not reflect the common viewpoint of all the students. Too few responses would not produce a reliable result.

According to Huong, if the score was too low, the teachers had to work with the board of managers to change their teaching methodologies. Otherwise, they just considered the students' feedback a reference for self-reflection.

I just keep the survey reports. I read them and reflect. I read the students' feedback to see if there's anything I can adjust to meet their demands. As I said 
VIETNAMESE EFL TEACHER SELF-EFFICACY IN PRACTICE

earlier, because of the small number of responses and unreliable data, I only consider the comments that are suitable. For example, in the same class, lazy students can complain that I give too much homework. But for hard-working students, they want me to assign more work. Students may want more or less, but I will adjust in a reasonable way.

The students' feedback had little influence on some teachers but was a strong influence for others. In Huong's opinion, students' feedback reflected their enjoyment of the lessons rather than her teaching effectiveness. Therefore, she would not attempt to address everything her students mentioned in the survey. She only adjusted her lessons in a way that she saw as reasonable.

Linh also stated that the feedback had hardly any influence on her. If the students gave positive feedback, the teachers did not get any rewards. If they gave negative feedback, there was no punishment. She said that the feedback surveys were of no use. She maintained her own style of teaching despite what feedback the students gave about her.

Duong had another way of eliciting the students' feedback. She observed her students' participation and reactions in her classes. She could tell whether they were satisfied, and whether the activities were suitable or not. Duong also judged the effectiveness of her lessons based on the students' progress or the students' learning outcomes.

In summary, students' feedback had a strong association with teacher self-efficacy. For most of the participants, students' feedback about their teaching influenced teacher self-efficacy because such comments reflected what they considered to be the effectiveness of their teaching. Positive feedback was taken to indicate that they had used effective teaching strategies and successfully addressed their students' needs. In contrast, for some teachers, students' feedback suggested their enjoyment of the lessons rather than the teaching effectiveness. Negative feedback did not make their self-efficacy deteriorate. Some teachers doubted the reliability of the data, which resulted in insignificant influence on teacher self-efficacy.

\subsection{Peer-Observation and Peer Modelling}

In the pre-observation interviews, the participants mentioned peer-observation and peermodelling. With peer observation, the teachers observed their colleagues' teaching in their 


\section{VIETNAMESE EFL TEACHER SELF-EFFICACY IN PRACTICE}

classes and learnt useful teaching tips and strategies from them. With peer-modelling, the teachers were observed in their teaching in the classroom and given feedback about their teaching. This learning through observation and constructive feedback about teaching helped the teachers improve their pedagogical knowledge, which fostered teacher self-efficacy.

When Linh first came to the university to work, she was asked to come to other teachers' classes. She chose both experienced and novice teachers because they gave her various views about teaching. She learnt the classroom management strategies of the senior teachers, and the flexibility and creativity of the young teachers.

I still remember my early days. I observed a senior teacher. The lesson was quite boring, not very exciting. However, I learnt the way she made use of the blackboard.

She recalled that during the lessons, the teacher wrote and rubbed off many things on the board but she always kept the key points of the lesson on a corner. Throughout the lesson, students always kept in mind what they had to remember. The teacher also summarised the main points at the end of the lesson. However, when observing new teachers, Linh always looked for their creativity and devotion. She gave an example.

When teaching process essay, one teacher brought real tea and her tea set to demonstrate the steps in making tea. The students were very excited. The lesson was very effective.

After the observation, Linh gave her feedback on a piece of paper. There were several dimensions to comment on, for example, lesson structure, the connection between activities, and classroom management strategies. If she felt comfortable, she could give comments in a personal talk. However, she only judged the younger teachers.

In addition to observing other teachers, Linh was observed by the managers of the faculty and some other teachers. The managers wrote their comments to her, but others did not. Nevertheless, Linh doubted the reliability of the comments. Because they did not frequently observe her classes. They only came for a short a period of fifteen to twenty minutes. Linh assumed that they could not have an overview of her teaching practice. 
VIETNAMESE EFL TEACHER SELF-EFFICACY IN PRACTICE

Similar to Linh, Huyen's teaching was influenced by her observation of other teachers when she first came to work at the university. Other teachers and the board of managers recommended some experienced teachers who received positive feedback from students. Huyen contacted them to arrange an observation time. She learnt a lot from her observations such as how to organise group work activities, how to lead into the lesson, and how to manage the class. Nevertheless, as a novice teacher with little experience, she did not give them any comments. She just learnt what she thought was interesting and useful. Recently, when she had to sign a new contract, some teachers from the board of managers or subject managers and some experienced teachers came to observe her classes. Then they gave her feedback in a closed meeting. She appreciated their truthful comments and very helpful suggestions to improve her teaching.

Mai, Huong, and Duong also appreciated what they learnt from observing other teachers' classes. Mai saw this as"valuable experience" while Huong noted down what she found "useful and interesting". However, the teachers said that they only did observations for a short period when they first came to the university. Huong explained that she was eager to learn because at that time she was young with little experiences and she had much free time. Nowadays, she was too busy with such a heavy workload. She could only manage to teach the assigned classes. Similarly, Mai had hardly managed to observe any classes recently.

Now, although I know that I should continue doing it, I hardly manage to do it. I don't have much time available for that. The workload is quite heavy. Usually, teachers who have more than five years of teaching share their experiences informally in their daily talks.

As Mai mentioned, the sharing between teachers became personal and informal.

Acknowledging the importance of peer-observation, Duong volunteered to do it after her probation. However, she did not give any feedback to the observed teachers due to her position as a newcomer.

Because when I asked to observe their classes, I went there to learn, not to criticise them. Of course, in each lesson that I observed, there are good points and not 
VIETNAMESE EFL TEACHER SELF-EFFICACY IN PRACTICE

very good points. I learn from both sides. I haven't got a chance to talk to them about that. It's quite sensitive.

When Quynh taught a subject for the first time, she would ask more experienced teachers for permission to observe their class. She learnt how they made use of the teaching materials, how they engaged the students and how they managed a large class. She was observed by the faculty managers and some other teachers before she signed a new contract. She received mostly positive feedback from them.

We are observed by the faculty managers and some other teachers before we sign a new contract or increase our salary. I'm happy that they mostly gave me good comments. (Pre-observation interview)

Quynh said that the knowledge she acquired in her observations of other teachers' classes and the feedback that other teachers gave her had some positive influence on her teaching practices.

To summarise, peer-observation and peer-modelling improved teachers' pedagogical knowledge, which, as a result, enhanced teacher self-efficacy.

\subsection{Personal Characteristics}

The teachers' personal characteristics determined their attitude, effort, and devotion to teaching. The most common quality mentioned by four out of seven teachers is passion. According to Minh, Duong, Trang, and Mai, they were effective teachers because they were passionate about teaching. In addition, they reported having some other pertinent personal characteristics.

Duong explained that her passion in teaching made her a dedicated teacher. She loved her job and her students. She tried to design creative and effective lessons using supplementary documents and giving precise feedback.

I spend lots of time searching, designing extra activities for my students so that every student can join in. I also spend time giving them detailed feedback. Of course, I can't do that all the time but I always try my best. I think my devotion for my students is still at a high level. My philosophy is that my students must 
VIETNAMESE EFL TEACHER SELF-EFFICACY IN PRACTICE

somehow gain something if they attend my lesson. They must progress. (Duong Pre-observation interview).

In addition, she said she was a responsible teacher.

I start and finish my class on time. When I have to cancel any class, I always teach them extra time later. (Duong - Pre-observation interview).

In Duong's case, her attitude towards her job reflected her self-efficacy. Her personality as a dedicated teacher allowed her to devote much time and effort in teaching, which created lessons that engaged her students.

Similarly, Minh considered herself to be "passionate about teaching English", and "thoughtful and considerate" (Minh-Pre-observation interview). She gave an example that when she used a new textbook, she thoroughly considered it to see what was good or bad about the book, what she could exploit from the book, or what she needed to find extra documents. Moreover, she always cared about the students' attitude to learning. Their excitement and eagerness made her "happy" (Minh-Pre-observation interview). However, if the students in her classes seemed to be indifferent and inattentive, she questioned herself about the students' reactions. She reflected on what happened in the class to find solutions. She set specific targets for the lesson and connected the lessons to the students' lives. In Minh's case, her passion for teaching refers to the use of the teaching materials and her consideration of students' feedback. In other words, Minh judged herself an efficacious teacher because she could make good use of the textbook as well as other reference material and be able to manage students' misbehaviours in the class.

Similar to Minh, Trang reported some personal qualities that supported her teaching. She said she was a passionate and understanding teacher. The students were her greatest concern when she taught. She tried to make her students satisfied with her lessons.

Like other foreign language teachers, I think I am passionate about teaching. I care about students' feedback, whether they are satisfied with the lesson or not. When I feel that the students are not happy with my lesson, I ponder how to make my lessons more interesting. (Trang - Pre-observation interview) 
VIETNAMESE EFL TEACHER SELF-EFFICACY IN PRACTICE

Similarly, Mai considered herself as a passionate, dedicated, and responsible teacher. She loved teaching. She spent a lot of time outside the classroom searching for extra documents, designing additional activities, and preparing for her lessons. She always cared about her students. She thought that her teaching would have great influence on them. Therefore, she needed to always update her pedagogical knowledge, teaching methodologies, and content knowledge.

Huong mentioned the two important qualities of being moral and competent, as well as referring to her passion for teaching and her teaching abilities

Moral refers to ethical issues. It means the love for your job and how properly you perform your job according to conventional standards. Competent refers to abilities and skills.

She specified that an effective English teacher should be highly competent in the target language. She suggested that teachers should reach certain levels of some standardised tests like IELTS, TOEIC, TOEFL, or CEFR. She thought that when a teacher was more proficient in English, they would be more confident in teaching. She explained that when she taught something, she needed to make sure that she was an expert or understood it well. Otherwise, she could not answer students' questions or help them improve. Pedagogical knowledge is another important aspect of being competent. Huong believed that by having pedagogical skills, she could deliver her lessons more effectively. Huong also mentioned some other qualities which she called "bonus qualities".

Besides, I think an effective teacher should have some bonus qualities to inspire their students like the ability to encourage, persuade, motivate, and engage students more in their classes. Teachers also need to have broad view to assess and judge their students' demands because knowledge plays the central role but we also need to consider learners' demands.

Huong considered her students the center of her lessons. Her instructional and managerial strategies relied heavily on her perception of the students.

Trang reported her age as an advantage over other teachers. 
VIETNAMESE EFL TEACHER SELF-EFFICACY IN PRACTICE

I think I'm quite young, which makes me closer to my students. As foreign language is a dynamic subject, I can give my students examples of their interest (Trang-Pre-observation interview)

The reason for this is generational difference. The smaller the age-gap between the teacher and her students, the closer the relationship between them was perceived to be. Considering the students her peers, Trang thought for the students from her point of view. She understood their individual expectations, their preferences in learning, and their interests which helped her design engaging and inspiring lessons.

In addition to be passionate, Mai reported herself as a creative teacher with good interpersonal skills.

English is a special subject. It requires a lot of interaction between teachers and students. To have effective lessons, I must have good interpersonal skills. Teaching English doesn't mean just teach language items. Teachers of this subject need to create and design language activities. So I need to be creative.

Mai's said that her confidence in communicating and her creativity attracted students' attention and participation in class activities, which made her lessons effective.

Linh described herself as a patient and easy-going teacher. Her teaching style depends on the students' learning attitudes. She thought it was no use being strict on the students when they were not serious about their study. Conversely, she was patient with students who showed interests in learning.

I don't mean that I let my students do whatever they want. I mean I'm tolerant. If, for some reasons, a student forgets to do his homework or forgets his book, I just give him a tender reminder. Of course, I have to I warn them sometimes to get them to be more disciplined. I'm patient with my students to encourage and motivate them.

Trang revealed some elements constraining to her teaching. She mentioned the quality of her voice and speaking speed. 
VIETNAMESE EFL TEACHER SELF-EFFICACY IN PRACTICE

People often say that the tone of my voice is a bit high. It's not emotive enough. Furthermore, I speak quite fast. I think these issues hinder my teaching. Although I try to change, it's a habit so it's quite difficult to improve. (Trang Pre-observation interview)

Although Trang was aware that her voice and speaking pace hindered her teaching, it was quite hard for her to change.

To recap, the teachers mentioned some personal characteristics that had a strong relationship with their self-efficacy. These characteristics included the passion for their job, responsibility, creativity, and building a good relationship with students by being patient, thoughtful, considerate, understanding, and friendly. Their determination, attitude, and devotion to teaching facilitated how the teachers built relationships with learners, something these teachers valued greatly. Additionally, some teachers also valued the importance of being competent in the target language. Skills in the language and as a classroom presence are likely to increase confidence in performance.

\subsection{Teacher Autonomy}

Some teachers expressed that they had considerable freedom in selecting teaching content, allocating teaching time in class, assessing and giving feedback to students, using supplementary documents and teaching resources. The freedom enabled teachers to address students' needs and interests then set targets for their class. Because self-efficacy is to do with confidence in achieving certain tasks, a sense of personal control in doing those tasks is likely to be associated with the teachers' confidence in doing them.

\subsubsection{Teacher Autonomy in Selecting Teaching Contents.}

According to Minh, the course outline did not provide teachers with any specific targets. The faculty managers understood that the students needed to learn business English. Therefore, they selected a business English book. Each teacher decided on their own targets and what they needed to teach. Minh read the targets from the textbook, then identified what she wanted her students to achieve. For each unit, she considered the topic and the sections. Then she usually set the main targets for her students in class and what they should do at home. The freedom brought much flexibility for her as a teacher. She could teach what she wanted to some extent, which consequently complimented teacher self-efficacy. 
VIETNAMESE EFL TEACHER SELF-EFFICACY IN PRACTICE

Like Minh, Huong stated that her teaching effectiveness was influenced by her autonomy in selecting the teaching content. She could choose whether to teach all sections mentioned in the book or skip some parts and use materials from other sources. This meant that time allocation in each lesson was teachers' own decision.

The board of managers set a syllabus with the amount of time allowed and what we have to cover. Then each teacher sets their own goals for single lessons. For example, I focus on teaching my students' reading, speaking, listening, and writing skills in business context. I try to match what I teach in class with the exams at the end of the term so that my students can have highest scores.

Huong's teaching was geared towards the final exam. She taught what she thought the students would be tested on. The higher the scores the students received, the better she judged her teaching.

Linh said that she sometimes skipped some parts in the textbook which she found unsuitable for her students.

For example, there's a unit about writing persuasive essay. I think it's too hard for my students. So instead of teaching that, I ask my students to write sentences and paragraphs. They can learn to write essays in the following semesters.

She explained that she would first design the content according to her perception of students' proficiency. If the students' language competence exceeded the targeted level of the book, she would give her students extra work., and vice versa, if the book was too difficult for her students, she would focus on simple and fundamental knowledge. In Linh's case, her freedom to decide on teaching content helped her lessons match the students' ability. In other words, her lessons were likely to be effective when they were comprehensible to the students.

Huyen compared the teachers of the general English division and English for specific purposes (ESP). She said that the ESP teachers had the same slides to use in their classes. Meanwhile, Huyen and other teachers prepared for their own lessons. 
VIETNAMESE EFL TEACHER SELF-EFFICACY IN PRACTICE

To recap, some teachers described their freedom in selecting teaching materials in the pre-observation interviews. This allowed them to address their students' needs, meet their proficiency or get high scores in examinations. The ability to determine what to teach possibly added to teacher self-efficacy.

\subsubsection{Teacher Autonomy in Time Allocation.}

However, our teaching differs among classes. For example, some classes prefer translation activities. We will spend more time on those activities and ask them to do other exercises at home. If they want to do writing, then we will do writing in class and other exercises at home. (Pre-observation interview)

The students' preference greatly influenced the teacher's time allocation.

Likewise, in each unit, Huong chose a topic which she thought more interesting for her students. She would spend more time on that topic.

Similarly, Linh said she decided her teaching speed. She clarified that she could quickly go through the books or spend more time on it as long as she covered all ten units in a semester. For example, she could teach a unit in two class meetings (six periods) or she could also teach two units in a class meeting.

In addition to a level of freedom to choose teaching materials, the teachers reported their independence in class time allocation. Such initiatives resulted in some flexibility for the teachers. They could alter their teaching plan so as to reach their expected outcomes.

\subsubsection{Teacher Autonomy in Assessing and Giving Feedback.}

Minh showed great confidence in her teaching. As observed in her class, she did not check the students' attendance although it was a compulsory task for teachers. She explained as follows.

I don't usually check the students' attendance. I'm not very meticulous when assessing their attendance. I think if the students feel engaged and motivated, they will show up in the class.

This implies that she was certain about students' attendance. She was confident that the students would come to the class because they found it interesting. 
VIETNAMESE EFL TEACHER SELF-EFFICACY IN PRACTICE

Minh's assessment of the homework was rather flexible.

I haven't thought about how I would assess the portfolio. I'm not sure whether I would add bonus point to the attendance or not. But my students are not very serious about that. They don't do it because they are marked. They do the assignments and they learn from those. They are first year students so they are still excited and eager to learn. (Minh - Pre-observation interview)

Instead, she evaluated the students' contribution in class activities. She said she was quite generous when assessing the students. In her opinion, $10 \%$ did not say much about the students' actual language competence (attendance accounted for $10 \%$ of the students' total score). She valued more how much knowledge they had learnt and how much progress they had made.

According to the teachers, the total score of a student comprised three components, namely: attendance, a mid-term test, and an end-term test. The end-term tests were computerbased. When a student logged onto their test account, the system would automatically administer a test. The teachers had little control over that test. Nevertheless, they had much flexibility in designing the mid-term tests. The tests must follow certain criteria in terms of difficulty, length, form and time. The teachers made their own decision on what to cover in the tests. They could either adopt or adapt them from different sources or design by themselves. More precisely, Linh said that the end-term test did not cover everything in the book. When they designed the test, they were required to include specific skills. If Linh felt something was important and she wanted to test the students, she would put it in the questions. Although the faculty would check the tests before making final decisions, they usually approved them.

The teachers' freedom to design the mid-term tests according to what they taught in the class positively influenced their belief about the effectiveness of their lessons. They believed that being tested on class material would result in more opportunities for higher scores, which strengthened their sense of being efficacious teachers.

\subsubsection{Teacher Autonomy in Using Supplementary Documents.}

Three teachers exploited other course books, i.e. textbooks from other universities or other books rather than the textbook. Minh said that some of the classroom activities were either adapted or adopted from the books that she bought. She bought many books about business 


\section{VIETNAMESE EFL TEACHER SELF-EFFICACY IN PRACTICE}

English. When she found something suitable for her lessons, she would use it. She gave an example of a lesson in which the students were asked to describe a process and a product. She searched her IELTS books for a chocolate making process. The students were very excited because chocolate was a very familiar topic. As can be seen from Minh's example, the materials that she used related directly to the topic in the textbook and piqued the students' interest.

Huong also bought some reference books.

We have to pay for most of the course books ourselves. We have to find and buy the supplementary books to match with students' proficiency and needs in different classes. (Huong - pre-observation interview)

Huong's use of the modal verb "have to" suggests that she was not happy about that. She hoped the university would provide more teaching resources in the library. To deal with the issue, she made use of the resources on the Internet.

To teach a section in the course book, I search for some websites to find extra materials. Some of them are very useful. For example, Teachers to teachers. (Huong - pre-observation interview)

According to Huong, the website had some activities. She just needed to choose and adapt those activities to fit her classes. For example, she could shorten the time spent on an activity or spend more time explaining a point if her students did not understand.

Likewise, Trang usually searched the Internet for extra activities. Just like other teachers, Trang chose the ones relating to the lesson. More importantly, she emphasised that the activities should be interesting and suitable for her students' proficiency. Although praising the Internet, Trang highlighted that because there were too many things on the Internet, it took much more time than she expected to find suitable activities.

In Trang's opinion, the use of extra activities was a strategy to manage the students.

To maintain discipline, I try to design some extra activities. I think if the activities are interesting and engaging enough, the students get more involved. They will not be talking or doing something else. (Trang -Pre observation interview) 


\section{VIETNAMESE EFL TEACHER SELF-EFFICACY IN PRACTICE}

On one hand, the freedom to choose their own supplementary documents seemed to make the teachers more confident than just using prescribed textbooks. On the other hand, sourcing these materials took time. To solve the problem, Trang sometimes designed extra activities. The criteria for those activities were similar to those that the teachers sourced from the Internet. They needed to be engaging, based on students' interests so that they could draw students' attention and participation. She added that she sometimes created fun, competitive activities to make students feel excited.

Like Duong, Huyen, Linh, and Mai, Trang chose activities that matched students' language competence, knowledge and age.

I can't treat my students like young children. I can't ask them to sing or dance like in a kindergarten. The students should have at least some knowledge about the topic. The activities are not too difficult nor too easy so that everybody can join in. (Trang -Pre observation interview)

To sum up, the teachers reported having independence in selecting and using textbooks as well as supplementary documents. They made decisions based upon their perceptions of the students' proficiency, their interests, and what they thought useful for their students.

\subsubsection{Teacher Autonomy in Professional Development.}

The teachers reported that their faculty organised seminars and conferences for them to share experience with their colleagues. All of the teachers attended these activities. While most of the teachers did not say much about the benefits of those professional development activities, Minh was excited about them. Minh said that when attending conferences, she compared her teaching with her colleagues' teaching practice to identify which things they were doing in the same way, which things were doing differently, and which way was more effective. Later, she tried to apply some new strategies in her classes. She could also see her colleagues' difficulties and suggested some solutions for them.

According to Linh, who was not "very interested in such activities" (Linh -preobservation interview), teachers have different motivations to join in professional development activities.

Other teachers may take some short courses on ELT, research methods, and so on but I don't. I don't have any motivation. Other teachers do it because 
VIETNAMESE EFL TEACHER SELF-EFFICACY IN PRACTICE

they are preparing for their PhD overseas or they want to be promoted. I'm not interested in that. I don't see any benefit for my teaching. Moreover, I'm very busy teaching at the school. I don't have time for things like that. (Linh-preobservation interview)

Like Linh, Mai shared that not all the teachers in her faculty were keen on professional development activities. However, Mai herself could spend time on those activities.

In my case, my children are now grown-up. I have more free time. Other teachers may think what I have done is out of their reach, but for me, it's just a job I should do. (Mai - pre-observation interview)

Only Minh, Duong, and Mai participated in external and international conferences. They talked about the benefits of these for them. Mai stated that she was able to reflect on her teaching from engaging with different aspects and different approaches. She could see her teaching practice in different ways, and experience new methods that she had not used before. She learnt how to increase students' autonomy and how to motivate students. She knew how to look at an issue from students' perspectives as well as teachers' perspectives.

Other activities Mai mentioned were reading books, searching for useful websites, and reading news from the internet to keep herself updated. Duong and Trang also claimed the Internet was useful for professional development with many useful webinars and forums comprising teaching plans, classroom activities, and teaching resources. Huong and Duong said they were "lucky" because they were chosen to attend an in-service training course. They found the course to be very useful.

Minh has a different approach to professional development. She not only participated in the English Language Faculty's seminars and conferences but also attended seminars of other faculties. For example, she said she wrote a paper for a seminar on corporate social responsibility and attended a conference. She said teachers needed to have social knowledge as background. Therefore, sometimes she took short courses on law, business planning, and intellectual property organised by other faculties. Although the faculty did not provide any support for such courses, she was still happy to pay for them. The reasons were as follows. 
VIETNAMESE EFL TEACHER SELF-EFFICACY IN PRACTICE

Then when I had to teach relevant issues, I felt much more confident. I was able to share with my students some stories I learnt from the courses. My lessons would be much more interesting. I myself felt more knowledgeable. (Minh-Preobservation interview)

These professional activities were beneficial for Minh. They helped to increase her sense of efficacy in teaching. She emphasised that

I think we should take the initiative in professional development activities.

We will have more chances. (Minh-Pre-observation interview)

In short, some teachers attended professional development activities because it was compulsory. Some others participated of their own volition. It seems that the teachers with higher autonomy in professional development benefited more from such activities than the others.

\subsubsection{Teacher Autonomy in Selecting Teaching Resources.}

To prepare for a lesson, the teachers mentioned that they could either rely on or modify the textbook or select other materials.

Minh, Quynh, and Huyen all reported making use of the textbooks. However, they did it for different reasons. Minh said that when she used old textbooks, she prepared a lot of extra activities. However, when she was teaching using a new textbook for first year students with high levels of English proficiency, she did not have to spend much time searching for extra activities. This textbook was new to the students. According to the faculty's policy, the high proficiency students could skip the programme for first year standard students. The students studied the programme for second year students. Although those students were freshman with no background knowledge of business, they learnt things like internship, marketing, job applications, and job interviews. These topics were very new for the students. There were so many new words and concepts and they had not learnt those skills, even in Vietnamese. Therefore, Minh made use of the textbook, rather than using other documents. Her aim was to have the students understand the main points of the units. According to Minh, the teachers' book and other supplementary materials that went with the textbook were very helpful. The students 


\section{VIETNAMESE EFL TEACHER SELF-EFFICACY IN PRACTICE}

could learn from the supplementary materials too. These were the reasons why she relied mostly on the textbook.

Quynh was teaching business correspondence for third year students. She was provided with a very detailed syllabus which laid out what teachers and students had to do in each lesson. Compared to teachers in the general business English division, Quynh said that she followed the syllabus very closely. The teachers who were teaching that subject designed the supplementary book to meet the university's policy and the students' needs. They made it suitable for their students. As a result, Quynh and the other teachers did not have to use other resources or design extra activities. They made use of the textbook. Both Minh and Quynh said that the textbooks were suitable for the students. In addition, they had appropriate supplementary documents that came with the textbooks. Those materials helped them save time when preparing for the lessons. Having a textbook they could rely on meant she felt more confident. Quynh reported another reason for her use of the textbook as follows.

We don't have many activities in the class because of huge number of students. We focus on teaching them new knowledge, help them understand and apply firstly in the exams, then in the jobs in their future. (Quynh-preobservation interview)

Huyen gave a different reason why she used the textbook. She said that she had to cover a huge amount of material in a limited time. Therefore, instead of using other resources, she made the information and skills in the textbook the first priority.

In short, the participants made use of the textbooks for different reasons including students' limited background knowledge and proficiency, appropriateness of the textbook, supporting documents, or time constraints.

\subsection{Teachers' Perception of Teaching Context}

The teachers reported in the pre-observation interviews the influences of their perception of the teaching context. Their perception of students' English language proficiency, students' perceptions of English as a subject, and classroom conditions helped them select appropriate teaching materials, design suitable activities and teaching strategies. This potentially consolidated teacher self-efficacy, whereas the heavy workload and low income resulted in negative physiological states and diminished teacher self-efficacy. 


\section{VIETNAMESE EFL TEACHER SELF-EFFICACY IN PRACTICE}

\subsubsection{Students' Proficiency.}

The teachers' perception of the students' proficiency had a great impact on their teaching, especially in multilevel classes. There is evidence from the pre-observation interviews that the more the teachers know about the students' language competence, the more efficacious they reported feeling.

At the beginning of the term, Minh said that she gave a test to find out the students' levels. The results showed her that some of the students could achieve 8.0 in the IELTS exam but some others were more likely to reach 6.0. There was a big range of competencies among the class. Minh used different strategies to help her students benefit from her class. For example, she said that when she asked them a question, some students were not able to answer it. They could not perform as well as other students did. In that case, she asked herself for possible reasons. If she thought they were lazy, she would tell them immediately. She highlighted that it was unacceptable not to be engaged with learning. However, if their lack of responses to questions was because of their ability, she would ask them about their difficulties. The students might explain that they were the A group which means they took Math, Physics, and Chemistry in the university entrance exam. They had spent most of their high school time learning those subjects. In contrast, they might say they were from the countryside where they had not had many opportunities to learn English. Whatever reasons they gave, Minh encouraged them to learn in class. She paid more attention to the weaker students.

If they can speak a few sentences, I praise their effort. I put them in pairs or groups and ask their partners to help them. I check with the partners how they were doing. When they see that I care about them more than care about other students, they will be more attentive and responsible for their study. (Minh - Preobservation interview)

Similar to Duong, Quynh described her students' language competence as varied.

The students' proficiency is diverse. In the first two years, if they show their certificates of certain level, like 7.0 IELTS, they don't have to attend English classes. But in the last two years, all students have to learn English for specific purposes. That's why in a class we have multilevel students. (Quynh - Preobservation interview) 


\section{VIETNAMESE EFL TEACHER SELF-EFFICACY IN PRACTICE}

Quynh was teaching writing, a productive skill. She explained that unlike multiple choice tests, the students had to create their own work. Her students' level of proficiency was considered a constraint for Quynh in her teaching. The variation in students' language ability and the big class size made it hard for Quynh to organise classroom activities. Moreover, in the writing classes, Quynh required her students to produce appropriate letters. She also emphasised that in order to pass the exam or achieve high scores, they had to practise regularly. Therefore, most of the time in class, she asked them to do exercises from the textbook. Huong used a different method of dealing with the wide range of English proficiency among her students by designing different tasks so that all students were involved in her lessons.

I assign different tasks. For example, with students who are eager to speak out, I give them more speaking activities. But with students who are less confident in speaking, I design different activities so that they can be involved. In my university, the gap of proficiency between students is too big. Some students reach 8 or 8.5 of the IELTS but some may not reach 5.0. I usually pay more attention to the lower level students although I don't want to drag the whole class down. I give those students priorities because if they feel abandoned or isolated, they will never progress. (Huong - pre-observation interview)

The varied proficiency levels influenced Huong's instructional strategies. Instead of preparing the same activities for the whole class, she designed different tasks or modified them for students of different abilities.

Like Huong, when conducting a classroom activity, Linh paid close attention to students' proficiency. She wanted to provide equal learning opportunities for every student. For group work activities, she divided students into groups of mixed levels. She believed that in group work, the more able students would provide some help to the less able ones. If they worked individually, the more competent students would dominate the class and the others would be left behind. Moreover, Linh was flexible in organizing group work. Sometimes, she put the less proficient students and the more proficient students in separate groups. She thought that being with other students of similar proficiency would enhance their confidence and creativity. Although the teacher gave the students the same task, the requirements for each group was different. For example, with lower level students, she would expect them to generate some ideas 
VIETNAMESE EFL TEACHER SELF-EFFICACY IN PRACTICE

and be able to speak them out within their groups. Meanwhile, the more proficient students were asked to make a presentation in front of the class. Then the teacher would give them detailed feedback on their pronunciation, grammar, and content.

Duong used similar strategies in her classes to manage the range of proficiencies. Although it was time consuming, she still searched and designed some team-work activities so that the students could support each other. In addition, she assigned some projects outside the classroom.

I have some projects for my students to work on outside the classroom. The high-level students feel excited with those projects while the lower ones feel challenged. They can ask for help from their teacher or friends.

The outside classroom projects required the students to interview foreigners on particular topics. The projects helped them learn how to work independently and use English more confidently. It also created a good chance for the students to practise English outside the classroom, which made their learning more practical.

During her teaching, Trang would notice if any student was struggling or needed extra help. She would give those students further clues or scaffolding. Trang's expectations for students at different levels differed. When she asked for answers to a question, with lower level students, she required them to give the answer only. However, with higher level students, she asked them to give a justification or an explanation.

Likewise, Mai would spend more time with lower level students and support them more than the others.

I have to prompt them very carefully and slowly. Without the teacher's help, they may give up on the task. So I encourage and also force them to speak. In the least, they can produce a "product", even if it's not a complete one. I believe that if they can do these one or two times, they can overcome their fear and do it by themselves the following times. (Mai-Pre-observation interview)

Mai designed exercises or activities with the appropriate level of difficulty for each group. For more advanced learners, Mai sometimes gave them more chances to 


\section{VIETNAMESE EFL TEACHER SELF-EFFICACY IN PRACTICE}

show their abilities. For the lower level students, Mai thought that they would feel more confident if they could learn new knowledge or a skill.

Huyen tried to put her students into groups in which more able students could help less able ones so that they all reached the subject requirements.

To sum up, all the teachers experienced the variation in students' English language proficiency. Most of the teachers were confident in dealing with the issue and they used different strategies. Only Quynh considered the range of English language proficiencies a constraint to her teaching.

\subsubsection{Students' Perception of the Subject.}

The teachers said that most of their students highly valued English. According to Huong and Duong, the students considered English important not only because this subject accounted for a relatively high proportion of their total GPA but also because the language would be very useful for their future. Most of them regularly attended her classes. They followed Huong's instructions and excitedly participated in the classroom activities. Huong said that she felt more passionate about teaching when she was respected. She had the motivation to be more committed and devoted. As a result, this made her teaching more effective.

Since the English courses had a high number of credits, most of Linh's students tried their best to achieve high scores. However, according to Linh, the students only valued the scores, not the real knowledge that they learnt from the subject. Their learning motivation in classes was low.

In terms of learning attitude, they don't highly value English. Maybe the learning programme is too easy for them, or the content is not interesting and different from the end-term test. They try to gain a high score in that test but they don't learn anything from the lessons in the class. (Linh-pre-observation interview)

Linh clarified that during a term, the students learnt four skills of listening, reading, writing and speaking in class. Then they were tested on those skills, except for speaking. There were a hundred questions in the test. However, the content of the questions and the content of what they learnt in class was quite different. The test bank was designed by many teachers. 


\section{VIETNAMESE EFL TEACHER SELF-EFFICACY IN PRACTICE}

Although some of them did not teach that skill, the teachers were still required to design the test.

The students found no connection between what they learnt in class and what they were asked in the test. Consequently, they went to the class just to meet the attendance requirements. They bought other books from the store and practised the skills by themselves. They practised how to answer the questions quickly, how to listen well. They might go to the English centres outside the school to have extra lessons and practice. Lin felt that they did not appreciate what they learnt in class.

Due to the students' learning attitude, Linh felt demotivated and discouraged in finding new teaching methods and updating the teaching content. She had two solutions to the problem. First, she tried to finish the units that she was asked to do. Sometimes, she challenged her students with some extra activities. Second, she marked the students' participation in the class and their progress. Before the end of the term, she gave her students a summary test which covered the main knowledge during the term. Only those students who passed the summary test could attend the end-term test.

To summarise, students' attitude towards the teaching and learning English at the university influenced the teachers' self-efficacy. They felt motivated, encouraged, and positive about their teaching when their students highly valued the subject. However, they felt negative when the students undermined the importance of the subject and the teachers' job.

\subsubsection{Classroom Conditions.}

Most of the teachers complained about the insufficient classroom conditions. Huong said that in some rooms, there were speakers but no computer. It made Huong feel unhappy and tired because she had to run from one building to another to get the speakers, especially during peak hours when everybody had to queue in long lines to wait for the lifts. She had to be prepared for these issues and needed to be very flexible in preparing her lessons.

It's very tiring running from the $11^{\text {th }}$ floor of one building to the $5^{\text {th }}$ floor of another to get the speaker, especially in "peak" hours. (Huong - Preobservation interview)

Similar to Huong, Linh, Duong and Minh also complained about lack of resources to present material in the classroom. In Duong's classes, sometimes, the speakers broke down. 
VIETNAMESE EFL TEACHER SELF-EFFICACY IN PRACTICE

Sometimes, the CD players suddenly stopped working. There were rooms with a speaker but without a projector and vice versa. To solve the problems, during the first lesson, Duong checked for any problem that she may encounter then found her own solution. For example, she had to bring her own laptop and a speaker to the class if there was no speaker in the room. If there was no projector, she would make use of the blackboard and only gave handouts with exercises, not the slides of her teaching. Linh had to think ahead for alternative solutions in case her teaching plan did not work.

Additionally, both Trang and Mai described the classrooms as very hot.

In summer, the classrooms are very hot. Ifeel very tired. Some rooms don't have a projector or speakesr. There is no anti-virus software installed in the school's computers. It's annoying that sometimes we can't open a file or it gets damaged. If we don't use the school's computer, we can bring our own laptops. But it's very inconvenient. (Trang - Pre-observation interview)

The classroom facilities had a negative influence on the teachers, impacting their health and emotional status, which in turn made them less confident that they could teach effectively .

Moreover, some teachers had difficulties in managing big classes. Quynh was teaching big classes with an average number of students of over a hundred. She relied heavily on the equipment like a computer, microphone, loudspeaker and projector.

Sometimes the computer doesn't work. Some rooms don't have a projector. I'm teaching very big classes. If I don't have things like a microphone, speaker, and projector, I'm afraid I can't teach. (Quynh - Pre-observation interview)

The teaching facilities played an important role in Quynh's teaching. The classrooms were not well-equipped, which had impacted negatively on her ability to teach. The big class sizes also impacted her instructional strategies.

The number of students in my classes is very big, up to 150 students. It's very hard for me to pay equal attention to all of them. When I check their work or 
VIETNAMESE EFL TEACHER SELF-EFFICACY IN PRACTICE

give feedback, I cannot check all of them. It takes too much time. (Quynh-Pre-

observation interview)

In short, the teachers' beliefs about their teaching effectiveness were influenced by the availability of teaching equipment in the classroom and class size.

\subsubsection{Workload and Income.}

Duong reported that her workload was too heavy. She reported that she had to teach too many hours in a week, and that she felt stressed sometimes. In particular, it influenced the way she gave feedback to the students.

I can't give detailed feedback to my students when I have too many classes to manage. I don't have enough time.

When marking students' work, she could not give the meticulous comments she would have liked to because with an average of six classes a week and around forty students in each class, her workload was very sizable.

On average, Huong had to teach seven to eight full time classes per week, plus some part-time and joint-programme classes. One of the reasons for this was that she was not married. The managers believed that she had more time than other married teachers with children. The other reason related to her income. The more classes she taught, the more money she would be paid. She explained that:

To be honest, my salary is not low in comparison with salary of other teachers but I can't live comfortably with such salary. I can't totally devote to my teaching. I don't complain because it's a problem across the country. But I wish I could live on my salary and I could live with my career and devote to my career.

To deal with the problem, she had to teach extra classes. As a consequence, she sometimes felt exhausted.

Sometimes, I feel I can't deal with such huge work load. My health doesn't allow me to do so. 
VIETNAMESE EFL TEACHER SELF-EFFICACY IN PRACTICE

The heavy workload made her very tired. She could not manage to teach all her classes as effectively as she should be able to. In other words, the heavy workload and low income had negative influences on the teacher.

Huyen had to spend a lot of time planning for her lessons and searching for extra documents. Additionally, she had to spend her own money on printing or copying the handouts for her students. It was not only time consuming but also expensive. Huyen was not well paid and this influenced her motivation to do her job.

It's not worth spending so much time and energy. We feel demotivated.

To support her living costs, Huyen had to do other jobs to earn extra money. She spent less time preparing for the lessons at her university. She said that it influenced the quality of her lessons.

The workload and salary from the university negatively influenced the teachers' professional and personal life. They had to keep a balance between them. They thought they were not as effective as they could be if they were well paid for the work they did.

\subsection{Teachers Playing Different Roles.}

Linh and Trang mentioned the influence of their role as housewives. They had to spend much time taking care of their families. As a result, they could not devote so much time to their jobs.

For me, the wife's role has some influence on my job. My family is a nuclear one. I myself have to take care of my daughter. I don't get much support from my husband. Sometimes, I can't arrange my working schedule to balance my two roles of a teacher and a housewife. (Trang - Pre-observation interview)

Another teacher, Duong said that as she was single, she was assumed to have more free time than other married teachers. She was assigned more work. She said she felt not as effective as she could be because she had other personal jobs to do in addition to her teaching jobs.

To summarize, as women teachers, the participants played dual roles of both teachers and housewives. The expectations for them to play both roles equally well may diminish their selfefficacy because of competing demands on their time. 
VIETNAMESE EFL TEACHER SELF-EFFICACY IN PRACTICE

\subsection{Section Summary}

The participants reported a number of elements that influenced their self-efficacy. There were alignments between the elements and sources of self-efficacy in Bandura's (1997) theory. The first and most powerful of these is mastery experiences. The teachers' past teaching experiences provided them with enactive mastery experiences. Their knowledge of what needed to be taught contributed positively to cognitive mastery experiences. They also gained vicarious experiences through the observation of peers' classes and peer modelling. Professional development activities such as seminars, workshops, and conferences also provided vicarious experiences to the teachers as they had opportunities to learn from others' experiences. Students' feedback about teaching acted as social persuasion and could either enhance or diminish teacher self-efficacy. Classroom and working conditions (including collegiality) contributed to the teachers' physiological states. Importantly, in addition to the above sources of self-efficacy that align with Bandura's model, the data showed the influences of personal, institutional, and cultural elements on teacher self-efficacy as follows.

Table 19

Beliefs about Influences on Teacher Self-Efficacy

Personal influences _ - Past teaching experiences

- Teachers' content knowledge

- Personal characteristics

- Teachers' perception of the teaching context

\begin{tabular}{|c|c|}
\hline Institutional influences & $\begin{array}{ll}\text { - } & \text { Collegiality } \\
\text { - } & \text { Professional development } \\
\text { - } & \text { Feedback about teaching } \\
\text { - } & \text { Peer observation and peer-modelling } \\
\text { - } & \text { Teacher autonomy }\end{array}$ \\
\hline
\end{tabular}

Cultural influences

- Teachers' roles

- Feedback about teaching

- Collegiality 
The influences of such internal and external elements will be discussed further in the next chapter.

\section{How do Teachers with Different Profiles of Self-Efficacy Differ in Their Teaching Practice?}

This section compares the teaching practices of teachers with different self-efficacy profiles. It draws on the classification of the teachers as higher, medium, and lower self-efficacy that was made during the participant selection process.

\subsection{Higher Self-Efficacy Teachers}

Two participants in the higher self-efficacy group - Duong and Minh - were purposively selected for interviews and observations. These two teachers had the same overall self-efficacy score of 4.04, which was the highest of all the sample. They differed slightly in self-efficacy scores across three domains of classroom management, instructional strategies, and student engagement (see Table 19). In this section, I will present the classroom observation data to show similarities and differences in teaching practice across three domains.

Table 20

Overview of Teachers with Higher Self-Efficacy Scores

\begin{tabular}{llll}
\hline & Average & Duong & Minh \\
\hline Overall self-efficacy & 3.91 & 4.04 & 4.04 \\
\hline Self-efficacy for student engagement & 3.98 & 3.78 & 3.70 \\
\hline Self-efficacy for classroom management & 3.85 & 4.20 & 4.67 \\
\hline Self-efficacy for instructional strategies & 3.91 & 4.13 & 3.75 \\
\hline
\end{tabular}

\subsubsection{Classroom Contexts and the Teachers' Reflection on Their Satisfaction with}

\section{the Teaching.}

Duong was observed once in a second-year class. This was the second term Duong had taught the class and she knew the students very well. The room was a standard university language classroom and could accommodate around forty students. Inside the room, the tables were placed in rows of two blocks with an aisle in the middle. There were thirty-eight students attending the lesson. 
VIETNAMESE EFL TEACHER SELF-EFFICACY IN PRACTICE

Duong said that she was not very satisfied with the lesson. She said that it was just around $60-70 \%$ of her expectation. She explained that she had prepared some activities for the students but she felt that she should have prepared more. Especially for the warm-up section, if she could do it again, she would find a video instead of using photos. She thought that the students would feel more engaged with a video.

Despite having high level of self-efficacy in the survey, Duong was not very confident when talking about her teaching practice.

Minh was observed in a first-year class with higher English proficiency. Students in this class must be minimally at the B2 level of the CEFR (Common European Framework of Reference for Languages). For English subjects, they skipped the first year of the standard programme and started with the second year programme.

Both the classroom size and the class size were smaller than other classes that I observed. There were thirty students in the class who were sitting in two blocks of rows (in contrast to a standard class of around 40 students). Minh did not see any constraints from the classroom setting. Although she had to rearrange the students' seats for some activities, she could manage it easily.

Talking about her feeling about the lesson, Minh said she was satisfied with her teaching.

"In general, I'm happy with the lesson."

In short, Minh and Duong were teaching classes of different proficiency levels. There were fewer students in Minh's class than in Duong's. While Minh reported to be satisfied with her teaching in the observed session, Duong said her teaching did not meet her expectations.

\subsubsection{Classroom Management.}

Duong's students chose their own seats. Duong said that students usually sat where they felt comfortable. More students were sitting at the front and the back of the class, under the ceiling fans. Very few of them were sitting in the middle of the room. According to Duong, they tended to sit near the fans because they were studying in the afternoon and it was quite hot. Although she could ask them to sit in rows to make the class better organised, Duong thought if they felt more comfortable, the lesson would be more effective. 
VIETNAMESE EFL TEACHER SELF-EFFICACY IN PRACTICE

I think if they feel more relaxed, the lesson will be more effective. So I just let them choose their seats.

Duong reported that the classroom setting had some influence on the organisation of the classroom activities. When doing group discussion or pair work, the students had to move to sit with their partners or they had to turn their heads to them.

It somehow influences the effectiveness of the classroom activities. If possible, I wish that table were placed in a circle or U-shape, not in rows. The students could easily do group work activities.

To deal with the large number of students in her class, Duong asked her students to discuss in groups. She explained that she used a lightly modified activities from the textbook. For example, the book asked students to work in pairs but because of the class size, she asked them to work in groups of four or five.

To summarise, to manage the class, Duong rearranged students' seats and adapted activities from the textbook. Meanwhile, Minh did not report any difficulty in managing her class.

\subsubsection{Engaging Students.}

Minh and Duong used different strategies to engage their students.

At the beginning of the lesson, Duong noted attendance by calling names from the class list. She clarified that this was compulsory and she did it at the beginning of the lesson to avoid the students arriving late. Some students arrived to class thirty minutes late. Duong considered it a very bad habit as it influenced everyone in the class. Therefore, she set a rule for her class that a student would be marked as absent if they were more than ten minutes late. She added that sometimes she took the roll at the end of the lesson to avoid students walking out early or playing truant after the break.

To capture the students' attention, Duong walked around the classroom while she asked them to do group work. She thought that many students were passive learners. While some students were listening and doing the exercises, some played with their phones or did something else. By walking around the room, she could identify what they were doing and remind them to 
VIETNAMESE EFL TEACHER SELF-EFFICACY IN PRACTICE

follow her instructions if needed. She would tell them individually in Vietnamese, using the mother tongue to manage the students.

All the students in Duong's class were asked to participate in the classroom activities. To ensure their participation, Duong used different strategies of selecting who to answer her questions.

With the difficult topics which requires rich vocabulary, I pick volunteers because more proficient students are more confident, and they can generate more ideas even when they work together in groups. With easier topics, I randomly pick any of them. I check to make sure that every student has equal chances to speak.

The class I observed was special to Duong because she had taught them two continuous semesters, so she knew who a more or less able learner was. Sometimes, when they discussed in groups, she noticed that some students were very passive. They did not participate in the discussion. She intentionally picked those students out during questioning to warn them. In Duong's opinion, students' participation had some influence on the teacher's emotions. For example, if the students were excited and eagerly joined in the activities, then the teachers would feel encouraged and motivated. She would love her job more and be more passionate.

Not only did she consider the students' participation in the activities, Duong was also concerned about their comprehension. Walking around the room, she could see how her students were doing, and whether they understood her request. Then she could adjust the lesson accordingly. Duong gave an example that if they could not answer the oral questions the first time, she may play the recording the second or even third time. Or she could pause to facilitate them. She would also explain new words or give them some guidance. After checking students' answers to the questions in the book, Duong asked questions to ensure depth of understanding.

Duong tried to enhance her students' confidence so that they could communicate with other people in English. During the observation, she called them to stand in front of the class and give short talks. She justified this by saying that many students in that class were very shy and that if they stood at their desk, they would speak so softly that other students could not hear them. Therefore, she asked them to stand in front of the class to make them feel more confident. Duong would like to make this a habit so that they would not be shy when speaking in public. 
VIETNAMESE EFL TEACHER SELF-EFFICACY IN PRACTICE

She believed that speaking to their friends was much easier than speaking to strangers. They needed to practice speaking that way. However, she allowed one student to speak from his seat.

It's a special case. It's not the first time I called him. I had called him several times before. If he stands in front of his friends, he will tremble then stammer. He can't speak fluently even in Vietnamese. So I had to let him stay at his desk. Besides, he was sitting at the front desk. And when he spoke, he turned his face to his friends. I think that's fine.

Duong used strategies to nurture the students' confidence.

Students' engagement was important to Minh's teaching. While the students were discussing, Minh walked around the classroom.

I would like to make the students feel that I care for them and that they are supervised. I do that for every speaking activity. They are the first year students. They still well behaved. If I don't walk around, I think they will still follow my instructions. But if I walk around, they will be more engaged.

Minh tried to maximise the students' understanding of the lesson by giving them practical examples. She shared with them how she succeeded in applying for a scholarship and how her friends found their jobs overseas. She thought that connecting her lessons to life experience is relevant to the students' motivation and would help the students remember the lesson.

I would like to connect parts of my lessons in that way so the students would remember my lessons more easily.

The students' interests influenced Minh's strategies of engagement. The examples she gave the students were relevant to their lives. In the lesson about job applications, Minh shared with the students her story of applying for a scholarship.

I thought that story was very suitable. I was teaching them about job applications. Applying for scholarships is even more relevant to the students than job applications. The stages are similar. I think the students would be interested in my story and it relates to the lesson. 
VIETNAMESE EFL TEACHER SELF-EFFICACY IN PRACTICE

When the teacher considered the needs and interests of the students, they were more involved in the lesson. This meant that the students' curiosity and concentration were likely to be enhanced.

In short, while Duong engaged her students' attention and participation in classroom activities with disciplinary strategies and by ensuring students' comprehension, Minh considered her students' needs and interests to encourage them.

\subsubsection{Instructional Strategies.}

This section describes how higher self-efficacious teachers' instructional strategies differed. More precisely, I will describe how these two teachers dealt with the students' proficiency, gave feedback, and what materials they used.

\subsubsection{Dealing with Students' Different Levels of English Proficiency.}

Both teachers used different ways to deal with the range of proficiencies in the classes.

The two teachers used Vietnamese at times. When giving instructions, Duong spoke English most of the time. However, she sometimes used Vietnamese. Her strategy relied on the students' proficiency.

I observe the class to see how they are doing. After giving instructions in English, the students with higher proficiency can do what I tell them today. But some other students don't understand. They can't go to the correct page or they don't know what to do. Maybe because they are less able learners or maybe they were not paying attention. So when I translate from English into Vietnamese, they know what to do and they should be more attentive.

The teacher used Vietnamese to ensure the students' comprehension and draw their attention to important components of the lesson.

The students' proficiency also influenced the teacher's selection of students to answer her questions.

With the difficult topics which require rich vocabulary, I pick volunteers because more proficient students are more confident, and they can generate more 


\section{VIETNAMESE EFL TEACHER SELF-EFFICACY IN PRACTICE}

ideas even when they work together in groups. With easier topics, I randomly pick any of them.

She endeavoured to provide as many chances as possible for her students but also tried to encourage their creativity and confidence.

Duong considered the students' use of mother tongue in her classes as normal.

I think in a class without any international students, speaking Vietnamese is unavoidable. Research shows that it's not a hindrance But I try to minimise the time the students speak Vietnamese. That's what I do when I walk around the classroom. For example, when I see a group speaking Vietnamese, I ask what their problem is and I provide them some new words or suggest some ideas.

Instead of banning the use of the mother tongue, Duong allowed her students to use the target language and provided support if the students were having language difficulties.

Student proficiency played an important role in Minh's teaching. In the first lesson, she conducted a survey about the students' proficiency. She was aware that the students in her class were not all at the same level. Because English was not their major in high school for some students, speaking skills varied. Minh responded to the different proficiencies by mixing students with different levels in group work. She also encouraged the more competent students to help the weaker ones. She tried to create equal chances for every student to learn.

I advised them to sit with the students with good speaking skills. I also told the better students to help the weaker ones, to create chances for the weaker ones to speak.

In addition, she provided less able learners with extra support during group work.

When the students do group work, I always notice how the weaker students are doing. I ask them a few questions to force them to speak. When they speak to me, they can make one sentence. When they speak to their friends, they can make two or three sentences. That's what I can control. Most of the students in this class have good speaking skills but I don't take it for granted that all of them are good. 


\section{VIETNAMESE EFL TEACHER SELF-EFFICACY IN PRACTICE}

Minh treated her students as individuals not as a whole class. In this case, the teacher's perception of the students' proficiency played a key role.

In group discussion activities, some of Minh's students discussed in Vietnamese. Similarly, Duong said the use of the mother tongue in foreign language classes was common. In addition, she suggested it was the nature of the subject.

Especially in specialized classes in English, for example business correspondence or translation classes, the students discussed $100 \%$ in Vietnamese. In general English classes, the topics are usually easier, the class size is smaller, the students have some input. So they tend to try to speak English. In big classes, it's very hard to control the students' use of Vietnamese.

Minh understood that the content knowledge that she was teaching was new and difficult to her students. The students did not have sufficient background knowledge and language competence to have lessons only in English. Therefore, the students' use of Vietnamese was expected. She did not force the students to speak English throughout her class. Instead, she "tried to encourage them".

Minh gave an example from another lesson.

In another class today, I taught them about marketing. At the beginning, I asked them to give me their definition about marketing either in English or Vietnamese. When they stood up, they spoke Vietnamese. I told them that such definitions were easy to give in English. Then they translated into English. So I think when the topics are difficult, let the students brainstorm in Vietnamese. I sometimes speak Vietnamese too. Especially when I tell them stories, because I think this makes the stories more interesting.

It can be seen from Minh's example that she also used Vietnamese to make the students more engaged in her lesson.

To summarise, because of the limitations in the students' proficiency, both teachers used the mother tongue to ensure the students' comprehension of the lesson. Vietnamese was also 


\section{VIETNAMESE EFL TEACHER SELF-EFFICACY IN PRACTICE}

used to maintain classroom discipline. Students of mixed abilities were put together in group work but one teacher would give further support for lower proficiency students.

\subsubsection{Giving Feedback and Assessing Students.}

Minh and Duong gave feedback to their students using similar criteria.

Duong tended to give direct feedback to the students right after they finished speaking. Because language skills were integrated into the business English curriculum, the teacher gave feedback on her perception of what the students needed to improve in their language skills immediately.

Minh was strict on students' doing homework. She was responsible for what she assigned the students to do. She said that she always checked and gave feedback on students' work. She gave an example of a writing lesson in which she asked them to write one email at home and bring it to the class. In the following lesson, she showed the students her writing, then asked them to compare hers and theirs. She found it time saving to check the students' work that way. Furthermore, she would provide one-to-one correction if any students requested.

Unlike some other teachers who assign homework without checking it, Minh asked the students to do her homework regularly and put it in a portfolio. She would frequently check the portfolio to identify what the students had learnt, what they were good or not good at, and how much they had improved. Although she did not mark the students' work, she gave the students comments on their work. Then the students learnt from her feedback. Minh's checking strategies enhanced students' learning. Although it was time-consuming, Minh thought it was an effective strategy.

In classroom activities, Minh used her sense of effective functional communication and experience to give students feedback.

If I show them a sample about making a phone call, I would give them very detailed feedback. For example, if you want to hold the line, you have to say this. If you want to leave a message, you have to say this. Your intonation should be like that. I don't have specific criteria but I have a sense of good communication. I usually give feedback basing on that sense. 
VIETNAMESE EFL TEACHER SELF-EFFICACY IN PRACTICE

In summary, the way that Minh gave feedback and assessed her students was similar to Duong. They both assigned students projects to be done outside of class and based on their perceptions of effective communication rather than standardised criteria to assess their work.

\subsubsection{Materials for Teaching.}

Duong assigned some projects outside of class for her students. Each semester she asked her students to do a project focusing on two skills. For example, if she was teaching using the Market Leader textbook, she would ask her students to do the case study of each unit. She put them into groups. The students would discuss, write reports, and present. Every two weeks, there would be a group presentation. She would mark the presentations. If she was teaching reading or listening skills, her students would do a listening and reading log. The students did the exercises every week and kept them in a portfolio. Each class meeting, she randomly checked some students and gave them feedback. If they had any difficulties, she would give them extra help. At the end of the semester, the students handed in the portfolios to be marked. The teacher was the one to decide on the percentage of the project score. Although it accounted for a small proportion of their total score, the students felt encouraged to do it. Duong explained further that she would like to make use of the students' free time outside of class and to maximize a learner autonomy as well as provide them some independent learning strategies. For example, the students had to find the materials by themselves, and choose the most suitable learning strategies.

Additionally, Duong prepared some supplementary activities. She searched for the ideas from the Internet.

I got them from google images. I searched for the topic of the lesson then I chose some suitable ones. I chose various pictures of different adventurous activities like caves, mountains, and forests.

I think I learnt this technique from my teachers at university, from the videos I watched on the internet and from my own experience. I have used it before and I saw that my students were very interested so I used it again in this lesson. Moreover, this activity is easy to design. I can enhance students' imagination, and they can generate ideas. Sometimes, they tell stories that go beyond my expectation. With this activity, I don't need to prepare other things like paper and markers. 
VIETNAMESE EFL TEACHER SELF-EFFICACY IN PRACTICE

Duong' successful teaching experiences contributed greatly to her teaching. Her success in other classes made her confident to reuse it with the class I observed

Minh made use of the textbook. She explained that previously, she had to prepare a lot of extra activities. However, she was teaching a new textbook for high proficiency first year students. In her opinion, the book was quite new to the students. Because the students were freshmen, they did not have much background knowledge about business. Therefore, instead of searching for other resources, Minh relied mostly on the book.

The faculty's policy is that the students with higher proficiency will skip the programme for first year standard students. They learn the programme for second year. They just enter the university then they learn things like internship, marketing, job application, job interview. Those topics are too new to the students. There are so many new words and concepts. They haven't learnt those things even in Vietnamese. So I would like to make use of the book rather than using other documents.

However, Minh also designed some extra activities for her class. Her ideas derived from other books.

I'm aware that I'm teaching at Foreign Trade University. I'm teaching Business English. I bought English books for different majors such as English for management, for marketing, and law. I don't have background knowledge in those subjects so I bought and read relevant books. When I teach them I have a certain level of confidence. I don't want to teach just language items. When I have content knowledge, I felt more confident. I think I must have those books to teach Business English.

Minh was confident in her language competence and content knowledge. Reading books and attending certain courses improved her self-efficacy.

When they were to open the Law faculty, I attended two courses called Legal English and English for Contracts. I took a course in auditing. I participated in a class of the Sunderland Pmrogramme of Banking Academy. 


\section{VIETNAMESE EFL TEACHER SELF-EFFICACY IN PRACTICE}

Those books and courses helped Minh improve her background and content knowledge. As a result, she felt more confident in her teaching. Moreover, she would save time searching for supplementary documents for her lessons. It should also be noted that there were no regulations that force the teachers in the faculty to attend those courses.

In short, while Duong adopted and adapted extra activities from the Internet for her class, Minh made use of the textbook and other books that were relevant to her lessons.

\subsubsection{Comparison of the Two Teaching Practices.}

Minh and Duong had the same overall self-efficacy score. However, their scores differed slightly across three components. Duong had higher scores in self-efficacy for classroom management and instructional strategies but Minh scored much higher than Duong in selfefficacy for student engagement. From the interviews, Minh showed that she was more confident about her teaching than Duong. Minh said she was satisfied with her class that I observed whereas Duong lamented that the lesson did not meet her expectations.

There were some similarities and differences in the two teaching practices. Both teachers understood their students' proficiency quite well. Duong had been working with this class the previous term and Minh conducted a placement test in the first lesson. Their perceptions of the students' language competence influenced their instructional strategies. In both classes, the students were diverse in their proficiency. To address this, Duong and Minh organised group activities in which they put students of mixed levels together and they would provide extra support for students of lower language competence when needed. The diversity affected Duong's selection of students to answer her questions and the language used in her class. According to Duong, the language used in group discussion was not important, whereas use of the target language in their presentation was. Minh, on the other hand, found it hard to control the students' use of mother tongue. Duong switched from English to Vietnamese when she noticed that some students were not paying attention or getting lost. In this case, Vietnamese was used as a tool to manage the class. However, Minh felt more relaxed when talking to her students in Vietnamese. Moreover, she said that speaking in Vietnamese made her stories easier to understand, and consequently, the students would be more engaged. In other words, the mother tongue was used as a strategy to engage students. 


\section{VIETNAMESE EFL TEACHER SELF-EFFICACY IN PRACTICE}

In terms of materials for teaching, Duong made use of the textbook more than Minh did. Minh asked the students to complete most of the activities and exercises in the book. Meanwhile, Duong selected certain sections that she thought they were important and matched the students' language competence. Although they both prepared extra classroom activities, they used varied resources. Duong considered the Internet her greatest resource. Minh made copies from other books. Noticeably, both teachers mentioned that in the observed lesson, they re-used activities. The students' positive feedback and reactions indicated that they had had a successful lesson. Therefore, they used the activities again with other classes. Their mastery experience played an important role in this area.

Outside the classroom, the students were requested to do homework. Both teachers assigned the students weekly homework and had them compile it in a portfolio. The teachers regularly check the students' work and give them feedback. Duong said that she would like to "make use of the students' free time" and encourage students' independent learning. Minh expressed her responsibility when assigning homework. In her opinion, checking the students' homework implied that she was serious about it. It was not just for reference. It was a compulsory task that all students must accomplish.

To engage students, both Duong and Minh secured the students' attention throughout the lessons by walking around the room, randomly selecting students to answer questions and check comprehension. Duong showed that she made use of her strategies to manage students' behaviour. She checked the students' attendance at the beginning of the lesson. She explained that it was a compulsory task designed to force the students to attend her classes. By contrast, Minh did not check the students' attendance. She explained that attendance only accounted for $10 \%$ of the total score, which was only a small proportion. She said she was generous when giving the students' scores for their attendance. Instead, she involved the students in her lesson by giving them examples aligning with their interests. She reported that when the students felt interested, they would be engaged. Duong was more concerned than Minh about the students' confidence when using the target language in class. This is probably because the students in Duong's class were at a lower level than Minh's.

As an advantage of a class with higher proficiency, Minh's class was located in a better equipped and smaller room than Duong's class. Minh did not encounter any difficulty in 
VIETNAMESE EFL TEACHER SELF-EFFICACY IN PRACTICE

managing the class. Meanwhile, Duong had to rearrange the students' seats. She wished that the tables would be placed in a circle or U-shape so that the students could easily do group work. Because of the large number of students in her class, Duong had to modify the activities from the textbook.

Table 21 summaries the similarities and differences in the teaching practice of two teachers with highest scores of self-efficacy.

Table 21

Similarities and Differences in the Teaching Practice of Teachers with Higher Self-Efficacy

\begin{tabular}{|c|c|c|}
\hline & Minh & Duong \\
\hline \multirow[t]{5}{*}{ Similarities } & \multicolumn{2}{|c|}{ Deal with students' diverse English proficiency: } \\
\hline & - $\quad$ Organisir & Organising group work \\
\hline & \multicolumn{2}{|c|}{ Provide extra support } \\
\hline & \multirow{2}{*}{\multicolumn{2}{|c|}{$\begin{array}{l}\text { Assign outside classroom project for students } \\
\text { Secure students' attention during the lesson }\end{array}$}} \\
\hline & & \\
\hline \multirow[t]{4}{*}{ Differences } & \multicolumn{2}{|c|}{ Use of the mother tongue } \\
\hline & To engage students & To manage the class \\
\hline & \multicolumn{2}{|l|}{ Teaching materials } \\
\hline & Use of different sources & Mainly textbooks \\
\hline
\end{tabular}

\subsection{Medium Self-Efficacy Teachers}

Three teachers were purposively selected from the group of medium self-efficacy scores for the second phase of this study. These teachers reported the same score for self-efficacy for instructional strategies of 3.75 and differed slightly in the aspects of student engagement and classroom management (see Table 22). The upcoming section will describe their teaching practices.

Table 22

Overview of Teachers with Medium Self-Efficacy Scores

\begin{tabular}{lllll}
\hline & Average & Mai & Huong & Trang \\
\hline Overall self-efficacy & 3.91 & 3.85 & 4.00 & 3.93 \\
\hline $\begin{array}{l}\text { Self-efficacy for student } \\
\text { engagement }\end{array}$ & 3.98 & 3.80 & 4.10 & 4.00 \\
\hline $\begin{array}{l}\text { Self-efficacy for classroom } \\
\text { management }\end{array}$ & 3.85 & 4.00 & 4.11 & 4.00 \\
\hline $\begin{array}{l}\text { Self-efficacy for instructional } \\
\text { strategies }\end{array}$ & 3.91 & 3.75 & 3.75 & 3.75 \\
\hline
\end{tabular}




\subsubsection{Classroom Contexts and the Teachers' Reflection on Their Satisfaction with}

\section{the Teaching.}

Mai was teaching general English to a second-year class. She was using the textbook called Market Leader, which is an integrated skills book with different sections in a unit, for example, listening, reading, grammar, and vocabulary. There were 31 students in the class. The room could accommodate up to 60 students which is not the university standard language classroom. Although the room is quite big, the teacher was not equipped with any microphone. It was quite hot in the room because there were only two fans, and no air conditioner. The classroom setting was the same as other observed classes. The teacher said she was not very satisfied with the lesson, rating it as "okay".

Huong was teaching a second-year class. Similar to Mai, she was using the textbook called Market Leader. There were 31 students in the class. The room was in standard size for a language class. The classroom setting was the same as other observed classes. She said she was satisfied with the lesson.

I'm not totally happy with everything but in general, I'm satisfied because I reached some targets that I set.

Huong clarified that she focused on two main points in the lesson and after the lesson, the students could do what she expected them to do.

Trang's class was smaller than other classes I observed. There were only twenty students. The room was of standard language classroom size. The classroom setting was similar to other classes. She reported being satisfied with the lesson.

In short, the three teachers were teaching three classes which are different in terms of number of students, classroom size, and equipment. They also expressed different levels of satisfaction with their teaching practice.

\subsubsection{Classroom Management.}

This section presents strategies that the teachers used to manage their classrooms.

The students in Mai class chose their own seats. According to Mai, the students who arrived early had more choices of where to seat. Then the late comers tended to sit at the back of 
VIETNAMESE EFL TEACHER SELF-EFFICACY IN PRACTICE

the class or next to the ones they felt comfortable with. Although being in the same class, they were not close to everyone in terms of relationship.

\section{It's their habit to sit with their close friends.}

The students' seats did not have much influence on Mai's classroom management. However, Mai thought that it influenced the organisation of activities to some extent. For example, because the tables were placed in rows, when she asked her students to discuss in groups, it was hard for the students to turn back. Mai also emphasised that some tables were too crowded. Mai found it a little bit hard to control.

If I don't pay attention to every single student, I can lose some students' attention. For example, they don't do their exercises as I ask them to. They forget their books. If two or three students share a book, the effectiveness of my lesson can be decreased.

Mai did not feel very confident in managing the class because she could not pay close attention to every single student if they were squeezing in a table.

Huong's class setting was similar to Mai's. As she reported, this did not have much impact on the classroom activities but it influenced her instructional strategies. Instead of letting the students sit where they chose, Huong had to rearrange their seats for group or pair activities. She came closer to the students and spoke louder.

I have to speak louder so that everyone including those sitting at the back of the class can hear me. I have to walk closer to them. As a result, I get tired more easily than usual. From the students' side, if they sit too far from the teacher, they may lose their attention and they may not totally understand the lesson.

The classroom setting made it a little difficult to organise the activities. It was slightly stressful for the teacher.

According to Trang, the students chose their own seats. The close friends tended to sit together. However, she noticed that the students in the class were quite flexible. They often changed their seats. In classroom activities, Trang wanted the students of mixed proficiency in a 


\section{VIETNAMESE EFL TEACHER SELF-EFFICACY IN PRACTICE}

group. Therefore, sometimes she rearranged their seats. In a group discussion activity, Trang put the students in groups with the same numbers.

As you see, most students were sitting in the front rows, and some of them were at the back. The number of students in a row was not equal. Therefore, when I asked them to work in groups of four, I had to rearrange them to make it equal. I also wanted to mix the students of different proficiencies together so they could support each other. I also wanted to bring them new partners. If they always work with the same people, they will feel bored.

Trang aimed to create groups of mixed proficiency in which the more competent students could help the lower ones.

To summarise, the three teachers used similar strategies to manage the class which were re-arranging students' seats or mixing students of varied proficiency.

\subsubsection{Engaging Students.}

The three teachers with medium levels of self-efficacy employed various strategies to engage their students.

Huong paid close attention to the students' engagement during the lesson. She set the time limit very clearly for classroom activities so that the students would be more attentive and creative. To keep the discipline in the class, Huong set a rule of being on time. She checked the students' attendance at the beginning of the lesson. Being on time means that the students could join in all the activities and follow the teaching procedures.

While students were doing group work, she walked around the classroom. She explained that she would like to ensure the students' attention.

If I just sit at my desk and let the students do what they want, some of them may get distracted by other things and forget what they have to do. So I think that when I walk around the classroom and ask them questions, they feel that they are supervised. Thus, they will pay more attention.

This technique also helped Huong increase students' participation in the classroom activities. She walked around the classroom to see how her students were doing. If they were 
VIETNAMESE EFL TEACHER SELF-EFFICACY IN PRACTICE

following the teacher's instructions and they could perform the tasks accordingly, the teacher would not interfere. Nevertheless, if they were struggling or going too fast without sufficient examples and reasonable justification, Huong would offer guidance.

Huong randomly called her students to answer her questions. This not only kept the students attention but also their involvement in the activities. If they were inattentive or did not participate, they could not answer the questions and would miss some important information.

I randomly picked one student from each group. I didn't assign any student to be group representative before the discussion. I didn't let them choose the representative either. Because if they vote for someone, that student tends to have more chances to speak than the others. When I pick a student, I look at the class list and I choose the ones who I didn't call earlier. I want all of them to have an equal chance to speak to me.

Huong used this strategy to make all the students involved in her lesson. In other words, she saw each chance to speak in front of the class as a learning opportunity.

Huong considered students' interest an important element when she prepared for her lessons. She searched for videos from the Internet that she thought would draw the students' attention and gave the students practical examples.

I chose that example because that singer has a great influence on youth. He is a trendy image. The students feel more interested if I give them an example that closely connects to their life. That example helps them understand and remember the lesson more easily. So I try to connect my lesson with students' life.

In addition to giving the students equal chances of learning in class, Mai secured their attention and participation in the classroom activities by walking around the room when they were discussing.

When I walked around, the students felt that they were supervised. As a result, they would be more focused.

While walking around, Mai identified whether any students needed support. She said that if she did not show up at their table, they did not dare to ask in front of the class. The students 
VIETNAMESE EFL TEACHER SELF-EFFICACY IN PRACTICE

preferred individual help. Mai also corrected their mistakes or facilitated their discussion. As a result, the quality of the group discussion activity was improved.

According to Mai, her students were eager to learn from other resources than the textbook. They preferred practical issues to academic issues. Consequently, she connected her lesson to the real world by giving them a concrete example. She gave them an example of Ebay.

That is a very typical example in the world but it is not very popular in Vietnam. Not many of the students know about it. I gave them that example to get them closer to what's there in the world. I mean keeping them updated with global trends. It is also a practical example. So I would like my students to learn not only from the books but also from the real world.

The students' interests influenced Mai's instructional strategies.

At the beginning of the lesson, Trang checked the students' attendance. She aimed to ensure that all the students were on time. She explained that latecomers could distract other students and influence her teaching. As mentioned earlier, the observed class had small number of students, so Trang could easily tell whether a student attended her lesson. Sometimes, she called their names from the class list to answer her questions. If the student did not show up, their attendance score would be subtracted.

I can also tell who's absent by looking at their regular seats or their close friends. Sometimes, I call them to answer my questions during the lesson. If they are called, and they don't show up, I know that they play truant.

Checking students' attendance was used as a way to ensure that the students attend the lessons.

To get the students involved in the lessons, Trang flexibly organised classroom activities for individual people, in pairs or in groups. She liked to create a fun learning environment. In a word game, the teacher asked her students to unscramble a list of words taken from the textbook. Instead of letting them do it by themselves, she put them in groups.

This game was quite easy. It's boring if they play individually. But if they play in group, it is much more fun. 


\section{VIETNAMESE EFL TEACHER SELF-EFFICACY IN PRACTICE}

In addition, she also considered their interests and other age-related psychological issues. She said that had to select the questions for discussion that suit her students' proficiency, interests and age. As most of the students were around nineteen years old, she thought that the students usually like something that could be considered shocking. Therefore, she used a ghost video as a warm-up activity.

Because the topic of today's lesson is "fear", the video relates to that topic. I used it as a warm-up activity. It is short, shocking, and requires no followup activity.

Involving students in the teaching process was another strategy of student engagement. When checking the students' work, instead of giving direct answers, the teacher asked them to check with their friends.

All of them have to work together. They talked to their partners, discussed their answers and found the explanations.

While the students were discussing or doing the assigned tasks, the teacher walked around the room.

I would like to check the students' participation in the activity, whether they were doing what I asked them to do or they were doing something else.

Trang employed that strategy to ensure that all the students were engaging in the classroom activities. Moreover, she tried to guarantee that all the students had the equal opportunity to participate.

To encourage the students to join in a classroom game, Trang put the students in groups then they competed with each other. She gave the winners bonus points to make them feel more excited and eager.

To recap, different strategies were used to engage students. Huong set time limit for class activities. All of the three teachers in this group, Trang, Huong and Mai secured students' attention and participation by walking around and checking on students' activities, purposively selected students to answer teacher's questions, and cared about students' interests. Trang 
VIETNAMESE EFL TEACHER SELF-EFFICACY IN PRACTICE

attempted to create equal learning opportunities for her students with fun and relaxing games and activities.

\subsubsection{Instructional Strategies.}

\subsubsection{Dealing with Students' Different Levels of Proficiency.}

During her teaching, Mai had autonomy in choosing the language to use. Unlike some teachers who switched to Vietnamese sometimes to draw students' attention or to secure students' comprehension, Mai spoke English all the times in the observed class.

I speak English in this class because I expect them to understand spoken English. Even if they are not able to speak English well, they will be forced to listen to spoken English, which gives them some input in English. Moreover, I intentionally spoke very clear and simple English, so I suppose they will more or less understand what I was saying.

Instead of direct translation from English into Vietnamese, Mai repeated slowly and clearly in English. She also paraphrased her sayings with simple vocabulary.

Mai had different strategies when selecting students to answer her questions. Sometimes, she chose volunteers from some groups to present. Sometimes she called students from the list or randomly assigned someone.

I give the top priority to the volunteers. They are usually better students in the class. Sometimes, even if I don't call them, they still speak out. It's like a chance for them to show their abilities. The other students are usually less able learners. They may know the answers but they are too shy. They tend to push other people to talk although they all discuss in their group. In that case, I pick one student who hasn't had as many chances to talk as the other group members.

Mai tried to create equal chances for her students to learn. With more difficult questions, she tended to pick more advanced students. With simpler questions, she would give lower level students opportunities to practise.

When doing group discussion, some students spoke Vietnamese. In Mai's opinion, this was not a serious problem. 
VIETNAMESE EFL TEACHER SELF-EFFICACY IN PRACTICE

Whether speaking Vietnamese in an English class is a problem or not really depends on the teacher's expectation of each class. With this class, because the students have different proficiency levels, I just expect them to say something, either in Vietnamese or English. Then when I call students from other groups to present, they can listen to English. So at least the students cooperate in the classroom activities and can learn something. But if the students make use of Vietnamese, I mean if they can speak English but they don't, then it's a problem.

Mai considered the students' engagement in the activity more important than the language they were using. She respected the students' autonomy in using the mother tongue. She paid more attention to their output.

Huong thoroughly considered the students' language competence. She chose the resources outside the textbook in accordance with the students' proficiency. Although Huong was teaching some classes using the same textbook, she did not apply the same plan. She made changes across classes based on the students' levels.

For example, in my lesson today, I showed them a video called "Where do good ideas come from?". But I don't show it to every class. I only show it to classes with higher proficiency, and I skip this activity with lower classes.

The students' proficiency also impacted the teacher's use of the mother tongue. With lower level classes, when teaching new words, Huong translated directly from English into Vietnamese. However, with higher level classes, she explained or paraphrased the terms in English. She demonstrated how to express the same thing in different ways and helped the students learn the context to use the new words. Huong was not very concerned about the students' use of Vietnamese in the class. She was not worried about which language they used when discussing an abstract topic.

It's unavoidable that they speak Vietnamese sometimes to convey their ideas. I care more about the results. As long as they can present their discussion in English, which language they use to discuss is not a matter of concern.

In Huong's point of view, whichever language the students used to discuss was not a serious problem, as she cared more about what they generated after the discussion. 
VIETNAMESE EFL TEACHER SELF-EFFICACY IN PRACTICE

Thanks to the small number of students in her class, Trang knew her students' level of proficiency quite well. Many times in the interview, Trang mentioned how the students' proficiency influenced her teaching. For example, when searching the Internet for the warm-up activity, she found many videos relating to the topic of the lessons. She made the selection according to her perception of the students' language competence.

There are many suggestions on the Internet. I had to select the ones that suit my student's proficiency, interest and age.

When she designed supplementary activities, she gave thorough consideration to students' proficiency. Although repeating the same word-matching activity with several classes, the teacher had to adapt it to meet the students' language competence.

If the students' proficiency was quite low, they couldn't understand the questions, and they would easily become a demotivated. So I carefully chose the reading passages and designed suitable questions.

The word "carefully" suggests that the students' proficiency played an important role in the teacher's decision. She had to consider it thoroughly before selecting the reading passage and designing the activity.

The students' proficiency also influenced the teacher's selection of students to answer her questions in class. Trang tried to provide equal chances to speak to all her students. However, with more difficult questions, she reported that she often called more proficient students. Less proficient students were usually asked simpler questions.

Most of the time in Trang's class, she spoke English. However, when teaching vocabulary, after explaining new words in English, she translated them into Vietnamese or asked the students for the Vietnamese equivalents. She explained that she aimed to reinforce the students' comprehension of the new terms.

With the higher level classes, I just explain in English. But with lower level classes, I have to explain in English then give the Vietnamese equivalents. If I don't translate into Vietnamese, the students don't really understand the terms. 
VIETNAMESE EFL TEACHER SELF-EFFICACY IN PRACTICE

Trang's perception of the students' proficiency influenced her selection of materials, language used and the selection of students in the class. Moreover, it also impacted the teachers' organisation of the classroom activities which will be demonstrated in the following section.

In summary, to accommodate students' diverse language competence, Trang and Huong sometimes used Vietnamese while Mai consistently used English but with simple language and slow speed when necessary. They designed and selected activities to match students' proficiency. Moreover, they all considered students' use of the mother tongue in class as normal in foreign language classes.

\subsubsection{Giving Feedback and Assessing Students.}

The way the teachers with medium scores of self-efficacy assess and give feedback to their students differed greatly.

In Mai's class, she not only checked the students' attendance but also valued their participation in the class.

Their participation is used to mark their attendance. Because in my class, attendance does not just mean presence. It also refers to the students' involvement in classroom activity.

In Mai's opinion, valuing the students' participation would encourage them to join in the classroom activities. The students would be more responsible for their engagement and their learning attitude will be more positive. Moreover, it helped Mai to know her students better which later decided the students' final score.

You know, some of them are doing very well in class. But for some reasons, they do not do well in the tests. I will consider their participation to add some bonus points to their final score.

Mai was the one to decide on her students' scores. Although the faculty asked the teachers to mark their students' attendance, Mai did not just check their presence in her classes but also their participation in her lessons.

Mai gave her students' feedback on what skills they were working on. 


\section{VIETNAMESE EFL TEACHER SELF-EFFICACY IN PRACTICE}

This is an integrated skills class. It depends on what skill the students are working on. For example, in that speaking activity, I commented on two main areas. First, I give them feedback on the ideas or content of their answer. I explain to them whether they have answered the question or not. Second, I commented on the language aspects. For instance, I let them know if their word choice was suitable or not; the sentence structure was grammatically correct or not; the pronunciation was good or not.

There were no fixed criteria for the teachers to give feedback to their students. Mai focused on two main areas of ideas and language issues.

Trang reported having high autonomy in assessing students. The students had three subscores of attendance, mid-term test, and final exam. The teachers had no control over the final exam because it was computer-based. The students do the test on the computer and the system automatically generates their scores. However, the teachers had autonomy to design the mid-term test. Instead of giving the students one mid-term achievement test, Trang gave her students several progress tests then took the average of the scores.

I can ask my students to do several tests during the term and take the average score. I can ask my students to write different types of essays to make the mid-term writing score. I designed my own tests, had my own assessment criteria, set my own time. The faculty does not really encourage the teachers to do that. However, they do not ban it. It's quite flexible.

She gave the students' feedback on aspects including speaking skills like pronunciation, organisation of ideas, and participation in group work.

Similar to Trang, Huong had high levels of autonomy in assessing students and giving feedback. Huong encouraged her students' participation by giving bonus points for their attendance or mid-term test. She may add some points to their total scores if they frequently and effectively joined in classroom activities. Huong had autonomy in giving feedback to her students. Because there was no common scheme or criteria given by the faculty, Huong used the marking criteria of some standardised tests to give feedback.

For example, with speaking activities, I use the criteria of the IELTS speaking test to give feedback. I comment on their pronunciation, fluency, 
VIETNAMESE EFL TEACHER SELF-EFFICACY IN PRACTICE

grammar, and vocabulary. With reading activities, I focus more on their

comprehension. In general, I use the marking criteria of the standardised tests to give feedback.

This section has shown significant differences in the ways the teachers assessed and commented on their students' work. Such divergence reflects differences in the teacher enactment of their autonomy.

\subsubsection{Materials for Teaching.}

Mai, Huong, and Trang used various sources of materials for their teaching.

When observing Mai's class, I saw that most of her exercises and activities were taken from the textbook.

The faculty encourages us to make full use of the textbook. It is like the spine for all teachers to stick to. The managers have to work hard and make careful choice of the textbooks which are suitable for the students and the university context. We have been using the book for a couple of years and we see that it matches our students' needs and demands as well as the university's policies. So my top priority goes to the textbook. Only if the students feel that their proficiency is much higher than the level of the textbook or we have much time left in a lesson, I will search for other resources.

Mai made use of the textbook because from her teaching experience, she found it suitable for her students and the university. She highly appreciated her managers' choice of the textbook.

Unlike Mai, who made used of the exercises and activities from the textbook, Huong and Trang used other resources. Huong, for example adapted an activity from the Internet and she had used it many times with other classes.

I have done this many times in other classes but with little modification for different classes. As I observed, the students' feedback about the activity is quite positive. They said they felt motivated, more inspired. And as a former student, I feel that knowledge taught through an audio-visual way is more memorable. 


\section{VIETNAMESE EFL TEACHER SELF-EFFICACY IN PRACTICE}

Conducting the same activities with different classes and having positive feedback from students made Huong more confident. Therefore, she continued doing it with other classes.

In addition to working experiences, Huong's learning experiences contributed greatly to her teaching. For example, she showed her students a video clip that her teachers had previously showed her.

I got it from a class I attended earlier. It's called Business Strategies. My teacher showed us this video. I found it very interesting and motivating. When I planned for my lesson today, I saw that I could match the video with my lesson.

She used a bell to draw the students' attention.

I learnt it from a class sponsored by the 2020 project. I was very impressed when my teacher used the bell. I thought I could use it in my classes. And in fact, it works effectively in my classes. The students know when they should listen up.

Huong's learning experiences influenced her instructional strategies and classroom management.

The materials the teachers used for their classes included the textbook and activities they learnt from the Internet or in-service training courses. The selection of the materials depended on the teachers' perceptions of the appropriateness for their students.

\subsubsection{Comparison of Three Teachers' Teaching Practices}

Comparing the three components of teacher self-efficacy, it is noticeable that the three teachers reported to be at the same level of self-efficacy in instructional strategies (3.75). Huong showed the highest efficacy in student engagement and classroom management. In general, all three teachers felt happy about their teaching.

The teachers shared some common teaching techniques and strategies to manage the classroom and students' proficiency levels and engagement. Mai and Huong valued students' participation in the classroom activities and added bonus points accordingly to their partial and total scores. Trang used accumulative tests instead of only one mid-term test. This shows that the teachers had much freedom in assessing their students. The teachers were quite varied in their 


\section{VIETNAMESE EFL TEACHER SELF-EFFICACY IN PRACTICE}

assessment criteria. For speaking activities in class, Mai gave feedback on ideas and some language issues. Huong used the standardised tests assessment criteria to make judgement. Trang commented on general speaking skills such as pronunciation, fluency, and grammar.

To deal with students' varied language competence, all the teachers let the students use Vietnamese in class. However, only Huong and Trang spoke Vietnamese when teaching. They aimed to reinforce the students' comprehension. Mai spoke English throughout the lesson using simple sentence structures and popular vocabulary. Mai and Trang employed the same strategy of selecting students to answer their questions. The more difficult questions would be answered by more competent students and vice versa. The students' proficiency influenced the teachers' selection of teaching materials. Mai thought that the textbook was suitable for the students, therefore, she made use of it. By contrast, Huong and Trang used the Internet to find supplementary documents or ideas for their classroom activities. Interestingly, Trang used the reading passage to design the activities. She showed a high level of self-efficacy in instructional strategies.

The teachers applied similar strategies to engage students in the lessons. Their lessons were designed to meet the students' interests. Mai emphasised that she would like to connect her lessons to the use of language in real life. They all checked the students' attendance at the beginning of the lesson. While the students were doing group or pair work, the teachers walked around the room and provided support to those students who were struggling. It is significant that Trang asked the students to do peer-correction. As can be seen, Trang was very flexible with the strategies she used to engage her students.

In summary, the teachers applied rather similar strategies in their teaching practices.

Table 23 summarises these similarities.

Table 23

Similarities and Differences in the Teaching Practice of Teachers with Medium Scores of SelfEfficacy

\begin{tabular}{lcl}
\hline & Huong & \multicolumn{1}{c}{ Mai } \\
\hline Similarities & - & Re-arranged students' seats \\
& - & Mixed students of varied proficiency \\
& - & Matched the lesson with the students' interest \\
& - & Checked on students' attendance \\
\hline
\end{tabular}




\begin{tabular}{|c|c|c|c|c|}
\hline & - & \multicolumn{3}{|c|}{ Secured students' attention } \\
\hline & - & \multicolumn{3}{|c|}{ Allowed students to use Vietnamese in class } \\
\hline & - & \multicolumn{3}{|c|}{ Valued students' participation in classroom activities } \\
\hline & - & \multicolumn{3}{|c|}{ Sometimes used Vietnamese } \\
\hline & - & \multicolumn{3}{|c|}{ Walked around and checking on students' activities } \\
\hline & - & \multicolumn{3}{|c|}{ Purposively selected students to answer teacher's questions } \\
\hline \multirow[t]{3}{*}{ Differences } & \multicolumn{3}{|c|}{$\begin{array}{l}\text { Set time limit for class } \\
\text { activities }\end{array}$} & $\begin{array}{l}\text { Used fun and } \\
\text { relaxing games and } \\
\text { activities }\end{array}$ \\
\hline & \multicolumn{2}{|c|}{$\begin{array}{l}\text { Used the standardised tests } \\
\text { assessment criteria }\end{array}$} & $\begin{array}{l}\text { Gave feedback on } \\
\text { ideas and some } \\
\text { language issues }\end{array}$ & $\begin{array}{l}\text { Commented on } \\
\text { pronunciation, } \\
\text { fluency, and } \\
\text { grammar. }\end{array}$ \\
\hline & \multicolumn{2}{|c|}{$\begin{array}{l}\text { Used outside-textbook } \\
\text { materials }\end{array}$} & $\begin{array}{l}\text { Mainly used the } \\
\text { textbook }\end{array}$ & $\begin{array}{l}\text { Used outside- } \\
\text { textbook materials }\end{array}$ \\
\hline
\end{tabular}

\subsection{Lower Self-Efficacy Teachers.}

Among the teachers in the lowest scores group, three were chosen for interviews and observations. These teachers reported having different level of self-efficacy across three aspects (see Table 24).

Table 24

Self-Efficacy Profiles of Teachers with Lower Scores

\begin{tabular}{llll}
\hline & Quynh & Huyen & Linh \\
\hline Overall self-efficacy & 3.48 & 3.74 & 3.41 \\
\hline Self-efficacy for student engagement & 3.60 & 3.70 & 3.40 \\
\hline Self-efficacy for classroom management & 3.53 & 3.67 & 3.22 \\
\hline Self-efficacy for instructional strategies & 3.30 & 3.88 & 3.63 \\
\hline
\end{tabular}

\subsubsection{Classroom Contexts and the Teachers' Reflection on Their Satisfaction with}

\section{the Teaching.}

Linh was observed in a first-year class. The students were at elementary level in English language proficiency and they were studying in their first term at university. There were 39 students in the class. The tables were placed in rows and divided in two blocks with an aisle in the middle. According to Linh, the students chose their own seats. 
VIETNAMESE EFL TEACHER SELF-EFFICACY IN PRACTICE

I think whoever comes earlier sits in the front rows and the latecomers sit at the back.

Reflecting on the lesson, Linh expressed her dissatisfaction.

It's not as effective as I expected. The activities did not go very smoothly.

Linh's expressions show that she was not happy with her teaching that day. She explained that the students were probably still shy because they were freshmen. Everything was new to them. Moreover, they had only had two lessons previously with this teacher. Linh reported that they did not understand her instructions very well. She compared the class with some others.

I organised the same activities with other classes which I had been teaching for around six weeks. The students were very excited. I think they know each other and know me better than the students in this class. They felt more confident and comfortable.

Even though Linh felt she was successful with other classes and she used the same activities with this class, she did not feel satisfied.

During her teaching, Linh carefully considered the students' characteristics such as the student - teacher relationship, student engagement, and students' level of English proficiency.

Huyen was observed in one of her second-year classes. The students were studying general Business English in their third term. They were using the textbook called "Market Leader". There were 37 students in the class. Similar to Linh's class, Huyen's students chose their own seats.

Huyen expressed high level of confidence in her teaching of the class. She thought that her students understood what she taught them. They acquired some knowledge. She was happy with her teaching and she did not think of anything that she wished to change about the lesson.

At the moment, I don't want to change anything because what I did is suitable for my students. It matches with the students' proficiency.

Huyen was very confident that her teaching met the students' needs.

Quynh was teaching business correspondence. In a semester, she conducted 20 lessons. Each lesson lasted for 150 minutes. She was using the "Oxford Handbook of Commercial 


\section{VIETNAMESE EFL TEACHER SELF-EFFICACY IN PRACTICE}

Correspondence" (Ashley, 2003) as a main textbook. The students were assessed using a midterm test and a final examination. They were both paper based. The teachers designed the midterm test for their own classes. The final examination material was selected by the subject manager who selected questions from the test bank. In the test, the students wrote a letter and translated three short paragraphs from Vietnamese into English.

Quynh was not happy about the lesson I observed.

I was not happy because the students did not do the exercises before they came to class. It took so much time in class for them to finish the exercises. I think I should be stricter with them.

Quynh had assigned homework for the students to do before the class. She planned ato check their answers during the lesson to save time. However, the students hadn't done the homework. Quynh had to give them time to finish.

To recap, Quynh was teaching a class with a much larger number of students than Huyen and Linh. Huyen expressed her satisfaction with her teaching in the class I observed while the other two teachers did not. The upcoming sections present similarities and differences in the teaching practice of these teachers across three domains of teacher self-efficacy (classroom management, student engagement, and instructional strategies).

\subsubsection{Classroom Management.}

To manage their classes, Linh and Huyen applied similar strategies while Quynh used a different one.

I was sitting at the back of Linh's class and taking notes during the observation. Sometimes, I could not hear the teacher. When a student stood up and answered the teacher's question, I hardly heard anything. Linh agreed with me that the students may have had the same problem. The main reason was the classroom size. Linh said it was too big for a language class. Further, there was no microphone for the teacher. The room was on the first floor. Linh observed that sometimes the students were distracted by the outside noise. As a result, Linh was afraid that her lessons would not be effective.

The size of this classroom is too big. It's double the size of other rooms. It's on the first floor. Sometimes the students are influenced by the outside noise like the motorbike noise, people 
VIETNAMESE EFL TEACHER SELF-EFFICACY IN PRACTICE

talking, or music from the aerobic and dancing classes. They may not hear me very clearly and lose their attention. The activities I give them may not be as effective as I expect.

The students in Linh's class chose their own seats when they arrived at the class. They were sitting in rows. To make them sit more comfortably when discussing in groups, Linh rearranged them.

\section{I asked them to move to make them more active.}

Linh explained that sitting in the same place for nearly three hours made some students sleepy. Moreover, from her experience, Linh understood that working with the same partners for a long time made students feel bored and demotivated. Knowing their partners so well, the students tended to assign one student to be their representative who would answer the teacher's questions or present for the whole group. Therefore, Linh would frequently change their seats.

Changing their seats means changing their partners.

As Linh clarified, changing students' seating positions had a positive influence on the effectiveness of group work.

Huyen also managed her large class by organising group work to save time. She believed that group work created equal learning opportunities for her students. After doing a group discussion activity, Huyen called some students to speak up.

I could only call some students, not all groups because I didn't have enough time. There are 39 students in this class. It's impossible to call them all. So I just pick representatives.

She did not assign who she would call prior to the discussion so all the students had to participate.

When asked about the classroom setting, Quynh reported that it was her biggest constraint.

It's the biggest constraint to my teaching, to be honest. It's very hard.

The classroom itself was big in size. It could accommodate 150 students. In the class I observed there were 123 students. Quynh just mentioned her difficulties when managing so 


\section{VIETNAMESE EFL TEACHER SELF-EFFICACY IN PRACTICE}

many students in such a big room. She was reluctant to say anything further about her management.

Although Quynh tried to involve all the students in her lesson, some of them were observed doing other things rather than learning, such as reading comics, talking to each other, and using Facebook. She said that she could not control them all. She considered the class size a constraint to her teaching.

You know, this class is very big. It's very hard to control them all. I kept reminding and warning them during the course that you have to listen and take notes of the lectures, you have to practise at home. That's the best I can do. Their involvement and participation depend on their perception of the subject, their motivation, and their learning style.

Although Quynh used a range of different strategies to engage her students, she recognised that student engagement also depended on some issues which were outside her control as a teacher.

In short, both Linh and Huyen rearranged the students' seats during their lessons so that all of them could be involved in classroom activities and be attentive. Due to the large number of students in her class, Quynh numbered her students so she could call on them to answer questions.

\subsubsection{Engaging Students.}

Linh was concerned about the students' participation in the classroom activities. She secured the students' attention by asking one student to repeat what another student had said. She said that she would like all the students to listen when someone else was talking. This technique also allowed her to check the students' comprehension of her questions as well as their understanding of what their friends had said.

When the students were discussing in groups, Linh walked purposefully around the classroom. She thought that the students would feel "scared" and follow her instructions. She wanted to ensure that all the students were working. She would give them support when they needed it. While walking, she collected interesting and useful language items that the students were using. She gave them feedback. She thought that the students learned from both correct and incorrect answers. 
VIETNAMESE EFL TEACHER SELF-EFFICACY IN PRACTICE

Usually, I walk around to collect useful language or expressions that the students use then show them to the whole class. I compliment them if they make good use of the language. Otherwise, I correct them.

To enhance students' participation in the classroom activities, Linh was flexible about which language was used, English or Vietnamese. When giving instructions, she sometimes spoke Vietnamese to ensure that all the students understood her. She called the students from the class list to answer her questions, not only to get to know their faces but also to make sure that all of them participated and all of them had an equal chance to speak in the class.

Linh placed particular emphasis on building a good relationship between her and the students, mentioning it three times in the interview because these first-year students had not got used to the new learning environment yet and they were developing new friends and getting used to new teachers. The methods of teaching and testing were different from their high schools. Previously, in high school, the dominant teaching method was grammar-translation. The teaching was exam oriented. The students did multiple choice tests. Now, they were being taught with a communicative approach with more interactive activities. They would have speaking and listening tests in addition to reading and writing ones. It took some time for them to be familiar with their new way of learning. Consequently, for the first few lessons, the students tended to be reserved. They did not excitedly participate in the classroom activities. Linh thought that if the students had known her for longer time, they would have performed better.

\section{Maybe after a couple of more lessons, they will become more active and confident.}

To build good relationships with the students, she showed a smiley friendly face most of the time. She explained that this would make the students feel relaxed and motivated. As a result, they would become more involved in the classroom activities. Linh did not know any students in the class prior to the lesson. She had a list of their names and she randomly called some students from the list to answer her questions. She said that she would like to remember them by name and to build up a relationship with them step by step.

To check the students' attendance, Huyen called their names from a class list and they responded. She could do it at any time during her lessons, either at the beginning, in the middle or at the end of the lesson. Sometimes, she called the students to show her their homework. She 


\section{VIETNAMESE EFL TEACHER SELF-EFFICACY IN PRACTICE}

could check the homework and attendance at the same time. Huyen was very inventive in checking the students' attendance, using different and unpredictable ways. To secure the students' attention, Huyen asked all of them to do the same task and then she randomly called some of them to answer her questions. She would remind them to keep quiet and be attentive when they made too much noise.

To enhance the students' participation in the classroom activities, Huyen walked around to check what they were doing and how they were doing. If they had any problems, she would support them. Also, she would like to make sure that all the students were following her instructions.

I walked around to check what they were doing and how they were doing. If they have any problem, I will support them. Also, I would like to make sure that all the students are doing what I ask them to do. For example, if they are discussing in Vietnamese, I will ask them to use English.

Huyen allowed the students to choose their own seats so that they felt the most comfortable. She explained that if she treated them as in their high schools where teachers allocate their seats, she would be wasting her time. She said she could manage the class wherever the students sat. However, in terms of instructional strategies, the setting had some influences. When using group work, Huyen had to rearrange the students' seats.

It just has a little impact on the organisation of classroom activities. Because close friends tend to sit together, they seem to have the same partners in groups. Therefore, I have to rearrange their seats to mix them up.

Being with different partners for different activities made the students feel fresh. As a result, they would get involved more in the activities. Huyen said this grouping method could build students' team work skills and improve the students' relationships. Furthermore, changing the students' seats was a technique to focus the students' attention on the tasks.

Those students who choose to sit at the back of the class are usually less attentive than the others. So, sometimes I ask them to change their seats to draw their attention. 
VIETNAMESE EFL TEACHER SELF-EFFICACY IN PRACTICE

The students would be influenced by their peers to do the group work. Moreover, they would feel they were being supervised by their teacher. As a result, they would follow the teacher's instructions and join in the activities.

Huyen was concerned about the students' comprehension. In the listening activity, she played the recording twice. In her opinion, the students were unlikely to get the right answers after the first listen so she let them listen and find the answer by themselves first. Then she played the recording again slowly, sentence by sentence so that the students could clearly understand the recording. For more practice, she sent them the recording and asked them to listen again at home.

I tried to help them understand the recording in class. But if they still don't understand, I advise them to listen more at home. I email them the audio files.

In the reading activity, she asked them to summarise the reading passage. Her purposes were to help the students remember what they had read and learn new vocabulary. She often asked them to make a summary map or fill in the gaps.

Summarising the passage helps the students remember what they have read. First, they read the passage several times to get the main points, collect the information then put them together. It also helps students learn vocabulary. I can ask them to make a summary map or fill in the gaps.

Huyen had a range of strategies to improve the students' comprehension of receptive language.

Quynh usually checked the students' attendance at the beginning of the lesson. Sometimes she did it at the end of the lesson. She checked their attendance to ensure that they were following the attendance requirements which enabled them to take the final examination.

It's a rule that they have to go to class. They have to attend at least $80 \%$ of the total course. Otherwise they are not allowed to take the final exam. I check their attendance to make sure that they go to the class and to see who is qualified for the final exam.

Because there were so many students in the class, Quynh gave each of them a number. Instead of calling them by their names, she called them by numbers. She explained that doing so 
VIETNAMESE EFL TEACHER SELF-EFFICACY IN PRACTICE

helped save time. Calling the students by numbers suggests that the teacher did not know the students individually.

In Quynh's opinion, students' participation in classroom activities was important. She used different strategies to enhance their involvement. When checking the students' homework, she asked them to do peer-correction.

They can learn from their friends. They help each other to identify which answer is wrong or right. I think that they still can learn from their friends' mistakes. I give them the assessment criteria. They base their judgement on that.

This activity helped the teacher check which students had done the required homework and how they did it.

While the students were writing, the teacher walked around the classroom. She explained that she would like to check what and how they were doing. Moreover, when being supervised, she believed that the students were more attentive and responsible.

Quynh tried to maximise the students' comprehension of her lessons. She randomly selected one student to write her answer on the board. She intentionally chose students who did not seem to be prepared. This seemed to make the students alert, and Quynh explained that she liked to check the students' knowledge.

"I randomly called one student from my class list. I called when she was not prepared. Then I know what she has got in her mind like her vocabulary, her writing style. If I let her prepare and write on the board, she may look at the book for templates or search for samples or copy from her friends."

To sum up, the teachers with lower scores of self-efficacy engaged their students in classroom activities in different ways. As the class was new to Linh, she tried to build a good relationship with her students. In contrast, because of the large number of students, Quynh encouraged students' autonomy in doing and checking each other's homework. In addition, the three teachers shared some similar strategies such as checking students' attendance and securing students' attention and participation in group work. 
VIETNAMESE EFL TEACHER SELF-EFFICACY IN PRACTICE

\subsubsection{Instructional Strategies.}

\subsubsection{Dealing with Students' Different Levels of Proficiency.}

The students in the observed classes were reported to be diverse in their proficiency. To deal with the problem, Linh, Huyen, and Quynh used some common strategies.

According to Linh, most of the students in her class were at elementary level in their English language proficiency. More importantly, they were new to each other. Therefore, Linh considered the students' use of Vietnamese in class to be perfectly normal.

With this class, I don't think it's a good idea to force them to speak English all the time. Everything is too new for them. I just encouraged them. If I force them, they will feel less confident. They may not join in the pair or group work.

In general, Linh encouraged her students to speak English in class. She gave them a "bonus point" if they used English in classroom activities.

Linh added that the students' proficiency varied greatly within the class. However, she could not tell the level of each student. She hoped to find out after a few lessons. Once she had some knowledge of the proficiency levels of the students, she would arrange groups of students with varying levels of proficiency.

I will put them in reasonably small group to help them feel confident and comfortable.

Linh's strategy to deal with the students' proficiency was to enhance their confidence in using English.

Huyen was usually assigned to teach two or three classes using the same textbook. Because of this, she would prepare the same lesson plans for all the classes. However, depending on students' proficiency, she would make some adjustments to each lesson.

If I teach two or three classes in a semester using the same textbook, I use similar activities to save my time spent on preparing the lessons. I make modifications according to students' proficiency.

She clarified that with better classes, she would ask them to perform more difficult tasks which require a wider range of vocabulary ore more critical thinking, for example. With lower 
VIETNAMESE EFL TEACHER SELF-EFFICACY IN PRACTICE

classes, she would provide them with more clues. Within a class, she designed various activities; some could be more challenging and some were easier.

Huyen's opinion was that students should not speak English all the time. She felt that they needed to speak Vietnamese sometimes because their English language competence was limited.

It's unavoidable that the students may speak Vietnamese sometimes because their language competence is not good enough. It's forgivable if they speak Vietnamese sometimes. But I don't encourage them to use it frequently. If I see them discussing in Vietnamese, I will ask them to switch to English. I may provide them new words or expressions to help them convey their thoughts when they have difficulties.

Huyen tried to make her students speak English most of the time in the class. She sometimes spoke Vietnamese.

Because this subject is quite hard for the students, it's easier for them to understand in Vietnamese. Moreover, it's also easier for me to convey the knowledge in Vietnamese."

Quynh also spoke Vietnamese in class. In the last two years at university, the students learnt English for specific purposes. Unlike in the first two years when the students were classified according to their proficiency, third- and fourth-year students were mixed together. Despite the students' different levels of English proficiency, they had to learn the same material and concepts. As Quynh explained, if she used English all the time, not all students could comprehend her lesson. Moreover, speaking Vietnamese made her feel more confident when teaching.

Quynh did not worry about the students' use of the mother tongue.

No matter what language they use to discuss, I'm happy as long as they can write a letter in English.

When discussing, Quynh allowed the students to speak Vietnamese. In her opinion, using the mother tongue helped the students generate more ideas and share with their friends more easily. Only the language used in their writing was worthy of concern. 


\section{VIETNAMESE EFL TEACHER SELF-EFFICACY IN PRACTICE}

To recap, the three teachers acknowledged the differences in students' language competence. They addressed the problem by letting the students use Vietnamese in the class. They also sometimes used Vietnamese during their teaching. Classroom activities were designed according to students' proficiency.

\subsubsection{Giving Feedback and Assessing Students.}

Quynh and Huyen gave feedback and assessed their students' work using different criteria.

Like the students in the other participants' classes, the students in Quynh's class had to do a mid-term test designed by the teacher and a final exam designed by the subject manager. In addition, Quynh assigned her students a portfolio.

At the end of the term, I collect the students' portfolio which comprises their homework and the notes on the lessons. When I mark the portfolio, I know whether they took notes or not, what they learnt, how they did their homework. I collect the portfolios one week before the end of the term and return them to the students in the last week so that they have documents to review for the exam. Whoever gets an A will get 1 bonus point added to the mid-term test and 0.5 for a $B$.

The portfolio was used not only to check the students' learning to assess their achievement, but it also helped to engage the students more in the lessons.

Quynh used criteria to assess the students' writing.

First, I look at the overall structure of the writing. Then I look into details of each section to see whether they included the required sections or not. Next, I comment on grammar, spelling, and vocabulary.

Quynh said that she employed the same criteria with all students to create consistency in her assessment.

Huyen corrected her students' pronunciation immediately during speaking. She explained that if she waited until they finished, they may forget what they had said. A few years previously, there were separate sessions for pronunciation in the curriculum. However, these had been stopped now. Consequently, she tried to correct the students' pronunciation whenever she could. In addition, she usually commented on the content of the students' answers. 
VIETNAMESE EFL TEACHER SELF-EFFICACY IN PRACTICE

I usually comment on the content of their answers rather than grammar issues or vocabulary. Because my class is not a grammar class, I will not spend too much time on such issues.

It was the second time that Linh had taught the class, so she did not spend much time correcting students' mistakes. Instead, she encouraged her students to participate in classroom activities.

To summarise, the teachers in the lower self-efficacy group gave feedback and assessed their students' work in different ways, depending on the language skill they were teaching.

\subsubsection{Materials for Teaching.}

While Huyen and Quynh made use of the textbook for their teaching, Linh used a lot of activities from outside of the textbook.

As Linh said in the pre-observation interview, she had considerable freedom in her teaching. She prepared some extra activities outside the textbook. Linh considered the lesson I observed an ice-breaking session. Therefore, the activities were designed to be fun, easy, and not time consuming. To warm up, Linh conducted a word game. She learnt it from a teacher with whom she worked as a teacher assistant when she was a student.

When I was a student, I worked part time as a research assistant for British Council. A teacher used it as an ice-breaker activity. It's something fun before he actually started his lesson. He used it four times in the course of twenty lessons. It was very exciting. We had lots of fun.

Work experience, in this case, was the source of an idea for the teacher. In another situation, as a lead-in to the lesson, she employed an activity that she learnt from the Internet and had had success with over several semesters. She exclaimed that the students in other classes were very excited and eager to join in. However, the activity was not successful in the observed class.

This activity was not as successful as I expected.

Linh explained the reasons as she saw them. Maybe the students did not understand her because she was giving instructions in English. She was probably speaking too fast, or perhaps 
VIETNAMESE EFL TEACHER SELF-EFFICACY IN PRACTICE

the students were too shy to participate. Instead of giving up the activity, Linh quickly adjusted it.

At first, I thought I would ask them not to write their names but a few sentences about themselves. Their classmates would read their writing and guess who they were. However, if I had conducted the activity that way, there would be no interaction, no speaking activity. Then, I asked them to write their names. The students would come to the student with that name, greet each other and ask some questions. In this case, it would be easier for them to work in pairs than standing in front of the whole class and presenting.

Linh was able to adapt activities and remain calm and confident in different situations.

Linh was also flexible with the language she used in the class. In other classes, instead of direct translation from English into Vietnamese when the students did not understand, she would explain again slowly or paraphrase her expressions. However, in the class I observed, although she intended to speak English most of the time, she switched to Vietnamese when she realised that the students did not understand her instructions in the first activity. They did not participate enthusiastically.

Compared to the other two participants in this group, Quynh made the most use of the textbook in her classes. In her opinion, it was a good book which matched the students' average proficiency and the faculty's targets. Sometimes, she gave the students examples or sample answers from a supplementary book. This book was compiled by the teachers who were teaching Business Correspondence in the faculty. They collected papers from different sources then made a book for internal use. Quynh highly valued the book.

The book is very helpful. It saves me a lot of time searching for extra materials. The content is relevant to what I'm teaching.

Having a good textbook and a good supplementary book contributed greatly to Quynh's sense of self-efficacy.

Similar to Quynh, most of the class activities and exercises in Huyen's class were adopted or adapted from the textbook. However, she gave students handouts from another book. 


\section{VIETNAMESE EFL TEACHER SELF-EFFICACY IN PRACTICE}

In short, Huyen and Quynh made use of the textbook for their teaching, Linh used a lot of other activities that were not from the textbook.

\subsubsection{Comparison of Three Teachers' Teaching Practices}

Comparing self-efficacy profiles of the three teachers, Huyen had higher overall scores across three components than Linh and Quynh.

Although reporting to have the lowest score in self-efficacy for classroom management, Linh displayed confidence in her teaching practice. Her classroom was quite big without any microphone for the teacher. However, she managed to speak loudly. She also checked on what the students were doing to ensure that all of them were following her instructions. When the students seemed not to be very cooperative, she quickly adapted the activities to refocus their attention. Quynh, although reporting to have higher self-efficacy for classroom management, refused to talk about this. She considered it her biggest constraint. Linh demonstrated her confidence in giving instructional strategies. She was very flexible in her teaching. When unexpected situations arose, she solved the problems quickly. She was confident in searching for supplementary resources and implementing what she had learnt.

Quynh reported to have the lowest self-efficacy in instructional strategies while Huyen showed the highest among the three teachers. However, they employed quite similar strategies in their teaching. They both made more use of the textbook rather than using other sources. The extra handouts that Huyen gave her students were taken from a book she found by herself. Quynh took advantage of the supplementary book that she compiled with other teachers.

The three teachers used similar strategies to engage students during the lessons. They walked around the classroom to maintain the students' attention and ensure participation. They rearranged the seats and put them in groups of mixed levels to create equal chances of learning for all the students. They all valued the students' comprehension. They sometimes spoke Vietnamese instead of English to make sure that the students understood the lessons and were able to follow instructions. Moreover, they all let the students discuss in Vietnamese to help them feel more confident and comfortable. Notably, Quynh reported that using Vietnamese made her more effective in teaching. 
VIETNAMESE EFL TEACHER SELF-EFFICACY IN PRACTICE

To deal with students' diverse proficiency, Linh designed different activities with different levels of difficulty. Some could be easier and some could be more challenging. Huyen, however, mixed students of varied proficiency in groups so that they support each other in group activities.

Table 25 summarises the similarities and differences in their teaching practices.

Table 25

Similarities and Differences in the Teaching Practice of Teachers with Lower Scores of SelfEfficacy

\begin{tabular}{|c|c|c|c|}
\hline & Quynh & Linh & Huyen \\
\hline \multirow[t]{5}{*}{ Similarities } & - $\quad$ Secured studen & s' attention & \\
\hline & Rearranged stu & lents' seats & \\
\hline & Used Vietname & e during their teaching & \\
\hline & Mixed students & of various abilities & \\
\hline & Used diverse $\mathrm{c}$ & assroom activities & \\
\hline \multirow[t]{2}{*}{ Differences } & \multicolumn{2}{|l|}{$\begin{array}{l}\text { Refused to talk about } \\
\text { classroom } \\
\text { management }\end{array}$} & $\begin{array}{l}\text { Purposively selected } \\
\text { students to answer } \\
\text { questions }\end{array}$ \\
\hline & \multicolumn{2}{|l|}{$\begin{array}{l}\text { Mostly used textbook } \\
\text { and the } \\
\text { supplementary book } \\
\text { that she compiled } \\
\text { with other teachers. }\end{array}$} & Mostly used textbook \\
\hline
\end{tabular}

To summarise this section, I would like to highlight some main findings. Within each group of higher, medium, and lower scores of self-efficacy, the teachers displayed some similarities and differences in their teaching strategies. For example, both the teachers with higher scores of self-efficacy were more innovative in their assessment of student learning, using outside classroom projects for instance, but they differed greatly in their use of teaching materials. More importantly, similar teaching strategies were also recorded across all of the three groups. For instance, the teachers from all three groups had similar practices to secure their students' attention and deal with students' diverse levels of language proficiency. Regardless of the teachers' self-efficacy scores, the teachers' selection of teaching strategies reflected their perception of their students' characteristics, such as the students' proficiency, their interests, and 


\section{VIETNAMESE EFL TEACHER SELF-EFFICACY IN PRACTICE}

needs. In addition, other concerns about the context were evident across all the three groups, such as the availability of classroom equipment, class size, and classroom size. The teachers said that their teaching strategies developed from pre-service and in-service teacher training and development programs and activities, their past successful experiences, and their observation of others' teaching.

\subsection{Summary of Findings.}

This chapter has addressed the three research questions.

1. What are the self-efficacy profiles of EFL teachers working in a public university in Vietnam?

2. What do these EFL teachers report as influences on their self-efficacy in their classrooms?

3. How do teachers with different profiles of self-efficacy differ in their teaching practice?

Firstly, it has presented data of teacher self-efficacy profiles and demographic information. The participants were diverse in their educational backgrounds, age, teaching experience, and participation in professional development. They were teaching students of various levels using different textbooks. Their number of teaching hours also differed. On the scale of five, the participants reported an average score in overall self-efficacy that was above the central point of the scale as well as in its three domains. Each teacher seemed to have a unique profile of self-efficacy.

Secondly, this chapter has shown sources of and influences on teacher self-efficacy. The sources of mastery experiences, vicarious experiences, social persuasion, and physiological and affective states align with Bandura's (1997) theory of sources of teacher self-efficacy. These sources interacted dynamically with each other. In addition, this chapter has also emphasised the role of personal elements such as teachers' personal qualities, their knowledge, and experiences. Regarding classroom and institutional conditions, class size, availability of classroom equipment, institutional policies about professional and personal collegiality, teacher autonomy, and students' and staff's feedback about teaching were found to have an impact on teacher self- 
VIETNAMESE EFL TEACHER SELF-EFFICACY IN PRACTICE

efficacy. Teacher self-efficacy was also influenced by cultural elements such as teachers' roles outside of their profession and their evaluation of feedback about their teaching.

Finally, this chapter has compared the teaching practice of teachers in groups of higher, lower, and medium self-efficacy scores. Within each group, there were some similarities but more differences in teaching strategies. Similar strategies were recorded regardless of their selfefficacy score groups. The following chapter will discuss how these elements influenced the formation of teacher self-efficacy and teaching practice. 
VIETNAMESE EFL TEACHER SELF-EFFICACY IN PRACTICE

\section{Chapter V Discussion}

The methodology of this research has enabled teacher self-efficacy to be viewed from three different angles. First of all, a questionnaire developed by Tschannen-Moran and Hoy (2001) was adapted to measure teachers' self-efficacy scores across three domains of selfefficacy: classroom management, student engagement, and instructional strategies. Secondly, the teachers were interviewed to get more nuanced understanding of their self-efficacy, rather than just their self-efficacy scores. Finally, they were observed teaching in their classrooms and interviewed afterwards about their decision-making using video clips as a stimulus. In this chapter, I will analyze the nuanced nature of self-efficacy by weaving together the different sources of data. I will discuss the sources of self-efficacy and the contextual factors influencing teacher self-efficacy including personal, classroom and institutional, and cultural influences. I will discuss self-efficacy as a dynamic and contextual phenomenon. In each section, I will highlight the unique contribution of this study.

\section{Do the Teacher Efficacy Scale Scores Have a Relationship with Teaching Practice?}

The findings indicate no particular connection between the overall teacher self-efficacy scores and teaching practice. These findings are significant because this contradicted previous findings from literature. According to Bandura (1993) and Tschannen-Moran et al. (1998), teacher self-efficacy significantly impacts teachers' behaviours in the classroom. For example, teachers with higher self-efficacy seem to be more innovative, more flexible, willing to alter their teaching methods, better prepared for their lessons. Meanwhile, lower self-efficacy teachers tend to avoid or put less effort on challenging tasks. Therefore, after classifying the teachers into groups of higher, medium, and lower self-efficacy scores, it could be expected that the teachers across the three groups would display different teaching strategies and techniques and the teachers from the same category would use similar ones. This was not the case in my study.

For example, most of the teachers across the three groups used the mother tongue, Vietnamese, during their lessons. The most common explanation for their use of Vietnamese was to convey meaning of difficult language items which ultimately reinforce students' comprehension. In addition, some teachers used Vietnamese for different purposes. For example, one teacher with high level of self-efficacy maintained the discipline in the class through the mother tongue. When some students were being distracted, she spoke Vietnamese to get their 


\section{VIETNAMESE EFL TEACHER SELF-EFFICACY IN PRACTICE}

attention and reminded them to follow her instructions. Another teacher who was in the same group told her story to the students in their first language. She did not only used Vietnamese to ensure the students' understanding, but she also explained that speaking Vietnamese in this situation helped her create a warm and cozy atmosphere in the classroom. The teachers used the first language not because they were not self-efficacious in using the target language during their lessons. Instead, they used it either as an instructional strategy or a strategy to manage the class or engage students. Their selection of the language depended on their perceptions of the teaching context, especially regarding their students, rather than on their self-efficacy.

Another example of differences is in the use of the teaching materials. It was reported in the literature that the highly self-efficacious teachers would be more creative in their teaching (Bandura, 1997; Tschannen-Moran \& Hoy, 2001). Therefore, I expected that the teachers with the highest scores would use more supplementary materials than the textbooks. However, a teacher in the higher score group made use of the textbook. She explained that her students were freshmen. Their background knowledge was not sufficient to explore new knowledge outside the textbook. As a result, she spent time explaining the new terms in textbook, ensuring the students' understanding of the nature of the terms and how to use them in an English speaking context through the exercises in the textbook. Similarly, the teachers with lower self-efficacy scores also primarily used the textbooks because of their students' limited language competence.

The teachers in all three groups differed greatly in their assessing and testing methods. Some teachers assigned their students outside classroom projects to work on and then used them as a replacement of a formal in-class test. Some other teachers, in contrast, used accumulative tests instead of just one mid-term test. While some teachers mainly focused on the students' use of language, some other teachers paid more attention to such things like pronunciation and ideas development. Such differences derived from teacher autonomy but also related to their selfefficacy because they needed to be confident in the choices they made. As each teacher was given some freedom in the methods of assessing and testing her students, each of them applied this freedom in their own way.

The literature shows that teachers with low self-efficacy have difficulties in dealing with classroom problems (Woolfolk \& Hoy, 1990). Nevertheless, a participant in this study 


\section{VIETNAMESE EFL TEACHER SELF-EFFICACY IN PRACTICE}

confidently and flexibly overcame unexpected incidents during her teaching although she reported lower level of self-efficacy in the questionnaire.

In summary, Tschannen-Moran and Hoy's scale gave an overview of the participants' self-reported levels of self-efficacy. The groupings of higher, medium and lower scores were expected to predict teachers' similarities in their teaching practice in each group. However, the research data show that the scores on the self-efficacy scales did not predict any particular differences from one group to the other in the observed teaching practices or the reflections. This suggests the quantitative scales as self-reported data collection measure should not be the sole measure of teacher self-efficacy (Fang, 1996). A scale captured teacher self-efficacy from a set of static dimensions. In fact, teaching practice in the classroom was dynamic and interactive and influenced by other internal and external factors which will be discussed further in section 3 of this chapter.

\section{Interaction among Sources of Teacher Self-Efficacy}

My research data show some sources of teacher self-efficacy which align with Bandura's (1997) categories of mastery experiences, vicarious experiences, verbal persuasion, and physiological states. More interestingly, these sources were found to mutually interact with each other. This interaction has not been explored for EFL tertiary teachers in this context in other studies. This section describes these categories in detail and discusses how these sources interact with each other in the formation of teacher self-efficacy.

\subsection{Mastery Experiences.}

Firstly, I will discuss the forms of the participants' enactive mastery experiences and cognitive mastery experiences including teachers' knowledge about general and content pedagogical knowledge, subject content knowledge, and knowledge of the contexts. In addition, I will discuss how the mastery experiences interact with another source of teacher self-efficacy, social persuasion.

One form of mastery experience that the teacher reported was their past teaching experiences. The teachers judged their teaching as a success or a failure based on the students' behaviour in the classroom, the students' test results, and their students' and colleagues' feedback about their teaching. This process of evaluating their past teaching experiences was similar to the findings of Morris and Usher (2011), and Phan and Locke (2015). It is noticeable 


\section{VIETNAMESE EFL TEACHER SELF-EFFICACY IN PRACTICE}

that the teachers' judgements of their past teaching experiences were not original sources of selfefficacy (Morris et al., 2017). Instead, this source of self-efficacy was mediated by social persuasion.

Unlike the participants in the Tschannen-Moran and Johnson's (2011) study who said that only successful experiences were beneficial for their self-efficacy development, some teachers in my study did not make this clear distinction between successful teaching experiences and those they regarded as less successful. For those teachers, all experiences were valuable. Their successes or failures in the past helped to determine what the decisions they should make in the present. For example, the teachers drew on their prior experience of having taught the subject for several terms. They could easily identify the advantages, disadvantages as well as the relevance of each textbook for their learners' interests and levels. Similarly, they said they knew what materials were suitable, how to design appropriate activities, and how to use effective strategies in lessons. They learned from their teaching successes or failures. If the strategies or materials seemed to be successful in facilitating student learning, they would repeat them or do something similar. Otherwise, they would avoid using strategies they considered unsuccessful or find other ways to overcome particular issues. In other words, from what they had done before, these teachers could identify what they should do to teach lessons they considered effective. The process corresponds with the enactive mastery experience (Bandura, 1997). He said, "difficulties provide opportunities to learn how to turn failure into success by honing one's capabilities to exercise better control over events" (p.80). The participants built self-efficacy from prior experiences. This aligns with prior research that suggests practice influences teacher self-efficacy (Bautista \& Boone, 2015; Cantrell et al., 2003; Lumpe et al., 2012; Morris \& Usher, 2011; Smolleck \& Mongan, 2011).

As a form of mastery experience, the participants' judgement of their past teaching performance played an important role in the formation of their self-efficacy. According to Bandura (1997), achievements in the past strengthen people's belief in their abilities to perform similar tasks, whereas, failures weaken it. However, in my study, the participants' self-efficacy seemed to be enhanced by both successes and failures. With successful experiences, they said they would repeat the practices. With the unsuccessful ones, they would try a different practice that they thought would be effective. So instead of reducing their belief about their teaching 


\section{VIETNAMESE EFL TEACHER SELF-EFFICACY IN PRACTICE}

competences, they remained confident that they had the ability to improve it next time. In other words, they regulated their teaching to make it progress. This self-regulation differs from teacher to teacher. It depends on the teachers' beliefs about their ability to change or their locus of control (Rotter, 1966). This will be discussed further in section 3 of this chapter.

The teachers in my study reported the four groups of knowledge that Grossman (1990) categorized as having influences on self-efficacy: general pedagogical knowledge, subject matter knowledge, pedagogical content knowledge, and knowledge of context. These knowledges were linked to the teachers' background experiences, including their own learning at university. The participants were EFL teachers teaching English to students of different majors in a business university. The participants in initial survey had educational backgrounds that were either English Language Teaching or Interpreting and Translating, majoring in Business English. The teachers in the former group had advantages over the latter group in terms of pedagogical knowledge and pedagogical content knowledge because they were formally trained to be teachers of English for speakers of other languages but they may have gained little understanding of business English through their formal university education. A teacher described that she did not feel confident when teaching business terms in English. The other group with a business English major, in contrast, were confident about their subject matter knowledge but apprehensive about their pedagogical knowledge. In other words, the general pedagogical knowledge, the pedagogical content knowledge (knowledge about teaching English as a Foreign Language), and the subject matter knowledge (knowledge about general English language and English for specific purposes), and knowledge of the teaching context all contributed to the teachers' selfefficacy.

A similar conclusion was drawn from Palmer's study (2006). When studying various sources of self-efficacy in a primary science methods course, Palmer (2006) argued that in addition to four main sources of self-efficacy proposed by Bandura (1997), there are three other sources. The first possible source is science content knowledge which had been found earlier in the literature to have significant relationship with primary student teachers' self-efficacy. Science was a compulsory subject, but it was very difficult for many students to thoroughly understand it. They felt anxious and fearful of the subject. Therefore, understanding the subject matter represents a significant influence on the efficacy for teaching it. Palmer (2006) called it 
VIETNAMESE EFL TEACHER SELF-EFFICACY IN PRACTICE

“cognitive content mastery". According to Palmer (2006), this experience is distinctive from enactive mastery experience in Bandura's theory because it deals with teachers' understanding of the content knowledge rather than their success in teaching it. The second source found to have positive correlation with science student teachers was science pedagogical knowledge. Settlage (2000) found that a knowledge of science teaching methods improved pre-service teachers' selfefficacy. This is called "cognitive pedagogical mastery". Another source mentioned in Palmer (2006) is simulated modelling which means there was no teaching of real children. Instead, the students played the role of school students while their tutors assumed the role of school teachers. Such practice provided the student teachers with vicarious experiences, which will be discussed further in the upcoming section. Other researchers also acknowledged the role of teachers' content and pedagogical knowledge, for example (Bautista \& Boone, 2015; Morris \& Usher, 2011; Phan \& Locke, 2015; Tschannen-Moran \& McMaster, 2009). However, it is particularly interesting to see this playing out in in my study in the context of teachers of English and teachers of business English with different professional backgrounds in Vietnam.

In my study, the teachers mentioned the importance of both content and pedagogical knowledge. As they were working at the Faculty of English for Specific Purposes, their knowledge of general and business English could be classified as teachers' cognitive content mastery; and their knowledge of teaching skills referred to as "cognitive pedagogical mastery". The teachers graduated from English language teaching programmes were confident with their general English language and teaching methodologies knowledge. As mentioned above they felt secure when teaching general English but perceived low self-efficacy when explaining business terms. Meanwhile, the teachers with business or English for business background felt more competent with their business English knowledge but without formal training on how to teach English as a foreign language, they reported being less efficacious when teaching English language skills. Thus, the teachers' self-efficacy was very task-specific. The teachers' background and its interaction with the task influenced their self-efficacy. This signifies the dynamic nature of teacher self-efficacy because it changed according to the task and teachers' background. 


\section{VIETNAMESE EFL TEACHER SELF-EFFICACY IN PRACTICE}

In summary, the mastery experiences refer to teachers' past performance, subject content knowledge, and pedagogical knowledge. These elements interact with each other in a dynamic manner to contribute to teacher self-efficacy.

\subsection{Vicarious Experiences.}

This section discussed the forms of vicarious experiences, their interaction with social persuasion and physiological states, and the influences on teacher self-efficacy.

The participants of my research reported different professional development activities. Such activities provided them with vicarious experiences because through the observation of others' teaching or the sharing of their experiences, the teachers were prompted to reflect and improve their own teaching. In other words, they appraised their abilities in relation to what they perceived as the effectiveness of the other teachers. This comparison, as Bandura (1997) said, “operates as a primary factor in the self-appraisal of capabilities” (p.87).

This observation is in line with the earlier research which shows different forms of professional learning and development can contribute positively to self-efficacy. These include conducting action research (Cabaroglu, 2014; Henson, 2001; Mulholland \& Wallace, 2001; Shanks, Miller, \& Rosendale, 2012), in-service teacher education programmes (Ortaçtepe \& Akyel, 2015; Wyatt, 2013; Yoo, 2016))), peer coaching (Goker, 2006), and professional learning communities (Zonoubi et al., 2017).Teachers learn new knowledge through professional development activities and then apply the techniques successfully in their teaching practice. This process strengthens their beliefs in their ability.

Another form of teachers' vicarious experience emerging from my research was modelling, which means the teachers performed the teaching task in their classroom and were observed by their mentors, their coaches or their colleagues. Those observers gave the observed teachers feedback about their teaching. The teachers got both positive and negative feedback. With compliments, they would feel more confident and motivated. As a result, they felt more self-efficacious. Conversely, critiques resulted in self-doubt and diminished their self-efficacy. In other words, the social persuasion could lead to either positive or negative physiological states. In this case, I noticed an interaction between three sources of self-efficacy: vicarious experiences, social persuasion, and physiological and affective states. 


\section{VIETNAMESE EFL TEACHER SELF-EFFICACY IN PRACTICE}

The interview data in my study mentioned different forms of professional learning and development. First, all of the teachers talked out professional seminars and conferences in which they shared their experiences and innovative strategies (mastery experience and vicarious experience). They received feedback about their teaching (verbal persuasion). However, unlike Zonoubi et al. (2017), who found the positive influences of professional learning communities on teacher self-efficacy, the teachers in my research reported both positive and negative influences . While most of them said these activities were helpful to their teaching and made them feel more effective in their teaching, one teacher questioned the usefulness of the conferences and seminars she attended because their themes were either too general or irrelevant to her interests. She attended them just because they were compulsory. According to Cabaroglu (2014), when teachers have the freedom to choose the aspects of teaching that need improving based on their interests and concerns and address these through professional development, the professional development is more likely to enhance their beliefs about their abilities.

When teachers' freedom to choose the professional development activities to attend is considered in light of teacher autonomy, teachers' perceptions of what they needed may not align with what is being offered within the institution. Professional development activities may best benefit the teachers when they could choose what to attend to address their own strengths and deficits. They would confidently share their strengths or their successes in seminars and conferences. In other words, their vicarious experiences would strengthen their beliefs about their abilities. Additionally, when participating in activities that could suggest solutions to the teachers' concerns, the teachers would reflect on their teaching and improve their practice. However, if they are forced to attend the professional development sessions outside of their interests or concerns, they may consider the activities as time wasting and useless. Skaalvik and Skaalvik (2014) found that highly self-efficacious teachers were willing to experiment innovative teaching ideas and would alter their teaching practice for the progress of their learning and development. Therefore, if teachers could perceive benefits from professional development activities, it is likely that their self-efficacy would be improved.

Modelling was a form of vicarious experience in Bandura's (1997) theory and in this study the teachers were sometimes observed by senior teachers and managerial staff such as their mentors, subject managers, and the dean. They reported feeling nervous in these observations. 


\section{VIETNAMESE EFL TEACHER SELF-EFFICACY IN PRACTICE}

The reflecting on teaching in this situation was not a direct source of teacher self-efficacy. Instead, it was mediated by social persuasion. The nervousness and pressure they underwent during the observation seemed to have negative influence on their self-efficacy. However, the feedback they received, either positive or negative, was reported to be constructive and useful. As discussed in the section 2.1 of this chapter about mastery experiences, each teacher interprets other people's judgement about their teaching in a different way. Some people may feel less selfefficacious because of negative comments while some others consider such feedback as guidelines for improvement. This difference in teachers' interpretation reflects teachers' autonomy to regulate the feedback. If they view the feedback from a negative perspective, their self-efficacy will be diminished. On the other hand, their self-efficacy progresses if they perceive the feedback as constructive. During and even after the observation, the teachers did not have a chance to ask questions and give opinions about their teaching as well as the feedback. In this case, some aspects of teacher autonomy was limited. Probably, this is because the purpose of the observation was for promotion or upgrading their contract, rather than for their professional development. Because of the hierarchy in the relationship between them, the teachers felt junior to the observer. This will be discussed further in the section 3.2 of this chapter about cultural influences.

The teachers in my study mentioned peer observation as a form of vicarious experience. When observing the other teachers' teaching, the participants said they reflected on their own teaching and ideas that they thought suitable for their teaching. This happened without giving the person observed any critiques but just compliments. This reflects the "keeping face" norm in Vietnamese culture. Comparing to peer coaching in Goker's (2006) study, the teachers in my study did not have opportunities to negotiate strategies which could contribute to their sense of agency and autonomy. It is also important to consider the similarities between the observer and the observed ones. When the observer tends to consider the observed teacher their reflection in the mirror, they are more likely to attain a strong belief that they could successfully perform a similar task when they identify more common things between them.

A further element of professional development in my research was the sharing of supplementary documents. The teachers collaborated to compile these documents but they did not have any instructions how to use them to best advantage. In addition, they individually 


\section{VIETNAMESE EFL TEACHER SELF-EFFICACY IN PRACTICE}

reflected on the effectiveness of these materials but did not formally share the reflection and feedback with their colleagues. While the joint creation and sharing of materials indicated aspects of a professional community, other aspects such as the lack of reflection on the use of materials contrasted with the professional learning communities described in Zonoubi et al. (2017).

The participants acknowledged the informal sharing of supplementary documents and teaching experiences between teachers who had a close relationship. This will be discussed further under the institutional and cultural influences.

Professional development activities including professional conferences and seminars, peer observation, sharing of supplementary documents and teaching experiences contribute to the teachers' vicarious experiences, which are a source of teacher self-efficacy. The following section will discuss the findings relating to the third source: social persuasion.

\subsection{Social Persuasion.}

This section discusses different forms of social persuasion and its interaction with mastery experiences and physiological states.

Feedback about teaching can be classified as a form of social persuasion, which is a source of self-efficacy (Bandura, 1997). The participants of my research got feedback about their teaching through different channels: students, leaders, and colleagues. Each source of feedback influenced teacher self-efficacy differently. The students' feedback was collected through an online questionnaire once a term to ensure that the teaching quality met the university standard. The teachers who got less than three points out of five, would be consulted by the leaders to discuss their problems and possible solutions. Those who got over three points would not go through that process. As it was an optional task, not all students completed the survey. In some classes, a large number of students responded to the questionnaire, but in some other classes, only a smaller percentage of students did. This challenged the reliability of the feedback. Some teachers said that they did not consider the students' feedback as the reflection of their teaching because such feedback was only a few students' personal opinions. They would not adjust their teaching according to whatever the students suggested. Instead, they only changed what they thought "reasonable". These teachers had a strong sense of belief about what they should do in their classes. In other words, they had a strong belief about their abilities despite the student 


\section{VIETNAMESE EFL TEACHER SELF-EFFICACY IN PRACTICE}

feedback. These teachers could have formed a strong belief about their ability over time which made it difficult for them to see the need to change their practices. Bandura (1997) stated "when individuals are more confident in their self-appraisals than in the judgements of others, they are not swayed by what they are told about their capabilities" p.105). However, there is another possible explanation for the teacher's evaluation of students' feedback. As suggested by Braga et al. (2014) and Carrell and West (2010), the participating teachers may think students' feedback indicated their enjoyment of the class rather than the teaching quality. In addition, the students' judgement may be influenced by conditions such as the temperature and humidity in classrooms (Braga et al., 2014). Some of the participants in my study highly valued the student feedback. They used the feedback to adjust or even "perfect" their teaching.

It was interesting to note that most teachers relied on the formal questionnaires to get the students' feedback about their teaching. Only one teacher said that she considered her students' behaviour in the classroom more important than the results of the questionnaire. As with the student survey, this non-verbal form of feedback, student reaction, had the potential to foster teacher self-efficacy. In general, student feedback either positive or negative was one important element that could enhance teacher self-efficacy. This was contrary to the findings in Phan and Locke's (2015) study. They discovered in their study that the students' behaviour nurtured the teachers' belief about the effectiveness of their instructional strategies. Depending on the students' reactions, the teachers may feel positive or negative about their teaching competence. This contrasts with my finding that my participants' beliefs about their ability was not strongly influenced by the feedback from their students. There are two possible explanations for why the teachers in my study were less influenced by the students' feedback than in Phan and Locke's research. The first one is the teachers' English language competence. Phan's participants reported that their language proficiency had deteriorated since their graduation because they did not have much exposure to English. In fact, my informants reported in the survey that they had a high level of language proficiency and as a result, they felt confident to teach. Another explanation is how the university used students' feedback. At the university where this study was conducted, students' feedback did not contribute to the teachers' promotion process. As one teacher said, if they got high scores which implies positive feedback, they got no rewards. Similarly, if they got low scores or negative feedback, there was no punishment. As reviewed in section 3.2.3, teachers judged their past performance based on students' behaviours in the class 


\section{VIETNAMESE EFL TEACHER SELF-EFFICACY IN PRACTICE}

such as their engagement and their interest (Morris \& Usher, 2011; Phan \& Locke, 2015). In these cases, teachers' appraisals of their past teaching were not original sources of self-efficacy. They were mediated by social persuasion.

The teachers also got their leaders and colleagues' feedback about their teaching. Unlike the students' feedback which was collected once a term, the participants only occasionally got feedback from their leaders. The subject managers, team leaders, and the Dean only shared their opinions when they observed the teachers' classes. They evaluated the teachers' performance to extend the teachers' contracts. They commented on many aspects of the teaching practice such as the teachers' pronunciation, the use of materials, use of blackboard, and the appropriateness of the activities. The teachers found this feedback very helpful and constructive. As some teachers explained, they considered their leaders senior to them, especially in terms of teaching experience. As a result, their comments were appreciated. This aligns with Bandura's (1997) and Pajares' (2006) finding that the specific and sincere comments from a credible observer are found to be most powerful. From those remarks, they would know their strengths and weaknesses. Then they would use their strengths and address their weaknesses. Their sense of being efficacious was boosted.

In addition to the two formal kinds of feedback above, the teachers also heard about their teaching through small talk with their colleagues. They would tell their colleagues what they heard about them through a third party. In the research context, usually two teachers taught different skills to the same class in a semester. The students in such class may give one teacher their opinions about the other one. Usually, such feedback was positive because as a cultural issue, it is inappropriate for students to criticize or give negative comments on their teachers. Moreover, the teachers would tell their colleagues what they heard about them through other teachers. Again, these comments were usually positive because they did not want their colleagues to lose face by criticizing their teaching.

\subsection{Physiological and Affective States.}

The teachers' positive feelings about their teaching have been discussed under the section of social persuasion. In addition, the teachers also mentioned the negative influences of heavy workload on their physiological and affective states. Although teaching many hours at the university, the teachers were not well-paid. Their income did not meet their spending needs. As a 
VIETNAMESE EFL TEACHER SELF-EFFICACY IN PRACTICE

result, most of them had to teach extra classes which could be for a joint programme or other schools and even private tutoring. The heavy workload had significant influence on the teachers' physiological states. Some teachers said they felt "exhausted". Another teacher used the expression of "teaching worker" to describe her job. Such feelings made them underestimate their abilities to perform well in their teaching. This influence will be discussed further in the section on classroom and institutional influences and cultural influences (section 3.1 and 3.2 of this chapter).

Although there was no male teacher participating in my study, the finding about the physiological states was consistent with Klassen and Chiu's (2010) finding that female teachers tended to experience a heavy workload. They had to perform both domestic and professional tasks.

In summary, all the above-mentioned sources played important roles in the formation of teacher self-efficacy. However, these sources do not work independently. Instead, they interact with each other. For example, the interpretation of feedback about their teaching (social persuasion) is an indicator of the teachers' judgement of the success or failure of their teaching (mastery experience) which then influences their emotional arousal (physiological and affective states). This interaction reflects the dynamic feature of teacher self-efficacy.

\section{What Makes the Relationship between Teacher Self-Efficacy and Teaching Practice so Complex?}

While Bandura's (1997) categories of sources provides the foundation for understanding where self-efficacy comes from, there are a number of external factors that have a mediating influence on the development of self-efficacy. These can be classified as personal, classroom and institutional, and cultural influences.

\subsection{Classroom and Institutional Influences.}

\subsubsection{Classroom Conditions.}

The observational and interview data show that the teacher self-efficacy was significantly influenced by the classroom conditions. 


\section{VIETNAMESE EFL TEACHER SELF-EFFICACY IN PRACTICE}

\subsubsection{Class Size.}

One of the most common elements reported was class size. The teachers were more confident in managing classes with fewer students. As one teacher explained, with a small number of students, she could easily remember their names which made her feel closer to her students. Moreover, she could identify each student's individual strengths and weaknesses and select the teaching content and materials accordingly. On the other hand, with a class of over a hundred students, another teacher reported to have low self-efficacy in managing it because she could not control what the students did in the class. This finding does not correspond with what Raudenbush et al. (1992) found. In his study, he discovered a positive relationship between teacher self-efficacy and class size. He hypothesized that a small class would be easier for the teachers to manage. However, the teachers who were teaching bigger classes reported to have higher self-efficacy than those who were working with smaller groups of students. The difference between Raudenbush's and my findings are perhaps explained by the teaching contexts. The teachers in the two studies were teaching different disciplines (mathematics, science, social studies, vs English) in different schools (high school vs university). The class size influenced their self-efficacy in opposite ways.

\subsubsection{Availability of Classroom Equipment and Teaching Resources.}

Another element that substantially influenced teacher self-efficacy was the availability of classroom equipment, including technology. In language classes, the teachers said they needed equipment like a CD player or a computer with a speaker, a projector and a microphone to teach large classes. My participants relied extensively on such equipment in their teaching. However, in the research context, the participants said that most of the classrooms were not sufficiently equipped. In some classrooms, there was no computer. In other classrooms, there was no speaker or projector. Sometimes, the equipment just suddenly stopped working. These unexpected situations made the teachers feel unprepared. As a result, the teachers reported feeling less efficacious in their teaching. On the other hand, with a well-equipped classroom, the teachers found it easier to engage the students and design instructional strategies. They could make use of the equipment to show funny interesting videos, play interactive games, showing slides for their lessons. The teachers were familiar with the use of such equipment in their class since they had been students in schools, during their teacher training programmes, and also during their teaching at the university. Such equipment was taken for granted as essential for their teaching. 


\section{VIETNAMESE EFL TEACHER SELF-EFFICACY IN PRACTICE}

Their instructional strategies were reliant on the availability of such equipment and, without it, their self-efficacy was hindered.

It is interesting to highlight that, in the pre-observation interviews, some teachers did not mention any constraints from the classroom facilities available to them. However, when observing their teaching practice, they managed to overcome some of the unexpected difficulties. Some other teachers did talk about how such limitations as a lack of equipment negatively influenced their self-efficacy. In contrast, in the classroom, they managed it. With their knowledge of the classroom context, they became "self-equipped" for their teaching. Most of the teachers brought their own laptops and speakers. In addition, instead of relying on the projector, they printed off the handouts. So even though reporting classroom facilities as an element hindering their self-efficacy, the interview data show that most participants had high selfefficacy in overcoming such difficulties. This agrees with Tschannen-Moran and Hoy's statement that "efficacy beliefs influence teachers' persistence when things do not go smoothly and their resilience in the face of setbacks" (p.783). According to Rotter's locus of control (Rotter, 1976), the teachers in my study had a high sense of internal control. Their teaching efficacy in this area depended on their own behaviours rather than on external factors.

Teacher self-efficacy was influenced not by a single factor but by a combination of many interconnected elements. For example, class size had a connection with the teachers' perception of their students. The availability of teaching equipment linked to instructional strategies. The dynamic relationship among these elements influenced the teachers' sense of efficacy. As classroom settings and facilities differ from one classroom to another, teacher self-efficacy when teaching different classes may vary. This explains why self-efficacy is said to be context specific (Bandura, 1997; Tschannen-Moran and Hoy, 2001).

\subsubsection{Collegiality.}

The teachers reported that they had support from their colleagues as well as from the leaders. The leaders were classified into two groups of subject managers and the board of faculty managers. Unlike the board of faculty managers who were said to have little help to the teachers, the subject managers were praised by almost all the teachers for being understanding and supportive to them. In addition, the teachers also mentioned how their self-efficacy was influenced by their peers. Peer observation played an important role in the formation of teacher 


\section{VIETNAMESE EFL TEACHER SELF-EFFICACY IN PRACTICE}

self-efficacy. Learning by watching other people teach is a vicarious experience. For those being observed, the feedback they received afterwards was valuable. Receiving positive feedback on their performance (social persuasion) and collaborating with other teachers associated significantly with teacher self-efficacy (Cone, 2009; Klassen \& Durksen, 2014; TschannenMoran \& McMaster, 2009).

\subsubsection{Teachers'Autonomy.}

The participants were working under the supervision of their direct subject manager and other managerial staff in their faculty and university. There were policies that they had to follow. For example, they had to use the assigned textbooks and follow a given course outline. The students had to be assessed on their attendance, mid-term test, and final test. However, they also had much freedom in their job within the institutional constraints. Based on their perception of their students' needs and interests, they decided the teaching content which differed from class to class. Some teachers assessed students' attendance not only by their presence in the class but also their participation in the lessons. Similarly, each teacher could use their own criteria to design the mid-term tests. This, according to McGrath (2000), is teacher autonomy. In my study, the participants expressed their desire for self-direction in professional development such as their participation in professional conferences, seminars, and workshops. When the faculty organised such events, almost all the teachers attended as it was a compulsory task. Some teachers only attended their faculty's events but others participated as audience members or presenters at other conferences because they thought that they could benefit from them. The teachers did not provide much information about the macro constraints such as institution-external decisions made by the bureaucracies. This is because they believed that such constraints had no direct effect on them. Most of the constraints reported by the teachers belong to the micro group such as institution-internal decisions about syllabus, examination system, and textbook. As the teachers reported, at the beginning of the term, they were given a syllabus of what to teach in that term, comprising a guideline of which units to cover. However, the teachers were free to choose which parts to teach. As a result, they can select the parts that, in their opinion, were suitable for their students in terms of either proficiency, learning target, or their interests. Similarly, they were told only when to have the mid-term test but not what to include in the test. As a result, the teachers designed the tests in a way that helped their students have the highest scores they could. These opportunities for choice aligns with Dikilita and Griffiths's (2017) definition of teacher 


\section{VIETNAMESE EFL TEACHER SELF-EFFICACY IN PRACTICE}

autonomy as "teachers having control over their own professional development and practice" (p.35). In this study, they made their own decisions about their teaching plan, teaching practice, and teaching improvement. For each lesson, the teachers independently selected the teaching content. Then they chose the materials, prepared the worksheets and classroom activities, and decided on time allocation.

Teacher autonomy was found to have a moderate but positive correlation with teacher self-efficacy by Skaalvik and Skaalvik (2014). Highly efficacious teachers were independent in choosing the teaching materials and their teaching was adaptive with willingness to experiment innovative teaching strategies. Whereas, low self-efficacious teachers avoided challenges. However, my findings diverged from theirs. Each of the participants made use of different teaching resources to prepare for their lessons. Even though most of them reported using the Internet as a useful resource, they actually used different websites. So whatever the level of selfefficacy reported by the questionnaire, they exploited their autonomy in using teaching materials. In addition, the teachers were flexible in their teaching so that it could meet the students' needs and the teaching conditions. For example, not only the teachers with higher self-efficacy but also the ones with lower scores knew what they had to do to manage a class with a large number of students. Teachers with lower self-efficacy could deal with their students' proficiency just as well as the teachers with higher self-efficacy. Perhaps the range of scores between the two groups was not wide enough to reflect major differences in self efficacy but it is clear that the scores in the Teacher Efficacy Scale did not generally predict the teaching practice. However, one of the teachers from the lower self-efficacy group tended to avoid challenges in new teaching methods. Quynh refused to talk about her management of the class with over a hundred students. Another, Linh, in contrast, did not want to take part in conferences and seminars.

In this research context, the teachers made use of their independence to select the materials, design teaching plan, and be autonomous in using a variety of strategies in their teaching. When having the power to control their teaching, their sense of being efficacious was enhanced. In other words, teacher autonomy had positive relationship with their self-efficacy.

The procedure of teachers modifying their teaching according to their students' proficiency and interests to meet their needs and have good results in examinations refers to a 
VIETNAMESE EFL TEACHER SELF-EFFICACY IN PRACTICE

cyclical process called "teaching as inquiry" (New Zealand Ministry of Education, 2015) (see

Figure 8).

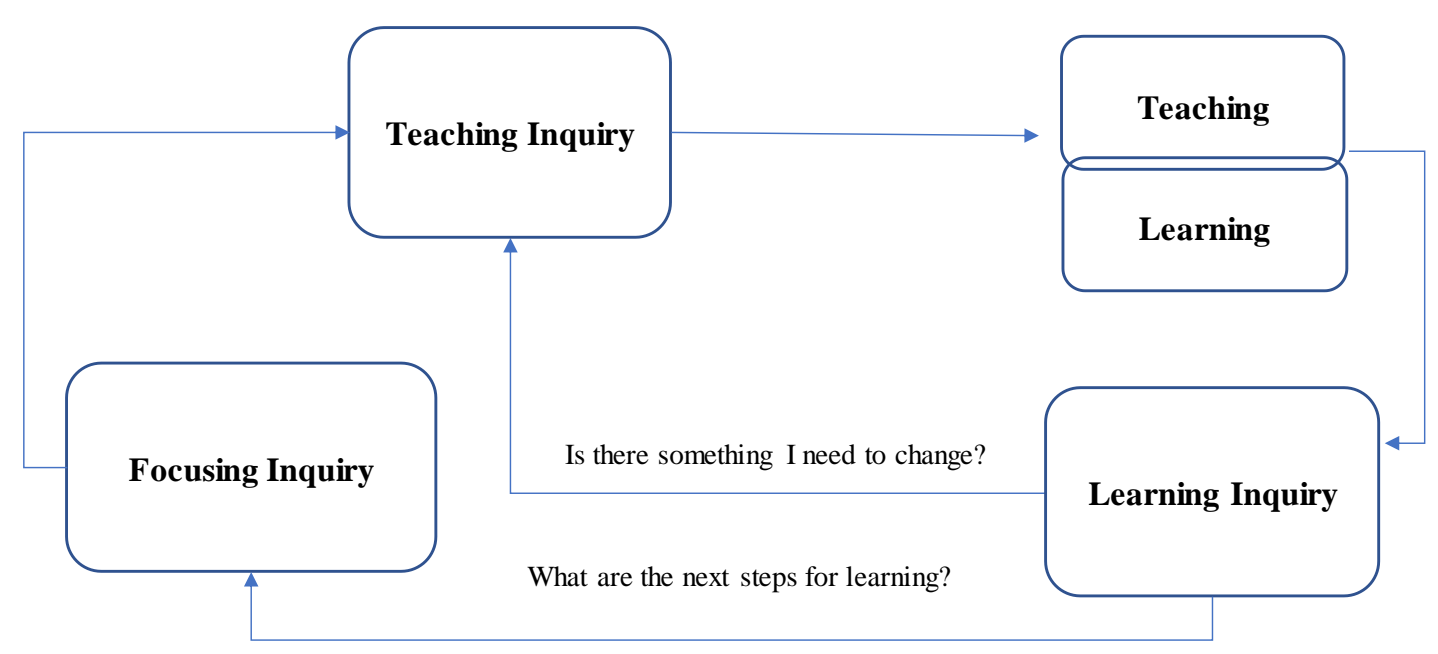

Figure 8: Teaching as Inquiry (adapted from New Zealand Ministry of Education, 2015 ).

In the focusing inquiry step, teachers use the available information to address the question "what is important and therefore worth spending time on, given where my students are at?" The answer to this question identifies what students' acquired knowledge and what they need to attain next, which they then base on to set goals. In the teaching inquiry, teachers plan their teaching and student learning aiming to reach the goals they set earlier. The strategies for their teaching are based on evidence from their own experience, their colleagues' experience, and from research. The guiding question in this stage is "What strategies (evidence-based) are most likely to help my students learn this?" During and after the teaching and learning processes, teachers use different assessment approaches to evaluate whether they have reached their set targets in the focusing inquiry step or the results of the teaching. From such analysis and interpretation, they identify the implications for future teaching. In my study, the participants considered students' outcomes as the reflection of their teaching effectiveness, which influences their self-efficacy. Therefore, if teachers can conduct the procedure of teaching as inquiry, it is likely that their self-efficacy will be enhanced.

The participants' autonomy in my study contrasts with the situation the teachers in the Phan and Locke (2016) had. They reported "feelings of powerlessness". During teacher meetings, they often kept quiet. They seemed to agree and be happy with whatever the leaders 


\section{VIETNAMESE EFL TEACHER SELF-EFFICACY IN PRACTICE}

said or asked them to do. However, they subsequently expressed their disappointment in journal entries using negative words like "nothing will be changed", "we have no voice", and "we can't change anything". Phan and Locke (2016) found this incident was a result of Vietnamese culture which "values group interdependence and mutual relationships and put little emphasis on individual agency" (p.121). Even though my study and Phan and Locke (2016) were both conducted in Vietnam which assumed to have similar cultural influences, each university has its own policies. The teachers in my research seemed to have higher level of autonomy than their counterparts in Phan and Locke's study.

\subsection{Cultural Influences.}

\subsubsection{Teachers Playing Different Roles.}

Prior to 1945, there was overt gender discrimination in Vietnam. Unlike men, Vietnamese women were not allowed to go to school. Their jobs were doing household work and looking after children. They had little or even no voice in decision making. In other words, they were undervalued (Tran, 2006). Since 1946, their position in the society has changed because of government policy (Tran, 2012). Now, more and more women are involved in social and employment activities. They are expected to be "gioi viec nuoc, dam viec nha" which means they should play their roles at work and at home equally well. Vietnamese women are likely to carry a double or triple role (Bourke-Martignoni, 2001). In this study, most teachers complained about the number of working hours. In addition to the actual teaching time in class, the teachers had to spend much time searching for materials, designing activities and worksheets, and then planning their lessons. This preparation time was just as much as the actual teaching time or even more.

In spite of extensive working hours, the participants' wages were low and did not meet their needs. Consequently, in addition to the official teaching at the university, they had to teach extra classes outside the university or the standard programme, and/or do private tutoring. Because of the low salary paid by the university, the workload for these teachers has thus been doubled. As a result, they reported negative physiological states like tiredness and even exhaustion and low job satisfaction.

At the same time, they also had to look after their children and do housework. As a result, they felt very tired. They thought they could not do their best in their jobs. As a source of self- 


\section{VIETNAMESE EFL TEACHER SELF-EFFICACY IN PRACTICE}

efficacy, the teachers' physiological states, in this case, negatively influence their self-efficacy beliefs (Bandura, 1997; Skaalvik \& Skaalvik, 2010). Phan and Locke (2015) also found that married female participants prioritized their family responsibilities but also considered their teaching roles very important to them. Their family roles were reflected as intrusion into their work because they generated negative emotions which diminished their self-efficacy. This finding is consistent with Greenglass and Burke's (2003) proposal that female teachers' high level of work stress might derive from gender differences in non-work aspects because women teachers performed both school tasks and domestic ones, which accumulated a much higher entire workload and higher conflict between work and family roles. It is unfortunate that there was no male teacher in my study. It would be interesting to compare how the men's roles and the women's roles influence their self-efficacy.

Even though there was only one teacher who talked about the disadvantage of being single, it is worth noticing that she was assigned more teaching hours than the others. She attributed this to the stereotype that single teachers should teach early morning and late afternoon classes. The other classes are assigned to the married teachers with school-age children as they needed to take them to school and pick them up. Moreover, because she was single, she was believed to have more free time than the others. The stereotype results in inconvenient teaching hours and a heavy workload for the teacher, which endangers teacher self-efficacy (Milner \& Woolfolk Hoy, 2003).

\subsubsection{Teachers' Evaluation of Feedback about Their Teaching.}

It is noticeable, as summarized in section 2.3, that the teachers valued their leaders' and peer feedback more than the students' feedback. There is a cultural element to this. The number of students in the group responding to the feedback questionnaires on their teachers may not have been the main reason. A cultural explanation is the credibility of the feedback. The participants possibly believed that their colleagues and leaders had knowledge and experiences to judge their teaching while their students did not. Bandura (1997) states that "the impact of persuasory opinions on efficacy beliefs is apt to be only as strong as the recipient's in the person who issues them". This belief depends on the perceived credibility and expertness of the persuaders. The more believable the source of information about one's capabilities, the more likely are judgements of personal efficacy to change and to be held strongly. People are inclined 


\section{VIETNAMESE EFL TEACHER SELF-EFFICACY IN PRACTICE}

to trust evaluations of their capabilities by those who are themselves skilled in the activity, have access to some objective predictors of performance capability or possess a rich fund of knowledge gained from observing and comparing many different aspirants and their later accomplishments (Bandura, 197, p.105)

In Vietnamese society, teaching is considered the most prestigious job of all. According to Phan and Locke (2016), Vietnamese teachers including EFL teachers, are socially respected. They are addressed as "thầy" not only by their students but also by the public. The term displays a "hierarchical relationship between teachers and students" (Phan \& Locke, 2016, p.112). Additionally, teachers are generally believed to have better knowledge than their students (Nguyen, 2012). The higher status and knowledge of the teachers possibly made them value the students' feedback less than the feedback of peers and superiors.

On the hierarchy of relationship between teachers, their colleagues and students, the students were at the bottom of the hierarchy. Meanwhile the teachers and their colleagues are at the same level and the managers are at the top. The managers and senior teachers were considered "credible observers" which means their feedback would be highly evaluated. Moreover, for a long time, teachers were considered the centre of the class. According to Hang (2017), audio-lingualism and grammar-translation were the dominant teaching methods in English language teaching in Vietnam when English was first introduced into the education system. Recently, especially after the introduction of the project named "The National Foreign Language 2020" in 2008, EFL teachers are encouraged to apply communicative language teaching (CLT) approach in their classes. However, together with some other factors such as large number of students in a class, learners' low motivation, and teachers' low proficiency, grammar-based examinations have constrained the implementation of CLT (Pham, 2004). As a result, many teachers returned to the traditional methods or adapt CLT principles to fit their teaching contexts (Hang, 2017).

\subsection{Personal Influences.}

\subsubsection{Personal Characteristics.}

Personal characteristics were reported to be an important element contributing to teacher self-efficacy. When being asked about the qualities that they had to be an effective teacher, most participants mentioned qualities like "passionate", "dedicated", and "hard-working". If the 


\section{VIETNAMESE EFL TEACHER SELF-EFFICACY IN PRACTICE}

teachers saw themselves as having these qualities, they would devote their time and effort to their preparation and teaching. As a result, they would feel confident about their teaching. This finding adds to Poulou's finding that "student teachers' personality characteristics, such as direct communication with pupils and positive stance/humour, and capabilities or skills such as the organization of teaching activities and ability to perceive pupils' needs, were highly rated sources of teaching efficacy" (Poulou, 2007, p. 211).

\subsubsection{Teacher Knowledge.}

Teachers' knowledge also played a crucial part in the formation of teacher self-efficacy. This has been discussed under the section of mastery experiences.

In addition to teacher knowledge of subject content and pedagogy, teacher self-efficacy was influenced by their knowledge of the context including knowledge of their students' characteristics and the teaching context. Research has found that as a contextual factor, students' characteristics might affect teacher efficacy. For example, Bejarano (2000) found that teacher perceived efficacy was not influenced by students' gender. However, it was discovered to be impacted by students' age. In the studies by Herman (2000) and Taimalu and Oim (2005), teachers were more efficacious when teaching younger learners. Teachers working with students from higher socioeconomic backgrounds reported to have a higher sense of efficacy than those working with students from lower status. My study indicated a positive relationship between the teachers' perception of knowing the students and teacher self-efficacy. This was evident in one teacher in the lower self-efficacy group who felt she did not know the students well because the observation happened early in the semester. Acknowledging students' interests, learning targets, and proficiency helped the teachers decide on the teaching materials, and design lesson plans and tests to meet the students' needs. This fostered teacher self-efficacy. This aspect of self-efficacy has not been explored in other studies.

Teachers' knowledge of other contextual factors like the classroom facilities and the, teaching materials, as well as their independence in making decisions also had significant impact on teacher self-efficacy.

To summarize, teacher self-efficacy was influenced by three groups of influences: personal, classroom and institutional, and cultural influences. The relationship among these influences is illustrated in the following diagram. 
VIETNAMESE EFL TEACHER SELF-EFFICACY IN PRACTICE

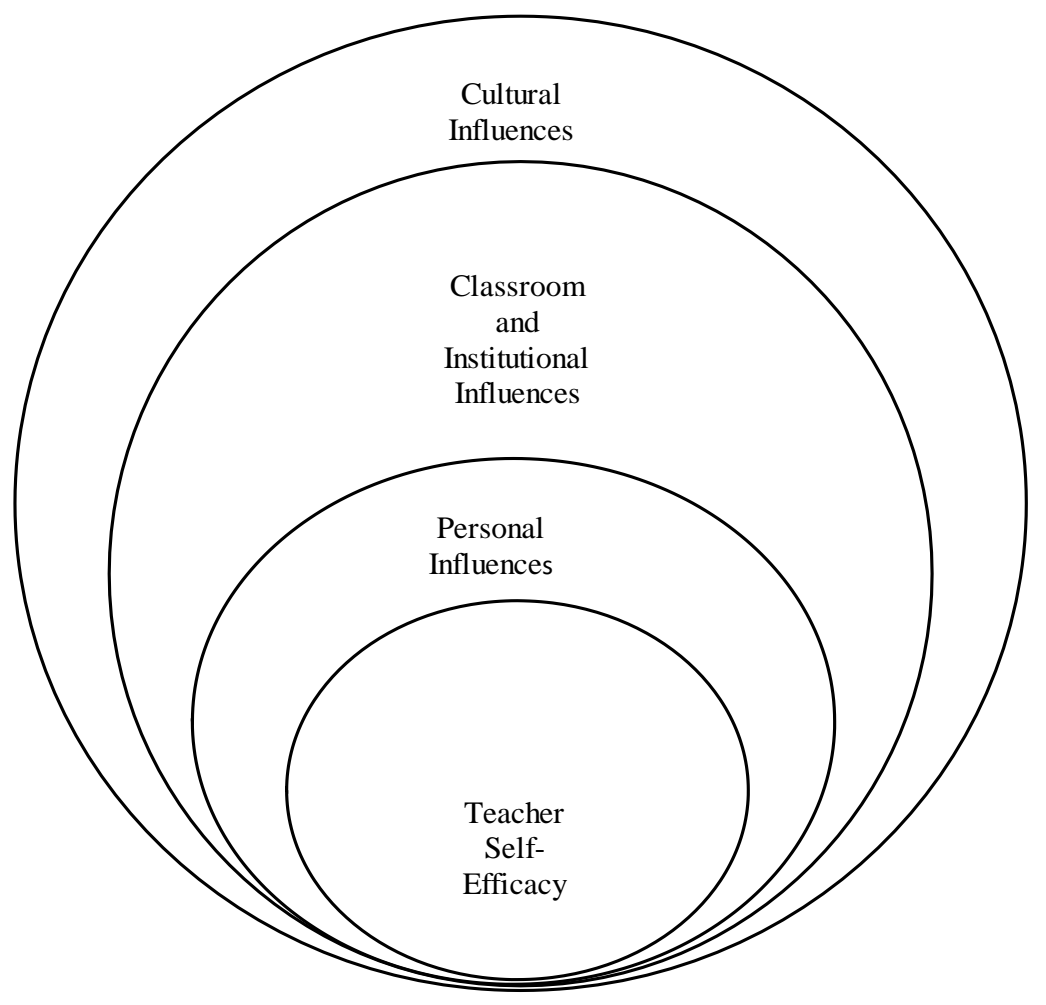

Figure 9: Influences on Teacher Self-Efficacy.

Teacher self-efficacy developed from the four sources namely mastery experiences, vicarious experiences, social persuasion, and physiological and affective states. Teacher selfefficacy is also influenced by personal, classroom and institutional, and cultural elements. Among personal influences, teacher knowledge plays an important part. Teachers in my research had different educational background. Some of them had the same major at university such as English Language Teaching and Business English. However, how much they knew about general English language, English for business, and pedagogical knowledge and the teaching context differed greatly. Among the elements of teachers' knowledge, their awareness of the context had some commonality with the classroom and institutional influences. The university decided on the number of students in each class, equipped the teaching facilities in each classroom, placed students in classes. In other words, the university decided the teaching context. Moreover, the institution also had an important role in collegiality or the relationship among the teachers and also between managers and teachers. The university assigns to the managers a certain level of authority to manage and support the teachers. The university organised professional development activities in which teachers shared and learned from each other. Similarly, the institution gave 
VIETNAMESE EFL TEACHER SELF-EFFICACY IN PRACTICE

teachers some freedom to make decision about their teaching. Yet, how teachers made use of their autonomy and how they benefitted from collegiality was very personal. The teachers' appreciation of the feedback about their teaching, as explained earlier, was impacted by culture but it was also influenced by the way the university collected and used the feedback.

\section{Chapter Summary}

Figure 10 summarises this chapter by showing the dynamic and contextual features of teacher self-efficacy and teaching practice. It also illustrates the unique contributions of this study by theorizing the relationships between the different influences on self-efficacy in this context.

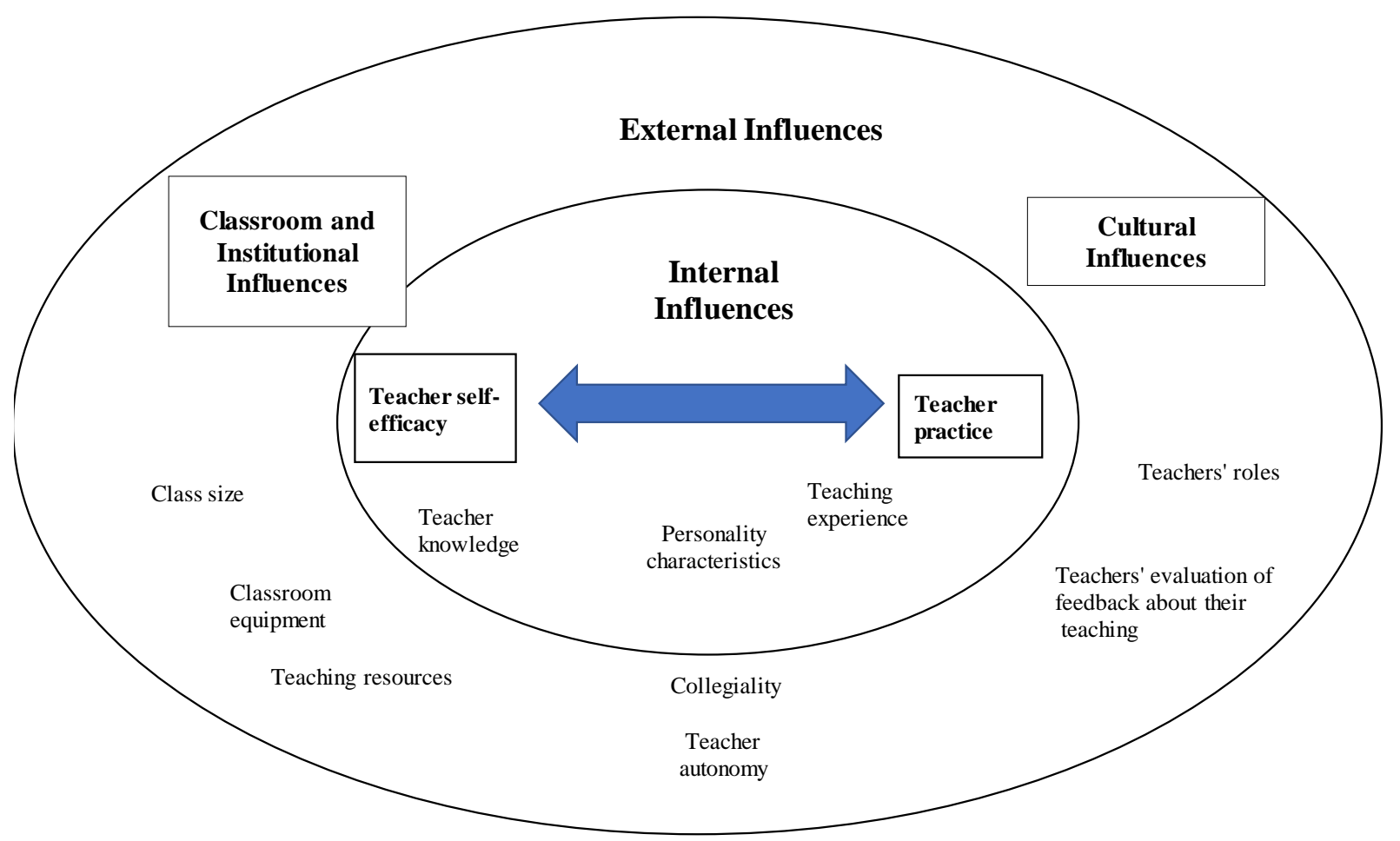

Figure 10: Internal and External Supports and Hindrances to Teacher Self-Efficacy and Teaching Practice

First of all, the diagram shows the reciprocal relationship between teacher self-efficacy and teaching practice. Teacher self-efficacy influences aspects of teaching practice such as testing and assessing their students, materials to use, and classroom activities. After teachers perform a teaching task, it becomes their past teaching experience. When the teachers consider their experience success, they become more self-efficacious and tend to use that practice again in 


\section{VIETNAMESE EFL TEACHER SELF-EFFICACY IN PRACTICE}

their future teaching. With practices that they consider to be failures, they tend to avoid those practices, or they might adjust them.

However, the relationship between teacher self-efficacy and teaching practice is complex because teacher self-efficacy and teaching practice are significantly influenced by both internal and external factors. The internal factors refer to the teachers' individual and personal elements, for example, their personal qualities, their knowledge, and experience. My data indicated that the external or contextual elements may outweigh the internal ones. The outermost layer is cultural factors which includes the teachers' perception about their roles at work and at home, and teachers' perceptions about their position. In Vietnamese culture teaching is a highly respected job. Society expects that teachers should be well-equipped with subject content knowledge, general pedagogical and subject content pedagogical knowledge. They should be well-prepared for their teaching in class. On one hand, this makes teachers more responsible. However, it can put pressure on teachers because often women teachers are expected to perform dual roles of both teachers and housewives and mothers equally well. How teachers perceive this cultural element would determine their beliefs and their teaching practice. Vietnamese culture creates a hierarchy between teachers, their colleagues, and students with students on the bottom tier. This order explains why the teachers participating in this study valued feedback from their colleagues more than from their students. But the way the teachers valued feedback was not only influenced by a cultural element but also by how the university collected and use the feedback. The institutional policies decide the number and language level of students in a class, the availability of teaching equipment, the level of autonomy for teachers, the workload, and working time for teachers. Teachers' perceptions of these factors interact dynamically with each other and help teachers answer the question of how much they believe they can perform a teaching task. To put it another way, teachers put themselves in a context to judge their self-efficacy. Because the teaching context varies, teacher self-efficacy also varies. For any teaching task, teachers make judgements about their ability to perform it in a specific context. This explains why some of the participating teachers reported had self-efficacy scores but still reported struggling in their teaching practice. Conversely, some others who rated their self-efficacy as low managed their teaching very well. This indicates that Tschannen-Moran and Hoy's scale to measure teacher self-efficacy may not reflect teacher's actual thought processes in a specific class situation. The items in the questionnaire may not indicate teachers' judgement and decision making in an 
VIETNAMESE EFL TEACHER SELF-EFFICACY IN PRACTICE

authentic classroom because the items do not account for the dynamic and interactive teaching process in an authentic classroom. 


\section{VIETNAMESE EFL TEACHER SELF-EFFICACY IN PRACTICE}

\section{Chapter VI Conclusion and Implications}

So far, I have presented the research background, theoretical framework, research methodology, findings, and discussion. To start this chapter, I will summarise these. Then, I will present implications from this study and recommendations for further research. This chapter closes with a personal statement.

\section{Summary of the Study}

Although teacher self-efficacy has been studied extensively over the last four decades, this research adds to the knowledge of this concept because it has provided a situated investigation of EFL teacher self-efficacy. It makes a unique contribution in three ways. Firstly, the triangulation of data has allowed teacher self-efficacy to be understood from multiple dimensions. Secondly, this study has brought to the literature an insight to self-efficacy of teachers of a specific subject which is English as a Foreign Language (EFL). Additionally, it has highlighted the influence of contextual features of the research site and Vietnamese culture.

This study found that teacher self-efficacy scores collected with the Teacher Sense of Efficacy Scale by Tschannen-Moran and Hoy's (2001) were not directly linked to their teaching practice. The quantitative measure captured teacher self-efficacy from a set of static dimensions whereas the teaching practice of the participants was a dynamic and complex process.

Teacher self-efficacy was found to be subject to a number of contextual influences, many of which aligned with Bandura's (1997) sources of self-efficacy: mastery experiences, vicarious experiences, social persuasion, and physiological states. It is worth highlighting that there was a dynamic relationship among these influences and therefore, at a more abstract level, among Bandura's sources.

This research has emphasised the contribution of personal elements, classroom and institutional, and cultural issues on teacher self-efficacy. Teacher self-efficacy in their teaching practice was influenced by individual elements such as teachers' personal characteristics and knowledge, and classroom and institutional issues like class size and availability of classroom equipment. Institutional policies about professional and personal collegiality, teachers' autonomy in making decisions, and student and staff feedback about teaching were found to have an impact on teacher self-efficacy. Moreover, teacher self-efficacy was also impacted by Vietnamese 
VIETNAMESE EFL TEACHER SELF-EFFICACY IN PRACTICE

cultural elements such as teachers' roles outside of their profession and teachers' evaluation of students', colleagues', and administrators' feedback about their teaching.

In summary, this research contributes to the literature of teacher self-efficacy in terms of methodology. A qualitatively driven mixed method approach was used. It combined quantitative profiles of groups of teachers with observations of classroom practice and interviews. The findings indicated that:

- The teachers' self-efficacy scores were not directly related to the teachers' classroom practice.

- The sources of self-efficacy interacted dynamically with each other.

- The teachers' self-efficacy was influenced by personal, classroom and institutional, and cultural elements

\section{Implications}

The EFL teaching at tertiary level in Vietnam has a number of problems, resulting in graduates are unable to use English effectively and confidently in their future careers. This section gives some implications for directly influencing teacher self-efficacy. An improvement in teacher self-efficacy for EFL teachers will potentially enhance the EFL teaching quality in Vietnam.

\subsection{Teacher Knowledge and Professional Development}

Mastery experience has been said to be the strongest source of teacher self-efficacy (Bandura, 1997). The findings of this research show that teachers' knowledge, as a form of cognitive mastery experience, plays an important role in the formation of teacher self-efficacy. This has implications for improving teachers' self-efficacy by improving teachers' knowledge.

First and foremost, if teachers are equipped with content knowledge, they are likely to have higher self-efficacy. The participants in this study were working at the Faculty of English for Specific Purposes. They were teaching the English for business purposes. Therefore, in addition to being proficient in general English skills, they were also required to be competent in business English. In-service training or induction programmes of business English for teachers with other backgrounds than a business background could provide the necessary knowledge for these teachers. 


\section{VIETNAMESE EFL TEACHER SELF-EFFICACY IN PRACTICE}

Although having an advantage in terms of content knowledge, teachers graduating from business universities reported disadvantages because of a lack of pedagogical knowledge. Hence, the second aspect of teacher knowledge to improve is pedagogical knowledge. Similar to content knowledge of English language and business English, induction or training programmes about English language teaching methodologies and other teaching relevant knowledge for the teachers are important if teacher self-efficacy is to be raised. As some of the participating teachers in my study had English language teaching educational background and the others had an education background in business, there can be "exchange" seminars or workshops in which they share their knowledge of business English and pedagogy. This peer modelling is highly likely to be effective as peers are seen as credible sources of self-efficacy.

Teacher knowledge about the teaching context also contributes significantly to teacher self-efficacy. Therefore, prior to their first class meeting, teachers should be provided with centralised computer information about students and information about the classroom setting and teaching equipment. They could also benefit from other teachers' successful experiences of how to use textbooks and exploit supplementary materials. Seminars and workshops to share such experiences would be useful.

As discussed in Chapter 5, appropriate professional development can contribute to teachers' self-efficacy in a number of different ways. Through watching or listening to others' recounts of their teaching (vicarious experiences), teachers gain both pedagogical and content knowledge (mastery experiences). The feedback, including critique and compliments that the presenters receive act as social persuasion which may have an impact on their feelings (physiological and affective states). Therefore, it is important to organize professional development activities that directly address teachers' needs and meet their interests. Directly meeting such needs and interests is likely to contribute to teacher self-efficacy.

The data from this research show that the participants improve their self-efficacy after watching their colleagues teaching in their classes. Yet, only the observers benefitted from such observation because they just watched others' teaching practice and took away beneficial ideas without the teachers who were observed getting any feedback. To ensure the process is beneficial for both the observed teachers and the observers, peer coaching could be used. This is a process in which two teachers work together both inside and outside the classroom. They prepare lesson 


\section{VIETNAMESE EFL TEACHER SELF-EFFICACY IN PRACTICE}

plans, develop supplementary materials then observe one another teaching in his/her class. After the observation, they give each other feedback about their teaching and they can discuss comments. During the process, teachers can make suggestions and provide support and assistance for each other. It is important that teachers have freedom in selecting their peers. Their self-efficacy would benefit the most from their vicarious experience if they find many similarities between them and their peers.

A similar form of professional development that has been found to have a significant relationship with teacher self-efficacy in particular and teacher development, in general, is professional learning communities. Language faculties and university administrators can organise collaborative activities like seminars, workshops or conferences in which teachers share their successful teaching experiences and innovative teaching strategies in a collegial atmosphere. In addition, teachers can observe their peers' teaching and provide positive and constructive feedback. The collaborative reflection fosters their self-efficacy and somehow develops their collective efficacy. It is equally important that supervisors, senior teachers, and experts are engaged in professional learning communities because they can provide support for teachers when they need it.

From the research findings, some participants praised the usefulness of the conferences, seminars, and workshops that they attended meanwhile some others complained about the relevancy of such activities. Therefore, it is important to give teachers freedom in choosing their professional development activities. They would benefit the most from the ones that meet their interests or address their needs.

This section has presented the professional developments that are likely to improve teacher knowledge including peer coaching and professional learning communities and highlighted the importance of teacher autonomy in selecting the activities to attend. The upcoming section will express how administrators could support the development of teacher selfefficacy.

\subsection{Support from Administrators}

The data from this research show the effects of classroom conditions and institutional policies on teacher self-efficacy. Among those elements, collegiality, especially support from administrators and managerial staff, stood out as positively affecting teacher self-efficacy. 


\section{VIETNAMESE EFL TEACHER SELF-EFFICACY IN PRACTICE}

The findings of my research show that some teachers were struggling to search for suitable teaching materials for their classes while some others made use of the textbooks because they thought the books addressed their students' needs and are appropriate for their proficiency. Therefore, to reach the top efficiency, the administrators and managing staff can give instructions on how to use the teaching materials and suggest useful supplementary resources.

In addition, it would be ideal if the number of students in each language class could be reduced to around twenty. This helps to foster the mutual relationship between teachers and students. A better understanding of each other makes it easier for teachers to manage the class, select appropriate teaching materials, and design suitable activities.

Due to the insufficient equipment in the classroom, the participating teachers said their teaching sometimes did not meet their expectations. The teaching practice would be more effective if the classrooms were well-equipped with computers, loud-speakers, and Internet access. It would also be better if the classroom setting were more flexible so that the teachers could easily organise group or pair activities.

In timetabling, it would be beneficial for school administrators and managerial staff to consider teachers' personal life. In addition to the teaching jobs, teachers also perform a role in their family which takes as much energy, time, and effort as their role at work, especially in Vietnamese culture. Teacher self-efficacy development can be supported if timetables are organised in such ways that give teachers time to reflect on then re-plan their teaching.

This research has shown the relationship between teacher autonomy and teacher selfefficacy. The more freedom teachers have in teaching, the higher their self-efficacy is likely to be. A certain amount of autonomy in choosing materials, designing classroom activities and assessing students can increase teachers' levels of self-efficacy. Additionally, they should be able to contribute to the faculty and university decision making process. If their needs and desires are heard, it is likely that their self-efficacy will be improved.

This study has found that the teachers benefitted from the professional development activities that met their needs and interests more than from compulsory events. Therefore, instead of general or too broad topics, professional development activities that address specific issues would nurture teacher self-efficacy. 
VIETNAMESE EFL TEACHER SELF-EFFICACY IN PRACTICE

Although students' feedback about teachers' teaching practice (social persuasion) plays an important role in the formation of teacher self-efficacy, the contribution of students' feedback in this study was insignificant because of the way the feedback was collected and how the administrators used the feedback. Therefore, I suggest that the feedback collection process would be more effective when it involves all students and is conducted in the middle and at the end of the term. It would be more efficient if subject managers and faculty managers discuss with all teachers the results rather than only consult with the ones with low scores or negative feedback.

\section{Limitations}

This research examined teacher self-efficacy from different sources of data: survey, observations, and interviews. Although the triangulation of data was used to describe teacher self-efficacy in a more comprehensive and nuanced way, there remain some methodological limitations.

The first limitation of the study is the use of self-report data. Teachers' responses to the questionnaire were subjective and influenced by personal and cultural characteristics such as perceptions of the Likert scale. This can create issues of reliability and validity of the quantitative data because these personal perspectives may influence how participants decide to select positions on a Likert scale. When classifying the teachers into groups of higher, medium, and lower self-efficacy, the range of the scores was not big and the standard deviation for the total self-efficacy scores needs to be considered as there was not a large variation in self-efficacy among the groups. Nonetheless, the data demonstrate the multitude of influences on self-efficacy and the dynamic nature of those influences. This would suggest that the self-efficacy of any one teacher is difficult to predict.

Second, the case-study design allowed me to have an in-depth investigation into the participants' self-efficacy, but the rich data allow some transferability, rather than generalizability.

Third, each teacher was observed only once in their class. This provided only a snapshot of their actual teaching. However, I triangulated this with the stimulated recall with the teacher to gather reports of teacher decision making processes.

Some researchers may debate whether self-efficacy can be observable and whether classroom observation is an appropriate methodology to study teacher self-efficacy. The 


\section{VIETNAMESE EFL TEACHER SELF-EFFICACY IN PRACTICE}

observational data supplemented the understanding of the teachers' decision-making processes through stimulated recall.

This is primarily a qualitative study with eight participants. However, these participants were purposively selected from a bigger pool of participants who completed the questionnaire. The questionnaire data allows a description of the self-efficacy profiles of a wider group of participants.

\section{Areas for Future Research}

Very little research on teacher self-efficacy has been conducted in Vietnam. So far, there has been only one other published study which investigated the self-efficacy of EFL lecturers at a technical university. The scope of the research context could be expanded by including other tertiary institutions and school types. Comparative studies across various cultures can be considered. In addition, researchers can investigate self-efficacy of teachers of other subjects in Vietnamese schools. Future researchers could design longitudinal studies to observe teachers in their classes multiple times. This allows researchers to examine the changes in teacher selfefficacy over time and under different circumstances.

\section{Closing Thoughts}

This study has investigated teacher self-efficacy of EFL teachers in a business-majored university in Vietnam. It has found the reciprocal relationship between personal factors and environmental factors, and behaviors, which is a tenet of socio-cognitive theory (Bandura, 1997). Moreover, it has addressed the role of context and culture in the formation of the participants' self-efficacy. Contextual and cultural elements contributed significantly to the development of teacher self-efficacy. This has shown the dynamic and complex nature of teacher self-efficacy. Therefore, using a questionnaire to measure teacher self-efficacy may not provide a complete holistic picture of teacher self-efficacy. It is important that teacher self-efficacy is studied in relation to contextual, cultural, and personal elements.

Teachers developed their self-efficacy through four sources among which mastery and vicarious experiences in forms of professional development play the most significant role. The most effective activities to be suggested are peer coaching and professional learning communities. However, teachers cannot benefit largely from such activities without support from the subject managers, faculty dean, and other managerial staff to organise the activities and give 
VIETNAMESE EFL TEACHER SELF-EFFICACY IN PRACTICE

them autonomy in teaching as well as in professional learning. Such implications arising from the study of teacher self-efficacy in this context have the potential to address the issues in EFL teaching quality in Vietnam.

As an EFL teacher, I have always been curious about teacher self-efficacy. When I was a novice teacher, I felt more self-efficacious when teaching speaking and listening skills than teaching reading and writing. I seemed to be more confident in teaching students of lower level of proficiency. I was reluctant to teach a new textbook. However, after a few years teaching and participating in professional development activities, my self-efficacy has changed significantly. This research has deepened my understanding of how that happened. I now acknowledge the contribution of the self-efficacy sources as well as the contextual and cultural influences on teacher self-efficacy. More importantly, this study indicates suggestions to improve teacher selfefficacy. I would like to end this thesis by saying that teacher self-efficacy is not a static trait but a dynamic belief system that is changeable according to the teaching context. 
VIETNAMESE EFL TEACHER SELF-EFFICACY IN PRACTICE

\section{Appendices}

Appendix A

The Common European Framework of Reference for Languages (CEFR)

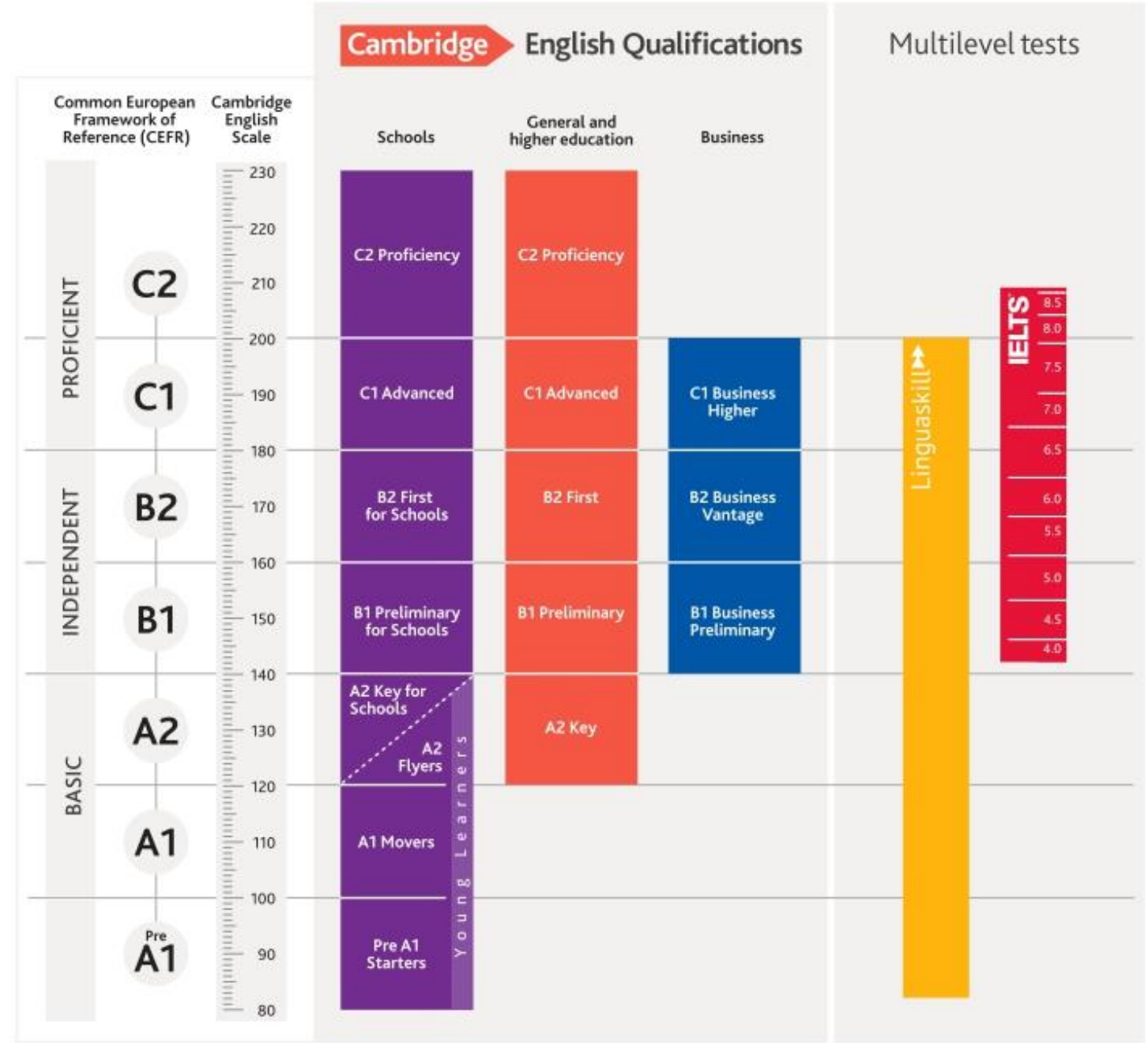


VIETNAMESE EFL TEACHER SELF-EFFICACY IN PRACTICE

\section{Appendix B}

Teacher Self-Efficacy Scale

Part 1: Teacher efficacy scale (adapted from (Tschannen-Moran \& Hoy, 2001)

\begin{tabular}{|l|l|l|l|l|l|}
\hline $\begin{array}{l}\text { Please indicate your personal opinion } \\
\text { about each of the statements below by }\end{array}$ \\
$\begin{array}{l}\text { circling the appropriate response at the } \\
\text { right of each statement. }\end{array}$ & & & & & \\
\hline I am confident that I am able to.... & & & & \\
\hline $\begin{array}{l}\text { secure students' attention throughout the } \\
\text { session }\end{array}$ & & & & & \\
\hline facilitate student participation & & & & & \\
\hline $\begin{array}{l}\text { motivate students who show very little } \\
\text { interest in English }\end{array}$ & & & & & \\
\hline $\begin{array}{l}\text { connect English learning with students' } \\
\text { life }\end{array}$ & & & & & \\
\hline $\begin{array}{l}\text { give students concrete experiences in } \\
\text { learning English }\end{array}$ & & & & & \\
\hline $\begin{array}{l}\text { establish a sense of community in my } \\
\text { classes }\end{array}$ & & & & & \\
\hline control disruptive behaviours in the class & & & & & \\
\hline get students to follow classroom rules & & & & & \\
\hline $\begin{array}{l}\text { teach English in a meaningful way that } \\
\text { connects to the use of English outside the } \\
\text { classroom }\end{array}$ & & & & & \\
\hline $\begin{array}{l}\text { determine the academic needs of my } \\
\text { students }\end{array}$ & & & & & \\
\hline $\begin{array}{l}\text { select appropriate written materials for } \\
\text { language teaching }\end{array}$ & & & & & \\
\hline
\end{tabular}


VIETNAMESE EFL TEACHER SELF-EFFICACY IN PRACTICE

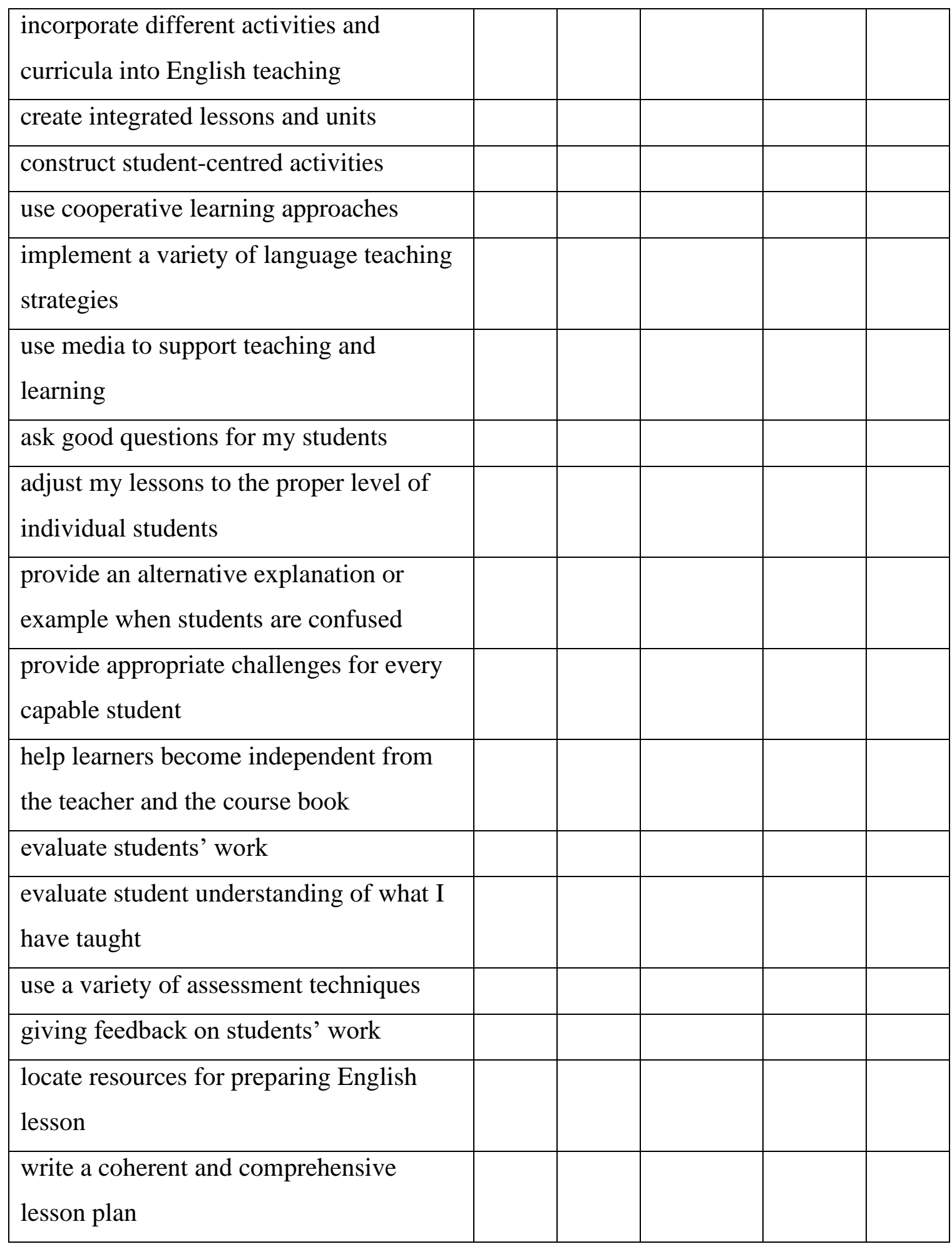

Part 2: Teacher background questionnaire (adapted from Yavuz, 2007)

Please complete or put a tick in the blanks.
1. Gender
( ) Male
( ) Female 
VIETNAMESE EFL TEACHER SELF-EFFICACY IN PRACTICE

2. Education

\begin{tabular}{|l|l|l|l|}
\hline & Department & Institution & Year of \\
& & & Graduation \\
\hline Bachelor & & & \\
\hline Master & & & \\
\hline PhD & & & \\
\hline
\end{tabular}

3. Years of experience in teaching ( ) 1-10 $\quad$ ( ) 11-20 $\quad$ ( ) over 20

4. Your position: ( ) Teacher ( ) Administrator ( ) Both

5. The number of classes you are teaching: ( ) $1 \quad$ ( ) $2 \quad$ ( ) $3 \quad$ ( ) $4 \quad$ ( ) 5 and above

6. Your students' levels of proficiency? (You can choose more than one option)
() Beginner
( ) Elementary
( ) Pre-Intermediate

() Intermediate

( ) Advanced

7. The average number of students in your classes: ( ) 20-30

( ) $31-40 \quad$ ( ) over 40
8. Teaching hours per week:
( ) $1-6$
( ) $7-12$
( ) $13-18$
( ) over 18

9. Any activities for professional development:

\begin{tabular}{|l|l|l|l|l|l|l|}
\hline & Never & Annually & Quarterly & Monthly & Weekly & Other \\
\hline $\begin{array}{l}\text { Attend in-service courses } \\
\text { regularly }\end{array}$ & & & & & & \\
\hline Attend conferences & & & & & & \\
\hline $\begin{array}{l}\text { Read books and journals on } \\
\text { ELT }\end{array}$ & & & & & & \\
\hline Carry out research in class & & & & & & \\
\hline
\end{tabular}

( ) other

10. Your confidence in using the target language 
VIETNAMESE EFL TEACHER SELF-EFFICACY IN PRACTICE

\begin{tabular}{|l|l|l|l|l|l|}
\hline & $\begin{array}{l}\text { Not } \\
\text { confident at } \\
\text { all }\end{array}$ & $\begin{array}{l}\text { Not very } \\
\text { confident } \\
\text { Speaking }\end{array}$ & $\begin{array}{l}\text { Neither } \\
\text { confident or } \\
\text { confident }\end{array}$ & $\begin{array}{l}\text { Somewhat } \\
\text { confident }\end{array}$ & $\begin{array}{l}\text { Completely } \\
\text { confident }\end{array}$ \\
\hline Reading & & & & & \\
\hline Writing & & & & & \\
\hline Listening & & & & & \\
\hline
\end{tabular}

Would you like to receive more information about the next phase of the research which involves observation in your classroom and an interview?

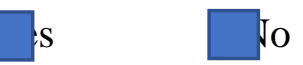

If yes, how should I contact you? 
VIETNAMESE EFL TEACHER SELF-EFFICACY IN PRACTICE

\section{Appendix C}

Guidelines for Individual Interviews and Stimulated Recalls

The interview will be conducted after the researcher observes the classroom. With different teaching practices in different classes, I will choose some appropriate questions from the list below.

\begin{tabular}{|c|c|c|c|}
\hline $\begin{array}{l}\text { Vietnamese } \\
\text { EFL teachers' } \\
\text { self-efficacy }\end{array}$ & \multicolumn{2}{|l|}{ Factors } & Guidelines for interviews and stimulated recalls \\
\hline \multirow[t]{4}{*}{$\begin{array}{l}\text { Perceptions of } \\
\text { personal } \\
\text { teaching } \\
\text { competence }\end{array}$} & \multirow[t]{3}{*}{ Strengths } & $\begin{array}{l}\text { Perception of English proficiency } \\
\text { levels and pedagogical knowledge }\end{array}$ & $\begin{array}{l}\text { As I have noticed, you mostly used English/Vietnamese when teaching. } \\
\text { Can you please explain why? } \\
\text { When teaching students various skills and knowledge, what is your strong } \\
\text { point? }\end{array}$ \\
\hline & & Personal qualities & $\begin{array}{l}\text { What do you think you have done successfully in this lesson? What } \\
\text { personal qualities help you do it? }\end{array}$ \\
\hline & & $\begin{array}{l}\text { Teaching recognition from students } \\
\text { and colleagues }\end{array}$ & $\begin{array}{l}\text { How do you get your students' feedback about your teaching? (Prompt: } \\
\text { Does your school collect students' feedback about your teaching? Are you } \\
\text { informed about their feedback?) }\end{array}$ \\
\hline & Deficits & Personal qualities & $\begin{array}{l}\text { What personal characteristics do you think can constraint your teaching? } \\
\text { What do you feel about your lesson today? }\end{array}$ \\
\hline
\end{tabular}


VIETNAMESE EFL TEACHER SELF-EFFICACY IN PRACTICE

\begin{tabular}{|c|c|c|c|c|}
\hline & & \multicolumn{2}{|c|}{ Teaching recognition from leaders } & $\begin{array}{l}\text { How do you get your colleagues'/ mentors'/ leaders' feedback about your } \\
\text { teaching? (Prompt: Have you ever been observed by your colleagues in } \\
\text { your class? How did they comment on your teaching?) }\end{array}$ \\
\hline \multirow[t]{6}{*}{$\begin{array}{l}\text { Contextualised } \\
\text { teaching } \\
\text { demand }\end{array}$} & \multirow[t]{6}{*}{ Constraints } & \multicolumn{2}{|c|}{ Managing roles } & $\begin{array}{l}\text { What challenges have you got as an EFL teacher? } \\
\text { Besides teaching, do you do any other jobs? What influences do they have } \\
\text { on your teaching? }\end{array}$ \\
\hline & & \multicolumn{2}{|l|}{ Collegiality } & $\begin{array}{l}\text { Have you got any close friends at work? What do you share to support } \\
\text { each other's work? How about your relationship with other colleagues? }\end{array}$ \\
\hline & & \multicolumn{2}{|c|}{$\begin{array}{l}\text { Professional development } \\
\text { opportunities }\end{array}$} & $\begin{array}{l}\text { What kind of professional development opportunities do you have? } \\
\text { (Prompt: Conferences? Seminars? Courses?) }\end{array}$ \\
\hline & & \multirow[t]{3}{*}{$\begin{array}{l}\text { Working } \\
\text { constraints }\end{array}$} & $\begin{array}{l}\text { Teaching } \\
\text { resources }\end{array}$ & $\begin{array}{l}\text { Most of your activities were taken from the course book. Why did you do } \\
\text { that? } \\
\text { Some of the activities you used were different from the course book? } \\
\text { Where did they come from? Why? } \\
\text { What sources did you get to design your classroom activities besides the } \\
\text { course book? }\end{array}$ \\
\hline & & & Syllabus & $\begin{array}{l}\text { Can you tell me a bit about the course that you are teaching? What are } \\
\text { your targets? What do you do to reach your course targets? }\end{array}$ \\
\hline & & & $\begin{array}{l}\text { Classroom } \\
\text { management }\end{array}$ & $\begin{array}{l}\text { What are the classroom rules that you set up to manage the class? Are the } \\
\text { rules the same for all classes you teach or are they different? }\end{array}$ \\
\hline
\end{tabular}




\begin{tabular}{|c|c|c|}
\hline & Unmotivated-less able learners & $\begin{array}{l}\text { Some students sitting at the back of the class were using facebook/ talking } \\
\text { about other things rather than the lesson. Did you notice that? Do you } \\
\text { usually encounter this situation? } \\
\qquad \text { Why did you do that to involve them in the lesson? Had you } \\
\text { done that before? Have you seen somebody did that? } \\
\rightarrow \text { Why did you just ignore them? } \\
\text { I noticed that some of your students were more engaged in your lesson } \\
\text { than some others. What do you think are the reasons? }\end{array}$ \\
\hline & Job security pressure & $\begin{array}{l}\text { What will happen if you get negative feedback from your students or } \\
\text { colleagues? }\end{array}$ \\
\hline & $\begin{array}{l}\text { Supervision and decision-making } \\
\text { process }\end{array}$ & $\begin{array}{l}\text { In your faculty, how often do you have meetings? What are the meetings } \\
\text { about? Do you have any voice in the meetings? }\end{array}$ \\
\hline & Status of the target language & What role does English have in your school curriculum and in the society? \\
\hline & $\begin{array}{l}\text { Traditional educational values and } \\
\text { norms }\end{array}$ & $\begin{array}{l}\text { What teaching methodologies are the most popular in your subject? Do } \\
\text { you follow the common ways or you have your own way? }\end{array}$ \\
\hline \multirow[t]{2}{*}{ Resources } & $\begin{array}{l}\text { Highly motivated, high-achieving } \\
\text { leaners }\end{array}$ & $\begin{array}{l}\text { I suppose that the proficiency of your students varies. What strategies do } \\
\text { you use to deal with highly motivated, high-achieving leaners? }\end{array}$ \\
\hline & Syllabus & $\begin{array}{l}\text { - What prevented you from reaching your teaching targets? Did you have } \\
\text { any problems with the classroom facilities or teaching resources? } \\
\text { - If you have the power to change, what will the changes be? }\end{array}$ \\
\hline
\end{tabular}


VIETNAMESE EFL TEACHER SELF-EFFICACY IN PRACTICE

Appendix D

Observation Schedule

\begin{tabular}{|c|c|c|}
\hline & $\begin{array}{l}\text { Strategies/ Methods the } \\
\text { teacher used to ... }\end{array}$ & Researcher's comments \\
\hline $\begin{array}{l}\text { secure students' attention } \\
\text { throughout the session }\end{array}$ & & \\
\hline facilitate student participation & & \\
\hline $\begin{array}{l}\text { motivate students who show } \\
\text { very little interest in English }\end{array}$ & & \\
\hline $\begin{array}{l}\text { connect English learning with } \\
\text { students' life }\end{array}$ & & \\
\hline $\begin{array}{l}\text { give students concrete } \\
\text { experiences in learning English }\end{array}$ & & \\
\hline $\begin{array}{l}\text { establish a sense of community } \\
\text { in my classes }\end{array}$ & & \\
\hline $\begin{array}{l}\text { control disruptive behaviours } \\
\text { in the class }\end{array}$ & & \\
\hline $\begin{array}{l}\text { get students to follow } \\
\text { classroom rules }\end{array}$ & & \\
\hline $\begin{array}{l}\text { teach English in a meaningful } \\
\text { way that connects to the use of } \\
\text { English outside the classroom }\end{array}$ & & \\
\hline $\begin{array}{l}\text { determine the academic needs } \\
\text { of my students }\end{array}$ & & \\
\hline $\begin{array}{l}\text { select appropriate written } \\
\text { materials for language teaching }\end{array}$ & & \\
\hline $\begin{array}{l}\text { incorporate different activities } \\
\text { and curricula into English } \\
\text { teaching }\end{array}$ & & \\
\hline
\end{tabular}


VIETNAMESE EFL TEACHER SELF-EFFICACY IN PRACTICE

\begin{tabular}{|c|c|c|}
\hline $\begin{array}{l}\text { create integrated lessons and } \\
\text { units }\end{array}$ & & \\
\hline $\begin{array}{l}\text { construct student-centred } \\
\text { activities }\end{array}$ & & \\
\hline $\begin{array}{l}\text { use cooperative learning } \\
\text { approaches }\end{array}$ & & \\
\hline $\begin{array}{l}\text { implement a variety of } \\
\text { language teaching strategies }\end{array}$ & & \\
\hline $\begin{array}{l}\text { use media to support teaching } \\
\text { and learning }\end{array}$ & & \\
\hline $\begin{array}{l}\text { ask good questions for my } \\
\text { students }\end{array}$ & & \\
\hline $\begin{array}{l}\text { adjust my lessons to the proper } \\
\text { level of individual students }\end{array}$ & & \\
\hline $\begin{array}{l}\text { provide an alternative } \\
\text { explanation or example when } \\
\text { students are confused }\end{array}$ & & \\
\hline $\begin{array}{l}\text { provide appropriate challenges } \\
\text { for every capable student }\end{array}$ & & \\
\hline $\begin{array}{l}\text { help learners become } \\
\text { independent from the teacher } \\
\text { and the course book }\end{array}$ & & \\
\hline evaluate students' work & & \\
\hline $\begin{array}{l}\text { evaluate student understanding } \\
\text { of what I have taught }\end{array}$ & & \\
\hline $\begin{array}{l}\text { use a variety of assessment } \\
\text { techniques }\end{array}$ & & \\
\hline $\begin{array}{l}\text { giving feedback on students' } \\
\text { work }\end{array}$ & & \\
\hline
\end{tabular}


VIETNAMESE EFL TEACHER SELF-EFFICACY IN PRACTICE

\begin{tabular}{|l|l|l|}
\hline locate resources for preparing & & \\
English lesson & & \\
\hline write a coherent and & & \\
comprehensive lesson plan & & \\
\hline
\end{tabular}




\section{Appendix E}

Information Sheet for Participants (Phase 1)

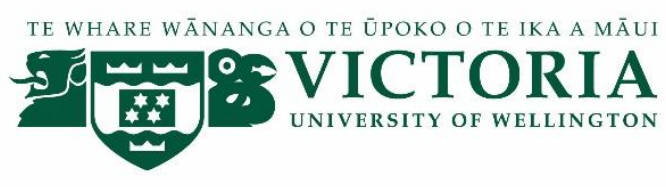

\section{What do Vietnamese EFL Teachers Believe about Teaching?}

\section{INFORMATION SHEET FOR PARTICIPANTS (PHASE 1)}

Thank you for your interest in this project. Please read this information before deciding whether or not to take part. If you decide to participate, thank you. If you decide not to take part, thank you for considering my request.

\section{Who am I?}

My name is Hoang, Thi Thu Ha. I was a lecturer of English as a Foreign Language (EFL) at Foreign Trade University in Vietnam. Now, I am a doctoral student in Education at Victoria University of Wellington, New Zealand. This research project is work towards my thesis.

\section{What is the aim of the project?}

I am investigating Vietnamese tertiary teachers' beliefs about aspects of their teaching. As a lecturer in EFL, I hope to get a better understanding of what Vietnamese EFL teacher believe about their teaching and how these beliefs affect their practice. This will identify ways to enhance teaching practice and may improve student achievement in learning English in universities in Vietnam.

This research has been approved by the Victoria University of Wellington Human Ethics Committee [provide approval number]. 
VIETNAMESE EFL TEACHER SELF-EFFICACY IN PRACTICE

\section{How can you help?}

My study has two phases, quantitative and qualitative, respectively. You can either take part in only the first or both phases. This information sheet is for the first phase in which you will be invited to response to a web-based survey about EFL teacher beliefs. It will take you about 10-15 minutes to complete the questionnaire. If you complete the questionnaire by the $31^{\text {st }}$ July 2016, you will be eligible to participate for the lucky draw for a gift voucher. At the end of the questionnaire, you will be asked whether you are willing to be observed and interviewed in the second phase of the project. If yes, you will be asked to provide contact details, and if you are selected for the interview phase, you will be given a separate information and consent form.

\section{What will happen to the information you give?}

The responses to this survey are anonymous. The data from the survey will be aggregated. If you decide that you wish to participate in the second phase of the research, then your data will be kept confidential and I will not name you or identify you in anyway. Access to the data is restricted to my supervisors and me. All data will be stored in password protected files and will be kept for three years, after which they will be destroyed.

\section{What will the project produce?}

The information from my research will be used in my $\mathrm{PhD}$ thesis. I may also use the results of my research for conference presentations, and academic reports. You will not be identified in my report. Pseudonyms will be used.

\section{If you accept this invitation, what are your rights as a research participant?}

You do not have to accept this invitation if you don't want to. If you do decide to participate, you have the right to:

- $\quad$ choose not to answer any question;

- $\quad$ be able to get a summary of the research findings;

- $\quad$ decide whether or not to take part in the second phase which includes classroom observation and interview.

If you have any questions or problems, who can you contact? 
VIETNAMESE EFL TEACHER SELF-EFFICACY IN PRACTICE

If you have any questions, either now or in the future, please feel free to contact either:

\section{Researcher:}

\section{Hoang, Thi Thu Ha}

School of Education

Victoria University of Wellington

University email address:ha.t.hoang@vuw.ac.nz

Telephone: +64 4639652

\section{Supervisors:}

\section{Dr. Carolyn Tait}

Role: Senior lecturer

School of Education

Victoria University of Wellington

Phone: +6449737267

Email: carolyn.tait @vuw.ac.nz

\section{AProf. David Crabbe}

Role: Dean of Education - Faculty of Education

Victoria University of Wellington

Phone: +64 4635603

Email: david.crabbe@vuw.ac.nz

\section{Human Ethics Committee information}

If you have any concerns about the ethical conduct of the research you may contact the Victoria University HEC Convener:

Associate Professor Susan Corbett.

Email: susan.corbett@vuw.ac.nz

Telephone: +64-4-463 5480 . 
VIETNAMESE EFL TEACHER SELF-EFFICACY IN PRACTICE

Appendix F

Information Sheet for Participants (Phase 2)

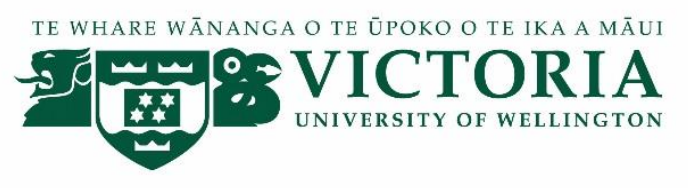

What do Vietnamese EFL Teachers Believe about Teaching?

INFORMATION SHEET FOR PARTICIPANTS (PHASE 2)

Thank you for your interest in this project. Please read this information before deciding whether or not to take part. If you decide to participate, thank you. If you decide not to take part, thank you for considering my request.

\section{Who am I?}

My name is Hoang, Thi Thu Ha. I was a lecturer of English as a Foreign Language (EFL) at Foreign Trade University in Vietnam. Now, I am a doctoral student in Education at Victoria University of Wellington, New Zealand. This research project is work towards my thesis.

\section{What is the aim of the project?}

I am investigating Vietnamese tertiary teachers' beliefs about aspects of their teaching. As a lecturer in EFL, I hope to get a better understanding of what Vietnamese EFL teacher believe about their teaching and how these beliefs affect their practice. This will identify ways to enhance teaching practice and may improve student achievement in learning English in universities in Vietnam.

This research has been approved by the Victoria University of Wellington Human Ethics Committee [provide approval number]. 
VIETNAMESE EFL TEACHER SELF-EFFICACY IN PRACTICE

\section{How can you help?}

My study has two phases, quantitative and qualitative, respectively. This information sheet is for the second phase. If you agree, I will observe your teaching in one of your English classes. Afterwards, I will interview you two times about what influences your teaching. The interviews will be conducted as soon after the observation as possible, but at your convenience. The first interview will be based on the field notes taken during the observation. The later one will be based on the video of your teaching. Each interview will last for approximately 30 minutes. The interview will be in Vietnamese. It will be audiorecorded, translated into English, then transcribed to be analysed. You can stop the interview at any time, without giving a reason. You can withdraw from the study up to two weeks after the second interview. If you withdraw, the information you provided will be destroyed. As a token of appreciation, I will give you a gift voucher.

\section{What will happen to the information you give?}

This research is confidential. I will not name you in any reports, and I will not include any information that would identify you. Access to the data is restricted to my supervisors and me. The interview transcripts, summaries and any recordings will be kept securely in a locked cabinet or password protected, and destroyed three years after the research ends by deleting or destroying all files and records. You will be sent a translation of the transcript of your interview to be checked and at that stage you may change or withdraw any information.

\section{What will the project produce?}

The information from my research will be used in my $\mathrm{PhD}$ thesis. I may also use the results of my research for conference presentations, and academic reports. You will not be identified in my report. Pseudonyms will be used.

\section{If you accept this invitation, what are your rights as a research participant?}

You do not have to accept this invitation if you don't want to. If you do decide to participate, you have the right to:

- $\quad$ choose not to answer any question;

- $\quad$ ask for the recorder to be turned off at any time during the interview; 
VIETNAMESE EFL TEACHER SELF-EFFICACY IN PRACTICE

- $\quad$ withdraw from the study up until two weeks after your second interview by sending me an email;

- $\quad$ ask any questions about the study at any time;

- $\quad$ receive a translation of your interview transcript;

- $\quad$ agree on another name for me to use rather than your real name;

- $\quad$ be provided with a summary of the findings;

If you have any questions or problems, who can you contact?

If you have any questions, either now or in the future, please feel free to contact either:

\section{Researcher:}

Hoang, Thi Thu Ha

School of Education

Victoria University of Wellington

University email address:ha.t.hoang@vuw.ac.nz

Telephone: +64 4639652

\section{Supervisors:}

Dr. Carolyn Tait

Role: Senior lecturer

School of Education

Victoria University of Wellington

Phone: +6449737267

Email: carolyn.tait@vuw.ac.nz

AProf. David Crabbe

Role: Dean of Education - Faculty of Education

Victoria University of Wellington

Phone: +64 4635603

Email: david.crabbe@vuw.ac.nz

\section{Human Ethics Committee information}


VIETNAMESE EFL TEACHER SELF-EFFICACY IN PRACTICE

If you have any concerns about the ethical conduct of the research you may contact the Victoria University HEC Convener:

Associate Professor Susan Corbett.

Email: susan.corbett@vuw.ac.nz

Telephone: +64-4-463 5480. 
VIETNAMESE EFL TEACHER SELF-EFFICACY IN PRACTICE

Appendix G

Information Sheet for the Dean

势

\section{What do Vietnamese EFL Teachers Believe about Teaching?}

\section{INFORMATION SHEET FOR THE DEAN}

Thank you for your interest in this project. Please read this information before deciding whether or not to allow me, the researcher, to conduct the research in your faculty. If you decide to participate, thank you. If you decide not to take part, thank you for considering my request.

My name is Hoang, Thi Thu Ha. I was a lecturer of English as a Foreign Language (EFL) at Foreign Trade University in Vietnam. Now, I am a doctoral student in Education at Victoria University of Wellington, New Zealand. This research project is work towards my thesis.

The main theme of my research is teacher self-efficacy which has been a prevalent research interest for decades. However, while some studies have investigated self-efficacy in an EFL teaching context, very little research has been done in a Vietnamese tertiary education setting. As a lecturer in EFL, I aim to get a better understanding of Vietnamese EFL teacher selfefficacy profiles and the relationship between self-efficacy and teaching practice. From the findings, I expect to find ways to enhance teacher self-efficacy.

This research has been approved by the Victoria University of Wellington Human Ethics Committee [provide approval number].

My study has two phases. In the first phase, the participants will be invited to response to a web-based survey questionnaire about EFL teacher self-efficacy. I hope that you can give me 
VIETNAMESE EFL TEACHER SELF-EFFICACY IN PRACTICE

the email addresses of the teaching staff so that I can send them details about this phase and a consent form to participate in the survey. In the qualitative phase, six teachers with different profiles of self-efficacy will be selected and I will observe in one of each their English classes. Using the field notes taken during the classroom observation, I will later interview the teachers about what influences their self-efficacy in the teaching practice. The interviews will be in Vietnamese. They will be audio-recorded, translated into English, then transcribed to be analysed. This research is confidential. I will not name the participants in any reports, and I will not include any information that would identify them. Only my supervisors and I will read the notes or transcript of the interviews. The interview transcripts, summaries and any recordings will be kept securely in a locked cabinet or password protected and destroyed three years after the research ends. Your university will not be identified by name.

If you consent, I will send you the information sheets and consent forms to the participants and the link to the questionnaire. I would be grateful if you could forward them to your colleagues in an email introducing me. My research will not be conducted without your permission to get access to your faculty and work with your colleagues. I will be grateful for your support.

If you have any questions, either now or in the future, please feel free to contact either:

\section{Researcher:}

\section{Hoang, Thi Thu Ha}

School of Education

Victoria University of Wellington

University email address:ha.t.hoang@vuw.ac.nz

Telephone: +64 4639652

\section{Supervisors:}

\section{Dr. Carolyn Tait}

Role: Senior lecturer 
VIETNAMESE EFL TEACHER SELF-EFFICACY IN PRACTICE

School of Education

Victoria University of Wellington

Phone: +6449737267

Email: carolyn.tait @ vuw.ac.nz

\section{AProf. David Crabbe}

Role: Dean of Education - Faculty of Education

Victoria University of Wellington

Phone: +64 4635603

Email: david.crabbe@vuw.ac.nz

\section{Human Ethics Committee information}

If you have any concerns about the ethical conduct of the research you may contact the Victoria University HEC Convener: Associate Professor Susan Corbett. Email susan.corbett@vuw.ac.nz or telephone +64-4-463 5480. 
VIETNAMESE EFL TEACHER SELF-EFFICACY IN PRACTICE

Appendix $\mathrm{H}$

Information Sheet for Students

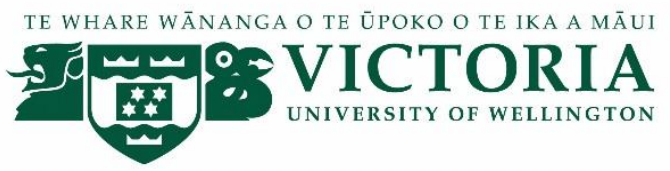

\section{What do Vietnamese EFL Teachers Believe about Teaching?}

\section{INFORMATION SHEET FOR STUDENTS}

Thank you for your interest in this project. Please read this information before deciding whether or not to take part. If you decide to participate, thank you. If you decide not to take part, thank you for considering my request.

\section{Who am I?}

My name is Hoang, Thi Thu Ha. I was a lecturer of English as a Foreign Language (EFL) at Foreign Trade University in Vietnam. Now, I am a doctoral student in Education at Victoria University of Wellington, New Zealand. This research project is work towards my thesis.

\section{What is the aim of the project?}

I am investigating Vietnamese tertiary teachers' beliefs about aspects of their teaching. As a lecturer in EFL, I hope to get a better understanding of what Vietnamese EFL teacher believe about their teaching and how these beliefs affect their teaching. This will identify ways to enhance teaching practice and may improve student achievement in learning English in universities in Vietnam.

This research has been approved by the Victoria University of Wellington Human Ethics Committee [provide approval number]. 
VIETNAMESE EFL TEACHER SELF-EFFICACY IN PRACTICE

\section{How can you help?}

My study has two phases, quantitative and qualitative, respectively. This information sheet is for the second phase in which I will observe one period of your English class. Your class will be video recorded. Your class will take place as usual. I will not interfere the lesson by sitting silently at the back of your class and taking notes. It would be great help for me if you just participate in the lesson as you usually do. If you do not want to be in the video, you will be seated so that your image will not be captured. More importantly, the video recordings themselves will not be used as the data. They will be shown only to your teacher and my supervisors. No parts involving students who do not want to participate will be included.

\section{What will happen to the information you give?}

This research is confidential. I will not name you in any reports, and I will not include any information that would identify you. Access to the data is restricted to my supervisors and me. All data will be stored in password protected files and will be kept for 3 years, after which they will be destroyed.

\section{What will the project produce?}

The information from my research will be used in my $\mathrm{PhD}$ thesis. I may also use the results of my research for conference presentations and academic reports.

\section{If you accept this invitation, what are your rights?}

You do not have to accept this invitation if you don't want to. It will not affect your academic progress if you choose not to participate. If you do decide to participate, you have the right to:

$$
\begin{aligned}
& \text { - } \quad \text { ask questions about the research at any stage; } \\
& \text { - } \quad \text { get a summary of the research findings. }
\end{aligned}
$$

\section{If you have any questions or problems, who can you contact?}

If you have any questions, either now or in the future, please feel free to contact either:

\section{Researcher:}


VIETNAMESE EFL TEACHER SELF-EFFICACY IN PRACTICE

\section{Hoang, Thi Thu Ha}

School of Education

Victoria University of Wellington

University email address:ha.t.hoang@vuw.ac.nz

Telephone: +64 4639652

\section{Supervisors:}

\section{Dr. Carolyn Tait}

Role: Senior lecturer

School of Education

Victoria University of Wellington

Phone: +6449737267

Email: carolyn.tait @ vuw.ac.nz

\section{AProf. David Crabbe}

Role: Dean of Education - Faculty of Education

Victoria University of Wellington

Phone: +64 4635603

Email: david.crabbe@vuw.ac.nz

\section{Human Ethics Committee information}

If you have any concerns about the ethical conduct of the research you may contact the Victoria University HEC Convener:

Associate Professor Susan Corbett.

Email: susan.corbett@vuw.ac.nz

Telephone: +64-4-463 5480 . 
VIETNAMESE EFL TEACHER SELF-EFFICACY IN PRACTICE

\section{Appendix I}

Information Sheet for Students (Vietnamese Translation)

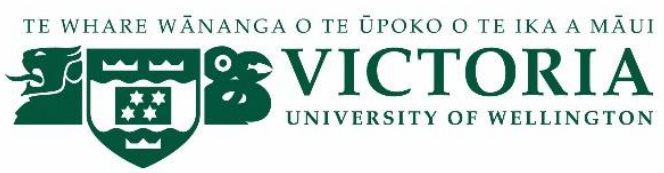

\section{Quan điểm của giáo viên Việt Nam về việc dạy tiếng Anh}

\section{PHIẾU THÔNG TIN DÀNH CHO SINH VIÊN}

Cảm ơn em đã quan tâm đến nghiên cứu này. Em hãy đọc kỹ thông tin dưới đây trước khi quyết định có tham gia hay không. Dù em có tham gia hay không, tôi cũng xin chân thành cảm ơn em.

Tôi là Hoàng Thị Thu Hà. Trước đây, tôi là giảng viên môn tiếng Anh tại trường đại học Ngoại thương. Hiện tại, tôi đang làm nghiên cứu sinh về giáo dục tại trường đại học Victoria, Wellington, New Zealand. Nghiên cứu này được dùng cho luận án của tôi.

Tôi đang nghiên cứu về quan điểm của giảng viên Việt Nam về việc dạy tiếng Anh. Với tư cách là một giảng viên tiếng Anh, tôi mong muốn được tìm hiểu sâu hơn về quan điểm của giảng viên Việt Nam về việc dạy tiếng Anh và ảnh hưởng của những quan điểm này với việc dạy học của họ để từ đó chỉ ra cách nâng cao chất lượng dạy và học tiếng Anh ở trường đại học ở Việt Nam.

Nghiên cứu này đã được Ban bảo vệ nhân quyền của trường đại học Victoria thông qua.

Nghiên cứu của tôi gồm hai giai đoạn, lần lượt là nghiên cứu định tính và nghiên cứu định lượng. Phiếu thông tin này dành cho giai đoạn hai. Lớp học của em sẽ diễn ra như bình thường. Tôi sẽ quan sát và quay phim lớp học của em. Tôi sẽ ngồi yên lặng ở cuối lớp và ghi chép để không làm ảnh hưởng đến lớp học. Tôi sẽ rất cảm kích nếu em tham gia vào lớp học như bình thường. Nếu em không muốn, em sẽ được xếp chỗ ngồi để em không bị ghi hình. Các đoạn phim cũng sẽ không được dùng làm số liệu. Chỉ có thầy/cô giáo của em và giáo viên hướng dẫn của tôi sẽ xem các đoạn phim đó. Và các đoạn phim có các em không muốn tham gia cũng sẽ không được sử dụng. 
VIETNAMESE EFL TEACHER SELF-EFFICACY IN PRACTICE

Nghiên cứu này sẽ được giữ kín. Tôi sẽ không nêu tên em trong bất kỳ báo cáo nào. Tôi cũng sẽ không đưa ra bất kỳ thông tin nào khiến em bị nhận diện. Chỉ có giáo viên hướng dẫn của tôi và tôi được tiếp cận dữ liệu. Tất cả dữ liệu sẽ được lưu trong các file có bảo mật và được lưu trong 3 năm, sau đó sẽ được hủy.

Cac thông tin thu thập được từ nghiên cứu này sẽ được dùng cho luận án tiến sĩ của tôi. Tôi cũng có thể trình bày kết quả nghiên cứu này trong các hội thảo hoặc báo cáo khoa học.

Em có thể tham gia nghiên cứu này hoặc không. Việc đó sẽ không làm ảnh hưởng đến kết quả học tập của em. Nếu tham gia, em có quyền:

- đặt câu hỏi về nghiên cứu này bất cứ khi nào em muốn;

- nhận được bản tóm tắt kết quả nghiên cứu.

Bất cứ khi nào em có câu hỏi về nghiên cứu của toi, xin liên hệ:

Nghiên cứu sinh:

Hoàng Thị Thu Hà

Khoa giáo dục

Trường đại học Victoria

Email: ha.t.hoang@vuw.ac.nz

Điện thoại: +64 4639652

Giáo viên hướng dẫn:

Tiến sĩ: Carolyn Tait

Giảng viên chính

Khoa giáo dục

Trường đại học Victoria

Email: carolyn.tait @vuw.ac.nz

Điện thoại: +6449737267

Phó giáo sư, tiến sĩ: David Crabbe

Trưởng khoa giáo dục

Trường đại học Victoria

Email: david.crabbe@vuw.ac.nz

Điện thoại: +64 4635603 
VIETNAMESE EFL TEACHER SELF-EFFICACY IN PRACTICE

Nếu em có thắc mắc về vấn đề nhân quyền của nghiên cứu này, xin liên hệ:

Đại diện ban bảo vệ nhân quyền

Phó giáo sư, tiến sĩ Susan Corbett

Email: susan.corbett@vuw.ac.nz

Điện thoại: +64-4-463 5480. 
VIETNAMESE EFL TEACHER SELF-EFFICACY IN PRACTICE

\section{Appendix J}

Consent form for the Dean

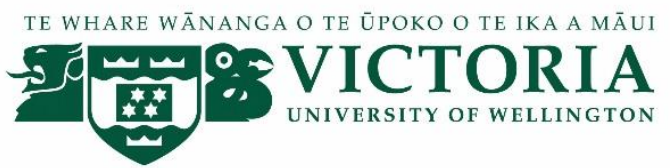

\section{What do Vietnamese EFL Teachers Believe about Teaching? CONSENT FORM FOR THE DEAN}

$\mathrm{I}$, as Dean of

University have been informed about the study of Mrs Hoang, Thi Thu Ha. I have read the information sheet and discussed further via email and telephone with the researcher. I am now fully aware of the research objectives, the research procedures, and the participants' roles.

I also understand that:

The data collected will be primarily used to produce the researchers' thesis and can be published in academic articles or presented in conferences.

All the participants are volunteers. They have the right to withdraw until two weeks after the second interview. They can deny, add, or modify any information in the transcript. They also have the right to refuse to answer any questions.

- Data will be collected anonymously in the survey and confidentially by using pseudonyms in the observations and interviews. Neither the participants' names nor the faculty's and university's name will be used in any publications or presentations based on the data from this research.

Data will be kept confidentially in a secure place or password protected and will be destroyed three years after the research is finished.

By signing this form, I consent to give the researcher permission to conduct her study at my faculty. 
Appendix K

Consent Form for Participants (Phase 1)

\section{What do Vietnamese EFL Teachers Believe about Teaching? CONSENT TO ANSWER A QUESTIONNAIRE}

Researcher: Hoang, Thi Thu Ha, PhD candidate, Faculty of Education, Victoria University of Wellington

- I have read the information provided and I have had an opportunity to email the researcher with questions. My questions have been answered to my satisfaction. I understand that I can ask further questions at any time.

I understand that:

- I may withdraw from this study be exiting the questionnaire before the final page, and any information that I have provided will be destroyed.

- $\quad$ The information I have provided will be destroyed three years after the research is finished.

- $\quad$ Any information I provide will be anonymous and the data will be aggregated.

- $\quad$ The results will be used for a PhD report and a summary of the results may be used in academic reports and/or presented at conferences.

- $\quad$ My name will not be used in reports, nor will any information that would identify me.

Before proceeding past this page, I give consent to be participate in the questionnaire. 
VIETNAMESE EFL TEACHER SELF-EFFICACY IN PRACTICE

\section{Appendix L}

Consent Form for Participants (Phase 2)

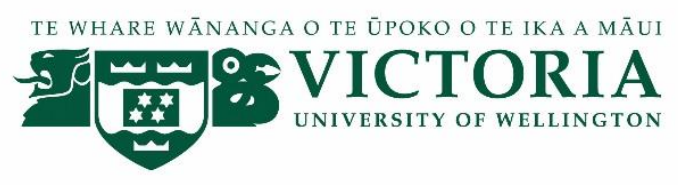

What do Vietnamese EFL Teachers Believe about Teaching?

\section{PARTICIPANT CONSENT FORM (PHASE 2)}

Researcher: Hoang, Thi Thu Ha, Faculty of Education, Victoria University of Wellington

I have read the Information Sheet and the project has been explained to me. My questions have been answered to my satisfaction. I understand that I can ask further questions at any time.

I agree that the researcher can observe and video-record my English classes and I will take part in an audio recorded interview.

I understand that:

- I may withdraw from this study up to two weeks after the second interview and any information that I have provided will be returned to me or destroyed.

- $\quad$ The information I have provided will be destroyed three years after the research is finished.

- $\quad$ Any information I provide will be kept confidential to the researcher and the supervisors. I understand that the results will be used for a $\mathrm{PhD}$ report and a summary of the results may be used in academic reports and/or presented at conferences. 
VIETNAMESE EFL TEACHER SELF-EFFICACY IN PRACTICE

- $\quad$ The researcher may ask me for further follow-up interviews to ensure that my views have been fully understood.

- I will have a chance to check the accuracy of the translation of the interviews.

I wish to receive feedback from this project by being sent a summary of the research.

$\begin{array}{ll}\square & \text { Yes } \\ \square & \text { No }\end{array}$

Signature of participant:

Name of participant:

Date:

Contact details: 
VIETNAMESE EFL TEACHER SELF-EFFICACY IN PRACTICE

\section{Appendix M}

Student Consent Form

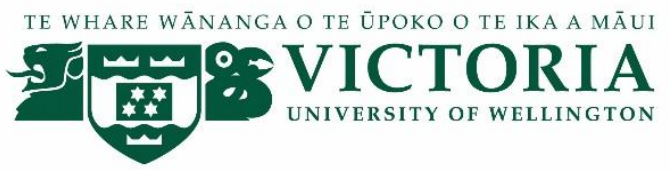

\section{What do Vietnamese EFL Teachers Believe about Teaching?}

\section{STUDENT CONSENT FORM}

This consent form will be held for three years.

Researcher: Hoang, Thi Thu Ha, Faculty of Education, Victoria University of Wellington

I have read the Information Sheet and the project has been explained to me. My questions have been answered to my satisfaction. I understand that I can ask further questions at any time.

I agree that I can be video-recorded in my English class.

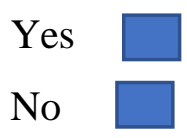

Signature of student:

Name of student:

Date: 
VIETNAMESE EFL TEACHER SELF-EFFICACY IN PRACTICE

Appendix N

Student Consent Form (Vietnamese Translation)

TE WhARE WĀNANGA O TE ŪPOKO O TE IKA A MĀUI

\section{Quan điểm của giáo viên Việt Nam về việc dạy tiếng Anh PHIẾU ĐỒNG Ý CỦA SINH VIÊN}

Nghiên cứu sinh: Hoàng Thị Thu Hà, Khoa giáo dục, Trường đại học Victoria

Tôi đã đọc kỹ phiếu thông tin và đã hiểu rõ về nghiên cứu này. Các câu hỏi của tôi cũng đã được giải đáp thỏa đáng. Tôi hiểu rằng tôi có thể hỏ thêm thông tin bất cứ khi nào.

Tôi đồng ý để được ghi hình trong lớp học tiếng Anh.

Chữ ký:

Họ tên:

Ngày: 
VIETNAMESE EFL TEACHER SELF-EFFICACY IN PRACTICE

\section{Appendix O}

Reflective Fieldnote

Date:

Time:

Teacher code:

Class code:

Classroom setting:

Total number of students:

Room organization:

Available teaching resources and conditions:

\begin{tabular}{|l|l|l|}
\hline Time/Duration & Incident & Comment \\
\hline & & \\
\hline & & \\
\hline & & \\
\hline & & \\
\hline
\end{tabular}


VIETNAMESE EFL TEACHER SELF-EFFICACY IN PRACTICE

Appendix $\mathrm{P}$

Ethics Approval

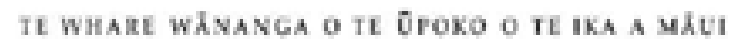

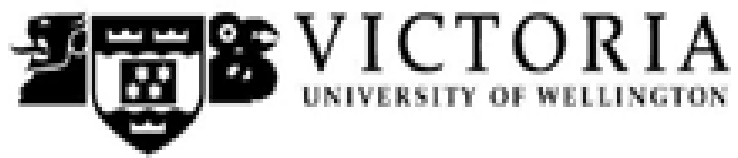

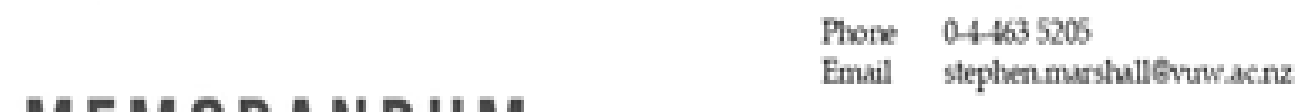

MEMORANDUM

\begin{tabular}{l|l}
\hline TO & Ha Hoang \\
\hline COPY TO & \\
\hline FROM & Dr Stephen Marshall, Acting Convener, Human Ethics Committee \\
\hline
\end{tabular}

\begin{tabular}{l|l}
\hline DATE & 25 June 2016 \\
\hline PAGES & 1 \\
\hline
\end{tabular}

\begin{tabular}{l|l} 
SUBJECT & $\begin{array}{l}\text { Ethics Approval: } \mathbf{2 3 1 6 9} \\
\text { Vietnamese English language teachers' self-eficacy }\end{array}$ \\
\hline
\end{tabular}

Thank you for your application for ethical approval, which has now been considered by the Standing Committee of the Human Ethics Committee.

Your application has been approved from the above date and this approval continues until 30 March 2019. If your data collection is not completed by this date you should apply to the Human Ethics Committee for an extension to this approval.

Best wishes with the research.

Stephen Marshall,

Acting Convener, Victoria University Human Ethics Committee 


\section{References}

Abu-Tineh, A. M., Khasawneh, S. A., \& Khalaileh, H. A. (2011). Teacher self-efficacy and classroom management styles in Jordanian schools. Management in Education, 25(4), 175181. doi:10.1177/0892020611420597

Allinder, R. M. (1995). An examination of the relationship between teacher efficacy and curriculum-based measurement and student achievement. Remedial and Special Education, 16(4), 247-254. doi:10.1177/074193259501600408

Almog, O., \& Shechtman, Z. (2007). Teachers' democratic and efficacy beliefs and styles of coping with behavioural problems of pupils with special needs. European Journal of Special Needs Education, 22(2), 115-129. doi:10.1080/08856250701267774

Armor, D., Conry-Oseguera, P., Cox, M., King, N., McDonnell, L., Pascal, A., . . Zeilman, G. (1976). Analysis of the school preferred reading program in selected Los Angeles minority schools Retrieved from Santa Monica:

Armour-Thomas, E. (1989). The application of teacher cognition in the classroom: A new teaching competency. Journal of Research and Development in Education, 22(3), 29-37.

Ashley, A. (2003). Oxford handbook of commercial correspondence (2 ed.): Oxford University Press.

Ashton, P. T. (1990). Editorial. Journal of Teacher Education, 41(1), 2-2. doi:10.1177/002248719004100101

Ashton, P. T., Buhr, D., \& Crocker, L. (1984). Teachers' sense of efficacy: A self- or normreferenced construct? Florida Journal of Educational Research, 26(1), 29-41.

Ashton, P. T., Olejnik, S. F., Crocker, L., \& McAuliffe, M. (1982). Measurement problems in the study of teachers' sense of efficacy. Paper presented at the annual meeting of the American Educational Research Association. New York.

Atay, D. (2007). Beginning teacher efficacy and the practicum in an EFL context. Teacher Development, 11(2), 203-219. doi:10.1080/13664530701414720

Aydin, Y. C., \& Hoy, A. W. (2005). What predicts student teacher self-efficacy? Academic Exchange Quarterly, 9(4), 123.

Bandura, A. (1977). Self-efficacy: Toward a unifying theory of behavioral change. Psychological Review, 84(2), 191-215. doi:10.1037/0033-295X.84.2.191

Bandura, A. (1991). Social cognitive theory of self-regulation. organizational Behavior and Human Decision Processes, 50, 248-287.

Bandura, A. (1993). Perceived self-efficacy in cognitive development and functioning. Educational Psychologist, 28(2), 117-148. doi:10.1207/s15326985ep2802_3

Bandura, A. (1997). Self-efficacy: The exercise of control. New York: Freeman.

Bautista, N. U. (2011). Investigating the use of vicarious and mastery experiences in influencing early childhood education majors' self-efficacy beliefs. Journal of Science Teacher Education, 22(4), 333-349. doi:10.1007/s10972-011-9232-5

Bautista, N. U., \& Boone, W. J. (2015). Exploring the impact of TeachME ${ }^{\mathrm{TM}}$ lab virtual classroom teaching simulation on early childhood education majors' self-efficacy beliefs. Journal of Science Teacher Education, 26(3), 237-262. doi:10.1007/s10972-014-9418-8

Ben-Peretz, M. (2011). Teacher knowledge: What is it? How do we uncover it? What are its implications for schooling? Teaching and Teacher Education, 27(1), 3-9. doi:10.1016/j.tate.2010.07.015 


\section{VIETNAMESE EFL TEACHER SELF-EFFICACY IN PRACTICE}

Benson, P. (2000). Autonomy as a leaners' and teachers' right. In B. Sinclair, I. McGrath, \& T. Lamb (Eds.), Learner autonomy, teacher autonomy: Future directions (pp. 111-117). Harlow: Longman.

Best, B. (2014). A study of elementary school Thai English teachers' percieved English proficiency and self-reported English teaching efficacy. Language in India, 14(7).

Borg, M. (2001). Key concepts in ELT: Teachers' beliefs. ELT Journal, 55(2), 186. doi:10.1093/elt/55.2.186

Borg, S. (2018). Teachers' beliefs and classroom practices. In P. Garret \& J. M. Cots (Eds.), The Rotledge Handbook of Language Awareness (pp. 75-91). New York and London: Rotledge.

Braga, M., Paccagnella, M., \& Pellizzari, M. (2014). Evaluating students' evaluations of professors. Economics of Education Review, 41(C), 71-88. doi:10.1016/j.econedurev.2014.04.002

Braun, V., \& Clarke, V. (2006). Using thematic analysis in psychology. Qualitative Research in Psychology, 3(2), 77-101. doi:10.1191/1478088706qp063oa

Brennan, M. D., \& Robinson, C. (1995). Gender comparison of teacher's sense of efficacy (ED: 384288). Retrieved from ERIC Digests Washington, DC:

Brouwers, A., \& Tomic, W. (2000). A longitudinal study of teacher burnout and perceived selfefficacy in classroom management. Teaching and Teacher Education, 16(2), 239-253. doi:10.1016/S0742-051X(99)00057-8

Brown, G. T. L., Harris, L. R., \& Harnett, J. (2012). Teacher beliefs about feedback within an assessment for learning environment: Endorsement of improved learning over student well-being. Teaching and Teacher Education, 28(7), 968-978. doi:10.1016/j.tate.2012.05.003

Bruce, C. D., Esmonde, I., Ross, J., Dookie, L., \& Beatty, R. (2010). The effects of sustained classroom-embedded teacher professional learning on teacher efficacy and related student achievement. Teaching and Teacher Education, 26(8), 1598-1608. doi:10.1016/j.tate.2010.06.011

Buehl, M. M., \& Beck, J. S. (2014). The relationship between teachers' beliefs and teachers' practices. In H. Fives \& M. Gregoire Gill (Eds.), International handbook of rsearch on teachers' beliefs (pp. 78-96). New York: Routledge.

Bumen, N. T. (2010). The relationship between demographics, self-efficacy, and burnout among teachers. Eurasian Journal Of Educational Research, 10(40), 16-35.

Burton, D., \& Bartlett, S. (2009). Key issues for education researchers. Los Angeles: Sage.

Cabaroglu, N. (2014). Professional development through action research: Impact on self-efficacy. System, 44(1), 79-88. doi:10.1016/j.system.2014.03.003

Çakiroglu, J., \& Boone, W. (2005). Pre-service teacher self-efficacy beliefs regarding science teaching: A comparison of pre-service teachers in Turkey and the USA. Science Educator, 14(1), 31-40.

Canrinus, E., Helms-Lorenz, M., Beijaard, D., Buitink, J., \& Hofman, A. (2012). Self-efficacy, job satisfaction, motivation and commitment: Exploring the relationships between indicators of teachers' professional identity. European Journal of Psychology of Education, 27(1), 115-132. doi:10.1007/s10212-011-0069-2

Cantrell, P., Young, S., \& Moore, A. (2003). Factors affecting science teaching efficacy of preservice elementary teachers. Journal of Science Teacher Education, 14(3), 177-192. doi:10.1023/A:1025974417256 
Caprara, G. V., Barbaranelli, C., Borgogni, L., Petitta, L., \& Rubinacci, A. (2003). Teachers', school staff's and parents' efficacy beliefs as determinants of attitudes toward school. European Journal of Psychology of Education, 18(1), 15-31.

Caprara, G. V., Barbranelli, C., Steca, P., \& Malone, P. S. (2006). Teachers' self-efficacy beliefs as determinants of job satisfaction and students' academic achievement: A study at the school level. Journal of School Psychology, 44(6), 473-490. doi:10.1016/j.jsp.2006.09.001

Carrell, Scott E., \& West, James E. (2010). Does professor quality matter? Evidence from random assignment of students to professors. Journal of Political Economy, 118(3), 409-432. doi: $10.1086 / 653808$

Chacón, C. T. (2005). Teachers' perceived efficacy among English as a foreign language teachers in middle schools in Venezuela. Teaching and Teacher Education, 21(3), 257-272. doi:doi.org/10.1016/j.tate.2005.01.001

Chan, W.-Y., Lau, S., Nie, Y., Lim, S., \& Hogan, D. (2008). Organizational and personal predictors of teacher commitment: The mediating role of teacher efficacy and identification with school. American Educational Research Journal, 45(3), 597-630. doi:10.3102/0002831208318259

Charmaz, K. (2013). Constructing grounded theory (2nd ed.). London: Sage.

Chesnut, S. R., \& Burley, H. (2015). Self-efficacy as a predictor of commitment to the teaching profession: A meta-analysis. Educational Research Review, 15, 1-16. doi:10.1016/j.edurev.2015.02.001

Chiang, M.-H. (2008). Effects of fieldwork experience on empowering prospective foreign language teachers. Teaching and Teacher Education, 24(5), 1270-1287. doi:10.1016/j.tate.2007.05.004

Cohen, L., Manion, L., \& Morrison, K. (2000). Research methods in education (5th ed.). London: Routledge Falmer.

Cohen, L., Manion, L., \& Morrison, K. (2007). Research methods in education (6th ed.). London: Routledge.

Cohen, L., Manion, L., \& Morrison, K. (2011). Research methods in education (7th ed.). New York: Routledge.

Coladarci, T., \& Breton, W. (1997). Teacher efficacy, supervision, and the special education resource-room teacher. Journal of EDucational REsearch, 90, 230-239.

Cone, N. (2009). Community-based service-learning as a source of personal self-efficacy: preparing preservice elementary teachers to teach science for diversity. School Science and Mathematics, 109(1), 20-30. doi:https://doi.org/10.1111/j.1949-8594.2009.tb17859.x

Cortina, J. M. (1993). What is coefficient alpha? An examination of theory and applications. Journal of Applied Psychology, 78(1), 98-104. doi:10.1037/0021-9010.78.1.98

Creswell, J. W. (2009). Research design: Qualitative, quantitative, and mixed methods approaches (3rd ed.). Los Angeles: Sage.

Creswell, J. W. (2012). Educational research: Planning, conducting, and evaluating quantitative and qualitative research (4th ed.). Boston: Pearson.

Creswell, J. W. (2013). Qualitative inquiry and research design: Choosing among five approaches (3rd ed.). Los Angeles: Sage.

Creswell, J. W. (2014). Research design: Qualitative, quantitative, and mixed methods approaches (4th ed.). Thousand Oaks: Sage.

Creswell, J. W., \& Plano Clark, V. L. (2011). Designing and conducting mixed methods research (2nd ed.). Thousand Oaks: Sage. 


\section{VIETNAMESE EFL TEACHER SELF-EFFICACY IN PRACTICE}

Cundale, N. (2001). What we preach? Stated beliefs about communicative language teaching and classroom questioning strategies. The Language Teacher, 25(5), 4-9.

Davis, M. M., Konopak, B. C., \& Keadence, J. E. (1993). An investigation of two chapter i teachers' beliefs about reading and instructional practices. Reading Reasearch and Instruction, 33(2), 105-133.

Dellinger, A. M. B. (2001). A study of the measurement and sources of teachers' self and collective efficacy beliefs in professional learning environments. (3021424 Ph.D.). Louisiana State University and Agricultural \& Mechanical College, Ann Arbor. ProQuest Dissertations \& Theses Global database.

Dellinger, J. B., Bobbett, J. J., Olivier, D. F., \& Ellett, C. D. (2008). Measuring teachers' selfefficacy beliefs: Development and use of the TEBS-Self. Teaching and Teacher Education, 24(3), 751-766. doi:http://dx.doi.org/10.1016/j.tate.2007.02.010

Denscombe, M. (2003). The good research guide for small-scale social research projects (2nd ed.). Maidenhead: Open University Press.

Denscombe, M. (2008). Communities of practice: A research paradigm for the mixed methods approach. Journal of Mixed Methods Research, 2(3), 270-283. doi:10.1177/1558689808316807

Denzin, N. K., \& Lincoln, Y. S. (2005). The SAGE handbook of qualitative research. Thousand Oaks: Sage

DiBella-McCarthy, H., McDaniel, E., \& Miller, R. (1995). How efficacious are you? The Council for Exceptional Children, 27(3), 68-72.

Dikilita, K., \& Griffiths, C. (2017). Developing language teacher autonomy through action research. doi:10.1007/978-3-319-50739-2

Do, H. T. (2006). The role of English in Vietnam's foreign language policy: A brief history. Paper presented at the 19th Annual EA Education Conference 2006, Perth, Australia.

Duffy, G., \& Anderson, L. (1984). Teachers' theoretical orientations and the real classroom. Reading Psychology, 5(1-2), 97-104.

Dunn, K., \& Rakes, G. (2011). Teaching teachers: An investigation of beliefs in teacher education students. Learning Environments Research, 14(1), 39-58. doi:10.1007/s10984-011-90831

Egyed, C. J., \& Short, R. J. (2006). Teacher self-efficacy, burnout, experience and decision to refer a disruptive student. School Psychology International, 27(4), 462-474. doi:10.1177/0143034306070432

Eisner, E. W. (1998). The enlightened eye: Qualitative inquiry and the enhancement of educational practice. Upper Saddle River: Merrill.

Elbaz, F. (1983). Teacher thinking: A study of practical knowledge. New York: Nichols.

Emmer, E. (1990). A scale for measuring teacher efficacy in classroom management and discipline. Paper presented at the annual meeting of the American Educational Research Association, Boston(MA).

Emmer, E., \& Hickman, J. (1990). Teacher decision making as a function of efficacy, attribution, and reasoned action. Paper presented at the annual meeting of the American Educational Research Association, Boston(MA).

Enochs, L. G., Smith, P. L., \& Huinker, D. (2000). Establishing factorial validity of the mathematics teaching efficacy beliefs instrument. School Science and Mathematics, 100(4), 194. doi:10.1111/j.1949-8594.2000.tb17256.x 


\section{VIETNAMESE EFL TEACHER SELF-EFFICACY IN PRACTICE}

Eslami, Z. R., \& Fatahi, A. (2008). Teachers' sense of self-efficacy, English proficiency, and instructional strategies: A study of nonnative EFL teachers in Iran. Teaching English as a SEcond or Foreign Language, 11(4).

Fang, Z. (1996). A review of research on teacher beliefs and practices. Educational Research, $38(1), 47-65$.

Farrell, T., \& Tun, S. T. K. (2008). Language policy, language teachers' beliefs, and classroom practices. Applied Linguistics, 29(3), 381-403.

Farrell, T. S. C., \& Lim, P. C. P. (2005). Conceptions of grammar teaching: A case study of teachers' beliefs and classroom practices. TESL-EJ: Teaching English as a Second or Foreign Language, 9(2), 1-13.

Fives, H., \& Looney, L. (2009). College instructors' sense of teaching and collective efficacy. International Journal of Teaching and Learning in Higher Education, 20(2), 182-191.

Ford, T. G., Van Sickle, M. E., Clark, L. V., Fazio-Brunson, M., \& Schween, D. C. (2017). Teacher self-efficacy, professional commitment, and high-stakes teacher evaluation policy in Louisiana. Educational Policy, 31(2), 202-248. doi:10.1177/0895904815586855

Gao, Y. (2014). Language teacher beliefs and practices: A historical review. Journal of English as an International Language.

García-Ros, R., Fuentes, M. C., \& Fernández, B. (2015). Teacher' interpersonal self-efficacy: Evaluation and predictive capacity of teacher burnout. Electronic Journal of Research in Educational Psychology, 13(3), 483-502. doi:10.14204/ejrep.37.14105

Garvis, S., \& Pendergast, D. (2011). An investigation of early childhood teacher self-efficacy beliefs in the teaching of arts education. International Journal of Education \& the Arts, 12(9), 1-16.

Gass, S. M. (2001). Innovations in second language research methods. Annual Review of Applied Linguistics, 21, 221-232.

Gass, S. M., \& Mackey, A. (2000). Stimulated recall in second language research. Mahwah: Lawrence Erlbaum Associates

Gencer, A. S., \& Cakiroglu, J. (2007). Turkish preservice science teachers' efficacy beliefs regarding science teaching and their beliefs about classroom management. Teaching and Teacher Education, 23(5), 664-675. doi:http://dx.doi.org/10.1016/j.tate.2005.09.013

Ghaemi, F., Shokrolahi, M., \& Hashemizadeh, S. M. (2015). The role of self-efficacy and autonomy in Iranian EFL teachers engagement. ELT Voices - International Journal for Teachers of English, 5(2), 58-67.

Ghasemboland, F., \& Hashim, F. B. (2013). Teachers' self-efficacy beliefs and their English language proficiency: A study of nonnative EFL teachers in selected language centers. Procedia - Social and Behavioral Sciences, 103, 890-899. doi:http://dx.doi.org/10.1016/j.sbspro.2013.10.411

Giang, T. (2011). Tren 53\% sinh vien kho dat chuan dau ra [More than 53\% of students find it hard to achieve the exit English level]. doi:https://tuoitre.vn/tren-53-sinh-vien-kho-datchuan-dau-ra-462236.htm

Gibson, S., \& Dembo, M. H. (1984). Teacher efficacy: A construct validation. Journal of Educational Psychology, 76(4), 569-582. doi:10.1037/0022-0663.76.4.569

Gillham, B. (2008). Observation techniques : Structured to unstructured (2nd ed.). London: Continuum International.

Goker, S. D. (2006). Impact of peer coaching on self-efficacy and instructional skills in TEFL teacher education. System, 34(2), 239-254. doi:10.1016/j.system.2005.12.002 


\section{VIETNAMESE EFL TEACHER SELF-EFFICACY IN PRACTICE}

Greene, J. C. (2007). Mixed methods in social inquiry (1st ed.). San Francisco: CA: Jossey-Bass.

Greenglass, E. R., \& Burke, R. J. (2003). Teacher stress. In M. F. Dollard, A. H. Winefield, \& H. R. Winefield (Eds.), Occupational stress in the service professions (pp. 213-236). New York: Taylor and Francis.

Greenwood, G. E., Olejnik, S. F., \& Parkay, F. W. (1990). Relationships between four teacher efficacy beleif patterns and selected teacher characteristics Journal of Research and Development in Education, 23(2), 102-106.

Grossman, P. L. (1990). The making of a teacher: Teacher knowledge and teacher education. New York: Teachers College Press, Teachers College, Columbia University.

Grossman, P. L., \& Richert, A. E. (1988). Unacknowledged knowledge growth: A re-examination of the effects of teacher education. Teaching and Teacher Education, 4(1), 53-62. doi:10.1016/0742-051X(88)90024-8

Guba, E. G. (1990). The paradigm dialog Newbury Park: CA: Sage.

Guo, Y., Connor, C. M., Yang, Y., Roehrig, A. D., \& Morrison, F. J. (2012). The effects of teacher qualification, teacher self-efficacy, and classroom practices on fifth graders' literacy outcomes. The Elementary School Journal, 113(1), 3-24. doi:10.1086/665816

Guo, Y., Dynia, J. M., Pelatti, C. Y., \& Justice, L. M. (2014). Self-efficacy of early childhood special education teachers: Links to classroom quality and children's learning for children with language impairment. Teaching and Teacher Education, 39, 12-21. doi:10.1016/j.tate.2013.11.005

Guskey, T. (1981). Measurement of the responsibility teachers assume for academic successes and failures in the classroom. Journal of Teacher Education, 32(3), 44.

Hackett, R. D., Lapierre, L. M., \& Hausdorf, P. A. (2001). Understanding the links between work commitment constructs. Journal of Vocational Behavior, 58(3), 392-413. doi:10.1006/jvbe.2000.1776

Hang, T. N. M. (2017). Contextual factors affecting the implementation of communicative language teaching in Vietnam. EFL Journal, 2(2).

Haq, M. U., \& Akhtar, M. (2013). Do school level and years of teaching experience really matter? An investigation of Pakistani teachers' self-efficacy beliefs. Middle-East Journal of Scientific Research, 16(5), 644-656.

Heneman, H. G., Kimball, S., \& Milanowski, A. (2006). The teacher sense of efficacy scale: Validation evidence and behavioral prediction (WCER Working Paper No. 2006-7). Wisconsin Center for Education Research, Madison, VI.

Henson, R. K. (2001). The effects of participation in teacher research on teacher efficacy. Teaching and Teacher Education, 17(7), 819-836. doi:10.1016/S0742-051X(01)00033-6

Hesse-Biber, S. N., \& Johnson, R. B. (2015). The Oxford handbook of multimethod and mixed methods research inquiry: Oxford University Press.

Hesse-Biber, S. N., \& Leavy, P. (2006). The practice of qualitative research. Thousand Oaks: Sage.

Hines, M. T., III. (2008). The interactive effects of race and and teacher self efficacy on the achievement gap in school. International Electronic Journal for Leadership in Learning, 12(11).

Ho, I. T., \& Hau, K.-T. (2004). Australian and Chinese teacher efficacy: Similarities and differences in personal instruction, discipline, guidance efficacy and beliefs in external determinants. Teaching and Teacher Education, 20(3), 313-323. doi:http://dx.doi.org/10.1016/j.tate.2003.09.009 


\section{VIETNAMESE EFL TEACHER SELF-EFFICACY IN PRACTICE}

Holden, C., \& Hicks, D. (2007). Making global connections: The knowledge, understanding and motivation of trainee teachers. Teaching and Teacher Education, 23(1), 13-23. doi:10.1016/j.tate.2006.04.031

Hoy, A. W., \& Spero, R. B. (2005). Changes in teacher efficacy during the early years of teaching: A comparison of four measures. Teaching and Teacher Education, 21(4), 343-356. doi:10.1016/j.tate.2005.01.007

Jafarigohar, M., \& Ganjabi, M. (2012). The relationship between teaching self-efficacy and percieved proficiency among Iranian language teachers. Middle-East Journal of Scientific Research, 12(8), 1119-1124.

Johnson, K. (1992). The relationship between teachers' beliefs and practices during literacy instruction for non-native speakers of English. Journal of Reading Behaviour, 20, 357-377.

Johnson, R. B., \& Christensen, L. (2014). Educational research : Quantitative, qualitative, and mixed approaches (5th ed.). Thousand Oaks: Sage.

Johnson, R. B., \& Onwuegbuzie, A. J. (2004). Mixed methods research: A research paradigm whose time has come. Educational Researcher, 33(7), 14-26.

Jorgensen, R., Grootenboer, P., Niesche, R., \& Lerman, S. (2010). Challenges for teacher education: The mismatch between beliefs and practice in remote Indigenous contexts. AsiaPacific Journal of Teacher Education, 38(2), 161-175. doi:10.1080/13598661003677580

Kang, N.-H. (2008). Learning to teach science: Personal epistemologies, teaching goals, and practices of teaching. Teaching and Teacher Education, 24(2), 478-498. doi:10.1016/j.tate.2007.01.002

Kartchava, E., Gatbonton, E., Ammar, A., \& Trofimovich, P. (2018). Oral corrective feedback: Pre-service English as a second language teachers' beliefs and practices. Language Teaching Research, 136216881878754. doi:10.1177/1362168818787546

Kass, E., \& Rajuan, M. (2012). Perceptions of freedom and commitment as sources of self-efficacy among pedagogical advisors. Mentoring \& Tutoring: Partnership in Learning, 20(2), $227-$ 250. doi:10.1080/13611267.2012.678973

Kilgore, K., Ross, D., \& Zbikowski, J. (1990). Understanding the teaching perspectives of firstyear teachers. Journal of Teacher Education, 41(1), 28-38. doi:10.1177/002248719004100105

Kim, Y. H., \& Kim, Y. E. (2010). Korean early childhood educators' multi-dimensional teacher self-efficacy and ECE center climate and depression severity in teachers as contributing factors. Teaching and Teacher Education, 26(5), 1117-1123. doi:10.1016/j.tate.2009.06.009

Klassen, R. M., \& Chiu, M. M. (2010). Effects on teachers' self-efficacy and job satisfaction: Teacher gender, years of experience, and job stress. Journal of Educational Psychology, 102(3), 741-756. doi:10.1037/a0019237

Klassen, R. M., \& Chiu, M. M. (2011). The occupational commitment and intention to quit of practicing and pre-service teachers: Influence of self-efficacy, job stress, and teaching context. Contemporary Educational Psychology, 36(2), 114-129. doi:10.1016/j.cedpsych.2011.01.002

Klassen, R. M., \& Durksen, T. L. (2014). Weekly self-efficacy and work stress during the teaching practicum: A mixed methods study. Learning and Instruction, 33, 158-169. doi:10.1016/j.learninstruc.2014.05.003 
Klassen, R. M., Tze, V. M. C., Betts, S. M., \& Gordon, K. A. (2011). Teacher efficacy research 1998-2009: Signs of progress or unfulfilled promise? Educational Psychology Review, 23(1), 21-43. doi:10.1007/s10648-010-9141-8

Kleinsasser, R. C. (2014). Teacher efficacy in teaching and teacher education. Teaching and Teacher Education, 44, 168-179. doi:http://dx.doi.org/10.1016/j.tate.2014.07.007

La Ganza, W. (2008). Learner autonomy - teacher autonomy: Interrelating and the will to empower In T. Lamb \& H. Reinders (Eds.), Leaenr and teacher autonomy: Concepts, realities, and responses. Amsterdam, Philadelphia: John Benjamins Publishing Company.

Labone, E. (2004). Teacher efficacy: maturing the construct through research in alternative pradigms. Teaching and Teacher Education, 20, 341-359.

Lam, Q. D. (2007). Teaching foreign languages at CSSH-VNU. VNU Journal of Foreign Studies, 23, 172-180.

Lambert, R. G., McCarthy, C., O' Donnell, M., \& Wang, C. (2009). Measuring elementary teacher stress and coping in the classroom: Validity evidence for the classroom appraisal of resources and demands. Psychology in the Schools, 46(10), 973-988. doi:10.1002/pits.20438

Lapadat, J., \& Lindsay, A. (1999). Transcription in research and practice: From standardization of technique to interpretive positionings. Qualitative inquiry, 5(1), 64-86.

Lapadat, J. C. (2000). Problematizing transcription: Purpose, paradigm and quality. International

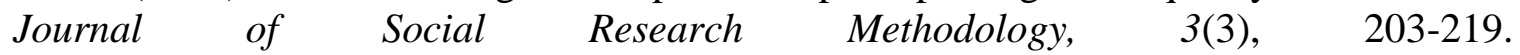
doi:10.1080/13645570050083698

Le, H. T. (2013). ELT in Vietnam general and tertiary education from second language education perspectives. VNU Journal of Foreign Studies, 29(1), 65-71.

Le, T. H. (2011). Hoc sinh khong giao tiep duoc bang tieng Anh [Students cannot communicate in English]. Tuoi tre. doi: http://tuoitre.vn/Bandoc/454395/Hoc-sinh-khong-giao-tiep-duocbang-tieng-Anh.html

Lim, C. P., \& Chai, C. S. (2008). Teachers' pedagogical beliefs and their planning and conduct of computer-mediated classroom lessons. British Journal of Educational Technology, 39(5), 807-828. doi:10.1111/j.1467-8535.2007.00774.x

Liu, S.-H. (2011). Factors related to pedagogical beliefs of teachers and technology integration. Computers \& Education, 56(4), 1012-1022. doi:10.1016/j.compedu.2010.12.001

Lumpe, A., Czerniak, C., Haney, J., \& Beltyukova, S. (2012). Beliefs about teaching science: The relationship between elementary teachers' participation in professional development and student achievement. International Journal of Science Education, 34(2), 153-166. doi:10.1080/09500693.2010.551222

Malinen, O.-P., Savolainen, H., Engelbrecht, P., Xu, J., Nel, M., Nel, N., \& Tlale, D. (2013). Exploring teacher self-efficacy for inclusive practices in three diverse countries. Teaching and Teacher Education, 33, 34-44. doi:10.1016/j.tate.2013.02.004

Martin, J. J., \& Kulinna, P. H. (2004). Self-efficacy theory and the theory of planned behavior: Teaching physically active physical education classes. Research quarterly for exercise and sport, 75(3), 288-297. doi:10.1080/02701367.2004.10609161

Martin, J. J., McCaughtry, N., Kulinna, P. H., \& Cothran, D. (2009). The impact of a social cognitive theory-based intervention on physical education teacher self-efficacy. Professional Development in Education, 35(4), 511-529. doi:10.1080/19415250902781814 


\section{VIETNAMESE EFL TEACHER SELF-EFFICACY IN PRACTICE}

Martin, N. K., Yin, Z., \& Baldwin, B. (1998). Construct validation of the attitudes and beliefs on classroom control inventory. The Journal of Classroom Interaction, 33(2), 6-15.

Martinussen, R., Ferrari, J., Aitken, M., \& Willows, D. (2015). Pre-service teachers' knowledge of phonemic awareness: Relationship to perceived knowledge, self-efficacy beliefs, and exposure to a multimedia-enhanced lecture. Annals of dyslexia, 65(3), 142-158. doi:10.1007/s11881-015-0104-0

McCormick, J., \& Ayres, P. L. (2009). Teacher self-efficacy and occupational stress. Journal of Educational Administration, 47(4), 463-476. doi:10.1108/09578230910967446

McCormick, J., Ayres, P. L., \& Beechey, B. (2006). Teaching self-efficacy, stress and coping in a major curriculum reform. Journal of Educational Administration, 44(1), 53-70. doi:10.1108/09578230610642656

McGrath, I. (2000). Teacher autonomy. In B. Sinclair, I. McGrath, \& T. Lamb (Eds.), Learner autonomy, teacher autonomy: Future directions (pp. 100-110). Harlow: Longman.

Meijer, C., \& Foster, S. (1988). The effect of teacher self-efficacy on referral chance. Journal of Special Education, 22, 378-385.

Melby, L. (1995). Teacher efficacy and classroom management: A study of teacher cognition, emotion, and strategy usage associated with externalizing student behavior. ProQuest Dissertations Publishing,

Merriam, S. B. (2002). Qualitative research in practice: examples for discussion and analysis (1st ed.. ed.). San Francisco: Jossey-Bass.

Merriam, S. B. (2009). Qualitative research a guide to design and implementation doi:http://site.ebrary.com/lib/vuw/Doc?id=10856838

Mertens, D. M. (2010). Research and evaluation in education and psychology: Integrating diversity with quantitative, qualitative, and mixed methods (3rd ed.). Los Angeles: Sage.

Mertler, C. A., \& Charles, C. M. (2011). Introduction to educational research (7th ed.). Boston: Pearson.

Meyer, W. U. (1987, 1987//). Perceived ability and achievement-related behavior. Paper presented at the Motivation, Intention, and Volition, Berlin, Heidelberg.

Midgley, C., Maehr, M., Hruda, L., Anderman, E., Anderman, L., Freeman, K., \& al., e. (2000). Manual for the patterns of adaptive learning scales. Ann Arbor: University of Michigan.

Mills, G. E., \& Gay, L. R. (2015). Educational research: Competencies for analysis and applications (11th ed.). Boston: Pearson.

Milner, H. R. (2002). A case study of an experienced English teacher's self-efficacy and persistence through "crisis" situations: Theoretical and practical considerations. The High School Journal, 86(1), 28-35. doi:10.1353/hsj.2002.0020

Milner, H. R., \& Woolfolk Hoy, A. (2003). A case study of an African American teacher's selfefficacy, stereotype threat, and persistence. Teaching and Teacher Education, 19(2), 263276. doi:10.1016/S0742-051X(02)00099-9

Mishra, P., \& Koehler, M. J. (2006). Technological pedagogical content knowledge: A framework for teacher knowledge. Teachers College Record, 108(6), 1017-1054. doi:10.1111/j.14679620.2006.00684.x

Mojavezi, A., \& Tamiz, M. P. (2012). The impact of teacher self-efficacy on the students motivation, and achievement. Theory and Practice in Language Studies, 2(3), 483-491. doi:10.4304/tpls.2.3.483-491 


\section{VIETNAMESE EFL TEACHER SELF-EFFICACY IN PRACTICE}

Morris, D. B., \& Usher, E. L. (2011). Developing teaching self-efficacy in research institutions: A study of award-winning professors. Contemporary Educational Psychology, 36(3), 232245. doi:10.1016/j.cedpsych.2010.10.005

Morris, D. B., Usher, E. L., \& Chen, J. A. (2017). Reconceptualizing the sources of teaching selfefficacy: A critical review of emerging literature. Educational Psychology Review, 29(4), 795-833. doi:10.1007/s10648-016-9378-y

Mulholland, J., \& Wallace, J. (2001). Teacher induction and elementary science teaching: Enhancing self-efficacy. Teaching and Teacher Education, 17(2), 243-261. doi:10.1016/S0742-051X(00)00054-8

New Zealand Ministry of Education. (2015). The New Zealand Curiculum for English-medium teaching and learning in years 1-13. Wellington: Learning Media Limited

Ngoc, K. M., \& Iwashita, N. (2012). A comparison of learners' and teachers' attitudes toward communicative language teaching at two universities in Vietnam. University of Sydney Papers in TESOL, 7, 25-49.

Nguyen, Q. T. (2013). The impact of context on a Vietnamese tertiary level English teacher's implementation of pair work. International Journal of Innovation in English Language Teaching and Research, 2(1), 27-46.

Nie, Y., Tan, G., Liau, A., Lau, S., \& Chua, B. (2013). The roles of teacher efficacy in instructional innovation: Its predictive relations to constructivist and didactic instruction. Educational Research for Policy and Practice, 12(1), 67-77. doi:10.1007/s10671-012-9128-y

Ortaçtepe, D., \& Akyel, A. S. (2015). The effects of a professional development program on English as a foreign language teachers' efficacy and classroom practice. TESOL Journal, 6(4), 680-706. doi:10.1002/tesj.185

Pajares, F. (1996). Self-efficacy beliefs in academic settings. Review of Educational Research, 66(4), 543-578. doi:10.2307/1170653

Pajares, M. F. (1992). Teachers' beliefs and educational research: Cleaning up a messy construct. Review of Educational Research, 62(3), 307. doi:10.3102/00346543062003307

Palmer, D. (2006). Sources of self-efficacy in a science methods course for primary teacher education students. Research in Science Education, 36(4), 337-353. doi:10.1007/s11165005-9007-0

Palmer, D. (2011). Sources of efficacy information in an inservice program for elementary teachers. Science Education, 95(4), 577-600. doi:10.1002/sce.20434

Pan, Y.-H., Chou, H.-S., Li, W.-T. H. C.-H., \& Hu, Y.-L. (2013). Teacher self-efficacy and teaching practices in the health and physical education curriculum in Taiwan.(Report). Social Behavior and Personality: an international journal, 41(2), 241. doi:10.2224/sbp.2013.41.2.241

Peng, J.-E. (2011). Changes in language learning beliefs during a transition to tertiary study: The mediation of classroom affordances. System, 39(3), 314-324. doi:10.1016/j.system.2011.07.004

Perera, H. N., Calkins, C., \& Part, R. (2019). Teacher self-efficacy profiles: Determinants, outcomes, and generalizability across teaching level. Contemporary Educational Psychology, 58, 186-203. doi:10.1016/j.cedpsych.2019.02.006

Pham, H. H. (2004). "Trained in the West, teaching in the East" : Vietnamese teachers returning from TESOL courses abroad / Pham Hoa Hiep. In H. H. Pham (Ed.). 


\section{VIETNAMESE EFL TEACHER SELF-EFFICACY IN PRACTICE}

Phan, N. T. T. (2015). Can I teach these students: A case study of Vietnamese teachers' selfefficacy in relation to teaching English as a foreign language. (Unpublished $\mathrm{PhD}$ thesis). The University of Waikato, New Zealand.

Phan, N. T. T., \& Locke, T. (2015). Sources of self-efficacy of Vietnamese EFL teachers: A qualitative study. Teaching and Teacher Education, 52, 73-82.

Phan, N. T. T., \& Locke, T. (2016). Vietnamese teachers' self-efficacy in teaching English as a Foreign Language: Does culture matter? English Teaching: Practice \& Critique, 15(1), 105-128. doi:10.1108/ETPC-04-2015-0033

Poulou, M. (2007). Personal teaching efficacy and its sources: Student teachers' perceptions. Educational Psychology, 27(2), 191-218.

Powers, S. W., Zippay, C., \& Butler, B. (2006). Investigating connections between teacher beliefs and instructional practices with struggling readers. Reading Horizons, 47(2), 121.

Rahimi, A., \& Riasati, M. (2015). The relationship between teacher autonomy and teacher efficacy. Modern Journal of Language Teaching Methods, 5(4), 618-623.

Raudenbush, S., Rowan, B., \& Cheong, Y. (1992). Contextual effects on the self-perceived efficacy of high school teachers. Sociology of Education, 65(2), 150. doi:10.2307/2112680

Reyes, M. R., Brackett, M. A., Rivers, S. E., White, M., \& Salovey, P. (2012). Classroom emotional climate, student engagement, and academic achievement. Journal of Educational Psychology, 104(3), 700-712. doi:10.1037/a0027268

Richardson, V., Anders, P., Tidwell, D., \& Lloyd, C. (1991). The relationship between teachers' beliefs and practices in reading comprehension instruction. American Educational Research Journal, 28(3), 559-586.

Riggs, I., \& Enochs, L. (1990). Towards the development of an elementary teacher's science teaching efficacy belief instrument. Science Education, 74, 625-638.

Ritter, J. M., Boone, W. J., \& Rubba, P. A. (2001). Development of an instrument to assess prospective elementary teacher self-efficacy beliefs about equitable science teaching and learning (SEBEST). Journal of Science Teacher Education, 12(3), 175-198. doi:10.1023/A:1016747713585

Roberts, J. K., Henson, R. K., Tharp, B. Z., \& Moreno, N. P. (2001). An examination of change in teacher self-efficacy beliefs in science education based on the duration of inservice activities. Journal of Science Teacher Education, 12(3), 199-213. doi:10.1023/A:1016708016311

Rose, I. S., \& Medway, F. J. (1981). Measurement of teachers' beliefs in their control over student outcome. Journal of EDucational REsearch, 74, 185-190.

Rots, I., Aelterman, A., Vlerick, P., \& Vermeulen, K. (2007). Teacher education, graduates' teaching commitment and entrance into the teaching profession. Teaching and Teacher Education, 23(5), 543-556. doi:10.1016/j.tate.2007.01.012

Rotter, J. B. (1966). Generalized expectancies for internal versus external control of reinforcement. Psychological Monographs: General and Applied, 80(1), 1-28.

Rubeck, M., \& Enochs, L. (1991). A path analytic model of variables that influence science and chemistry teaching self-efficacy and outcome expectancy in middle school science teachers. Paper presented at the annual meeting of the National Association of Research in Science Teaching, Lake Geneva, WI.

Rupley, W. H., \& Logan, J. W. (1985). Elementary teachers' beliefs about reading and knowledge of reading content: Relationships to decision about reading outcomes. Reading Psychology, 63(3-4), 145-156. 


\section{VIETNAMESE EFL TEACHER SELF-EFFICACY IN PRACTICE}

Rushton, G. T., Lotter, C., \& Singer, J. (2011). Chemistry teachers' emerging expertise in inquiry teaching: The effect of a professional development model on beliefs and practice. Journal of Science Teacher Education, 22(1), 23-52. doi:10.1007/s10972-010-9224-X

Saeidi, M., \& Kalantarypour, M. (2011). The relationship between Iranian EFL teachers' selfefficacy and students' language achievement. World Applied Sciences Journal, 15(11), 1562-1567.

Sapon-Shevin, M. (1990). Gifted education and the deskilling of classroom teachers. Journal of Teacher Education, 41(1), 39-48. doi:10.1177/002248719004100106

Sarıçam, H., \& Sakız, H. (2014). Burnout and teacher self-efficacy among teachers working in special education institutions in Turkey. Educational Studies, 40(4), 423-437. doi:10.1080/03055698.2014.930340

Schott, J. (2014). The promises, problems, and prospects of research on teachers' beliefs. In H. Fives \& M. Gregoire Gill (Eds.), International handbook of research on teachers' beliefs (pp. 25-42). London: Routledge.

Schwarzer, R., \& Hallum, S. (2008). Perceived teacher self-efficacy as a predictor of job stress and burnout: Mediation analyses. Applied Psychology, 57(s1), 152-171. doi:10.1111/j.1464-0597.2008.00359.x

Seidman, I. (2013). Interviewing as qualitative research: A guide for researchers in education and the social sciences (4th ed.). New York: Teachers College Press.

Settlage, J. (2000). Understanding the learning cycle: Influences on abilities to embrace the approach by preservice elementary school teachers. Science Education, 84(1), 43-50.

Shahzad, K., \& Naureen, S. (2017). Impact of teacher self-efficacy on secondary school students' academic achievement. Journal of Education and Educational Development, 4(1), 48-72. doi:10.22555/joeed.v4i1.1050

Shanks, J., Miller, L., \& Rosendale, S. (2012). Action research in a professional development school setting to support teacher candidate self-efficacy. SRATE Journal, 21(2), 26-32.

Shoji, K., Cieslak, R., Smoktunowicz, E., Rogala, A., Benight, C. C., \& Luszczynska, A. (2016). Associations between job burnout and self-efficacy: A meta-analysis. Anxiety, Stress, \& Coping, 29(4), 367-386. doi:10.1080/10615806.2015.1058369

Shore, J. R. (2004). Teacher education and multiple intelligences: A case study of multiple intelligences and teacher efficacy in two teacher preparation courses. Teachers College Record, 106(1), 112-139.

Shulman, L. S. (2013). Those who understand: Knowledge growth in teaching. Journal of Education, 193(3), 1-11. doi:10.1177/002205741319300302

Silverman, D. (2011). Interpreting qualitative data: A guide to the principles of qualitative research (4th ed.. ed.). Los Angeles: Sage.

Siwatu, K. O. (2011). Preservice teachers' sense of preparedness and self-efficacy to teach in America's urban and suburban schools: Does context matter? Teaching and Teacher Education, 27(2), 357-365. doi:10.1016/j.tate.2010.09.004

Skaalvik, E. M., \& Skaalvik, S. (2007). Dimensions of teacher self-efficacy and relations with strain factors, perceived collective teacher efficacy, and teacher burnout. Journal of Educational Psychology, 99(3), 611-625. doi:10.1037/0022-0663.99.3.611

Skaalvik, E. M., \& Skaalvik, S. (2010). Teacher self-efficacy and teacher burnout: A study of relations. Teaching and Teacher Education, 26(4), 1059-1069. doi:10.1016/j.tate.2009.11.001 


\section{VIETNAMESE EFL TEACHER SELF-EFFICACY IN PRACTICE}

Skaalvik, E. M., \& Skaalvik, S. (2014). Teacher self-efficacy and perceived autonomy: Relations with teacher engagement, job satisfaction, and emotional exhaustion. Psychological Reports, 114(1), 68-77. doi:10.2466/14.02.PR0.114k14w0

Smolleck, L. A., \& Mongan, A. M. (2011). Changes in preservice teachers' self-efficacy: From science methods to student teaching. Journal of Educational and Development Psychology, 1, 133-145.

Song, Y., \& Looi, C.-K. (2012). Linking teacher beliefs, practices and student inquiry-based learning in a CSCL environment: A tale of two teachers. International Journal of Computer-Supported Collaborative Learning, 7(1), 129-159. doi:10.1007/s11412-0119133-9

Stake, R. E. (1995). The art of case study research. Thousand Oaks: Sage Publications.

Sue, V. M., \& Ritter, L. A. (2012). Conducting online surveys (2nd ed.). Thousand Oaks: Sage.

Sullivan, P. N. (2000). Playfulness as mediation in communicative language teaching in a Vietnamese classroom. In J. P. Lantolf (Ed.), Sociocultural Theory and Second Language Learning (pp. 115-131). Oxford: Oxford University Press.

Swain, K. D., Nordness, P. D., \& Leader-Janssen, E. M. (2012). Changes in preservice teacher attitudes: Toward inclusion. Preventing School Failure: Alternative Education for Children and Youth, 56(2), 75-81. doi:10.1080/1045988X.2011.565386

Temiz, T., \& Topcu, M. (2013). Preservice teachers' teacher efficacy beliefs and constructivistbased teaching practice. European Journal of Psychology of Education, 28(4), 1435-1452. doi:10.1007/s10212-013-0174-5

Temple, B., Edwards, R., \& Alexander, C. (2006). Grasping at context: Cross language qualitative research as secondary qualitative data analysis. Forum: Qualitative Social Research, 7(4).

Thanh, P. T. H. (2011). An investigation of perceptions of Vietnamese teachers and students toward cooperative learning (CL). International education studies, 4(1), 3-12.

Thoonen, E. E. J., Sleegers, P. J. C., Peetsma, T. T. D., \& Oort, F. J. (2011). Can teachers motivate students to learn? Educational Studies, 37(3), 345-360. doi:10.1080/03055698.2010.507008

Thornberg, R., \& Charmaz, K. (2013). Grounded theory and theoretical coding. In The SAGE handbook of qualitative data analysis (pp. 153-169). London: Sage.

Throndsen, I., \& Turmo, A. (2013). Primary mathematics teachers' goal orientations and student achievement. Instructional Science, 41(2), 307-322. doi:10.1007/s11251-012-9229-2

Tilley, S. (2003). Transcription work: Learning through coparticipation in research practices. International Journal of Qualitative Studies in Education, 16(6), 835-851. doi:10.1080/09518390310001632171

Tilley, S. A., \& Powick, K. D. (2002). Distanced data: Transcribing other people's research tapes. Canadian Journal of Education, 27(2/3), 291-310. doi:10.2307/1602225

Tournaki, N., \& Podell, D. M. (2005). The impact of student characteristics and teacher efficacy on teachers' predictions of student success. Teaching and Teacher Education, 21(3), 299314. doi:10.1016/j.tate.2005.01.003

Trinh, T. T. H., \& Mai, T. L. (2018). Current challenges in the teaching of tertiary English in Vietnam. In J. Albright (Ed.), English tertiary education in Vietnam (First edition. ed.). New York: Routledge.

Tsangaridou, N. (2008). Trainee primary teachers' beliefs and practices about physical education during student teaching. Physical Education and Sport Pedagogy, 13(2), 131-152. doi:10.1080/17408980701345667 


\section{VIETNAMESE EFL TEACHER SELF-EFFICACY IN PRACTICE}

Tschannen-Moran, M., \& Hoy, A. W. (2001). Teacher efficacy: Capturing an elusive construct. Teaching and Teacher Education, 17(7), 783-805. doi:http://dx.doi.org/10.1016/S0742051X(01)00036-1

Tschannen-Moran, M., \& Hoy, A. W. (2007). The differential antecedents of self-efficacy beliefs of novice and experienced teachers. Teaching and Teacher Education, 23(6), 944-956. doi:10.1016/j.tate.2006.05.003

Tschannen-Moran, M., Hoy, A. W., \& Hoy, W. K. (1998). Teacher efficacy: Its meaning and measure. Review of Educational Research, 68(2), 202-248. doi:10.3102/00346543068002202

Tschannen-Moran, M., \& Johnson, D. (2011). Exploring literacy teachers' self-efficacy beliefs: Potential sources at play. Teaching and Teacher Education: An International Journal of Research and Studies, 27(4), 751-761. doi:10.1016/j.tate.2010.12.005

Tschannen-Moran, M., \& McMaster, P. (2009). Sources of self-efficacy: Four professional development formats and their relationship to self-efficacy and implementation of a new teaching strategy. The Elementary School Journal, 110(2), 228-245. doi:10.1086/605771

Usher, E. L., \& Pajares, F. (2008). Sources of self-efficacy in school: Critical review of the literature and future directions. Review of Educational Research, 78(4), 751-796. doi:10.3102/0034654308321456

Vu, T. T. N., \& Burns, A. (2014). English as a medium of instruction: Challenges for Vietnamese tertiary lecturers. The journal of Asia TEFL, 11(3), 1-31.

Walker, J., \& Slear, S. (2011). The impact of principal leadership behaviors on the efficacy of new and experienced middle school teachers. NASSP Bulletin, 95(1), 46-64. doi:10.1177/0192636511406530

Webb, R., \& Ashton, P. T. (1987). Teachers' motivation and the conditions of teaching: A call for ecological reform Philadelphia: Open University Press.

Wheatley, K. F. (2005). The case for reconceptualizing teacher efficacy research. Teaching and Teacher Education: An International Journal of Research and Studies, 21(7), 747-766. doi:10.1016/j.tate.2005.05.009

Wiersma, W., \& Jurs, S. G. (2005). Research methods in education: An introduction (8th ed.). Boston: Pearson.

Wilkins, J. (2008). The relationship among elementary teachers' content knowledge, attitudes, beliefs, and practices. Journal of Mathematics Teacher Education, 11(2), 139-164. doi:10.1007/s10857-007-9068-2

Wolters, C. A., \& Daugherty, S. G. (2007). Goal structures and teachers' sense of efficacy: Their relation and association to teaching experience and academic level. Journal of Educational Psychology, 99(1), 181-193.

Woolfolk, A. E., \& Hoy, W. K. (1990). Prospective teachers' sense of efficacy and beliefs about control. Journal of Educational Psychology, 82(1), 81-91. doi:10.1037/0022-0663.82.1.81

Wragg, E. C. (2012). An introduction to classroom observation (Classic ed.). London Routledge.

Wyatt, M. (2013). Overcoming low self-efficacy beliefs in teaching English to young learners. International Journal of Qualitative Studies in Education, 26(2), 238-255. doi:10.1080/09518398.2011.605082

Yavuz, S. (2007). Socio-demographic predictors of EFL teacher efficacy. Journal of Language and Linguistic Studies, 3(2), 304-324.

Yazan, B. (2015). Three approaches to case study methods in education: Yin, Merriam, and Stake. The Qualitative Report, 20(2), 134-152. 


\section{VIETNAMESE EFL TEACHER SELF-EFFICACY IN PRACTICE}

Yilmaz, C. (2011). Teachers' perception of self-efficacy, English proficiency, and instructional strategies. Social Behavior and Personality, 39(1), 91-100.

Yilmaz, H., \& Cavas, P. H. (2008). The effect of teaching practice on pre-service elementary teachers' science teaching efficacy and classroom management beliefs. EURASIA Journal of Mathematics, Science, and Technology EDucation, 4(1), 45-54.

Yin, R. K. (2003). Case study research: Design and methods (3rd ed. ed.). Thousand Oaks, Calif: Sage Publications.

Yin, R. K. (2012). Applications of case study research (3rd ed.). Thousand Oaks: Sage.

Yin, R. K. (2014). Case study research: Design and methods (5th ed.). Los Angeles: Sage.

Yinger, R. J. (1986). Examining thought in action: A theoretical and methodological critique of research on interactive teaching. Teaching and Teacher Education, 2(3), 263-282. doi:10.1016/S0742-051X(86)80007-5

Yoo, J. H. (2016). The effect of professional development on teacher efficacy and teachers' selfanalysis of their efficacy change. Journal of Teacher Education for Sustainability, 18(1), 84-94. doi:10.1515/jtes-2016-0007

Zee, M., \& Koomen, H. M. Y. (2016). Teacher self-efficacy and its effects on classroom processes, student academic adjustment, and teacher well-being: A synthesis of 40 years of research. Review of Educational Research, 86(4), 981-1015. doi:10.3102/0034654315626801

Zonoubi, R., Eslami Rasekh, A., \& Tavakoli, M. (2017). EFL teacher self-efficacy development in professional learning communities. System, 66, 1-12. doi:10.1016/j.system.2017.03.003 
VIETNAMESE EFL TEACHER SELF-EFFICACY IN PRACTICE 